JUL I 51965

\title{
FINAL SAFEGUARDS REPORT GARIGLIANO DEVELOPMENT PROGRAM
}

Compiled By: C.L. HOWARD

A. COLLING
U.S. ATOMIC ENERGY COMMISSION CONTRACT AT(04-3)- 189 PROJECT AGREEMENT 33

PATEN CLEARANCE OBTAINED. REEEASE TO THE PUBLIC IS APPROVED. PROCEDURES ARE ON FILE IN THE RECEIVING SECTION.

ATOMIC POWER EQUIPMENT DEPARTMENT GENERAL (g) ELETRIC

SAN IOSE, CALIFORWIA 


\section{DISCLAIMER}

This report was prepared as an account of work sponsored by an agency of the United States Government. Neither the United States Government nor any agency Thereof, nor any of their employees, makes any warranty, express or implied, or assumes any legal liability or responsibility for the accuracy, completeness, or usefulness of any information, apparatus, product, or process disclosed, or represents that its use would not infringe privately owned rights. Reference herein to any specific commercial product, process, or service by trade name, trademark, manufacturer, or otherwise does not necessarily constitute or imply its endorsement, recommendation, or favoring by the United States Government or any agency thereof. The views and opinions of authors expressed herein do not necessarily state or reflect those of the United States Government or any agency thereof. 


\section{DISCLAIMER}

Portions of this document may be illegible in electronic image products. Images are produced from the best available original document. 


\section{FINAL SAFEGUARDS REPORT}

FOR

\section{GARIGLIANO DEVELOPMENT PROGRAM}

by

C. L. Howard - APED

F. Santasilia - SENN

S. Viscuso - SENN

A. Colling - Euratom

L. H. Youngborg - APED

Approved:

S. Levy, Manager Heat Transfer and Reactor Development Program
T. Sorlie - APED

W. I. Collett - APED

A. C. Duckart - APED

L. K. Holland - APED

N. H. Barth - APED

Prepared Under

U. S. Atomic Energy Commission

Contract AT(04-3)-189

Project Agreement 33

for the

JOINT US-EURATOM

Research \& Development Program

Printed in U.S.A. Available from the

Clearing House for Federal Scientific and Technical Information

National Bureau of Standards, U.S. Department of Commerre

Spring/ield, Virginia

Price: 55.00 per copy 
LEGAL NOTICE

THIS DOCUMENT WAS PREPARED UNDER THE SPONSORSHIP OF THE ATOMIC ENERGY COMMISSION PURSUANT TO THE JOINT RESEARCH AND DEVELOPMENT PROGRAM ESTABLISHED BY THE AGREEMENT FOR COOPERATION SIGNED NOVEMBER 8, 1958, BETWEEN THE GOVERNMENT OF THE UNITED STATES OF .AMERICA AND THE EUROPEAN ATOMIC ENERGY COMMUNITY (EURATOM). NEITHER THE UNITED STATES, THE U.S. ATOMIC ENERGY COMMISSION, THE EUROPEAN ATOMIC ENERGY COMMUNITY, THE EURATOM COMMISSION, NOR ANY PERSON ACTING ON BEHALF OF EITHER COMMISSION:

A. MAKES ANY WARRANTY OR REPRESENTATION, EXPRESS OR IMPLIED, WITH RESPECT TO THE ACCURACY, COMPLETENESS, OR USEFULNESS OF THE INFORMATION CONTAINED IN THIS DOCUMENT, OR THAT THE USE OF ANY INFORMATION, APPARATUS, METHOD, OR PROCESS DISCLOSED IN THIS DOCUMENT MAY NOT INFRINGE PRIVATELY OWNED RIGHTS; OR

B. ASSUMES ANY LIABILITIES WITH RESPECT TO THE USE OF, OR FOR DAMAGES RESULTING FROM THE USE OF ANY INFORMATION, APPARATUS, METHOD OR PROCESS DISCLOSED IN THIS DOCUMENT.

AS USED IN THE ABOVE, "PERSON ACTING ON BEHALF OF EITHER C.OMMISSION" INCLUDES ANY EMPLOYEE OR CONTRACTOR OF EITHER COMMISSIONOR EMPLOYEE OF SUCH CONTRACTOR TO THE EXTENT THAT SUCH EMPLOYEE OR CONTRACTOR OR EMPLOYEE OF SUCH CONTRACTOR PREPARES, HANDLES, DISSEMINATES, OR PROVIDES ACCESS TO, ANY INFORMATION PURSUANT TO HIS EMPLOYMENT OR CONTRACT WITH EITHER COMMISSION OR HIS EMPLOYMENT WITH SUCH CONTRACTOR.

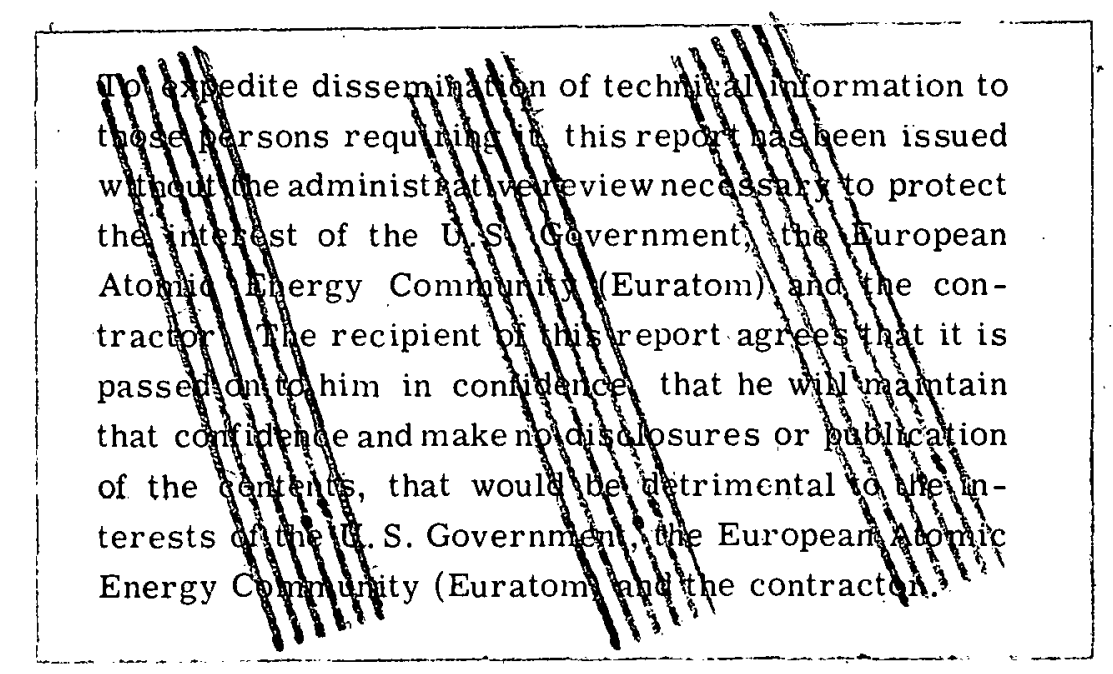

L N 5 


\section{TABLE OF CONTENTS}

SECTION I

SECTION II

SECTION III

SECTION IV
INTRODUCTION AND SUMMARY

Page

1-1

EQUIPMENT DESCRIPTION

2-1

A. Rod Oscillator System

2-1

1. Mechanical Description

2-1

2. Control and Safety Circuit

2-7

3. Equipment Design Calculations

$2-11^{<}$

4. Control Rod Worth

2-14

5. Equipment Tests

2-14

6. Accident Analysis

2-21

B. Instrumented Fuel Assemblies $\quad 2-30$

1. Description

2-30

2. Installation Procedure for Fuel Assemblies

2-38

C. Movable Ion Chambers

$2-41$

$3-1$

A. Safety Criteria . . . . 3-1

B. Tentative Test Sequence $\quad 3-5$

SAFEGUARDS LIMIT CRITERIA

A. Purpose of the Error Analyses 4-2

B. Probability Concepts 4-2

C. Error for Channel Flow Rate 4-5

D. Error in Reactor Power Determination 4-10

1. Error on the Primary Feedwater Flow 4-11

2. Error on Primary Steam Enthalpy . 4-11

3. Error on Feedwater Enthalpy $\quad \cdots \quad$ 4-12

4. Error on Secondary Feedwater Flow 4-12

5. Error on Secondary Steam Enthalpy 4-13

6. Error on the Clean-up System Heat Removal 4-13

7. Error on Heat Added to Rod Drive Coolant 4-13

8. Error on NSSS Heat Losses 4-13

9. Determination of the Standard Deviation of Reactor Power 4-14 


\section{TABLE OF CONTENTS (Continued)}

E. Error in Recirculation Flow Measurement 4-15

1. Error on the Pump Characteristic 4-15

2. Recalibration of Steam Generator : 4-15

3. Recirculation Flow Error for the Reference Case Test
Conditions

4. Core Leakage Flow 4-18

5. Total Core Flow Rate 4-18

F. Error in Core Power Distribution . 4 4-19

1. Error on Axial Wire Data 4-19

2. Error on Radial Power Distribution Calculations 4-20

3. Error on Local Peak Calculations 4-21

G. Error in In-Core Chamber Readings 4-22

H. Error in the Control Room Method of MCHFR Determination 4-25

I. Summary of Error Analysis 4-37

J. Improvements in MCHFR Determination 4-41

K. Discussion of Technical Specifications Changes 4-43

1. Minimum Critical Heat Flux Ratio 4-43

2. Overpower Allowance and High Flux Scram 4-44

3. Minimum Recirculation Flow at Rated Power 4-45

L. Effect of Normal Plant Transients 4-46

SECTION $\mathrm{V}$ SPECIAL TOPICS AND ANALYSES $\quad$ 5-1

A. Stability Analyses . 5-1

1. Analytic Methods 5-1

2. Pre-test Calculations 5-1

3. Dynamic Performance Criteria 5-10

4. Experimental Approach to Test Conditions 5-10

B. Boiling Outside Fuel Channels $\quad$ 5-12

C. Stoppage of Turbine Flow meters 5-20

D. Effcet of Fuel Non-Uniformity 5-23

E. Critical Heat Flux Calculations 5-23 


\section{TABLE OF CONTENTS (Continued)}

Page

APPENDIX A ACCURACY OF FLUX WIRE DATA

1. Wire Counting Statistics A-1

2. Wire Uniformity A-1

APPENDIX B LIST OF DIFFERENCES BETWEEN THIS REPORT AND PREVIOUS REPORT

DISTRIBUTION LIST 


\section{LIST OF ILLUSTRATIONS}

Figure

2-1

2-2

2-3

$2-4$

2-5

2-6

2-7

2-8

2-9

2-10

2-11

2-12

2-13

2-14

2-15

2-16

2-17

2-18

2-18a

$2-18 b$

2-19

2-20

2-21

2-22

4-1
Title

Page

Basic Rod Oscillator System Schematic

2-2

$2-3$

$2-4$

Control Rod Oscillator System Schematic

2-9

Allowable Peak-to-Peak Amplitude vs Frequency for Various Pressures across Rod Drive

Allowable Peak-to-Peak Amplitude vs Frequency for Various Horsepowers

Control Rod Oscillator Drive Module

2-16

Control Rod Oscillator Drive Module

$2-17$

Control Rod Oscillator Drive Module

$2-18$

2-19

$2-20$

Control Rod Drive and Probe Positioner

2-22

Position Sensor Output vs Position of Control Rod

$2-26$ Velocity of Rod vs Freque
Peak-to-Peak Amplitudes

Pressure at Various

Acceleration vs Frequency for One Pressure at Various Peakto-Peak Amplitudes

Garigliano Control Rod Scram Stroke vs Time

Arrangement - Instrumented Fuel System

Flowmeter

2-33

Instrumented Assembly Probe

2-35

$2-36$

Fuel Assembly (Part G-2 only)

2-39

Fuel Channel

$2-40$

2-42

2-43

Clianber Drive Mechanisim

4- 27 


\section{LIST OF ILLUSTRATIONS (Continued)}

Garigliano Calculated Transfer Function (Flux Response, $\% /$ Reactivity $\frac{\Delta \mathrm{k} / \mathrm{k}}{\beta}$, cents)

Power Produced in the Moderator Outside Fuel Channels vs Recirculation Flow

Void Fraction of Leakage Water in Core Region vs Core Active Length

Leakage Flow Exit Steam Quality vs Recirculation Flow

Reactivity Change vs Void Between Channels

Revised Results for Minimum Critical Heat Flux Ratio versus Recirculation Flow 


\section{SECTION I}

\section{INTRODUCTION AND SUMMARY}

\section{A. Introduction}

This report describes the Garigliano Development Program, outlines the reactor tests to be performed as part of the program, and presents the calculations which have been made to determine that the proposed tests are safe. The objectives of the tests are to (1) measure the reactor performance at conditions which simulate operation of the reactor at thermal powers 1.5 to 2 times greater than the present rating and (2) compare measured and calculated reactor performance and stability at various test conditions. The term "reactor stability" is used to indicate three aspects of reactor dynamic performance: absolute stability, relative stability and transient response.

The test equipment to be used for the tests includes four instrumented fuel assemblies, a control rod oscillator mechanism and a data recording system. The control rod oscillator will be used to oscillate one control blade a maximum amplitude of \pm 3 inches ( \pm 1 notch) at several frequencies between approximately 0.01 and $15 \mathrm{cycles} / \mathrm{sec}$. The test results include graphs of the transfer function of neutron flux response to a perturbation of reactivity.

As a guide to the future preparation of detailed test procedures, pre-test calculations of reactor stability and critical heat flux have been made for a variety of reactor flow rates and power levels.

In order to accomplish the test objectives several temporary changes in the plant Technical Specifications are requested. These changes are listed in the table on page 4-1. The limits requested are comparable to those used in previous tests on power reactors at Big Rock Point and Dresden.

The effects of these specification changes are discussed, and it is concluded that these reviced limits are adequate to provide assurance of reactor safety during the proposed tests. Parts of the Technical Specifications not listed in this report are unchanged and are applicable during the tests. At the conclusion of the Garigliano Development Program tests, these temporary specification changes will be terminated and the normal limits will again apply.

\section{B. Summary}

This report provides data on the proposed tests; the test equipment, possible malfunctions of the test equipment, test procedures and safety criteria, calculational uncertainties, effects 
of "normal" plant transients, and results of special safety analyses which have been conducted. The more important conclusions are as follows:

1. The control rod oscillator and its control and safety circuit have been designed to be failsafe with regard to both equipment malfunction and operator error. Analysis of possible accidents associated with the system shows that the protective devices are adequate to prevent damage to the reactor system and fuel, even if these accidents occur.

2. The four instrumented assemblies have no direct safety problems, except stoppage of the turbine flowmeters. Both the sizing of the inlet orifice to set the channel flow rate, and reactor calculational procedures will assume that the turbines have already stopped. Thus, no hazard exists even if both inlet and outlet turbines stop at the same time.

3. A previously discussed problem with the movable in-core flux chambers has been overcome by placing four fixed in-core chambers, one movable chamber and one flux wire irradiation tube in the same assembly. Thus, the possible failure of the movable chamber mechanism causes no change in normal plant procedures for calibrating and using the fixed in-core chambers.

4. A list of procedural safety criteria has been developed to ensure that the items are incorporated in the final detailed procedures.

5. Analysis of normal plant transients, such as generator breaker trip, at the most severe of the proposed test conditions shows that the peak of the fuel heat flux transient is only $10 \%$ which is well within the $20 \%$ overpower calculational allowance.

6. An extensive analysis of experimental error in determination of key reactor parameters has been conducted (assuming recent calibration of plant instruments and use of the most accurate plant instruments available) with the results listed below. These values are calculated for specific conditions of the proposed test with one loop natural circulation which is the closest approach to the reactor MCHFR limit. For other conditions, the error in MCHFR is greater, but also the MCHFR is greater so that the condition shown is the most severe condition encountered.

\begin{tabular}{|c|c|c|}
\hline Variable & $\begin{array}{c}\text { Probable Error } \\
(0.675 \sigma) \\
\% \\
\end{array}$ & $\begin{array}{c}\text { Maximum } \\
\text { Probable Error } \\
(1.645 \sigma) \\
\% \\
\end{array}$ \\
\hline Reactor Total Power & 0.62 & 1.51 \\
\hline Recirculation Flow (Core Total Flow) & 1.25 & 3,06 \\
\hline Channel Flow Rate & 1.86 & 4.52 \\
\hline Local Fuel Heat Flux & 5.26 & 12.8 \\
\hline Minimum Critical Heat Flux Ratio & 8.7 & 21.2 \\
\hline
\end{tabular}


7. The minimum critical heat flux ratio (MCHFR) is then as follows at the limiting reactor condition of one loop natural circulation at low subcooling, and at rated power of $506 \mathrm{MWt}$ :

$\begin{array}{lcc}\text { Expected Value of MCHFR } & \begin{array}{c}\text { At } \\ \text { Actual Power }\end{array} & \begin{array}{c}\text { At } 120 \% \text { of } \\ \text { Actual Power }\end{array} \\ \begin{array}{l}\text { Maximum Probable Error (21.2\%) } \\ \text { Lowest Probable Value, After Allowing for } \\ \text { Maximum Probable Error }\end{array} & \begin{array}{l}-0.41 \\ 1.93\end{array} & \underline{-0.32} \\ & 1.52 & 1.18\end{array}$

Thus, at the actual reactor power the MCHFR is above 1.52 and if an overpower transient of $20 \%$ occurs (and this is very rare) the MCHFR is above 1.18 .

8. The precautions taken against problems of reactor stability are adequate. First, pretest calculations have been made which show that the reactor is stable at the proposed test conditions. Second, the experimental procedures and high flux scram settings are adequate to provide protection even if the reactor were unstable.

9. The flow and heat transfer for the water outside the fuel channels have been analyzed. The amount of boiling and void formation has been determined and physics calculations of void coefficient and control rod worth indicate that no safety problems will be encountered.

10. The reactor has already been operated at several low flow conditions. The comparison of previous and proposed conditions is as follows:

$\underline{\text { Previous Operation }}$

Highest Power at Rated Flow, MWt

Highest Power at

2 Loops Natural

Circulation, MWt

Highest Power at

1 Loop Natural

Circulation, MWt.
506 $\underline{\text { Proposed Tests }}$

506

506

506*

*Or highest permitted by MCHFR limit. 
11. The pre-test calculations presented here are for the purpose of establishing the credibility of conducting the proposed tests. The safety of the reactor at each test condition is to be justified at the time of the tests by calculations based on measured values of flow, power and flux distribution.

12. After conducting these analyses of the proposed tests, it is concluded that:

(a) The proposed temporary changes in the plant Technical Specifications are safe, and

(b) The tests themselves, including both equipment and procedural safeguards are safe with regard to both the reactor system and the fuel.

The information in this report supercedes two previous informal reports:

"Preliminary Safeguards Report - Garigliano Development Program," by F. Santasilia and C. L. Howard, November 30, 1964.

"Safeguards Report - Garigliano Development Program," compiled by C. L. Howard, March 15, 1965.

The content is the same as the previous reports, except for revisions listed in Appendix B for the benefit of those already familiar with the previous reports.

\section{Background of the Development Program}

The program is officially titled "A Development Program on the Garigliano Nuclear Reactor." It is a joint U.S. - EURATOM cooperative program which is being conducted by Societa Elettronucleare Nazionale (SENN) under contract with EURATOM and by the General Electric Company (GE) under contract with the U.S. Atomic Energy Commission. SENN is in the process of being nationalized and the responsibilities of SENN will be assumed by ENEL. In most cases the same personnel will continue in the same work under ENEL.

The overall objectives of the program are (1) to accumulate, under normal operating conditions, data above that usually obtained by the utility for safe, efficient and reliable plant operation, (2) to evaluate such data and (3) to investigate the feasibility of improved plant performance of the Garigliano plant applicable to boiling water reactors. This program excludes specific design work that is required for an actual increase in the output of the Garigliano plant. 
In order to carry out this program the work has been divided into several tasks, as follows:

Task I Data Logging and Computer System

Task II · Pressure Vessel Sample Irradiation

Task III Instrumented Assemblies

Task IV Special Studies and Tests

A. Studies

-1 Core Evaluation

-2 Improved Measurements of Gross Power Distribution

-3 Safeguards Studies

B. Tests

-1 Stability Tests and Analysis

-2 Plant System Tests and Analysis

Task V Coordination

Although this safeguards report deals specifically with the reactor tests (Task IV-B) it also is related to the other tasks. The preparation of this report is part of the Safeguards Studies. The reactor tests utilize the instrumented fuel assemblies and the on-line computer to acquire data and to demonstrate the reactor safety at the operating conditions of the tests. The measurement of gross power distribution is an important aspect of reactor test conditions and safety. And, finally, the core evaluation studies are used to guide the selection of the reactor conditions which should be tested. 


\section{SECTION II}

\section{EQUIPMENT DESCRIPTION}

The special equipment to be used for the test program is described below, including:
A. Rod Oscillator System
B. Instrumented Assemblies
C. Movable Ion Chambers

The equipment descriptions are given to indicate the nature of the tests and the safety precautions incorporated as part of the equipment design. Reactor safety is not directly affected by the other equipment to be used, such as oscillograph and magnetic tape recording equipment.

\section{A. Rod Oscillator System}

The control rod oscillator is an electro-mechanical system which can move one control rod (blade) in a sinusoidal oscillation. The system is described below under the following:

1. Mechanical Description

2. Control and Safety Circuit

3. Equipment Design Calculations

4. Control Rod Worth

5. Equipment Tests

6. Accident Analyses

\section{Mechanical Description}

The control rod oscillator is an electro-mechanical system as shown in Figures 2-1 and 2-2. It is a feedback control system capable of maintaining a near sinusoidal movement of the control rod to match the desired sine wave which is generated by the variable frequency oscillator. If a scram occurs during operation of the system, an isolation valve stops the control rod oscillation and allows the rod to be inserted by the normal scram system.

The following description refers to the control rod oscillator system schematic shown in Figure 2-3.

a. The control rod drive is basically a hydraulic cylinder which is made up of an index tube and a collet finger arrangement which holds the control rod in a desired position, thus preventing the control rod from moving out of the core by its own weight. Each control rod index tube at Garigliano has 35 notches spaced every 3 inches, and the control rods are nor mally moved in 3-inch increments corresponding to the 35 notches. (Notch 35 is the fully-withdrawn position.) In order to achieve the desired oscillation amplitude of 


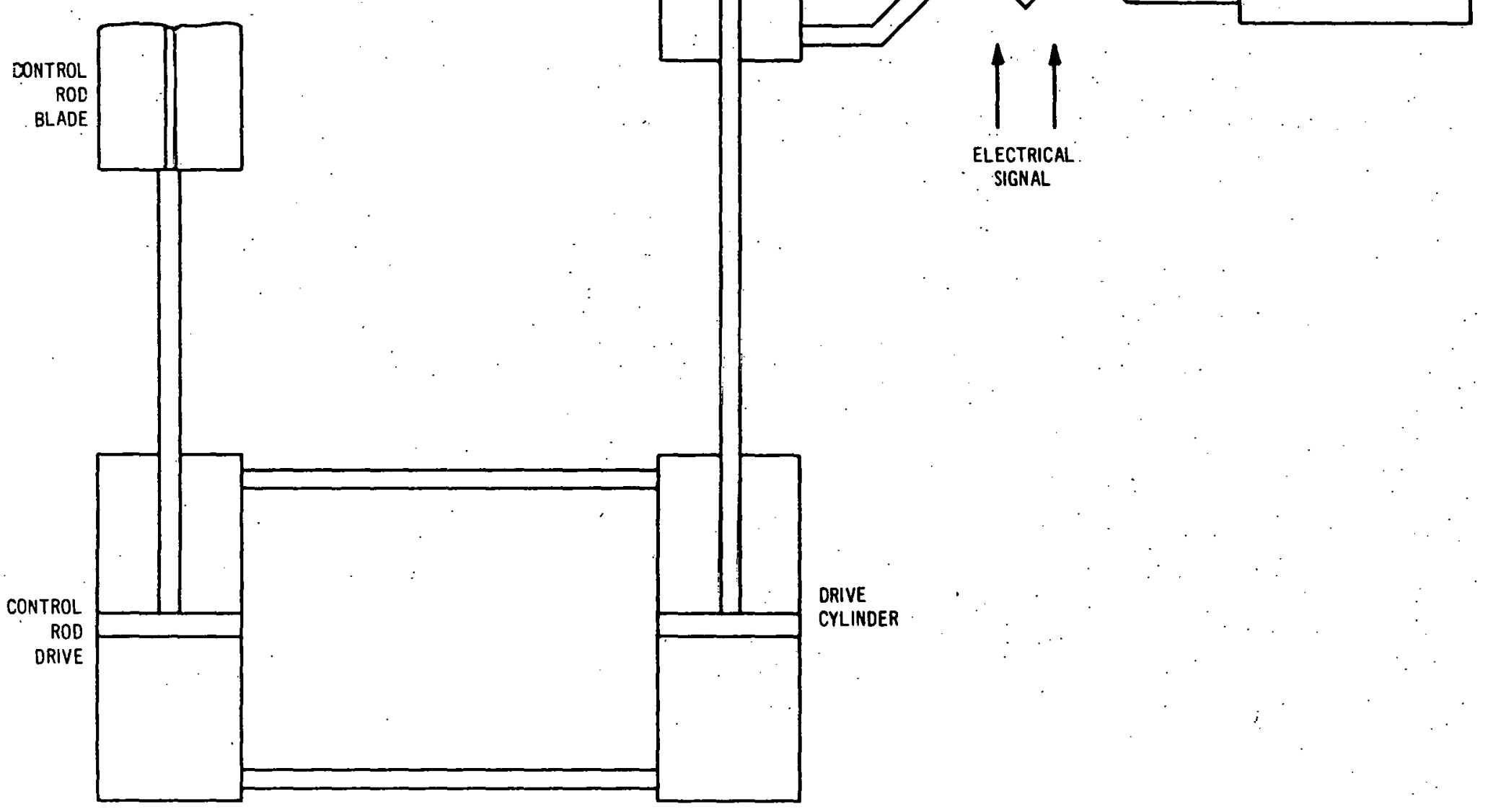




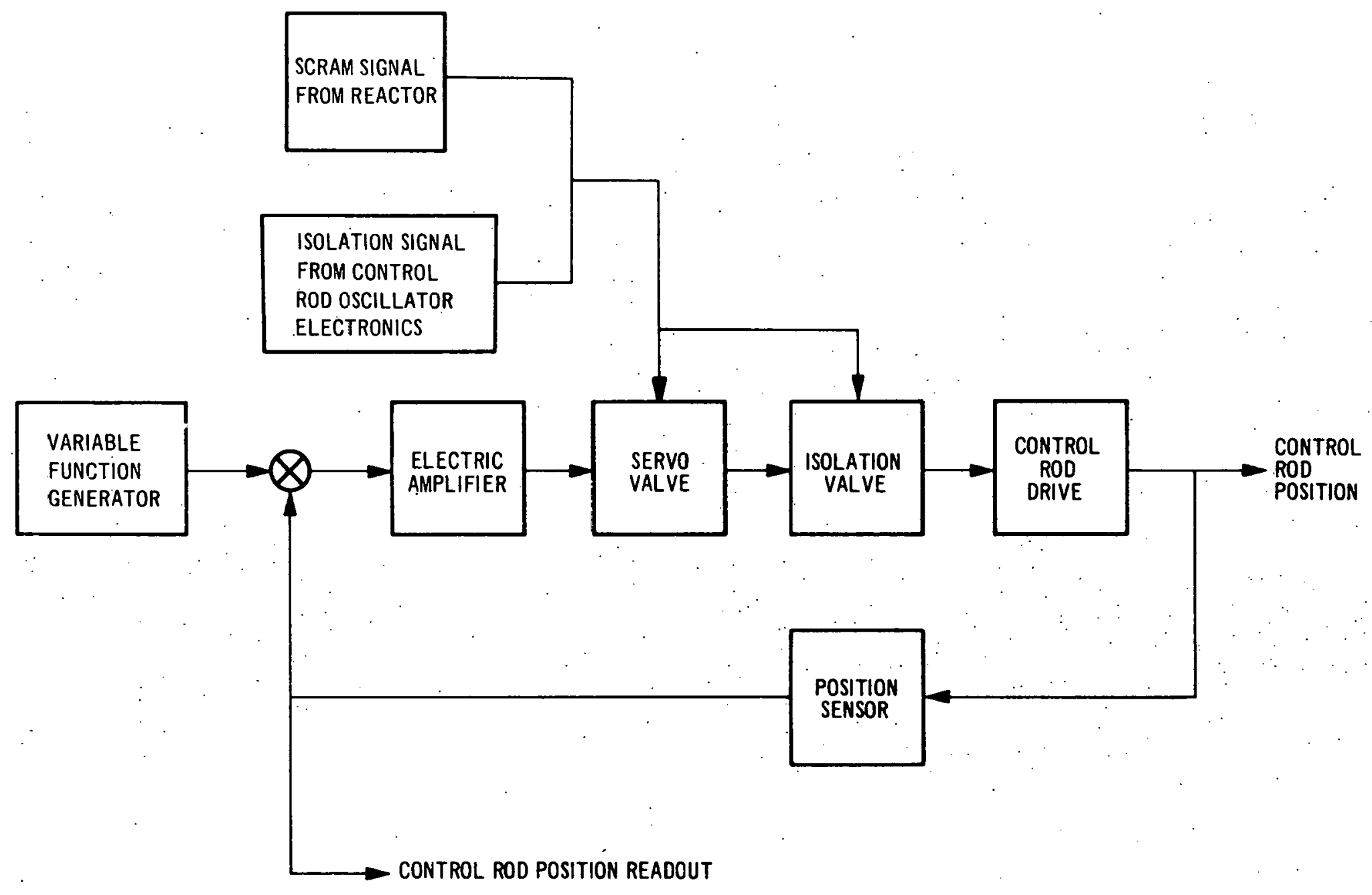




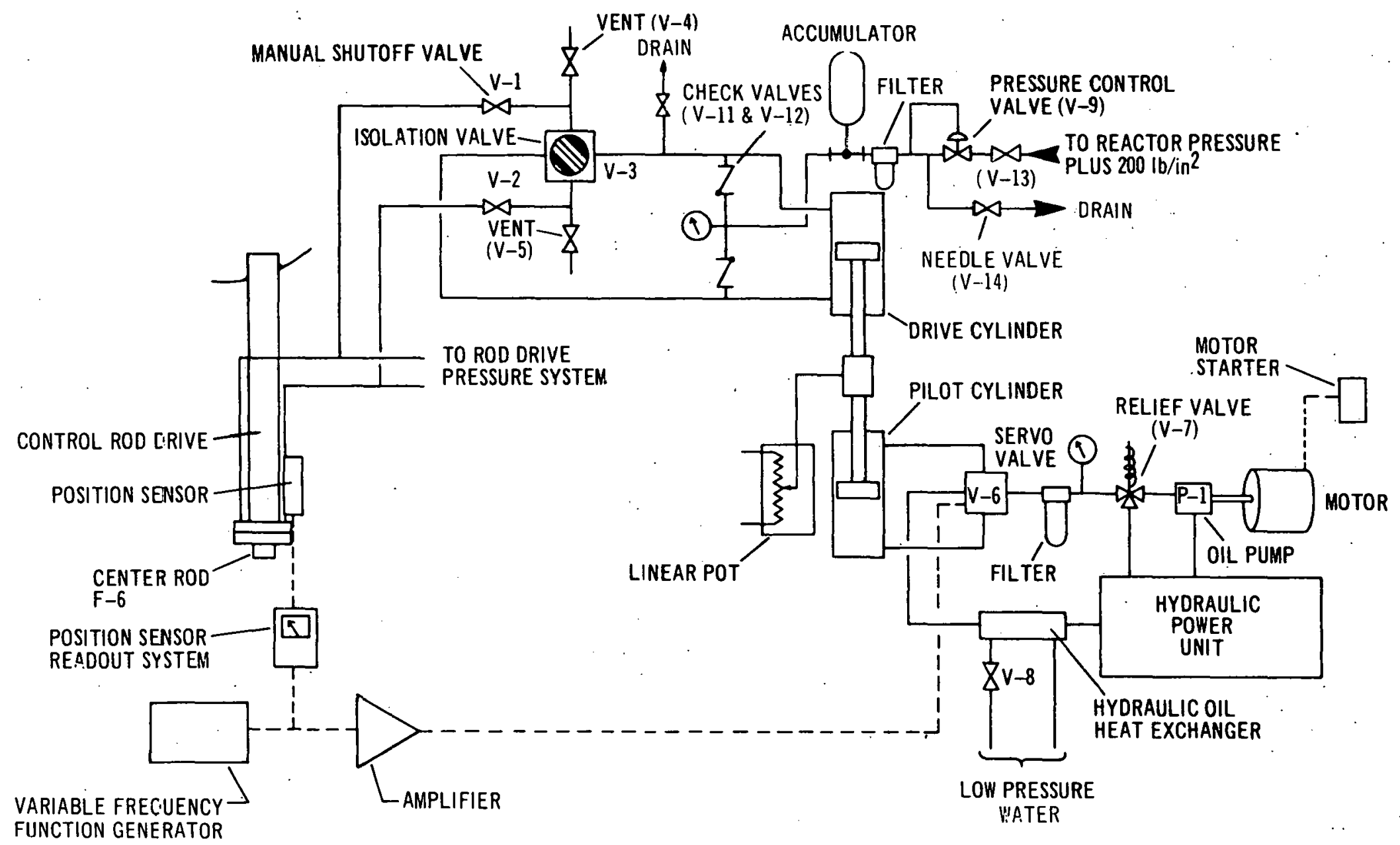


\pm 3 inches, it is necessary to remove a notch. Since the exact control rod pattern at the time of the tests is not yet known, notches at three locations have been removed; namely, 14,20 , and 26 . One of these locations will be satisfactory for any control rod pattern which may be encountered. All the rod oscillation tests will be run with the central control rod F-6 at one of these three positions.

This modified index tube will be supplied and it will be installed in the control rod drive $(F-6)$ at the time when the rod oscillator system is installed and it will be removed at the first shutdown after the rod oscillator tests.

b. Oscillation is obtained by first lifting the control rod off of the lower notch to the position between notches. The control rod can then be oscillated by varying the pressure above and below the index tube seals. The pressure variation is obtained by connecting a hydraulic cylinder (Drive Cylinder) across the ports of the Control Rod Drive and oscillating the piston of this Drive Cylinder thereby oscillating the control rod (Blade).

c. The hydraulic system, which makes up the Control Rod Oscillator System, consists of two closed and coupled hydraulic loops, called the Primary Hydraulic Loop and the Secondary Hydraulic Loop. The equipment has been assembled as a compact "module". This module is shown in the Equipment Test Section of this report.

d. The Primary Hydraulic Loop uses cold reactor feedwater as a working fluid and consists of:

(1) Control Rod Drive F-6

(2) Pressure transducers to measure the pressure applied to the drive cylinder.

(3) The isolation valve ( $\mathrm{V}-3$ ) which is a four-way, cylinder operated, open-centered land valve used as two two-way valves in parallel. When the rod oscillator system is isolated from the control rod drive system (i.e. the valve is closed) the valve is arranged such that a flow path exists only on the drive cylinder side. When the air solenoid valve is energized, the supply pressure moves the cylinder piston and the valve is turned $45^{\circ}$ ther eby opening the isolation valve. Now two flow paths exist between the rod oscillator system and the control rod drive system.

(4) Relief valves installed on the withdraw and insert pressure piping. These valves are set for 1750 psi to protect the system from over-pressure.

(5) The double-acting hydraulic drive cylinder which has a 6 inch bore and 6 inch stroke. The area of the large side of the piston is $28.3 \mathrm{in}^{2}$ and the area of the small side of the piston is $10.8 \mathrm{in}^{2}$. The large side of the piston is connected, through the isolation valve, to the insert port of the control rod drive and the small side of the piston is connected, through the isolation valve, to the withdraw port of the control rod drive.

(6) A bleed valve to permit positioning of the piston of the drive cylinder while the isolation valve is closed. 
e. The Secondary Hydraulic Loop uses oil as a working fluid and is mechanically coupled to the Primary Hydraulic Loop by means of a connecting shaft. The coupling shaft is connected to a linear motion potentiometer to be used for remote indication of the position of the cylinder within its stroke. The Secondary Hydraulic Loop consists of:

(1) The double-acting hydraulic Pilot Cylinder of 6-inch bore and 6-inch stroke similar to the Drive Cylinder.

(2) The Servo-Valve ( $V-6)$ which takes an electric signal and converts it to a proportional flow rate or pressure. The Servo-Valve is rated at $15 \mathrm{gpm}$ at $1000 \mathrm{psi}$ and $40 \mathrm{milli}-$ amperes for full flow.

(3) A filter to remove particles over 10 microns in size.

(4) A Relief Valve (V-6) which is used to set the oil pressure of the Secondary Hydraulic system.

(5) The Hydraulic Pump (P-1) is driven by a $17.5 \mathrm{hp} \mathrm{Reuland} \mathrm{electric} \mathrm{motor} \mathrm{(220/440}$ $\mathrm{VAC}, 3$ phase, $60 \mathrm{cps}$ ) which can be operated at $380 \mathrm{VAC}, 3$ phase, $50 \mathrm{cps}$ with only 10 percent decrease in power. The gear pump is rated at $12.5 \mathrm{gpm}$ at $2000 \mathrm{psi}$.

(6) A heat exchanger capable of removing $17.5 \mathrm{hp}$ of heat from the fluid. Flow of cooling water to the heat exchanger is controlled by means of Valve $(\mathrm{V}-8)$. Low pressure water is circulated through the heat exchanger.

(7) A Reservoir for storing the hydraulic oil used in the Secondary Hydraulic Loop.

f. Makeup of Control Rod Drive seal leakage water is provided by means of the Makeup Water System. This system consists of:

(1) Two $1 / 2$ inch Ball Check Valves $(\mathrm{V}-11$ and $\mathrm{V}-12)$. These check valves prevent the backflow of water from the Primary Hydraulic Loop to the makeup water system during oscillation.

(2) A Pressure Gage for determining the pressure level of the primary hydraulic system.

(3) The Pressure Control Valve (V-9) which regulates water pressure supplied from the reactor pressure plus 200 psi system. The pressure will be about 50 psi more than reactor pressure. This pressure will be controlled remotely at the rod oscillator control panel in the computer room.

(4) A Shutoff Valve $(V-13)$ installed ahead of the pressure control valve $(V-9)$.

(5) A Needle Valve ( $\mathrm{V}-14)$ to maintain a continuous flow through the pressure reducing valve, thereby never allowing the makeup pressure to exceed the remote pressure setting when the system is isolated. This valve is also used as a shutoff valve.

(6) A water filter to prevent particles over 20 microns in size from getting into the control rod drive mer.hanism.

(7) An accumulator, installed between the check valves and the water filter, which will smooth out any pressure pulses from the operation of the check valves. This 
accumulator will also help maintain the pressure constant at the point where the controller for the pressure control valve obtains its reference signal.

g. The position sensor equipment provides for an indication of the control rod position and supplies the feedback signal for the control circuit. (The probe positioner is shown in the Equipment Tests Section.) The system consists of:

(1) Hewlett-Packard magnetometer probe which senses the change in magnetic field strength from the magnet in the control rod being oscillated.

(2) A null coil around the probe which is used to null the effect of the magnets in the control rods near the control rod which is to be oscillated. This coil is also used for zero suppression of the signal from the probe.

(3) A probe positioner which is used to position the probe in the most ideal location along the side of the control rod drive. The distance from the center of the probe to the side of the control rod drive will be from 9 to 15 inches or 23 to $38 \mathrm{~cm}$. This is achieved by attaching the probe positioner on a control rod drive (E-5) near the central control rod drive and then rotating the probe positioner until a satisfactory distance is obtained. At this location, vertical motion of the probe is not impaired by any piping under the reactor or by the drive thimble stabilizer supports.

If, at the time of installation, it is determined that placing the probe positioner on control rod drive E-5 is not satisfactory another control rod drive would be chosen.

The probe is moved up and down by turning the lead screw. The lead screw is turned by a gear motor which is supplied by $110 \mathrm{VDC}$ and has a gear reducer on each end. The entire length of travel represents 10 turns at the lower gear reducer of the motor and a 10 turn potentiometer is attached to indicate the position of the probe.

\section{Control and Safety Circuit}

The control and safety circuit is designed to automatically shut down and isolate the rod os cillator system from the control rod drive if any of the following occur.

a. Reactor scram from any cause

b. High or low pressure in the insert or withdraw lines to the control rod drive.

c. Oscillating control rod moves out of the prescribed 6 inch range of oscillation.

d: Loss of power to the oscillator control circuit.

e. Loss of power to the hydraulic power unit.

f. Loss of nitrogen gas supply to the isolation valve control cylinder.

g. Reactor operator opens switch S-2 in control room. 
The control rod oscillator cannot be operated unless the reactor is operating; i.e., unless the reactor scram valves are energized, unless the hydraulic power unit is running, and unless the control rod position is within its specified limits.

The description of the Control and Safety Circuit shown in Figure 2-4 is as follows, starting from the top of the figure:

(1) The motor starter obtains its $380-\mathrm{VAC}, 3$ phase, $50 \mathrm{cps}$ power from the motor control center. The motor starter has one manual set of contacts $\left(\mathrm{S}_{3}\right)$ which must be turned on at the motor starter in the scram valve room. It also has a power relay $\left(R_{1}\right)$ which allows the motor to be started and stopped remotely from the rod oscillator control panel in the computer room.

(2) The motor for the hydraulic power unit will be started in the following manner: the 380$\mathrm{VAC}, 3$ phase, $50 \mathrm{cps}$ power is turned on at the motor control center, and the manual contacts $\left(\mathrm{S}_{3}\right)$ at the motor starter are closed. When the key locking switch $\left(\mathrm{S}_{1}\right)$ on the rod oscillator control panel is closed, relay coil $R_{1}$ will be energized which closes contact $K_{1}$, thereby energizing relay coils $R_{2}$ and $R_{3}$. When $R_{3}$ is energized, contact $K_{3}$ will be closed. This contact is the interlock for the motor and safety circuit. Thus, the isolation valve and servo-valve cannot be operated unless the motor, is running. Energizing relay coil $R_{2}$ closes contacts $K_{2(a, b, c)}$ which starts the motor and closes position indicating contact $\mathrm{K}_{2}$ pos and turns on the red light.

The green light indicates that relay coil $R_{1}$ is ready to be energized, and that switch $S_{1}$ is open. Therefore, the hydraulic power unit is ready to be started. Pushbuttons No. PB-1 and PB-2 are for emergency manual shutdown of the entire rod oscillator system. The pushbuttons are in two locations: in the scram valve room and on the rod oscillator control panel in the computer room.

(3) Safety Circuit. Relay $R_{4}$ energizes and de-energizes the isolation valve and the servovalve, and relay $R_{5}$ is the control relay for the safety circuit. The nine contacts which must be closed in order for relays $R_{4}$ and $R_{5}$ to be energized consist of: one manual switch in the reactor control room $\left(\mathrm{S}_{2}\right)$, two manual pushbuttons on the control rod oscillator panel in the computer room $\mathrm{PB}-4$ and $\mathrm{PB}-5$, an electronic trip unit that is essentially a limit switch which opens the circuit when the control rod is out of its predetermined oscillating range (this electronic trip unit obtains its signal from the control rod position sensor), one or both contacts from each scram bus $\left(\mathrm{K}_{A}\right.$ and $\left.\mathrm{K}_{\mathrm{B}}\right)$, one of which must be closed, one interlocking relay contact $\mathrm{K}_{3}$, the contacts of four water pressure switches, two on each line $\left(\mathrm{SP}_{1}, \mathrm{SP}_{2}, \mathrm{SP}_{3}, \mathrm{SP}_{4}\right)$, and one nitrogen gas pressure switch $\left(\mathrm{SP}_{5}\right)$. When the coil for the isolation valve and servo-valve relay $R_{4}$ is de-energized, relay coil $R_{6}$ is energized and contact $K_{6 a}$ is closed and the white light is on. This indicates that the isolation valve is not open but that all the pressure sensor and limit switches are closed and the system is ready to start. The time for relay $R_{4}$ to be de-energized is about 8 milliseconds. 


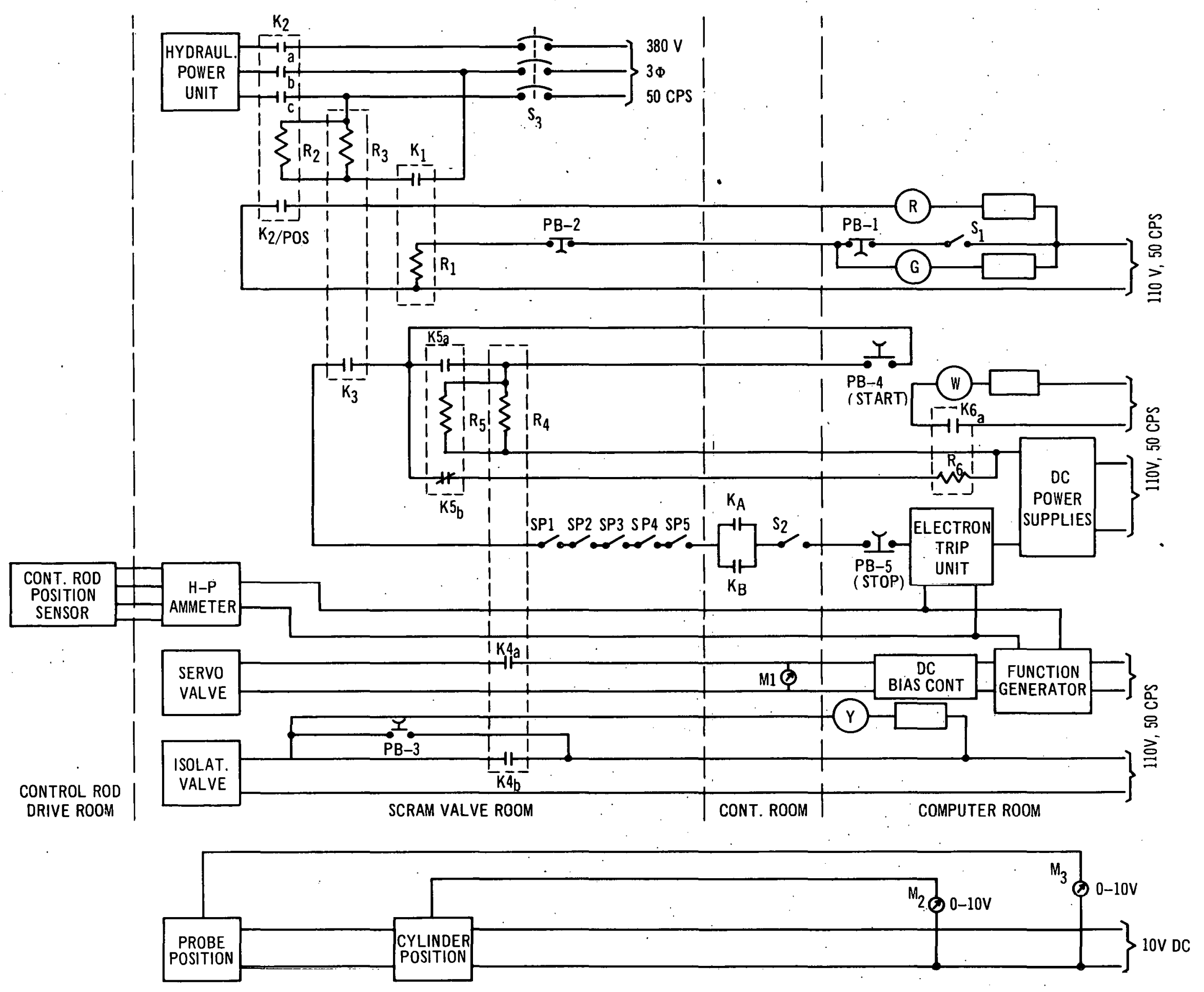


(4) Control relay $R_{5}$ provides for self-interlocking of the safety circuit. The discussion of this relay must be made in conjunction, with control pushbuttons PB-4 and PB-5. When the system is to be turned on, $\mathrm{PB}-4$ is pressed. At this position, the contacts $\mathrm{PB}-4$ and PB-5 are both closed; thus, relays $R_{4}$ and $R_{5}$ are energized. Contact $K_{5 a}$ of relay $R_{5}$ is closed, which locks-in relays $R_{4}$ and $R_{5}$. When PB-4 is returned to normal it is open but relays $R_{4}$ and $R_{5}$ remain energized. To shut off the system PB-5 is pressed. At this position, the contact of PB-5 is open, thus turning off the system.

(5). The power to the electronic trip unit of the safety circuit is $15 \mathrm{VDC}$, which is supplied to the circuit by two DC power supplies. Two power supplies are needed because the electronic trip unit requires input power of $+15 \mathrm{~V}$ and $-15 \mathrm{~V}$.

(6) The function of the yellow light is to indicate the position of the isolation valve. When the valve is open the light is off. Pushbutton PB-3 is provided so that the isolation valve may be operated independently from the rest of the system, for equipment test purposes. System operating procedures will clearly indicate when and how this pushbutton may be used. This pushbutton is inside the electrical control box on the rod oscillator system and the door is normally locked when the system is in operation.

(7) The control rod position sensor continually indicates the position of the control rod. This sensor is basically a Gaussmeter which senses the variation of the magnetic field due to the motion of the magnet in the oscillating control rod drive. The voltage-to-rod-position scale factor can be adjusted, as desired, to provide a feedback signal so that the response will be adequate.

(8) The function generator supplies a sinusoidal voltage. The frequency and amplitude may be adjusted as desired at the oscillator. This sinusoidal voltage from the function generator is electrically compared with the output of the position sensor and the error signal is amplified and is presented to the servo valve $(\mathrm{V}-6)$.

(9) The DC Bias control will enable the operator to manually null all unwanted DC from the control system circuit. The operator will manually move the control rod to the center of the 6 inch operating range with this DC Bias control before each oscillation test.

(10) The position of the probe and the position of the piston in the drive cylinder must be known during the tests. There is a 6 inch linear potentiometer attached to the drive cylinder piston shaft and a 10-turn potentiometer attached to the rear of the gear motor which makes 10 revolutions when the probe is moved from the bottom to the top of its travel. These two potentiometers are connected in parallel and are excited by 10 volts. Two $10 \mathrm{~V}$ voltmeters. $(\mathrm{M}-2, \mathrm{M}-3)$ are connected between the slide and ground of each potentiometer to indicate the position of the cylinders and the probe. 


\section{Equipment Design Calculations}

The rod oscillator system to be analyzed is shown in Figure 2-3. It is basically the same system which has been used at the Big Rock Point reactor. The mass of the control rod blade and index tube at Garigliano is $162 \mathrm{lb}$, compared to the Big Rock Point control rod drive mass of $140 \mathrm{lb}$. Since the weight is increased, a complete dynamic analysis was made. The design weight used in the calculations was $250 \mathrm{lb}$. This will allow for the mass of the water in the drive, and also give a slightly conservative answer.

The system pressure referred to in the following discussion is the pressure difference across the drive ports of the control rod drive. The absolute pressure of the rod drive when the drive is oscillating is reactor pressure (1000 psia) plus the system pressure.

The system pressure was calculated for various peak-to-peak amplitudes of the control rod oscillations. By plotting peak-to-peak amplitude of the rod oscillation versus frequency for a given system pressure, a family of curves of the allowable peak-to-peak oscillations was obtained, as shown in Figure 2-5.

The rod drive cylinders at SENN are coded for 1250 psi operating pressure. Operation at higher pressure has been investigated to determine whether the drive pressure will limit the operation of the oscillator mechanism. The reason for the $1250 \mathrm{psi}$ code stamp on the rod drives is that the drive housings were arbitrarily considered an extension of the reactor vessel, and the reactor vessel is rated for only $1250 \mathrm{psi}$. The control rod oscillator tests at Consumers Big Rock Point reactor used a peak control rod drive pressure of $1750 \mathrm{psi}$. The Consumers reactor rod drives are coded for 1750 psi operation, and have been operated successfully at that pressure. The pressure on the internal working parts of the drive is isolated from the reactor vessel. Detailed stress calculations for the Garigliano reactor show that a pressure of 1750 psi at $200^{\circ} \mathrm{F}$ will cause no damage to the drive. In view of these points, there seems to be no reason why the rod drive cannot be operated at $1750 \mathrm{psi}$. The drive cylinder pressure is still the limiting factor on oscillator amplitude at the higher frequencies.

The motor horsepower required to drive the system was calculated for different frequencies and peak-to-peak amplitudes of oscillation. Figure 2-6 is a curve for peak-to-peak amplitude versus frequency for a family of horsepowers. These curves are for continuous operation. Short time operation at higher power requirement will not result in motor overheating.

Based on the above analysis, it has been concluded that the Big Rock Point equipment size is adequate for the Garigliano application. The two primary parameters have been set as follows:

Drive motor

Control rod drive cylinder pressure.

\section{5 horsepower}

750 psi above the 1000 psi in the reactor vessel 


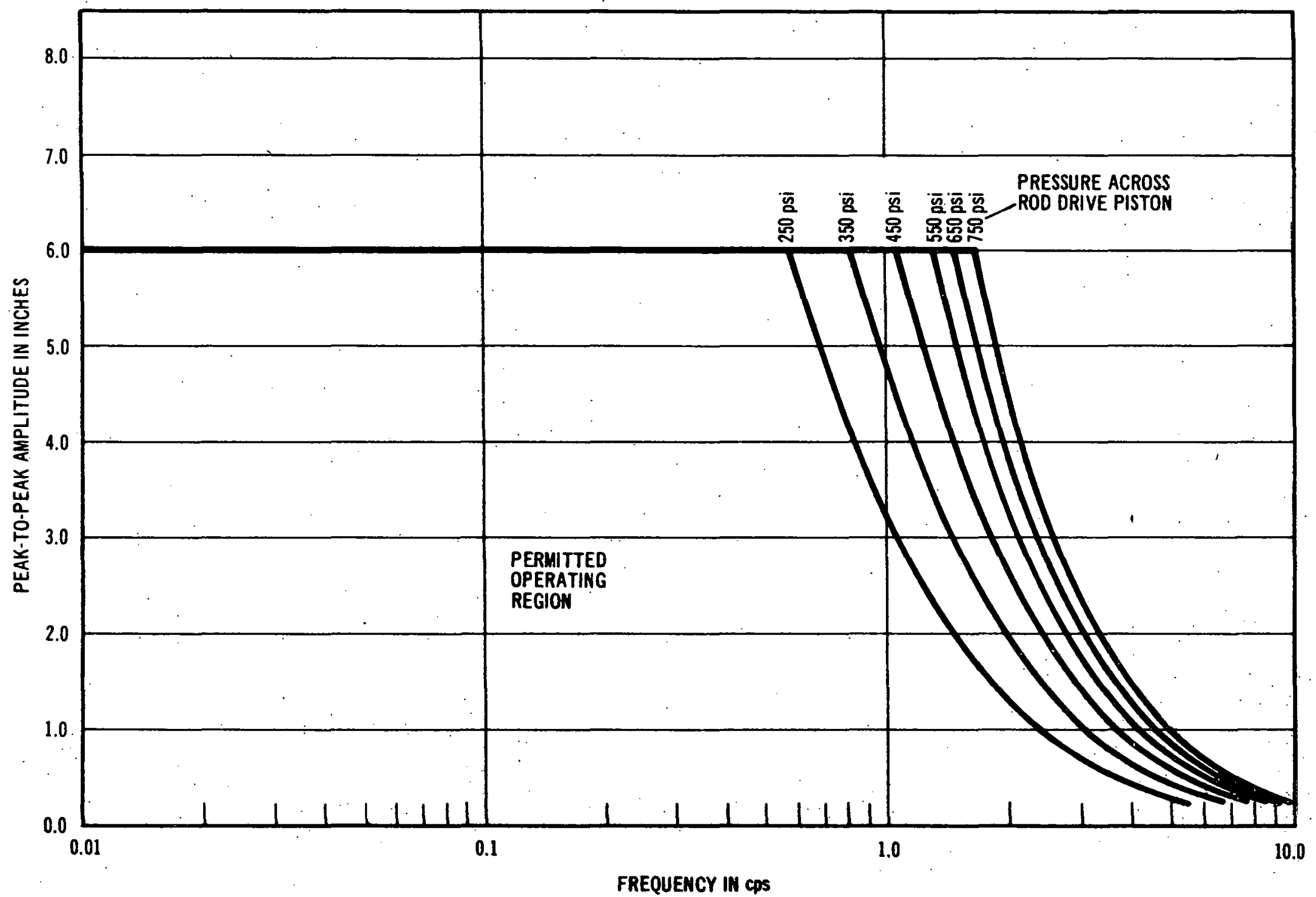

$\stackrel{i}{\stackrel{i}{N}}$

Figure 2-5. Allowable Peak-to-Peak Amplitude vs Frequency for Various Pressures across Rod Drive 


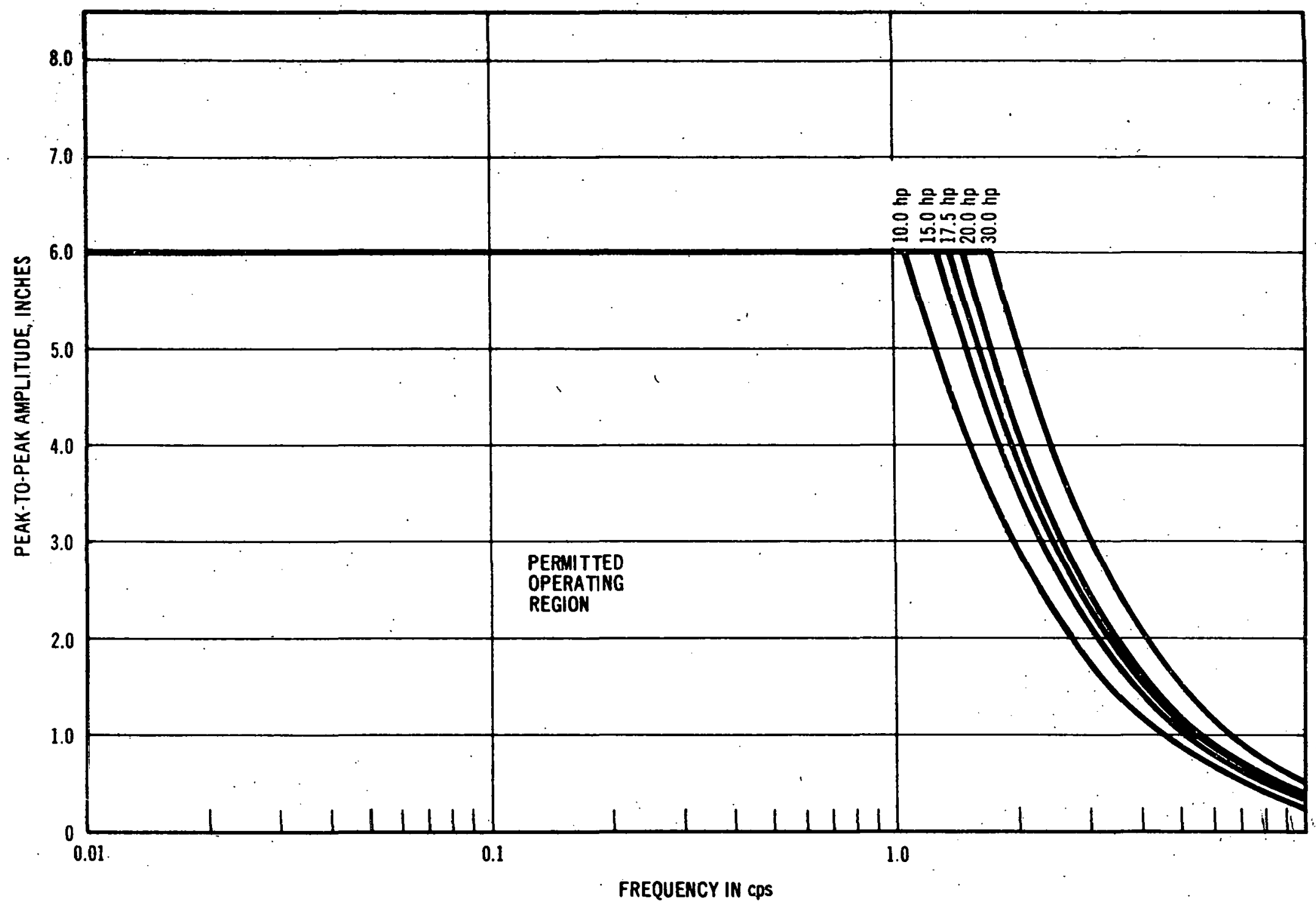


The corresponding limitations on oscillator amplitude and frequency have been calculated to be as shown in Figures 2-5 and 2-6. The limitations on amplitude and frequency will be measured during tests at San Jose on the entire rod oscillator system; and the operating limits for use at Garigliano will be based on the equipment tests rather than the calculated values reported here.

\section{Control Rod Worth}

The control rod oscillator is to be placed on the center control rod (F-6). The reactivity worth for a two-notch (6-inch) oscillation amplitude is highly dependent on both the position of the rod being oscillated and also the surrounding control rods. Preliminary information indicates that the reactivity worth will be between essentially zero and 50 cents $/ 6$ inches, depending on the control rod positions. The maximum worth is obtained when rod F-6 is inserted to the peak flux location and the surrounding rods are removed. The minimum worth is achieved when the surrounding rods are inserted further than F-6 and thus "shadow" the F-6 rod. The desired worth is intermediate between these two conditions.

It is desired to adjust the reactivity worth of rod F-6 and the oscillation amplitude so that the reactor neutron flux response is approximately \pm 5 to 10 percent from the average value, for each frequency tested. Each rod oscillator test will consist of a series of runs at different frequencies from about 0.01 to 15 cycles/sec. Each series is to be made at the same control rod pattern, but the oscillation amplitude is adjusted to give an easily measurable flux response ( \pm 5 to 10 percent) at each frequency. The maximum oscillation amplitude is limited by mechanical considerations at the frequencies above about $1 \mathrm{cycle} / \mathrm{sec}$, as has been discussed previously. The amplitude can be reduced as much as desired by reducing the output of the reference signal from the sine wave generator.

It is concluded that the desired flux response can be achieved over the whole range of frequencies (except for mechanical limitation above $1 \mathrm{cycle} / \mathrm{sec}$ ) by the independent adjustments of oscillator amplitude and control rod worth; i.e., control rod insertion pattern. The expected rod oscillator test results are shown in Section V-A of this report.

\section{Equipment Tests}

The rod oscillator system has been designed, assembled and is now being tested in San Jose, California, U. S. A. The assembled mechanical equipment module is shown in Figures 2-7, 2-8, $2-9$, and 2-10. The control rod drive and position sensor, as installed in the test facility, is shown in Figure 2-11. 
List of equipment corresponding to the numbers on the photographs in Figures 2-7, 2-8, $2-9,2-10$, and $2-11$.

1. 17-1/2 horsepower electric motor

2. Oil reservoir

3. Oil filter

4. Oil cylinder

5. Heat exchanger

6. Servo-valve

7. Electronics for probe output

8. Motor starter for $17-1 / 2$ horsepower motor

9. Electrical control box

10. Controller for pressure control valve

11. Isolation valve

12. Accumulator

13. Pressure control valve

14. Water cylinder

15. Pressure switches

16. Supply lines to the heat exchanger

17. Reactor pressure supply line

18. Reactor pressure plus 200 supply line

19. Valve used for test purposes

20. Lubricator for nitrogen

21. Nitrogen supply line for the isolation valve

22. Check valves

23. Water filter

24. Relief valve

25. Withdraw piping

26. Insert piping

27. Drain

28. Control rod drive

29. Probe positioner

30. Probe and null coil 
31. Extension to allow the probe to be moved a desired distance from the control rod drive for the tests at San Jose. (Will be removed before shipment. )

32. Nut (normal mounting for the probe - null coil assembly)

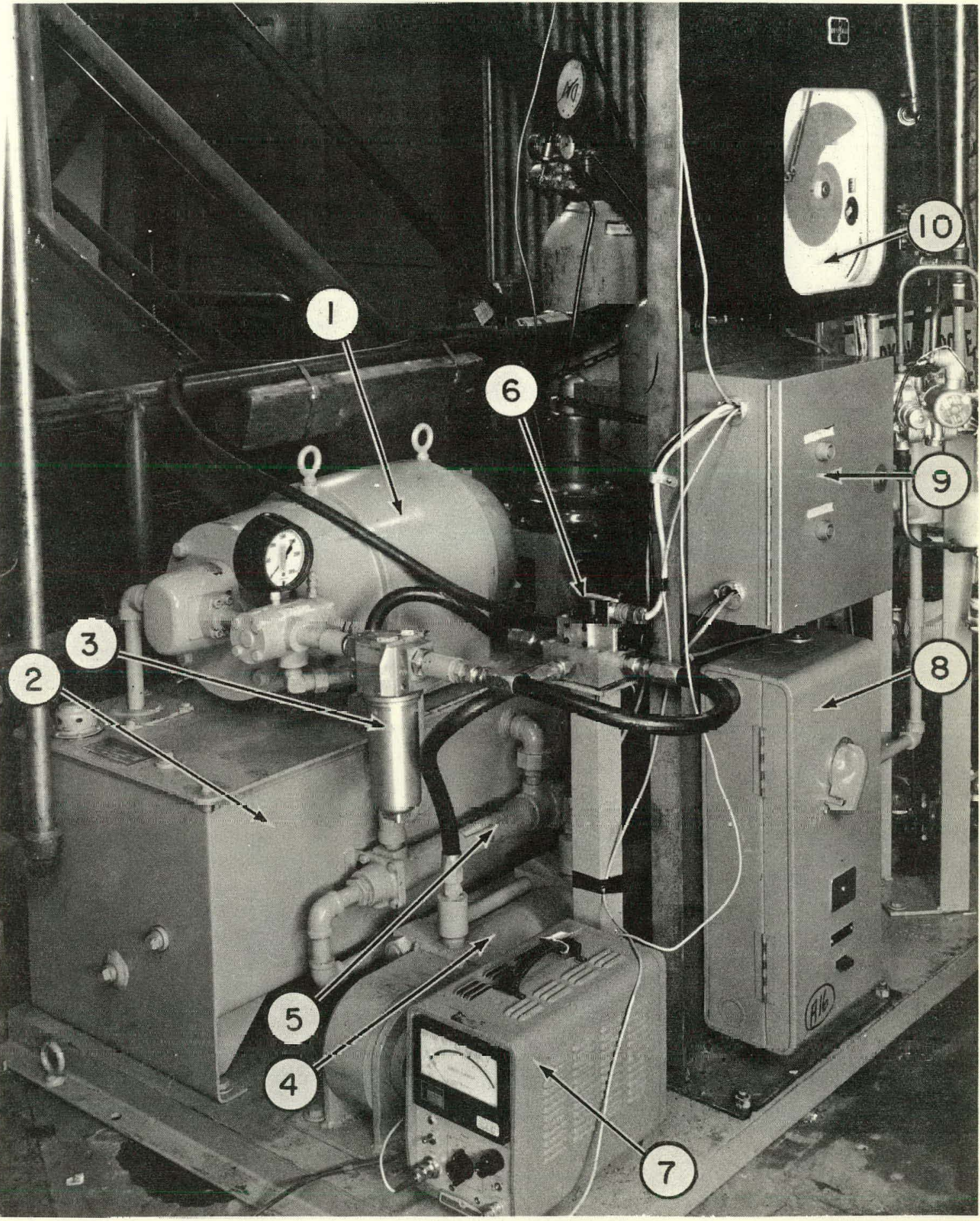

Figure 2-7. Control Rod Oscillator Drive Module 


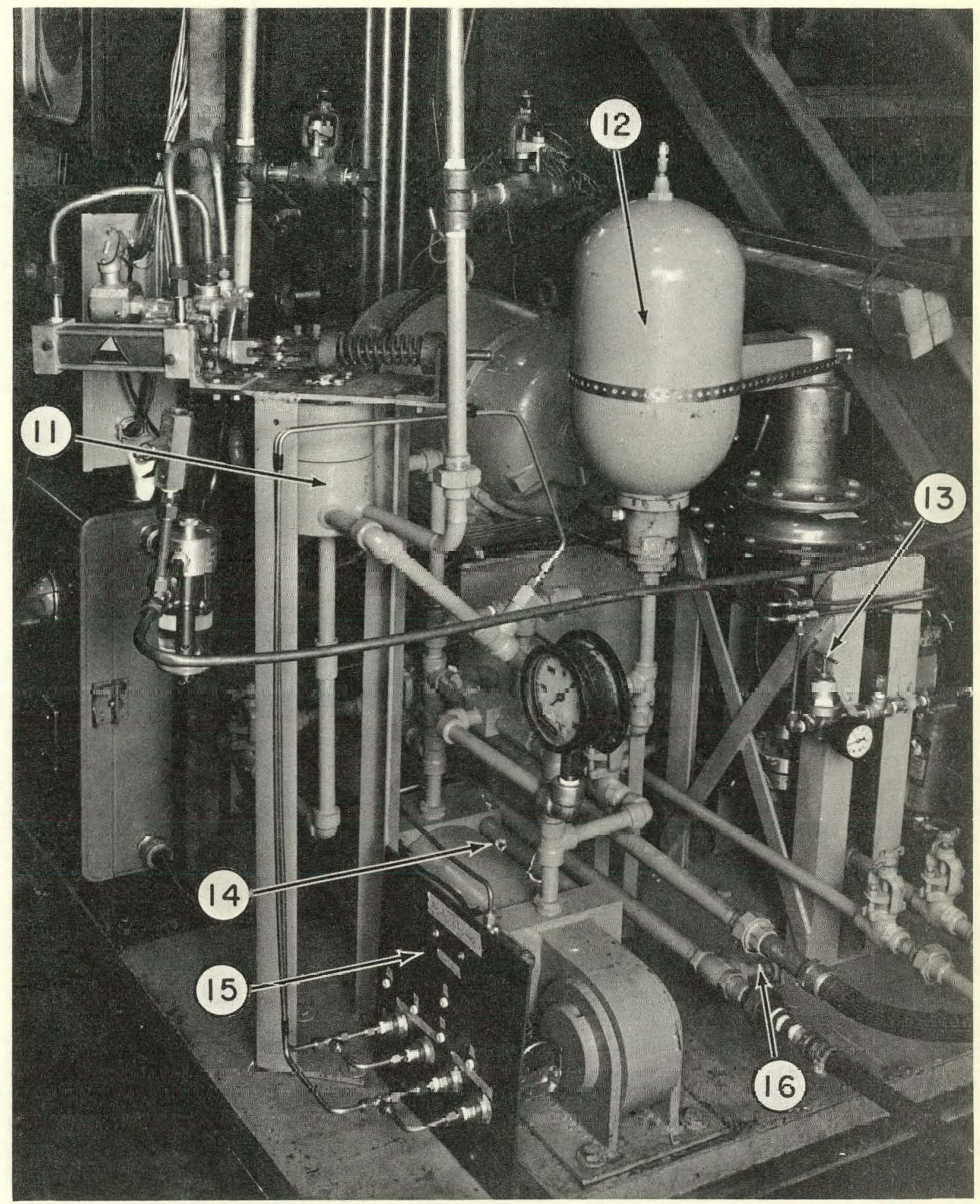

Figure 2-8. Control Rod Oscillator Drive Module 


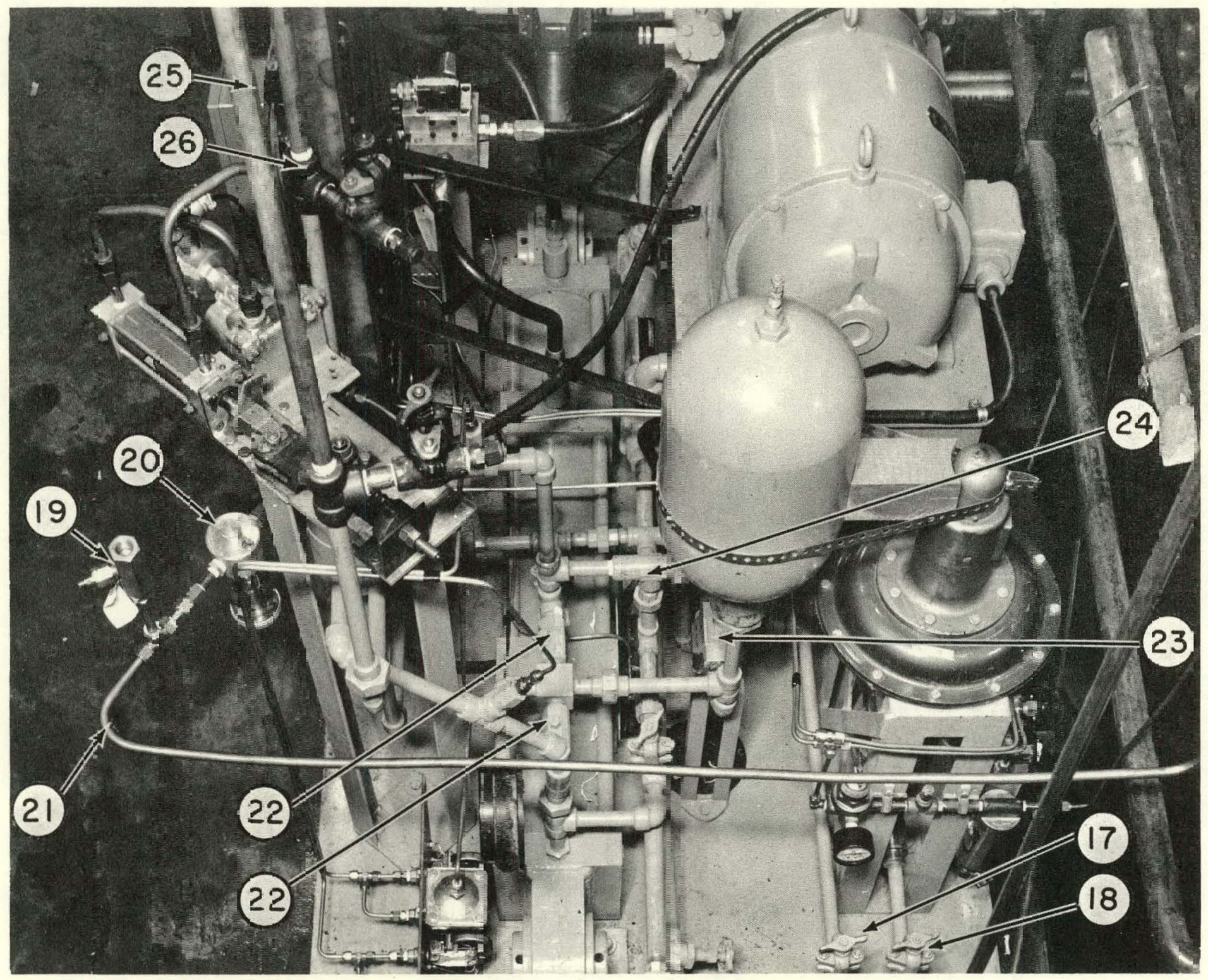




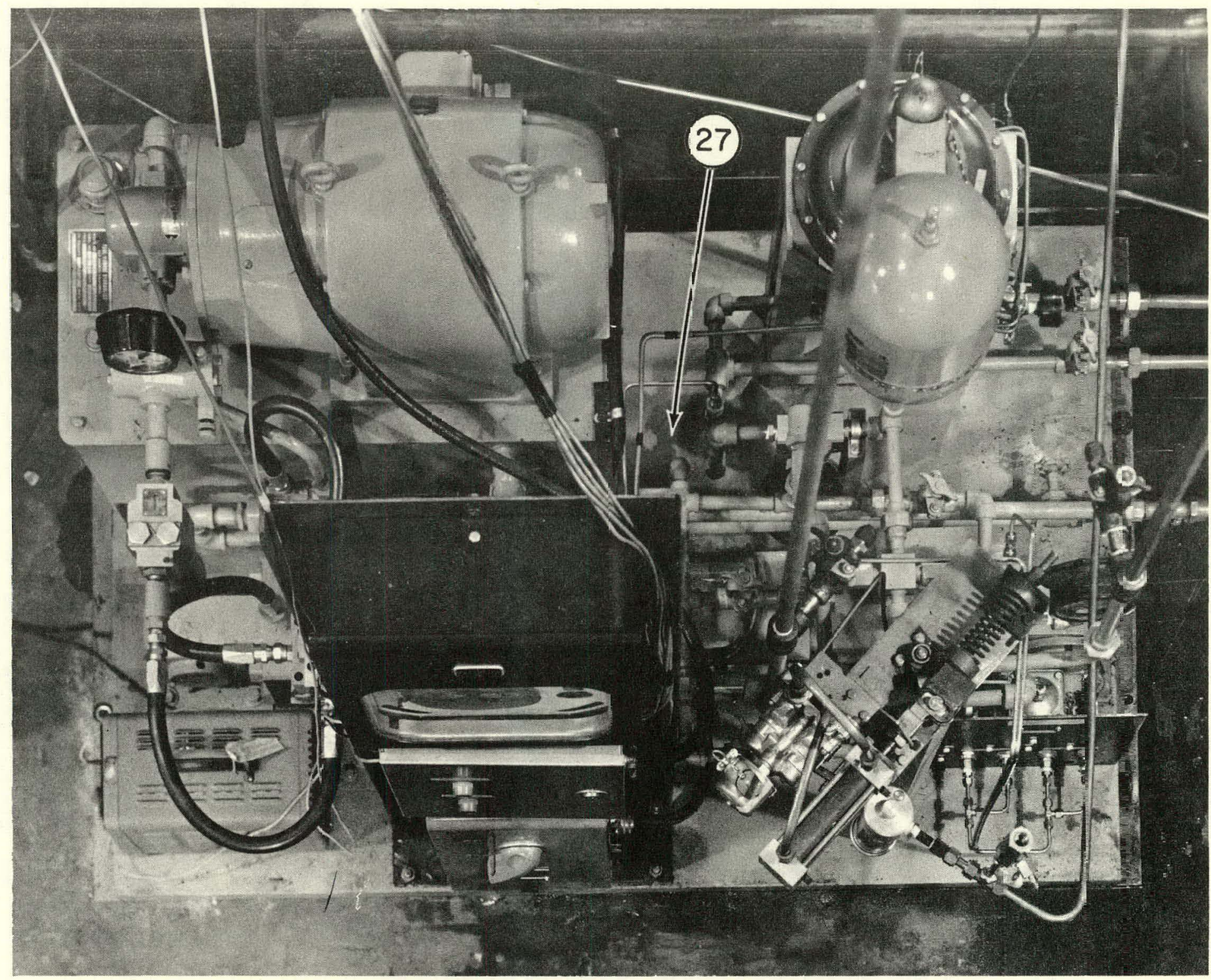




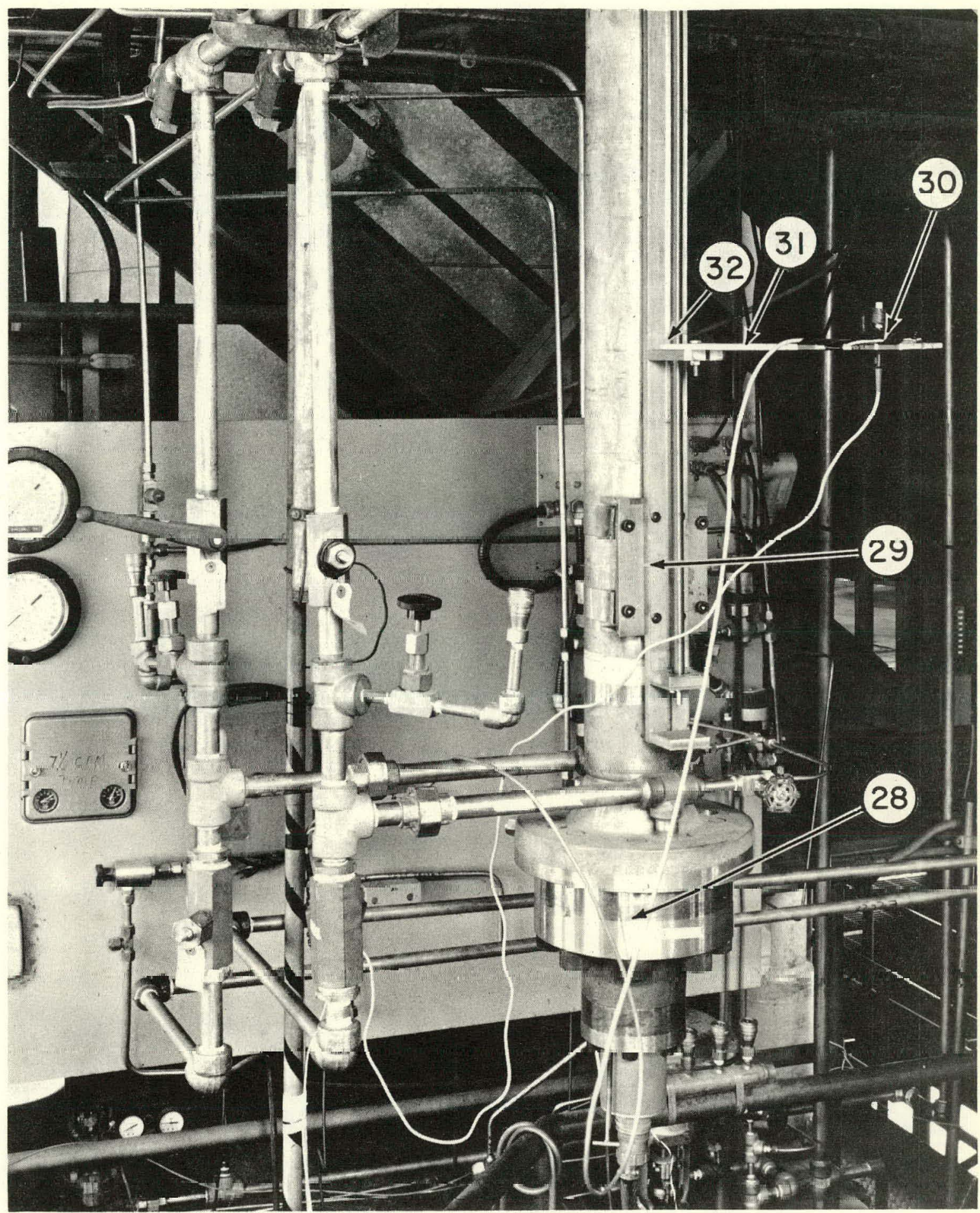

Figure 2-11. Control Rod Drive and Probe Positioner 
Test data has been obtained on the speed of operation of the isolation valve. Using 155 psig nitrogen from a gas cylinder to operate the valve and with zero pressure in the rod oscillator system the following was obtained.

\begin{tabular}{|c|c|}
\hline Action & $\begin{array}{c}\text { Time } \\
\text { (milliseconds) }\end{array}$ \\
\hline $\begin{array}{l}\text { Normal closure of valve }\left(45^{\circ} \text { rotation) }\right. \\
\text { (Valves are closed in } 1 / 2 \text { of } 45^{\circ} \text { rotation) }\end{array}$ & 22 \\
\hline $\begin{array}{l}\text { Normal opening, full travel } \\
60 \% \text { of stroke }\end{array}$ & $\begin{array}{r}140 \\
20\end{array}$ \\
\hline $\begin{array}{l}\text { Simulated slow leak in nitrogen supply - time for valve } \\
\text { closure }\end{array}$ & 22 \\
\hline $\begin{array}{c}\text { Simulated line break in nitrogen supply - time for valve } \\
\text { closure }\end{array}$ & 25 \\
\hline
\end{tabular}

These values are satisfactory as shown in the accident analyses.

The position sensor output, as the control rod is moved at constant speed, is shown in Figure 2-12. The linear range is about $2-1 / 2$ notches or $7-1 / 2$ inches for this test with the probe 12 inches from the side of the control rod drive.

The remaining equipment tests will demonstrate proper operation of the entire system over the range of frequencies and operating pressures that will be encountered at Garigliano. The maximum permissible amplitude for 1750 psi pressure at the control rod drive will be experimentally determined for each frequency.

\section{Accident Analysis}

The electrical control circuit has been designed so that it is fail-safe with respect to either equipment failure or operator errors. Specific design considerations and accident analyses are listed below.

a. If the reactor should scram for any cause, the control rod oscillator system will be isolated in about 20 milliseconds. This is less than the time required for the scram valves to start to open and therefore, the rod will scram normally with no interference from the oscillator system.

b. When the control rod oscillator is operating, the pressure difference across the drive piston is changing sinusoidally. To prevent over pressure of the control rod drive, pressure limit switches are installed on the insert and withdraw lines. If either pressure switch opens as a result of over-pressure, the control rod oscillator will be shut down and it will be isolated from the control rod drive, thus preventing over-pressure of the system.

The pressure switches for the high pressure limit will be set for 1800 psi even though the allowable pressure that the control rod drive may receive is $1750 \mathrm{psi}$. The reason for 


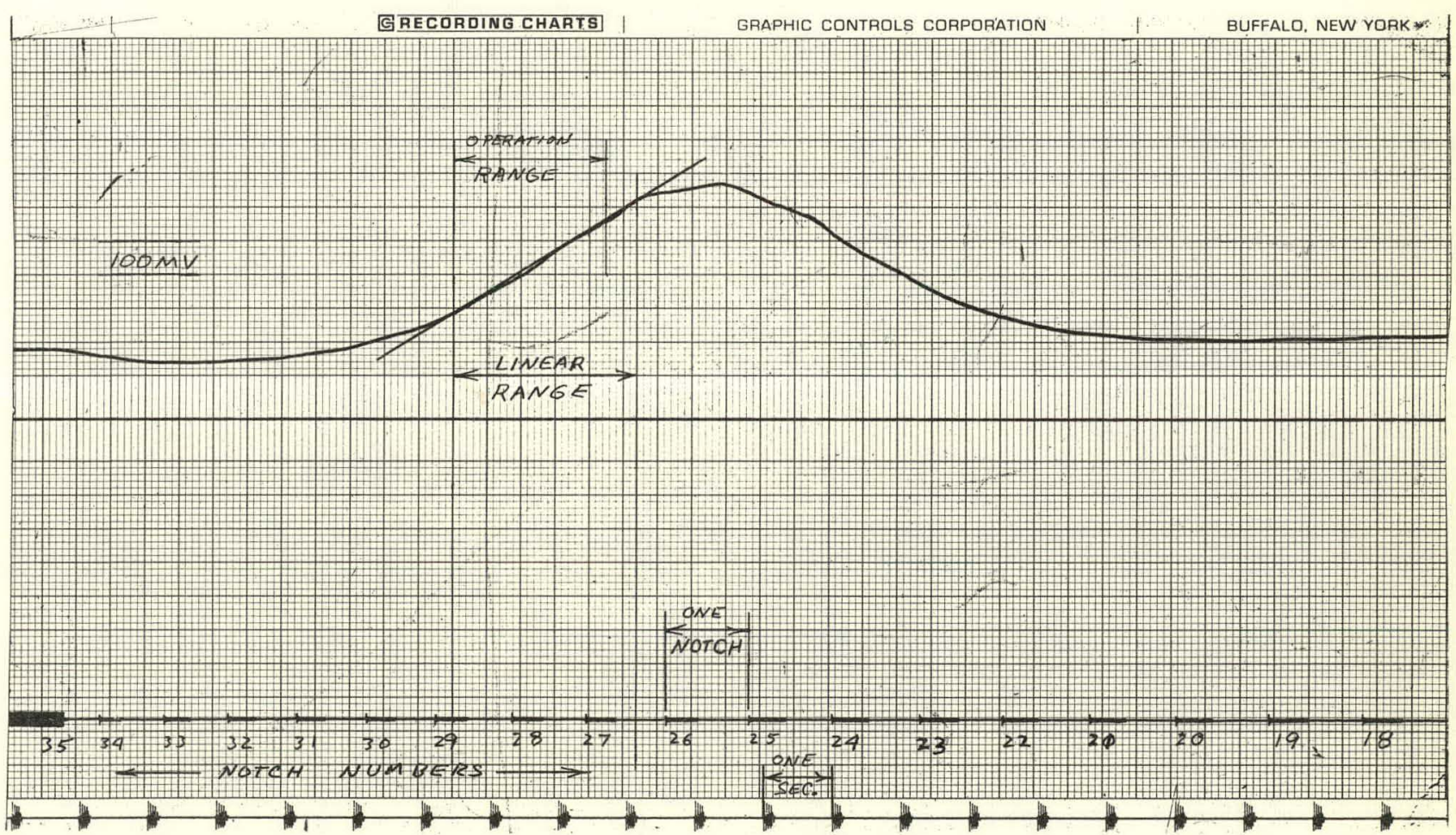

Figure 2-12. Position Sensor Output vs Position of Control Rod 
setting the pressure limit at the rod oscillator 50 psi above the allowable pressure that the drive may receive is because there will be at least 50 psi pressure drop from the pressure sensor to the control rod drive. When the tests of the rod oscillator are conducted at San Jose, pressure transducers will be installed at the rod oscillator system and at the control rod drive on the insert and withdraw lines; and the pressure will be recorded. The pressure piping from the control rod oscillator system to the control rod drive for the tests at San Jose has been designed to give approximately the same pressure drop as the piping from the control rod oscillator to the control rod drive for the piping at Garigliano.

c. Low pressure switches are installed on the insert and withdraw piping to isolate the system if a line break occurs in the insert or withdraw piping.

d. If the control rod moves out of its prescribed range of oscillation, the control rod oscillator system will be automatically isolated from the control rod drive.

e. Should the electrical control circuit lose power, relays $R_{4}$ and $R_{5}$ become de-energized and contacts $K_{4 a}$ and $K_{4 b}$ will open and isolate the rod oscillator system.

f. If the $380 \mathrm{VAC}, 3$ phase, $50 \mathrm{cps}$ power to the hydraulic power unit fails for any reason, relay coil $R_{3}$ will become de-energized and open contact $K_{3}$. This will cause the control rod oscillator system to become isolated from the control rod drive.

g. A pressure switch is installed in the nitrogen supply line to the isolation valve. Should a leak or break in the nitrogen supply line to the isolation valve occur, the control rod oscillator system will be isolated from the control rod drive.

h. The reactor control room operator may open switch $S_{2}$ and shut down the system, if required. This would be done if the reactor neutron flux became excessive (over $+15 \%$ ) for any reason. This switch also prevents operation of the oscillator without specific approval and knowledge of the control room chief operator.

i. Line break accident. There is a chance (very remote) that the withdraw or insert piping line to the control rod drive will develop a leak or rupture during oscillation. If this occurs, the control rod oscillator will be isolated from the control rod drive, and the inherent design features of the control rod drive will stop the control rod. This accident is no more severe than if one of the other drives developed the same problem during the normal operation of the control rod drive mechanism. Every precaution will be taken to prevent this accident from happening. Only high-quality, seamless, stainless steel, Schedule 80 pipe will be used in the installation of the control rod oscillator system, and the system will be hydro-tested to one and a half times its working pressure of 1750 psi to ensure that the piping and welds at all the joints are strong enough to withstand that pressure.

j. Effect of missing notches during normal operation. During normal operation of the reactor, the missing control rod notches affect operation only when the desired control rod pattern calls for a movement of rod F-6 past the notches in question. The rod must be 
moved in a two-notch step. Tests made during the plant startup ${ }^{(1)}$ showed that a twonotch step (notch 10 to 12) of a rod at the center of the core resulted in an average core power change of 1.5 percent of rated, and a local power change on an in-core chamber of 7 percent. Changes of this magnitude should not be a problem. If necessary, the change could be compensated by a change in secondary steam flow or motion of another control rod. Power reduction while making the two-notch rod position change is not necessary, but could be used in case of doubt.

k. Malfunction of electrical control system. When the control rod oscillator is operating, there is a conceivable possibility of some malfunction of the electrical system as a result of a component failure. This could send an improper signal to the control valve which would accelerate the control rod either in or out.

If this accident occurs, one of two methods of isolation will take place: (a) the system will be isolated when the high pressure limit for the insert or withdraw lines is reached, or (b) when the control rod is driven out of its permitted oscillating range, the trip unit will isolate the system. As an example of a severe accident of this type, assume that this accident will occur for the worst condition; that is, the control rod is 3 inches or one half of the distance away from the notch that represents the lower position in its oscillating range, and the velocity is at its maximum in the withdraw direction or 55 inches/ sec. This is the peak velocity for an oscillation amplitude of \pm 3 inches at 1.5 cycles/ second:

Also it is assumed that the malfunction occurs is such a way that the pressure is maintained at 1750 psi above the control rod drive piston, thus resulting in a steady acceleration in the withdraw direction. The $\Delta \mathrm{P}$ of the drive cylinder will be $1750-1000$ or $750 \mathrm{psi}$ and the force on the control rod drive will be $750 \mathrm{psi} \times 1.10 \mathrm{in}^{2}=825 \mathrm{lb}$ and the acceleration will be $825.0 / 250=3.3 \mathrm{G}$ 's plus $1 \mathrm{G}$ due to the acceleration of gravity.

After 3 inches of travel at steady acceleration the velocity would be 114 inches $/ \mathrm{sec}$. Actually the maximum velocity is limited by the flow rates through the hydraulic pump and servo valve (13 gpm). This corresponds to a control rod velocity of 50 inches/second. As a conservatism, made to allow for possible future modification of the drive system, the limiting velocity used is 100 inches/second for withdrawal and 33 inches/second for insertion. Since a rod withdrawal accident has been assumed, the 100 inches/second limiting value is used.

At this point the rod moves out of the specified operating range and the control rod oscillator will be isolated from the system by the trip unit. When the position of the control rod reaches the trip unit set point the isolation procedure will start. It will take 8 milliseconds for the trip unit to open relay $R_{5}$ and another 12 milliseconds for the isolation valve to close the lines between the control rod oscillator to the control rod drive. (The

(1) W. I. Collett, Personal Communication 
valve isolates the system in one half the time it takes to turn the full $45^{\circ}$ of valve travel. The total time, therefore, will be about 20 milliseconds. In that time, the control rod will travel 100 inches $/$ second $\times 0.020 \mathrm{sec}=2.0$ inches.

The distance of travel after the isolation is small because the hydraulic piston of the control rod drive will be closed except for the seal leakage. The system is essentially a dash-pot and the control rod will stop very rapidly. The collet finges will stop the control rod at the next notch or, at least, the second notch.

Thus even for very conservative assumptions, the rod would not travel more than one or two notches outside the prescribed oscillating range.

1. Stress on the Control Rod Drive. For a given sinusoidal oscillating frequency and amplitude, there is a maximum velocity and a maximum acceleration associated with this oscillating condition. By assuming that the motion of the control rod is sinusoidal, the maximum velocity and acceleration may be calculated as follows:

$$
\begin{aligned}
\alpha & =\text { amplitude of oscillation in inches } \\
\text { Position, } \mathrm{x} & =\alpha \sin 2 \pi \mathrm{ft} \\
\text { Velocity, } \mathrm{v} & =\alpha 2 \pi \mathrm{f} \cos 2 \pi \mathrm{ft} \\
\text { Acceleration, } \mathrm{a} & =-\alpha 4 \pi^{2} \mathrm{f}^{2} \sin 2 \pi \mathrm{ft}
\end{aligned}
$$

The maximum acceleration in G's will be

$$
a=\frac{\alpha 4 \pi^{2} \mathrm{f}^{2}}{12 \times 32.2} \text { (in G's) }
$$

By plotting rod velocity versus frequency for a given peak-to-peak amplitude and cross plotting the allowable pressure versus frequency (Figure 2-13) for a given peak-to-peak amplitude on the same curve, the maximum velocity attained for a given pressure can be obtained. This shows the maximum velocity which the control rod can have for the maximum allowable delta pressure across the rod drive ports. The maximum velocity will be nearly 55 inches/sec near $1.5 \mathrm{cps}$ and a 6 inch peak-to-peak amplitude. During a normal scram from full out to full in, the velocity of the control rod is about 70 inches/ sec. When the control rod oscillation tests are being performed, the maximum velocity is only 55 inches/sec which is well within the normal operation of the control rod.

Similarly, the maximum acceleration of the control rod may be obtained. Figure 2-14 shows that the maximum acceleration is about $3 \mathrm{G}$ 's. The acceleration from full out to full in of a normal scram is considerably larger than $3 \mathrm{G}$ 's. When the control rod oscillations are being performed, the maximum acceleration is only $3 \mathrm{G}$ 's, which is well within the normal operation of the control rod. 


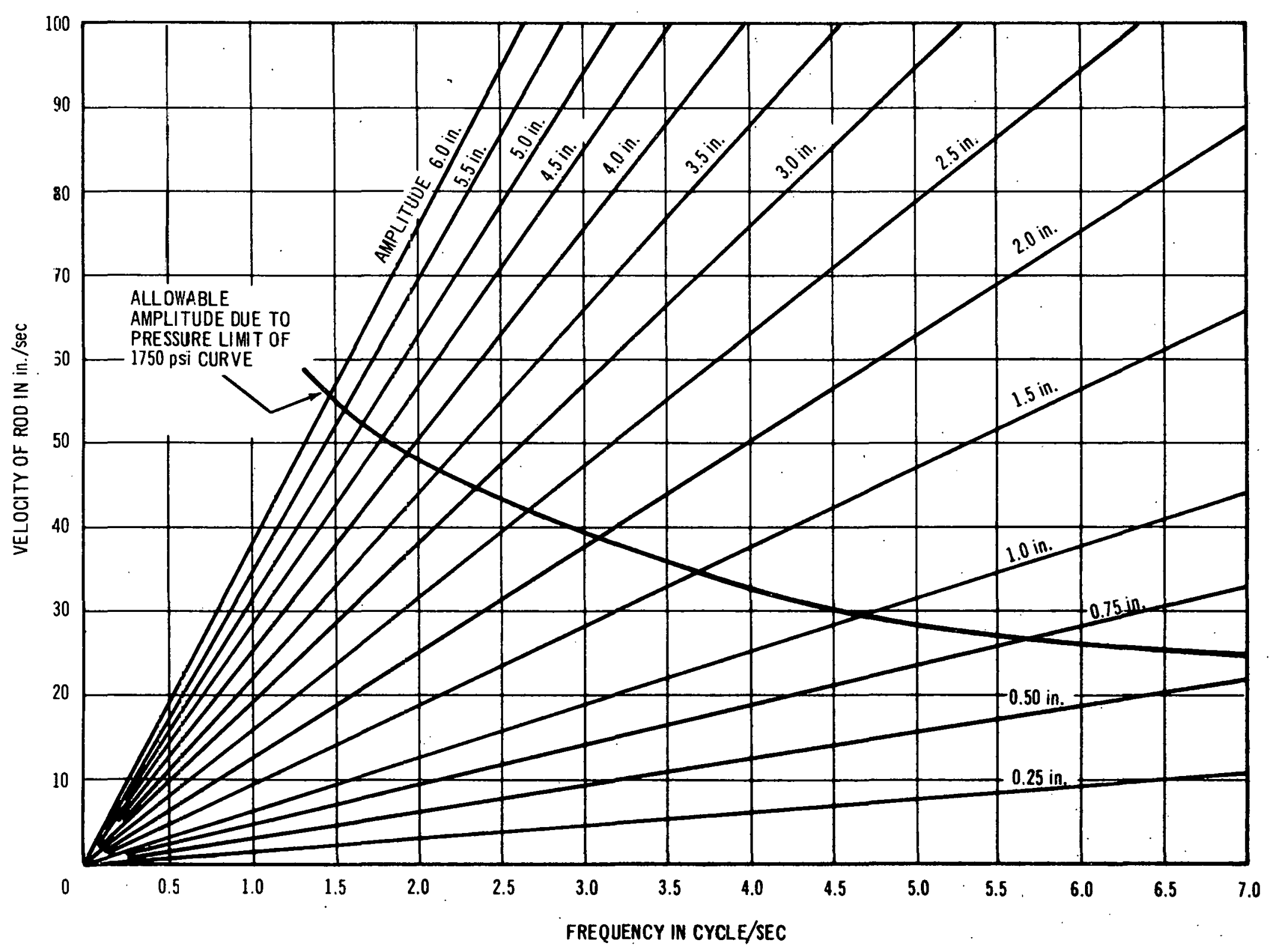

ஸे

Figure 2-13. Velocity of Rod vs Frequency for One Pressure at Various Peak-to-Peak Amplitudes 


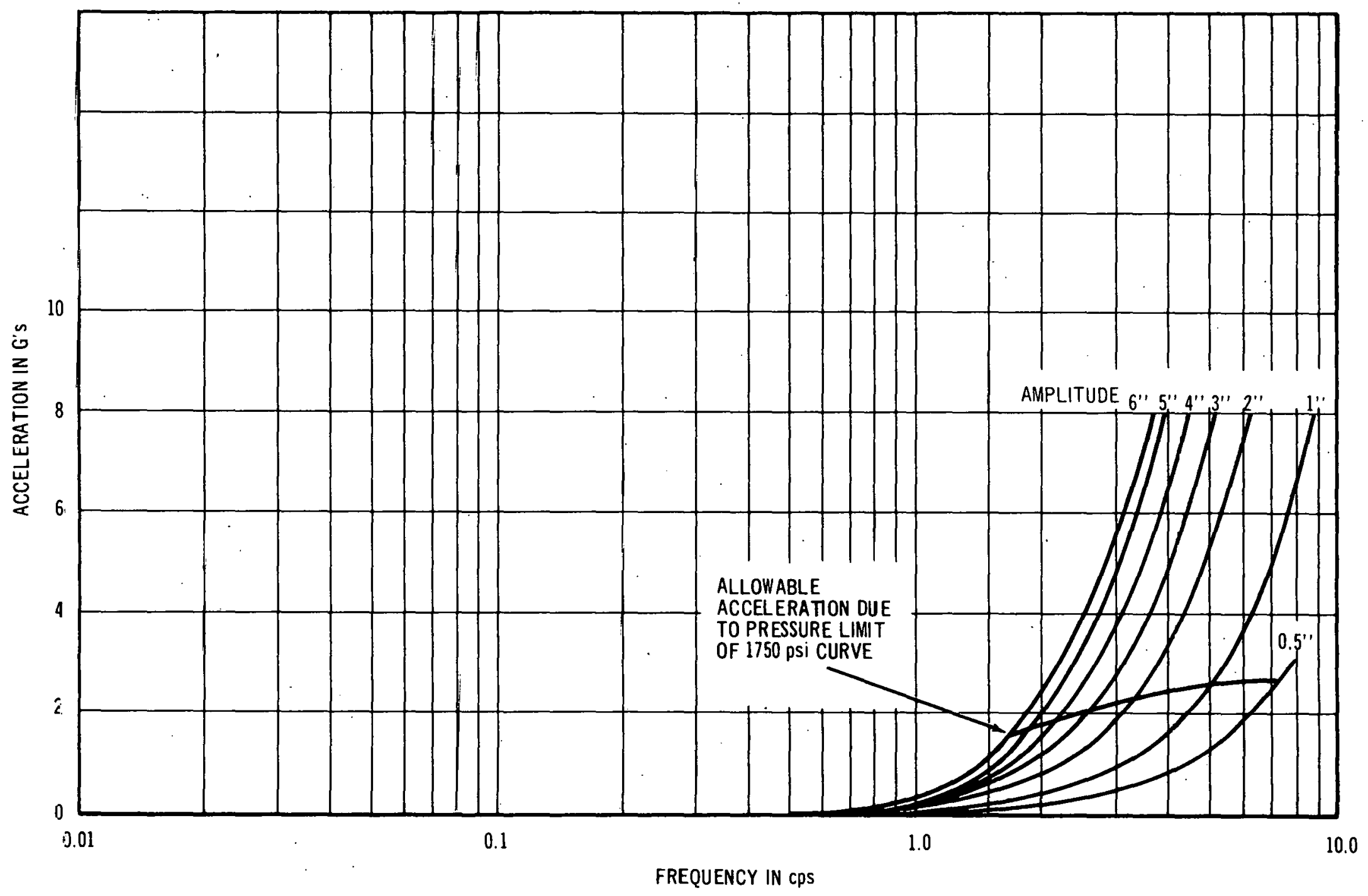

$\stackrel{N}{\sim}$

Figure 2-14. Acceleration vs Frequency for One Pressure at Various Peak-to-Peak Amplitudes 
Before the control rod drives were shipped to Garigliano, some of these production drives were tested in the test facility. Figure 2-15 shows the results of one phase of the tests. (1) The curve shows stroke in inches versus time in seconds. For these tests the vessel pressure was zero and the control rod was scramed from the accumulator pressure of 1400 psi.

It can be seen directly from the curve that in one second the rod has moved 73 inches for the upper limit and 65 inches for the lower limit.

The acceleration at the start of the scram can be estimated by two methods, theoretical and uniform acceleration.

Theoretical initial acceleration. When the scram is initiated, there exists a pressure of 1400 psi on the insert side of the piston and 0 psi on the withdraw side of the piston. Therefore, the $\Delta \mathrm{P}$ of the piston is $1400 \mathrm{psi}$. The acceleration may be calculated in the following manner:

$$
\begin{aligned}
a & =\frac{F}{W}=\frac{s \Delta P}{W} \text { (in G's) } \\
a & =\frac{3.3 \mathrm{in}^{2} \times 1400 \mathrm{lb} / \mathrm{in}^{2}}{250 \mathrm{lb}}=18.5 \mathrm{G}^{\prime} \mathrm{s}
\end{aligned}
$$

This is the theoretical acceleration at the instant the valve is opened. It is somewhat high because the valve does not open in zero time, but this acceleration may be thought of as an upper bracket for the true value.

Using the first data point and assuming uniform acceleration to compute the acceleration from the curve, the lower limit of the acceleration may be attained.

The acceleration may be found in the following manner.

$$
a=\frac{2 X}{t^{2}}=\frac{2 \times 3 \text { inches }}{(0.07)^{2} \sec ^{2}} \text { or } 3.18 G^{\prime} s
$$

$\overline{(1) J . ~ E . ~ B e n e c k i, ~ P e r s o n a l ~ C o m m u n i c a t i o n, ~ M a y ~} 1962$. 


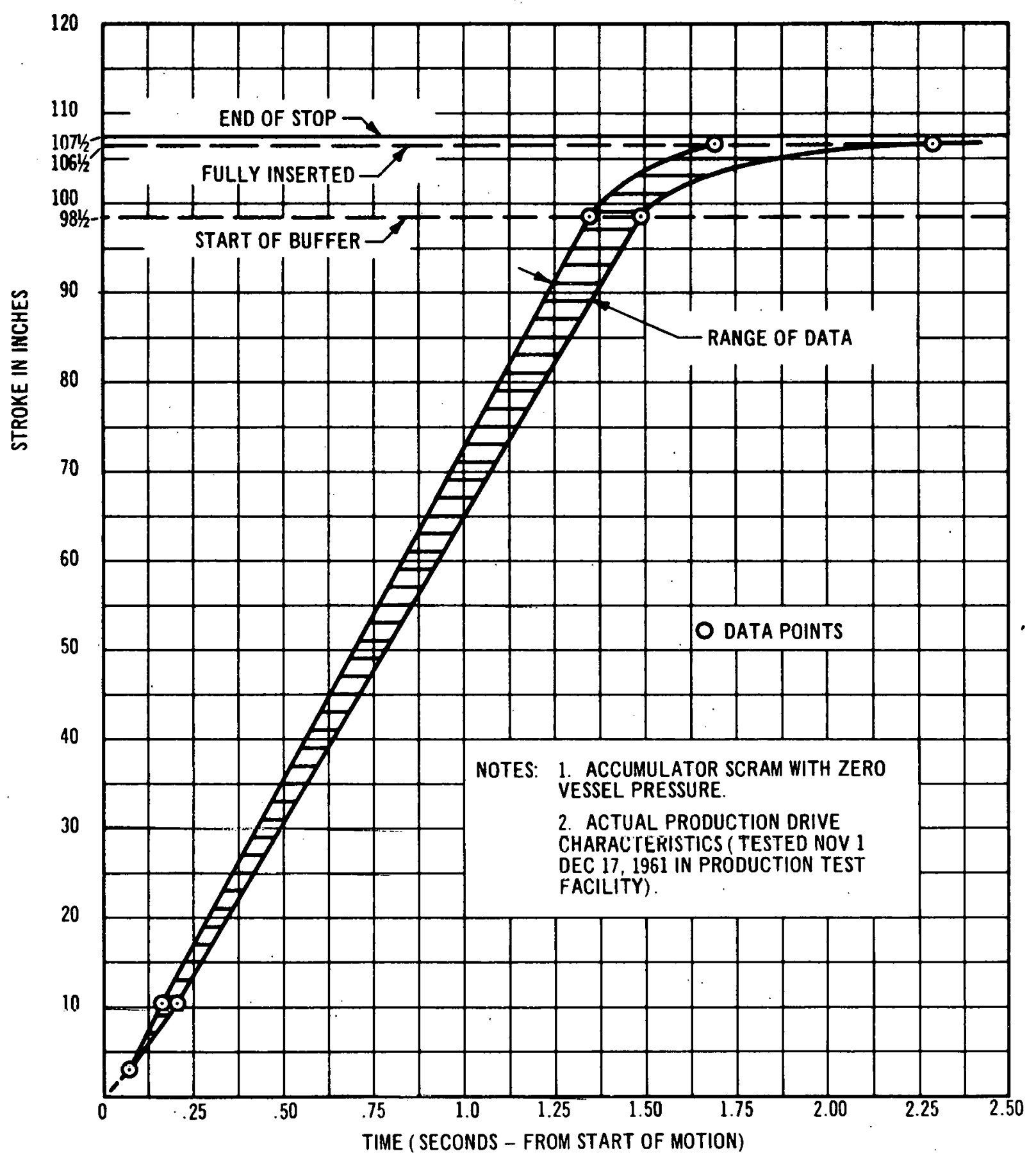

Figure 2-15. Garigliano Control Rod Scram Stroke vs Time 
This acceleration will be a lower limit because uniform acceleration was assumed for the first 0.07 seconds. The actual maximum acceleration will be between $3.18 \mathrm{G}$ 's and 18.5 G's. The design value used is $10 \mathrm{G}$ 's. In any case, the maximum acceleration when the control rod is being oscillated will be $3 \mathrm{G}$ 's or less, which is less than that for a scram.

The acceleration of the control rod in the withdraw direction will also be $3 \mathrm{G}$ 's during the oscillation. This will load in tension the mechanism which holds the index tube and control rod blade. The parts that perform this function have been tested to $10,000 \mathrm{lb}$ in tension and no deformation of the parts occurred. (1) The control rod blade has a weight of $100 \mathrm{lb}$ and the $10,000 \mathrm{lb}$ tension will correspond to $100 \mathrm{G}$ 's. Therefore, it is concluded that dynamic stress which the control rod experiences during the oscillation will not damage any parts of the control rod drive system.

\section{B. Instrumented Fuel Assemblies}

\section{Description}

Four instrumented fuel bundles will be installed at the Garigliano reactor. Each assembly will have inlet and outlet flowmeters of the turbine type, and inlet and outlet thermocouples to monitor coolant temperature. The general arrangement is shown in Figure 2-16.

Lower flowmeters will be attached to modified orifices so that the standard or if ice handling tool can be used to install and remove the flowmeters.

One fuel rod will be removed from the center of the fuel bundles to allow insertion of an instrument tube or "probe". This probe will house the flowmeter pickup coils, thermocouples and upper flowmeter. The handle on the fuel bundle will be modified so that the probe can be inserted into the center of the bundle. The fuel channel will be extended about 2 inches to provide a seat and fluid seal for the upper flowmeter housing. A latch will be provided on the probe assembly to keep the probe from working out of the fuel bundle during reactor operation.

The readout panel will consist primarily of the required signal conditioning equipment and two strip chart recorders. The 412 computer and the Stability Test oscillographs will provide the required data recording. The recorders will be used for recording selected variables and for equipment calibration. The signal conditioning equipment will consist of transistorized modular components, easily removable for repair and requiring a minimum of panel space. Spare components will be provided as required to ensure reliable operation during the test sequence.

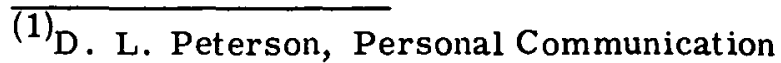




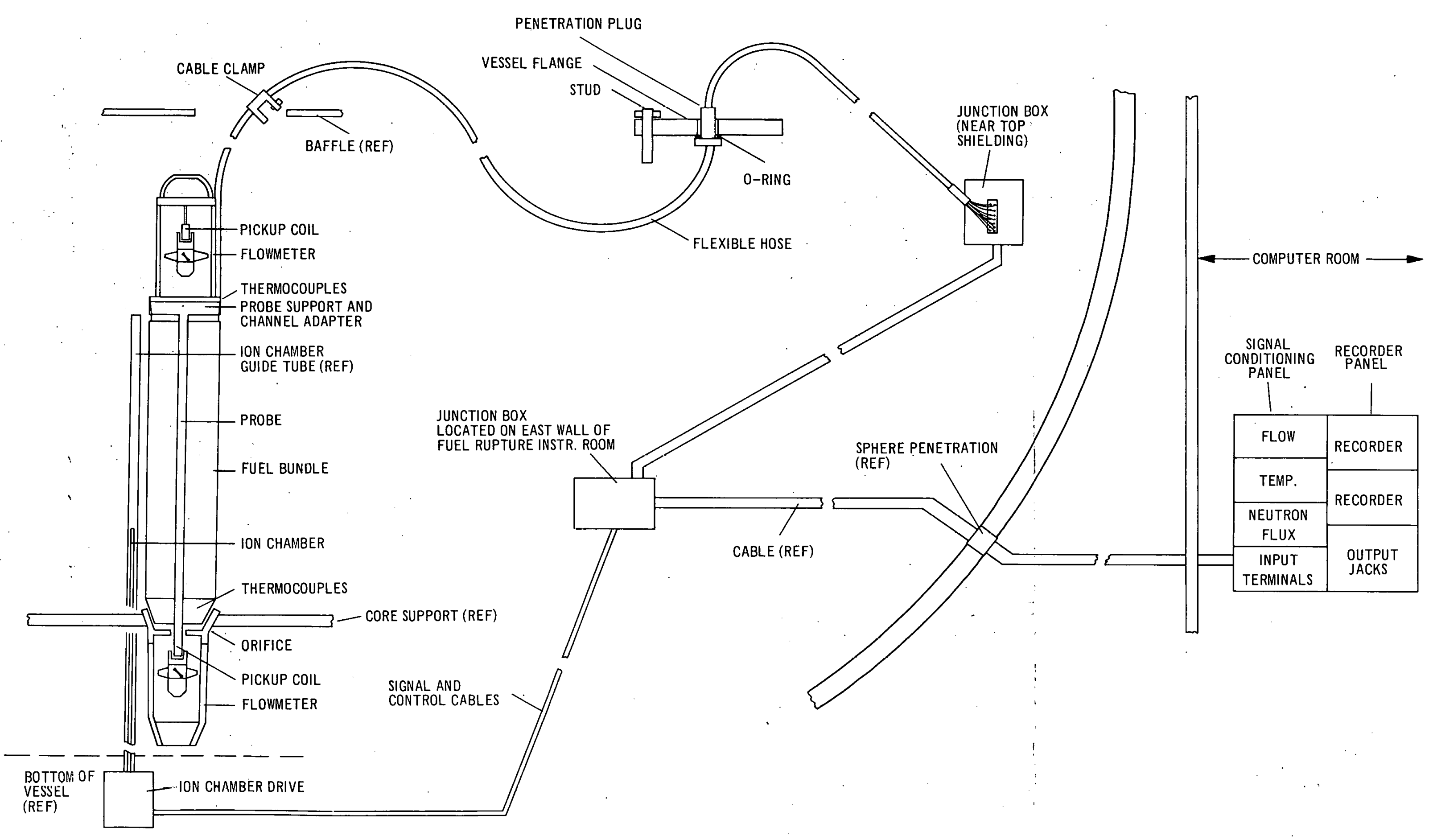


An equipment list and description of the system components are given below.

(1) Flowmeters

Flowmeters will be of the turbine type, similar in design to those in the Big Rock

Point Reactor of Consumers Power Company (See Figure 2-17). Differences will be only in size or blade angle in order to minimize pressure drop. Size of the outlet meters will be increased so that rotational speed at full power is about the same as the speed of inlet meters. The water velocity at the outlet is increased because of steam generated in the fuel assembly. Graphite bushings are used for the bearings because this design was found to give longer life than other materials which have been used previously.

(2) Thermocouples

Grounded inlet thermocouples (two) will be used for fast response and to reduce the effects of gamma heating. An identical thermocouple will be placed at the channel outlet. An ungrounded reference thermocouple will be placed at the channel outlet to serve as the saturated reference thermocouple for direct $\Delta \mathrm{T}$ measurement.

(3) Pickup Coils

Each flowmeter requires a pickup coil to sense the rotational frequency of the rotor. The coil is several thousand turns of ceramic insulated magnet wire wound on a HyMu80 bobbin. The coil is enclosed in a pressure-proof stainless-steel can and attached to mineral insulated cable.

(4) Probe Tube and Channel Adapter

The probe tube (See Figure 2-18) houses the pickup coil and the thermocouples, and is made to replace one of the fuel rods in the fuel assembly. The channel adapter provides the support for the tube and a support for the upper flowmeter, and makes a seal between the top of the channel and the upper flowmeter.

(5) Flexible Conduit (in-vessel)

A stainless steel flexible hose protects the thermocouple and pickup coil cables from damage.

(6) Cable Clamps (at turning vane)

To minimize vibration of cables and tubes, cable clamps will be installed on the rim of the center opening of the turning vane.

(7) Vessel Penetration Plugs

The penetration plugs provide the high-pressure seal where the signal cable and guide tuhes are brought out of the vessel. 


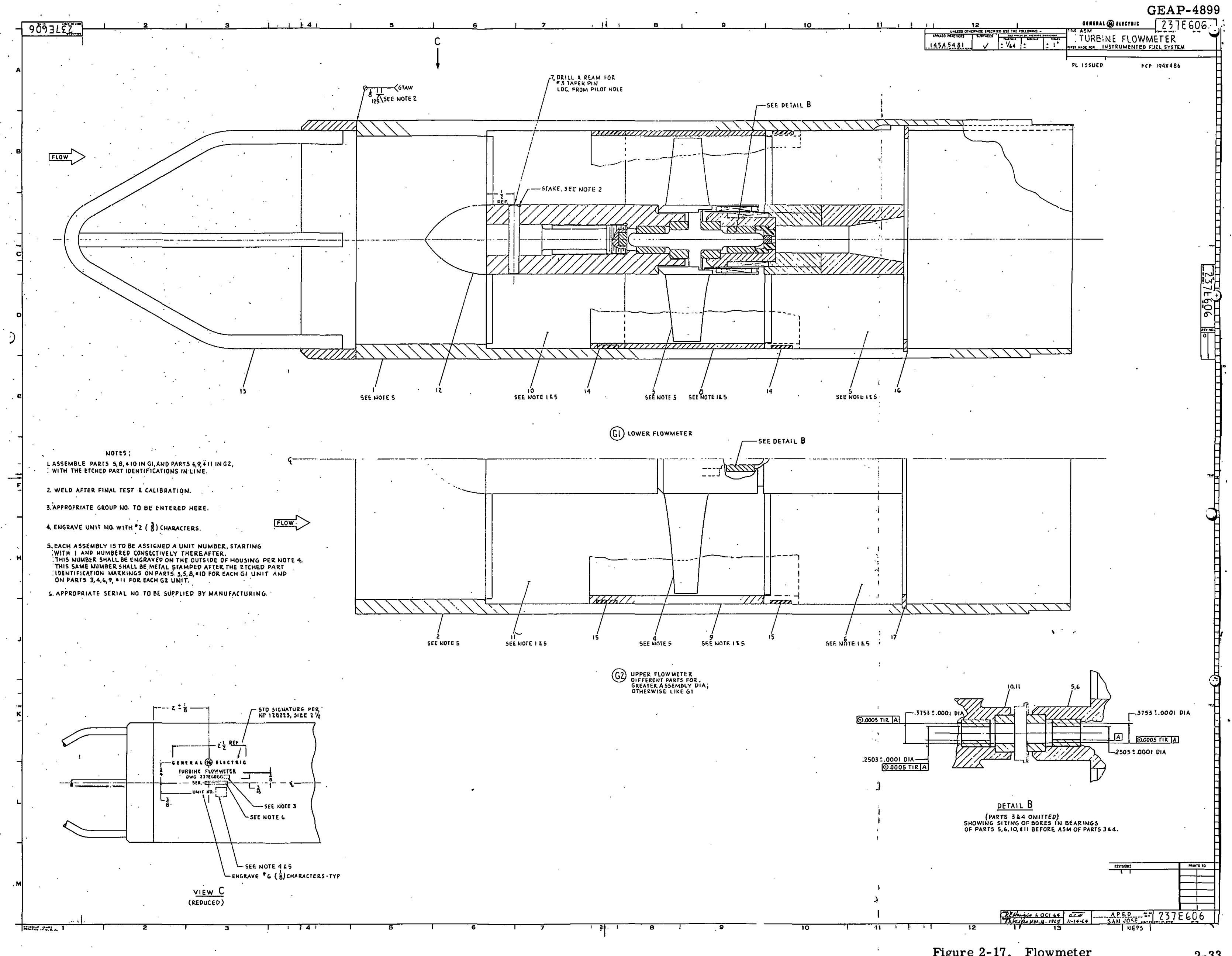




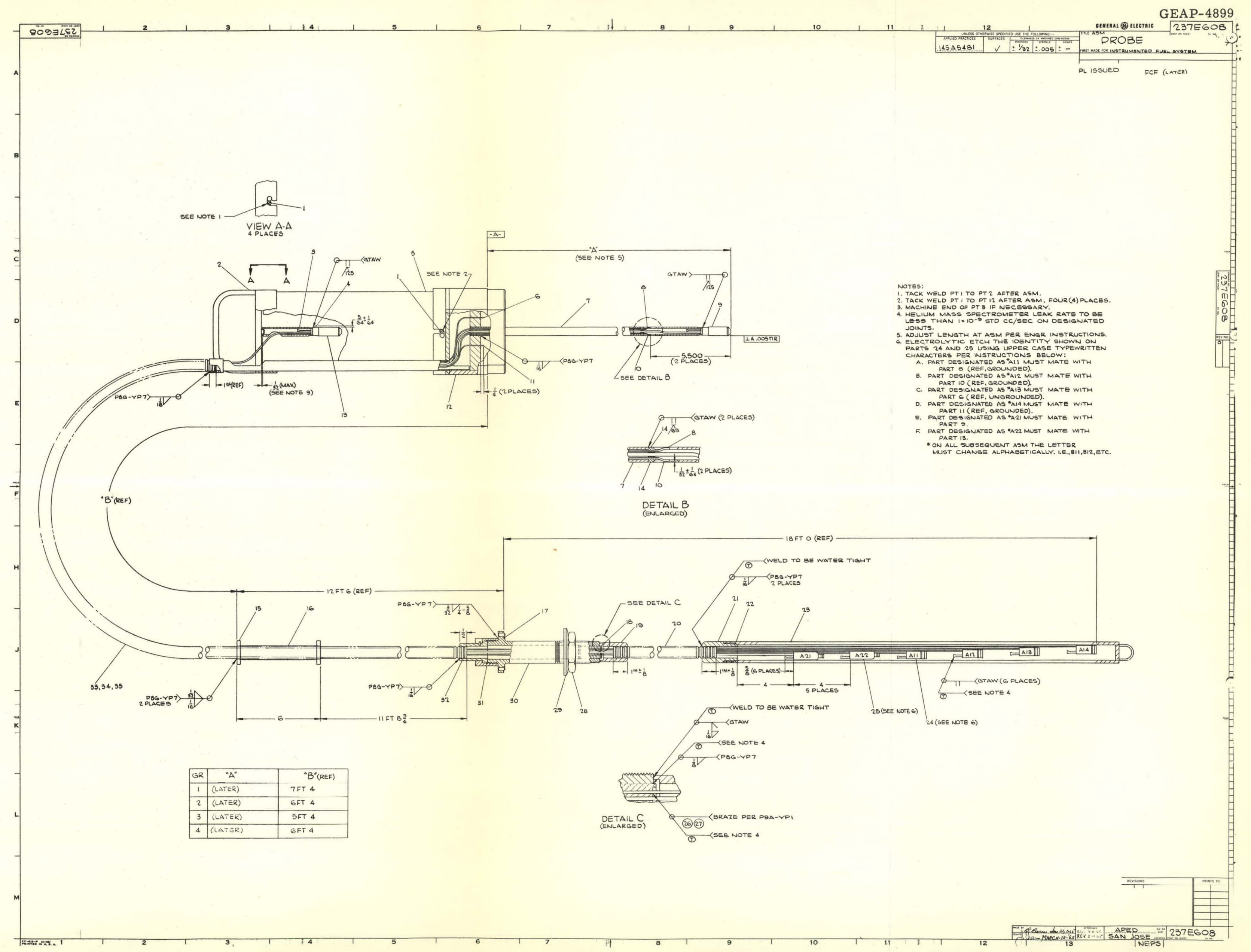




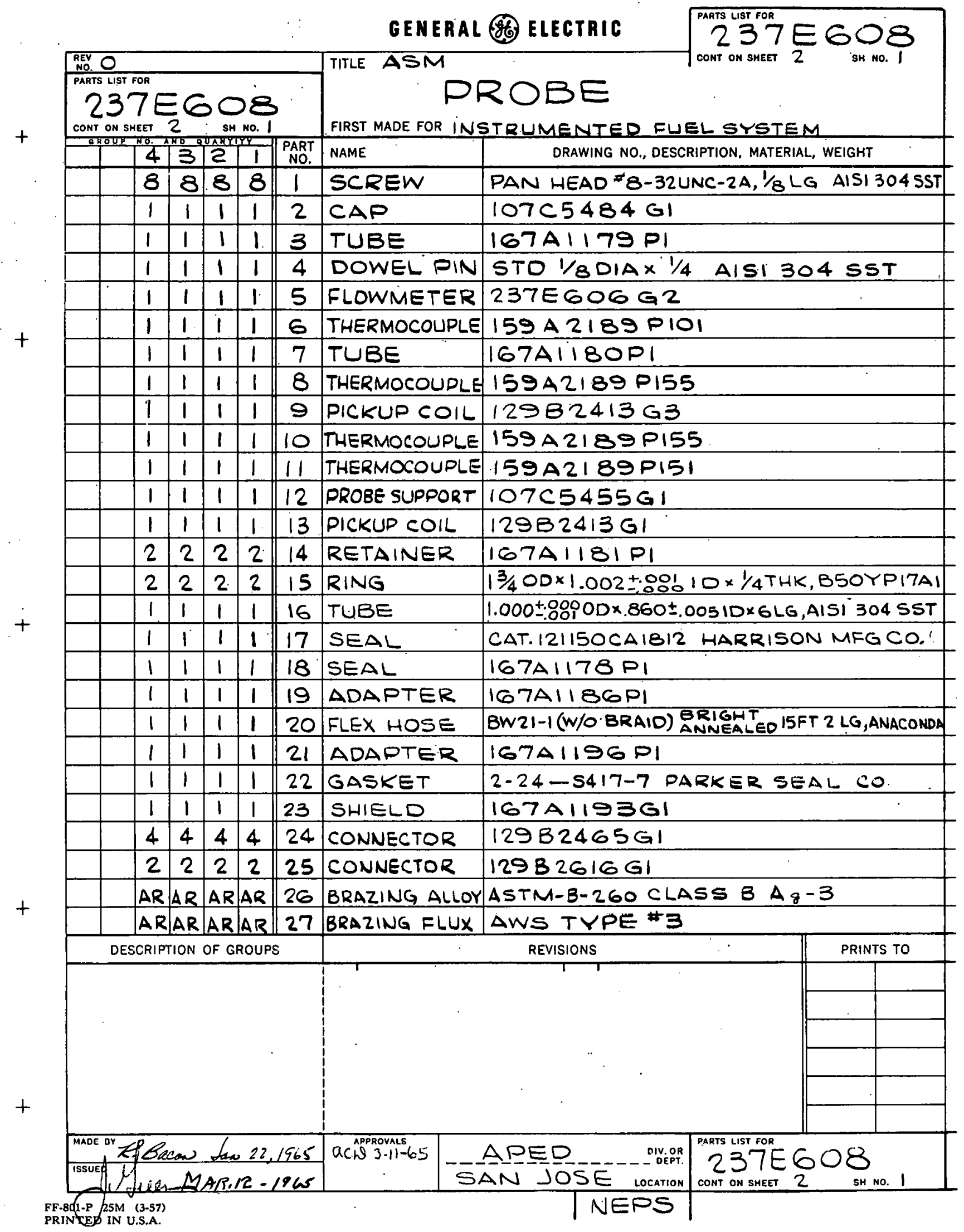

Figure 2-18a 


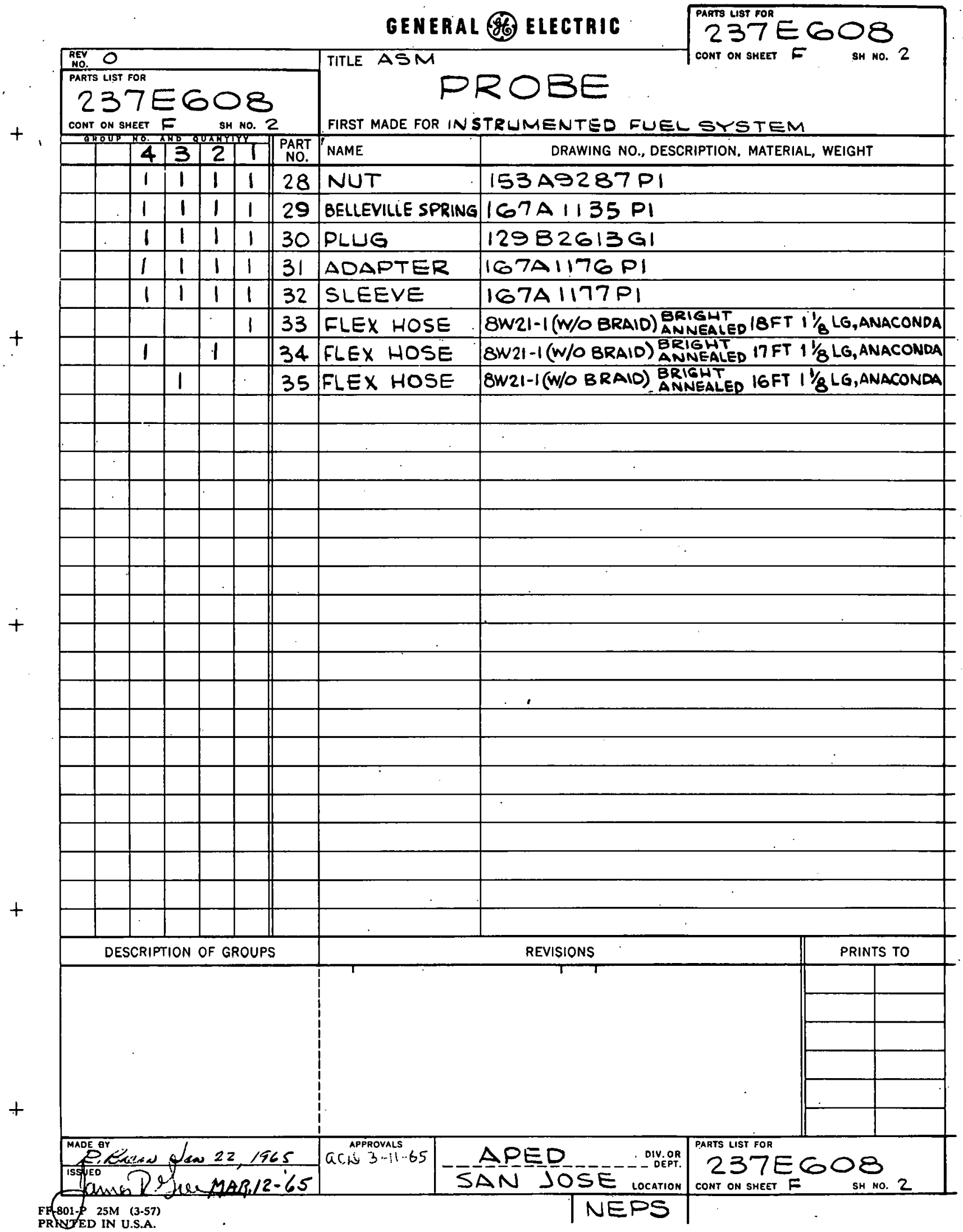


(8) Special Penetration Flange

The flange is a code-designed flange having holes through which the penetration plugs pass. The flange is thicker than normal to allow for the penetration holes.

(9) Bolts for Special Flange

Due to the thicker flange, extra long fastening bolts are provided to couple the flange to the penetration nozzle.

(10) Junction Box

An existing junction box near the refueling platform is used to connect the signal cables from the instrumented assembly.

(11) Cables

Cables and conduit will be supplied as required to make the electrical connections between the refueling platform junction box and the existing instrumented assembly junction box located on the east wall of the fuel rupture instrument room.

(12) Instrument Racks

Two instrument racks (approximately 6 feet high by 19 inches Panel width) will house the signal conditioning and readout instruments in the computer room.

(13) Flow Power Supplies

This unit supplies power to the flowmeter pickup coils as well as the flow ratemeter.

(14) Flow Signal Conditioner

This unit amplifies the flowmeter signal and supplies pulses to the flow ratemeter.

(15) Flnw Ratemeter

This unit receives the amplified pulses from the signal conditioner and converts the frequency signal to an analog dc voltage signal. The unit has a built-in calibration signal to check the operation of the unit.

(16) Differential Temperature MV/I Converter

This unit is a low-noise dc amplifier which amplifies the thermocouple signals to a usable level.

(17) Two-Pen Strip Chart Recorder

This instrument is used for recording any two of the instrumented assembly signals or for calibration and maintenance of the signal conditioning equipment. 
(18) Output Patch Panel

This unit serves as a signal center for connection of inputs to the stability test equipment or for connection to the two-pen recorders. The patch panel will also serve the signals from the stability test instruments and rod oscillator. Terminals will also be provided on this unit to connect the signals to the 412 computer.

(19) Modified Fuel Bundles

The fuel bundle itself is standard except that

a. The center fuel rod will be removed to make room for an instrument probe. (See Figure 2-19.)

b. Minor modification will be made in the spacers and tie plates to permit easy insertion of the instrument probe.

c. The channel. wall will be extended 2 inches at the top to make a seal with the top flowmeter adapter. The corners of this channel extension piece will be arranged to require no change in the springs or in the bolts used to fasten the channel to the top tie plate. (See Figure 2-20.)

d. - The single handle will be modified to leave the center of the fuel bundle open to receive the instrument probe.

2. Installation Procedure for Fuei Assemblies

The outline of the proposed procedure for final installation of the instrumented assemblies is as follows:

(1) Install special orifice cup with attached lower flowmeter by normal procedure.

(2) Use normal procedure and fuel handling grapple to place fuel bundle in the core.

(3) Insert instrument probe. This step requires care to avoid damage to the pickup coil at the lower end of the instrument tube. Hold the instrument probe assembly in the fuel handling grapple, and lower it slowly and carefully, while guiding it by hand as required. Insert instrument tube through fuel bundle. Fasten latch to hold down the instrument probc.

(4) Repeat above steps for the three other instrumented assemblies.

(5) Install baffle (turning vane) with cables passing through center hole.

(6) Install clamps that hold cables to reactor vessel baffle. This reduces vibration of cables.

(7) Install reactor veesel head, with cables passing through access port. 


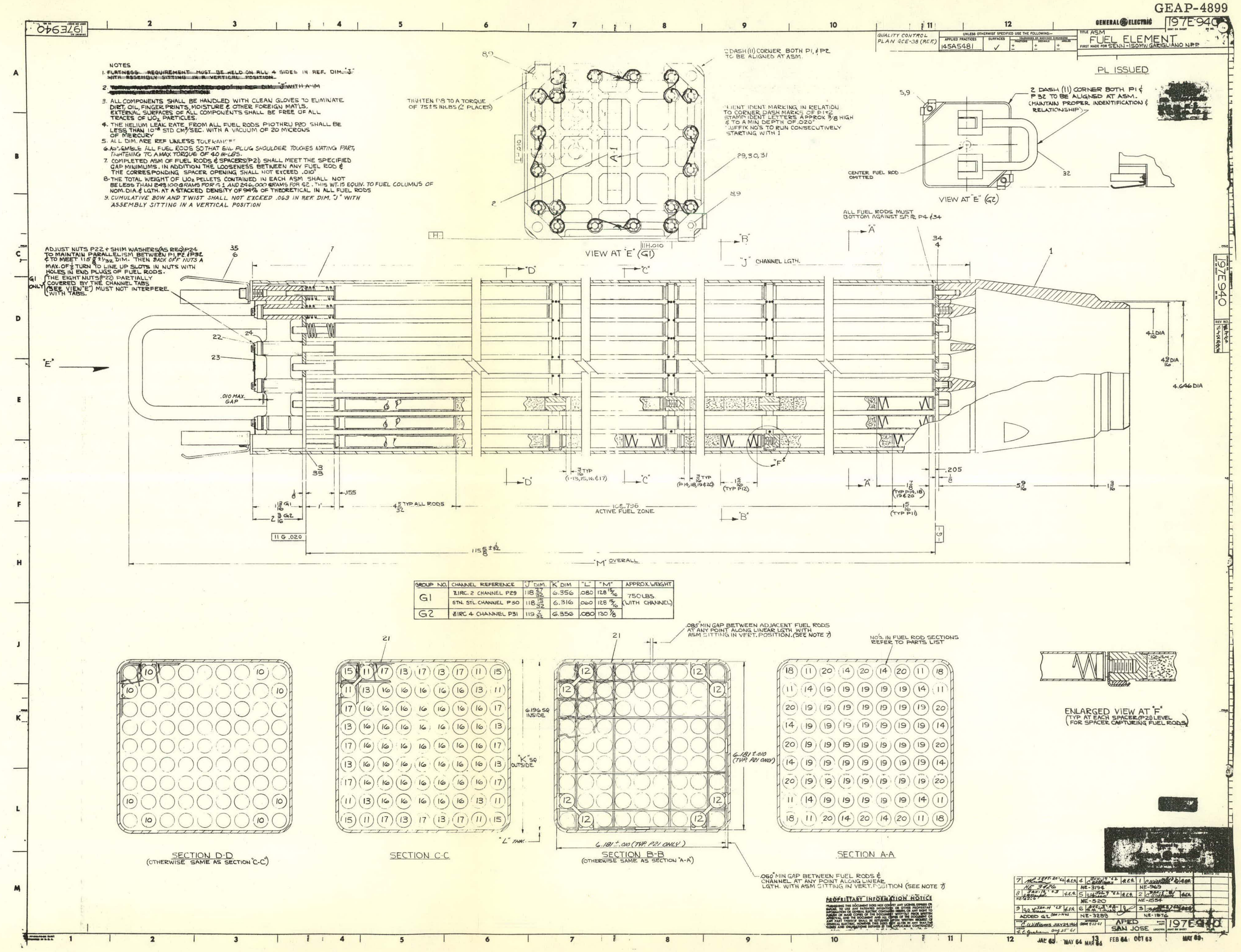

Figure 2-19. Fuel Assembly (Part G-2 only) 


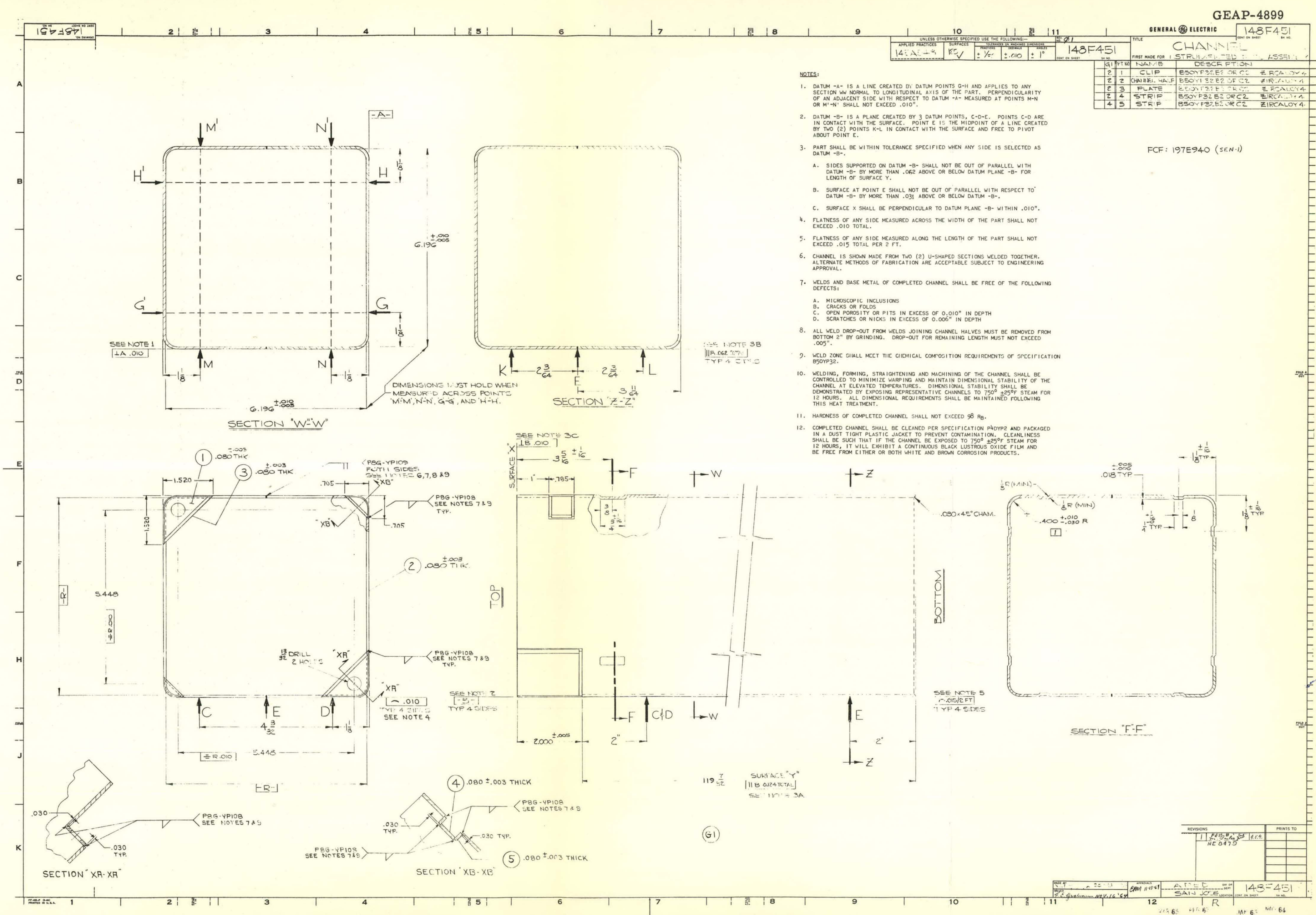


(8) Insert electric cables from instrument probe through special reactor vessel flange, and install flange.

(9) Install penetration unit in flange.

(10) Install cables in existing conduit, thus bypassing shield blocks above reactor vessel.

(11) Make connections at junction box above reactor vessel head, near refueling platform. The cables from the junction box above the vessel to the computer room will be already installed.

Accident analysis for stoppage of turbine flowmeters is presented in Section V-C.

\section{Movable Ion Chambers}

Four movable ion chambers are to be installed next to the corners of the four instrumented fuel assemblies. Each movable ion chamber will be in the same unit as the strings of four fixed in-core chambers and wire insertion guide tube.

Preliminary design evaluation of this method indicated that it would not be possible to include both the movable chamber and the flux wire guide tube in the same unit. However, more detailed examination of the installation has shown that it is possible. This greatly simplifies the calibration of the in-core chambers because the normal method of using flux wires is unchanged.

The general arrangement of the system is shown in Figure 2-16. The equipment required is as follows:

1. Four In-Core Flux Detector assemblies (four fixed chambers each), modified to add one $1 / 4$ inch OD by 0.049 inch wall guide tube in each assembly. Except for the additional tube, the assemblies are identical to existing in-core flux monitors.

2. Four Subminiature In-Core Detectors (1/8 inch OD). (Figure 2-21)

3. Four Chamber Drive Mechanisms. (Figure 2-22)

4. Four Flux Monitor modules (mounted in the readout panel). These units control the position of the movable chamber, and display position and flux signals. Trip circuits (2) allow the chamber to be moved only between preset limits.

The flux detector assemblies will be shipped with the subminiature detectors inserted into their guide tubes, and the drive mechanisms attached to the lower part of the assembly (insertion guide). This is done to minimize potential kinking of guide tubes or movable chamber cable.

Installation is accomplished as follows:

1. Remove existing flux monitor assemblies from designated locations (tentatively RE 108, RE 109, RE 112, RE 118). Use the ion chamber removal tool described in GEI 80801 , and use standard procedures. 







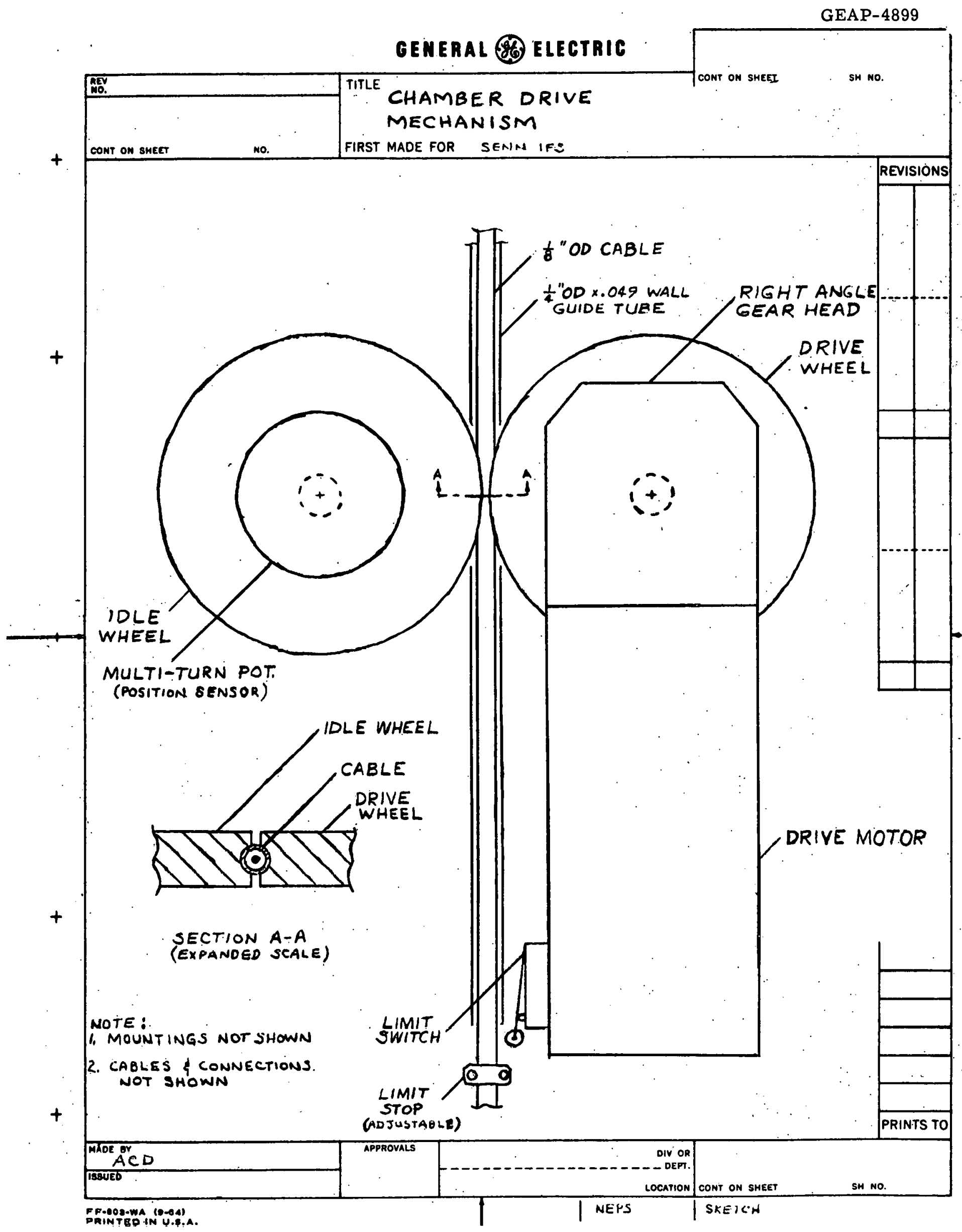


2. Insert new flux monitor assemblies into the vacated locations using nor mal installation procedures. Added care is required to avoid kinking the $1 / 4$ inch guide tubes during installation.

3. Connect the new plant fixed detectors and the flux wire tubes as they were previously.

4. Inspect the movable detector cable and drive and make sure that the cable is correctly : positioned and adjusted (See details in instruction manual to be issued later).

5. Connect the cables to the movable detectors and drive units. New cables will need to be installed to connect the drives and detectors to the computer room.

6. Connect the flux monitor module in the computer room and check that the detector travels in and out (visual observation). Calibrate the position indicator and set the limit trips. The "IN" trip should stop the unit about $1 / 2$ inch from the top of the guide tube. As a back-up the cable collar. should be adjusted so that the limit switch on the drive is actuated when the unit is about $1 / 4$ inch from the top of the guide tube.

7. The units are now ready for operation.

Malfunction of the drive unit, if it occurs, is not a problem to reactor operation because the fixed in-core chambers, and their calibration from flux wires, are not affected. Any malfunction of fixed chambers or wire insertion is no different than for normal plant equipment. 


\section{SECTION III}

\section{TEST PROCEDURES}

The test procedures are an important part of reactor safety. Detailed procedures are to be prepared prior to conducting the tests; therefore; they are not included in this document. However, the safety criteria and tentative test sequence are presented to show the important considerations which are to be incorporated in the detailed test procedures.

\section{A. Safety Criteria}

The following safety criteria have been established to form the basis for the detailed procedures:

1. All test procedures will be approved in advance by the Garigliano Plant Superintendent, IGEOSA Site Representative, and the GE Project Engineer for the Development Program. The procedures will specify the method for reaching the desired operating conditions, the tests to be conducted and the safety aspects to be given special consideration. A procedure section titled "Terminal Aspects" will specify test limits. The test will be terminated if these limits are exceeded.

2. Test coordination and supervision will be the responsibility of a "Test Engineer" designated by ENEL, in consultation with the IGEOSA Site Representative and the GE Project Engineer.

3. Responsibility for actually conducting the tests is held by ENEL. Thus, only designated ENEL personnel will operate the control room equipment and the control rod oscillator. Several reactor operators will be designated and specifically trained for this work.

4. Each reactor and plant condition that will be established, has been carefully analyzed, in order to predict the performance of the plant and determine safe limits which are not to be violated. These limits have been established taking in account all the possible uncertainties in the pre-test calculations and in the thermal and physics data to be evaluated during tests. These limits of reactor operation resulted from a careful investigation of previous high void tests performed at other boiling water reactors, extrapolations of Garigliano data taken during start-up tests and detailed pre-test calculations which have been carried out including margins of conservatism.

5. At each major reactor operating condition the reactor operating data will be compared to the predicted values. This comparison will indicate the validity of the predictions. Any difference will be taken into account in estimating the expected performance at the next reactor operating cundliouin. 
6. Before changing reactor operating conditions, the reactor conditions and limits will be estimated for the next operating condition. The change will not be made unless it is shown that the next condition will be within limits. If the change is not shown to be in limits a smaller step in reactor conditions will be used. Thus the reactor will not be changed into an out-of-limit condition. After the new reactor condition is reached, the limiting data will be checked to assure compliance with the limits before conducting any transient tests.

7. To avoid any condition of excessive neutron flux, the following limits are used:

Nominal in-core flux response for rod oscillator $\quad \pm 10 \%$

Maximum planned in-core flux response for any cause - rod oscillator, flux noise or transient tests $\quad+15 \%$

High flux (out-of-core picoammeter) scram setting, based on actual operating power $+20 \%$

8. When the power is to be increased, the calculation of reactor limits at the higher power will be made prior to increasing the high flux scram setting.

9. The CHFR for the instrumented fuel assemblies will be evaluated as though the turbine flowmeters had already stopped rotating. Thus turbine stoppage would not constitute a . problem.

10. The amplitude of the control rod oscillation at each frequency will be limited so that the 1750 psi limit on control rod drive pressure is not exceeded based on pressure measurements on the rod oscillator drive system. Also, an amplitude limit of \pm 3 inches (one notch) will be observed. The oscillator will be operated at frequencies between approximately 0.01 and 15 cycles per second.

11. The operability and correct setting of the control rod oscillator trip unit will be verified prior to each set of oscillator tests by moving the control rod one notch above and below the prescribed two-notch range and observing operation of the trip unit.

12. The calculations and safety considerations on which the test procedures are based are made in a conservative manner, and the limits themselves are conservative, so that adherence to these limits insures that the reactor is not brought to the extreme capability limits of the reactor system or fuel. 
13. The limitations of all plant equipment, including pumps, secondary steam generators, turbine, condenser, and feedwater heaters, are considered; and tests will not be conducted at conditions at which equipment damage would occur.

14. It is important to take precautions against the "cold water accident," since the reactor is to be operated in natural circulation and with high voids. The procedures will specify:

a. Procedural and mechanical means of preventing accidental starting of recirculation pumps during natural circulation operation.

b. Procedure for starting recirculation pumps at end of tests. The procedure is standard and includes: 1.) Pump discharge valve must be closed and small bypass valve open before pump is started, 2.) Secondary steam generator steam flow valve is closed before pump is started. 3.) Pump is started and water in recirculation loop is allowed to reach operating temperature, and 4.) the main pump discharge valve is opened slowly, while observing the increase in neutron flux.

15. Operability of the on-line process computer is not a requirement for safe conduct of the tests. However, if the computer is operating satisfactorily at the time of the tests, its accuracy and speed of calculation will be utilized to evaluate the reactor safety and performance limits.

16. Prior to the start of the reactor tests the important process instruments will be calibrated, including primary and secondary feedwater flow instruments, and recirculation flow instruments. Out-of-core and in-core flux instruments will be calibrated by normal plant procedures at the major steps in the test sequences.

17. As part of the test procedures, test "Warnings" and "Stops" will be issued. Warning and Stop conditions will be established later. Test Warnings mean that reactor operation will not be allowed to proceed without careful and continuous review of the data available. For example, a Warning would indicate when test license limits are being approached, or test conditions are different from those anticipated. Test Stops mean that the test will be terminated or held up pending further analysis or review of computed and experimental data. The test program can be continued or modified only if suitable adjustments can be made to alleviate these conditions. 
TABLE 3-1

TENTATIVE TEST SEQUENCE

\begin{tabular}{|c|c|c|c|c|c|c|c|}
\hline \multirow[t]{2}{*}{ Step } & \multirow[t]{2}{*}{ Power } & \multicolumn{2}{|c|}{ Flow } & \multirow{2}{*}{$\begin{array}{l}\text { Subcooling } \\
\text { Conditions }\end{array}$} & \multirow{2}{*}{$\begin{array}{l}\text { Wire Irradiation } \\
\text { Required }\end{array}$} & \multirow{2}{*}{$\begin{array}{c}\text { Estimated Total } \\
\text { Time for Test, } \\
\text { days }\end{array}$} & \multirow{2}{*}{ Remarks } \\
\hline & & Loops & Mode & & & & \\
\hline 1 & Rated & 2 & Forced & Rated & None & 1 & . \\
\hline 2 & Rated & 1 & Forced & High & None & 1 & \\
\hline 3 & $75 \%$ & 2 & Natural & Rated & Full & 1 &. \\
\hline 4 & Rated & 2 & Natural & Hi:sh & & . & \\
\hline 5 & Rated & 2 & Natural & Rated & Full & 1 & \\
\hline 6 & Rated & 2 & Natural & Lcw & : &. & . \\
\hline 7 & $75 \%$ & 1 & Natural & High & Full & 1 & 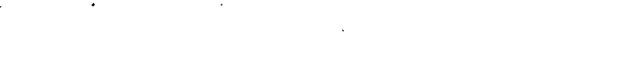 \\
\hline 8 & $90 \%$ & 1 & Natural & Rated & - & - & MCHF and Core Performance Check \\
\hline 9 & Rated & 1 & Natural & Rated) & & & \\
\hline 10 & Rated & 1 & Natural & Law & Full & $\because$ & \\
\hline 11 & Rated & 1 & Natural & High & & & \\
\hline 12 & $75 \%$ & 1 & Natural & High & Partial & $1 / 2$ & Peaked Radial Flux \\
\hline 13 & $75 \%$ & 2 & Forced & Rated & None & - & $\begin{array}{l}\text { To be done on return to full power } \\
\text { from other tests }\end{array}$ \\
\hline
\end{tabular}

Notes:

1. After a full wire irradiation, no tests will be scheduled for the following day while the data are analyzed. The plant will return to full power during these periods.

2. The plant will always be returned to full power after each day's testing.

3. Time of day for testing will be at SENN's convenience

4. Test steps $9 ; 10$, and 11 may require power reduction below rated, because of CHFR limits.

5. Tests to be conducted include:

a. Steady-state core performance neasurements, including "noise."

b. Control rod oscillation over a range of frequencies.

c. Pump trip tests.

d. Pressure transient "step" change. 


\section{B. Tentative Test Sequence}

The tentative sequence of reactor tests is shown in Table 3-1. At these test conditions some or all the following tests may be conducted:

1. Steady-state core performance; including flux "noise". measurement.

2. Control rod oscillation at frequencies between 0.01 and 15 cycles/second.

3. Pressure transient "step" change.

4. Pump trip tests - where applicable.

A high void test region map has been prepared and it is shown in Figure 3-1. The map indicates the operating region in which all the tests will be conducted. The operating region is determined on the map by (a) the curve of scram limit on the recirculation main valves, (b) the Reactor Power license limit and (c) the maximum recirculation pump capacity. The critical heat flux ratio or absolute value of heat flux may be further limitations under some conditions. The curves of recirculation flow versus reactor power have been determinated from SENN start-up tests and calculations made at APED. Also, constant reactivity operating lines are shown. These lines show the reactor power which will result if flow is changed and control rods held at a fixed position. For example, the lowest line determines operating points of the reactor if one or two recirculation pumps trip from full power. The intermediate line shows generally the same trend if the pump tripped at full power when only one pump was operating. The upper line has been drawn to demonstrate how a low recirculation flow condition, at full power, simulates the reactor uprated at about 150 percent of rated power and at full recirculation flow. The constant reactivity curves and the MCHFR (Minimum Critical Heat Flux Ratio) limit curve are only indicative since the MCHFR limit is based on an assumed power distribution. Further analyses will allow determination of more precise values at different power peaking factors and subcooling conditions. 


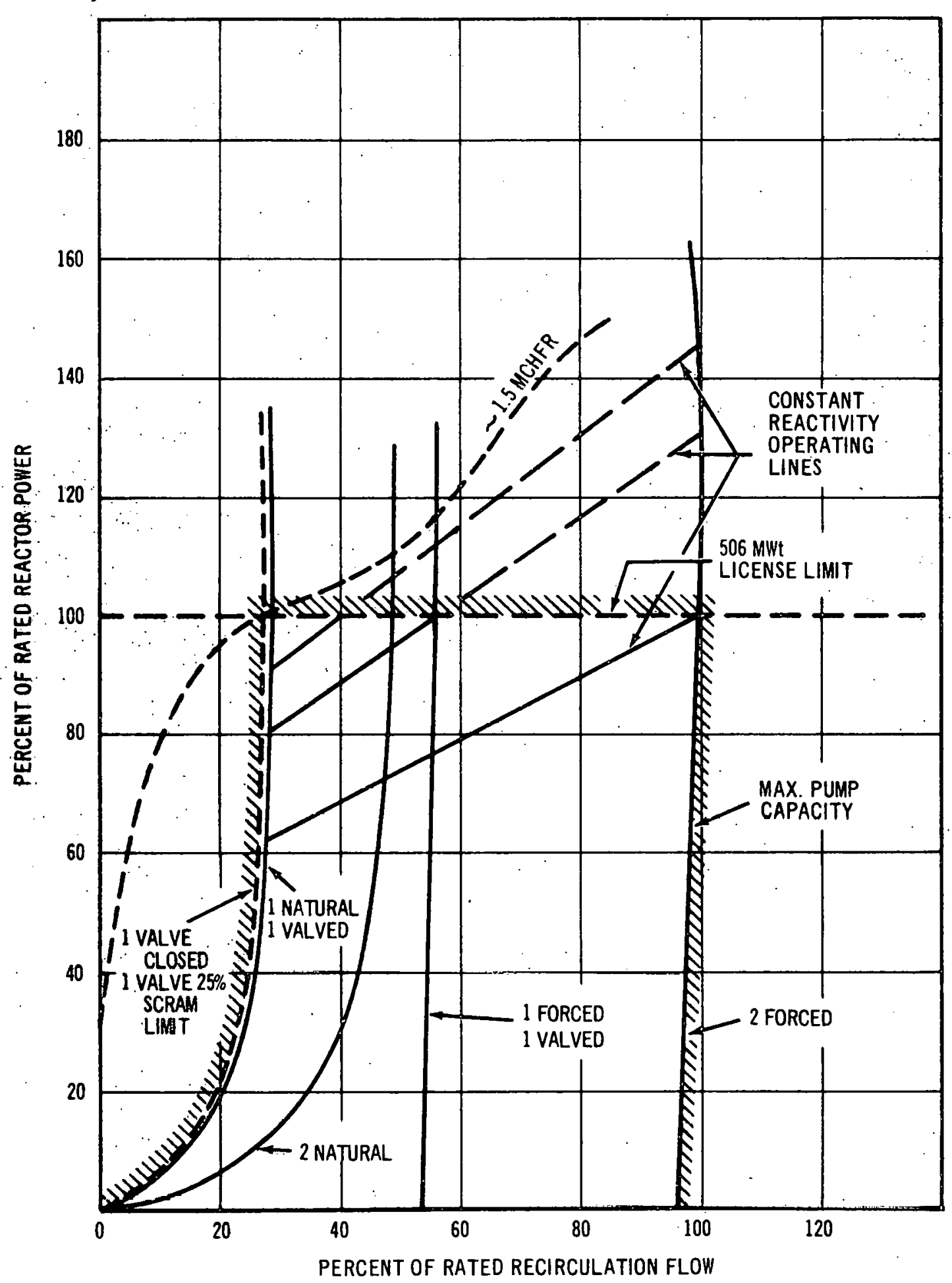

Figure 3-1. SENN High Void Test Region Map 


\section{SECTION IV}

\section{SAFEGUARDS LIMIT CRITERIA}

Temporary changes in, the Garigliano Technical Specifications have been requested as follows:

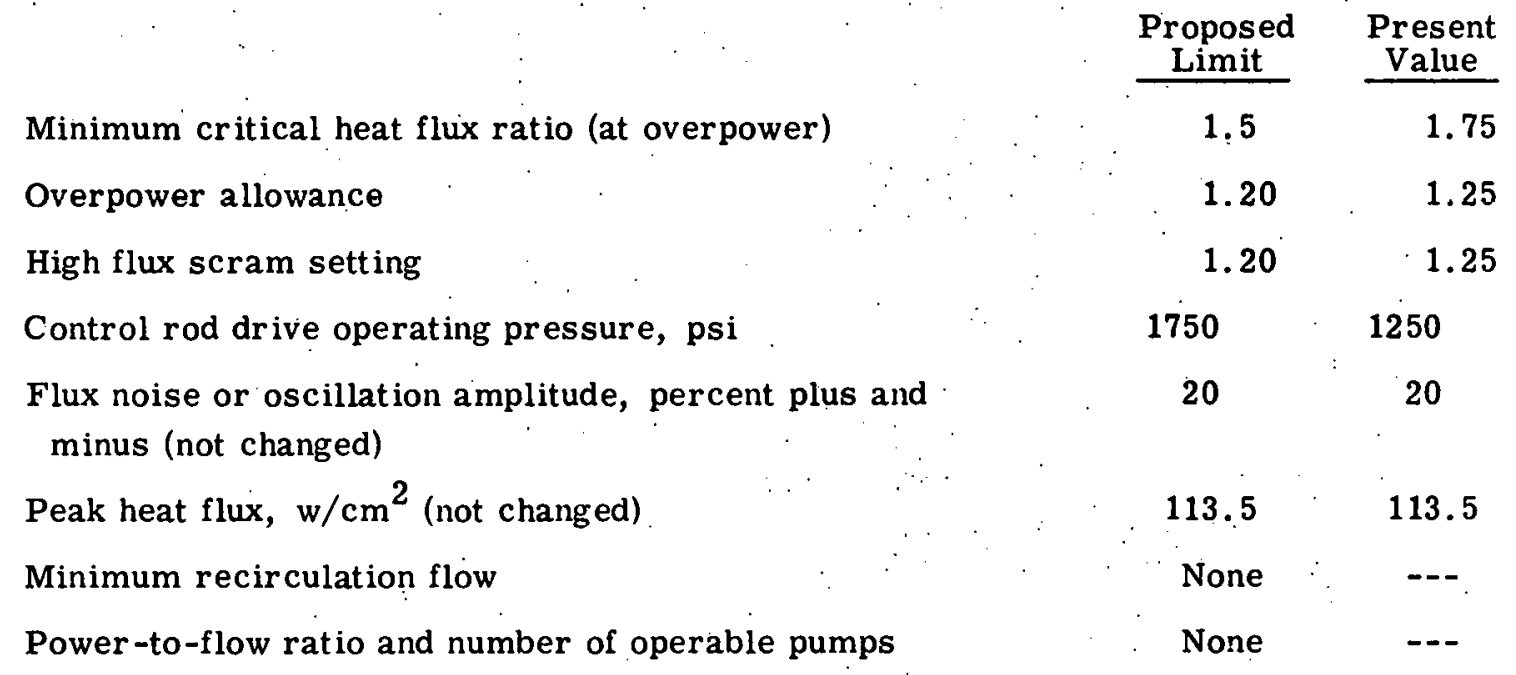

The information and calculations presented in this section of this report are supplied to justify adoption of the first two items:
Critical Heat Flux Ratio
1.50
Overpower Allowance
1.20

An error analysis has been conducted to determine the experimental and calculational uncertainties in the determination of critical heat flux ratio and other limits during the proposed tests at Garigliano. The analysis has been made on a statistical or probability theory basis. Some preliminary comments are made to indicate the probability concepts used in the analysis.

The analysis is presented under the following:
A. Purpose of the Error Analyses
B. Probability Concepts
C. Error Analysis for Channel Flow Rate
D. Error in Reactor Power Determination
E. Error in Recirculation Flow Measurement
F. Error in Core Power Distributinn 
G. Error in In-Core Chamber Readings

H. Error in Control Room Method of MCHFR Determination

I. Summary of Error Analysis

J. Improvements in MCHFR Determination

K. Discussion of Technical Specification Changes

L. Effect of Normal Plant Transients

\section{A. Purpose of the Error Analyses}

Certain parameters are frequently used as a measure of core performance, such as reactor power, maximum fuel rod heat flux, and minimum critical heat flux ratio. Operating licenses commonly specify limiting values for these parameters; and in evaluating consequences of accidents or nonstandard conditions, these parameters are commonly used as a measure of the severity of the resulting transients.

These parameters, however, cannot be directly measured, and therefore must be calculated, based partially on plant instrument readings. Thus, the over-all error in the calculated values of these parameters depends on many individual errors in instrument readings and calculations.

The purposes of the analyses which follow are:

(1) To report the individual errors entering into the calculation of reactor power, maximum fuel rod heat flux, and minimum critical heat flux ratio

(2) To combine these individual errors statistically to arrive at an over-all standard deviation in the values for these key parameters,

(3) To determine the over-all error, or standard deviation, in the evaluation of the key parameters at the design overpower condition, which is an arbitrarily defined operating condition which includes an overpower factor of 120 percent. Use of this factor does not imply that the occurrence of an overpower condition is expected.

\section{B. Probability Concepts}

The normal probability distribution is used as the basis of the analysis. This is used as a matter of calculational convenience. since this normal distribution can be used with good results for any distribution which is approximately symmetrical. The use of mathematics based on the normal distribution does not inply that data has been obtained to determine the for $m$ of the distribution function. However. most of the experimental errors entering the calculations would be expected to be normally distributed and thus it is reasonable to combine them according to the rules for normal distributions: 
The normal distribution is the familiar bell-shape curve:

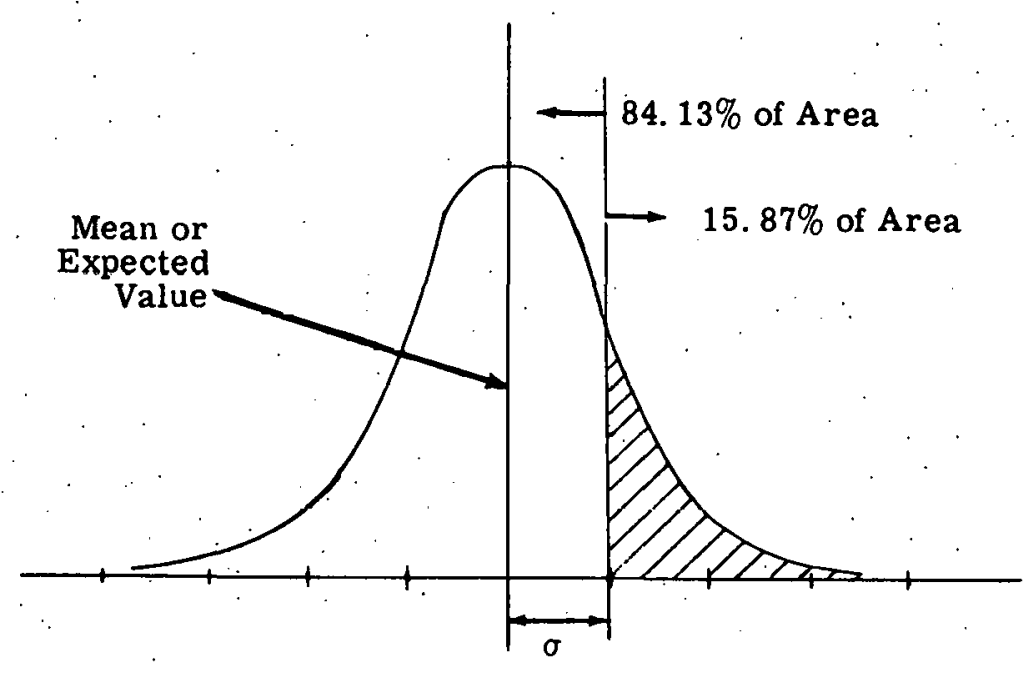

Some points of reference for the normal distribution are as follows ( $\sigma=$ standard deviation):

\begin{tabular}{|c|c|}
\hline $\begin{array}{c}\text { Deviation } \\
\text { from Mean } \\
\text { Value } \\
\end{array}$ & $\begin{array}{c}\text { Percent o } \\
\text { Data Belo } \\
\text { Value } \\
\end{array}$ \\
\hline $0.675 \sigma$ & 75.00 \\
\hline $\begin{array}{l}1 \sigma \\
1.645 \sigma\end{array}$ & $\begin{array}{l}84.13 \\
95.00\end{array}$ \\
\hline $\begin{array}{ll}2 & \sigma \\
3 & \sigma\end{array}$ & $\begin{array}{l}97.72 \\
99.87\end{array}$ \\
\hline
\end{tabular}

Great care must be exercised in applying the normal probability distribution to a particular set of data. This is especially true of the "tails"--values for $2 \sigma$ and $3 \sigma$. Often the normal probability distribution will give accurate results in the range of $\sigma=1$, but will give strange or erroneous results if applied for $\sigma \geqslant 2$. This will be illustrated by two specific cases:

1. Consider an instrument manufacturer who sells instruments guaranteed to have an accuracy of $\pm 1 \%$. After the instruments are manufactured, all the instruments are tested for accuracy. It is found that the accuracy of the instruments follows the normal probability distribution. However, some of the instruments at the "tails" of the distribution have errors greater than 1 percent. These are rejected and returned for repair or recalibration. The instruments that are within specification are shipped to the customer.

The customer who purchased the instruments now tests his instruments and finds that (1) the accuracy of his instruments follows approximately a normal probability 
distribution, but (2) the tails of the distribution are truncated and contain no instruments with errors above 1 percent.

2. The second case is given by Parzen: ${ }^{(1)}$

"A normal probability law has many properties that make it easy to manipulate. Consequently, for mathematical convenience one may often, in practice, assume that a random phenomenon obeys a normal probability law if its true probability law is specified by a probability density function of a shape similar to that of the normal density function, in the sense that it possesses a single peak about which it is approximately symmetrical. For example, the height of a human being appears to obey a probability law possessing an approximately bell-shaped probability density function. Consequently, one might assume that this quantity obeys a normal probability law in certain respects. However, care must be taken in using this approximation; for example, it is conceivable for a normally distributed random quantity to take values between $-10^{6}$ and $-10^{100}$, although the probability of its doing so may be exceedingly small. On the other hand, no man's height can assume such a large negative value. In this sense, it is incorrect to state that a man's height is approximately distributed in accordance with a normal probability law. One may, nevertheless, insist on regarding a man's height as obeying approximately a normal probability law, in order to take advantage of the computational simplicity of the normal distribution. As long as the justification of this approximation is kept clearly in mind, there does not seem to be too much danger in employing it."

The normal probability curve will be used for the analyses that follow; but the use of the normal curve to describe the "tails" of the distribution will be avoided, since there is good reason to suspect that the tails are actually smaller than the normal distribution would predict. For example, the instruments have been tested as in the example above to remove the tails of the distribution curve.

The standard deviation of some parameter of interest, $Y$, which is a function of a number of uncorrelated variables $\mathrm{X}_{1}, \mathrm{X}_{2}, \cdots-\cdots \mathrm{X}_{\mathrm{N}}$, with known standard deviations $\sigma .\left(\mathrm{X}_{1}\right), \sigma\left(\mathrm{X}_{2}\right)$, --- , can be calculated from the following relationship: ${ }^{(2)}$

$$
\sigma^{2}(Y)-\left(\frac{\partial Y}{\partial X_{1}}\right)^{2} \sigma^{2}\left(X_{1}\right)+\left(\frac{\partial Y}{\partial X_{2}}\right)^{2} \sigma^{2}\left(X_{2}\right)+\cdots\left(\frac{\partial Y}{\partial X_{N}}\right)^{2} \sigma^{2}\left(X_{N}\right)
$$

In the above, $\mathrm{X}_{1}, \mathrm{X}_{2},---\mathrm{X}_{\mathrm{N}}$ are all the variables which affect the parameter of interest, $\mathrm{Y}$. For instance, if the parameter of interest is critical heat flux ratio, some of these variables would be instrument readings, such as reactor flow rate; some would be calculated values, such as hot channel power peaking factor; and some would be dimensional quantities, such as the dimensions of individual fuel chämels, spacers, etc.

(1) E. Parzen, "Modern Probability Theory and Its Applications," John Wiley, N. Y. 1960, Page 238. (2) Bowker and Lieberman, Engineering Statistics, Prentice Hall, Inc., 1959. 
The expected value for each variable, $\mathrm{Xn}$, is the nominal, i. e., actual instrument reading, best calculated value with no intentional margin for conservatism, or nominal drawing dimension.

The standard deviation of each variable, $\sigma(\mathrm{Xn})$, about this nominal value depends on the instrument error, calculational accuracy, or drawing tolerance. It is assumed that all variables are normally distributed, the specified instrument accuracies can be considered to be $2 \sigma$ confidence limits, $*$ drawing tolerances are $3 \sigma$ confidence limits, and the accuracy of other values is determined by direct calculation of the standard deviation, $\sigma$. Thus, if accuracy of an instrument is specified at $\pm 1 \%$ then $2 \sigma=1 \%$, and $\sigma=0.5 \%$.

Based on the above, the expected value of $\mathrm{Y}$ is the nominal value calculated in the control room during operation based on actual instrument readings and calculational aids, such as design curves, nomograms, etc. Y will have a normal distribution based on the above assumption that all variables are normally distributed. Even if the variables are not normally distributed, the distribution of $Y$ would approach a normal distribution if there were many variables with approximately equal standard deviations. The value for $\sigma(Y)$ is a measure of the probable error in $\mathrm{Y}$.

Core performance calculations must be made routinely during normal operation to establish that the Core Operating Limitations imposed by the license are not exceeded. The accuracy of these control room core performance calculations depends on the accuracy of the plant instrumentation and also the accuracy of the calculational methods used, as certain parameters are based solely on plant instrumentation (such as reactor recirculation flow), some are based solely on control room calculations or the application of design calculations (such as flow distribution within the reactor), and some are based on a combination of measurements and calculations. The principal core operating limitations are examined in the analysis below.

\section{Error for Channel Flow Rate}

To investigate the errors in calculating the reactor core flow distribution a number of computer runs were made to determine the major cause and magnitude of errors at one loop natural circulation flow, rated primary steam flow, and half rated secondary steam flow. This represents the test condition where the MCHFR will be closest to the limiting value of 1.5. In each computer run one of the parameters governing the core flow distribution was assigned a percentage error with the remaining parameters unchanged. Each computer run then presents the effect of such an error upon the flow rate and CHFR in the most limiting channel in the core. The results from the computer runs are summarized in Table 4-1 and a short discussion of each run is presented below.

*Interpretation based on "Supplement to ASME Power Test Codes, Part'5, Measurement of Quantity of Materials; Chapter 4 Flow Measurement" $p 87$. 
Run No. 1:

The reference case with standard Garigliano reactor hardware and thermodynamic library and the following reactor conditions.

$\begin{array}{lcl}\text { Recirculation flow } & - & 6.0 \times 10^{6} \mathrm{lb} / \mathrm{h} \\ \text { Reactor power } & - & 506 \mathrm{MW}_{\mathrm{t}} \\ \text { Overpower factor } & - & 1.20 \\ \text { Secondary steam flow } & - & \text { half rated } \\ \text { Inlet enthalpy } & - & 437 \mathrm{Btu} / \mathrm{lb}\end{array}$

Run No. 2:

This case shows the effect of an error in the steam quality-steam void fraction relationship. An error of plus 10 percent is shown to result in a 0.7 percent reduction in the core MCHFR from the reference case.

Run No. 3:

This case shows the effect of an error in the Martinelli-Nelson two-phase friction multiplier. A plus 35 percent error is shown to result in a 1.4 percent reduction in MCHFR from the reference case.

Run No. 4:

The computer code uses an equivalent loss coefficient to account for pressure losses due to cross-flow past the control blades between the vessel inlet and the fuel bundle inlet or ifices. This case shows that a substantial ( 20 percent) error in the equivalent loss coefficient, applied to all channels, will have no effect on the MCHFR.

Run No. 5:

The lnss coefficients for the bundle inlet orifice and tie plate have been measured in loop flow tests. This case shows that 5 percent error in the measured loss coefficient, applied to all channels, does not change the MCHFR.

Run No. 6:

The abrupt two-phase multiplier assumes the homogeneous model. This case shows the effect of an error in the two-phase multiplier upon MCHFR. A plus 30 percent error is shown to result in a 1.4 percent reduction in MC HFR.

Run No. 7:

The fuel bundle friction factor has been measured in loop flow tests and found to agree very closely with smooth tube data. This case shows that a plus 10 percent error in the friction factor will result in a 0.7 percent reduction in MCHFR. 
Runs No. 8 and 10 :

These cases show the effect of a uniform crud buildup (all channels) in the upper and lower tie plates. A crud buildup of 0.005 inch causing a 3.6 percent reduction in flow area does not change the MCHFR.

Run No. 9:

The effect of a uniform crud buildup in the spacers is demonstrated in this case. A crud buildup causing a 25 percent reduction in spacer local flow area will result in a 1.4 percent reduction in the MCHFR.

Runs No. 11, 12, 13, 14, 15 and 16:

In these cases the effect upon the MCHFR of a series of manufacturing tolerances, applied to the most limiting channel in the core have been investigated. In all cases the tolerances cause no change in the MCHFR.

Run No. 17:

The effect of a reduction in spacer local flow area due to manufacturing tolerances is considered in this run. A 2 percent reduction in the local flow area of all three spacers in the most limiting channel is shown to result in a 0.7 percent reduction in MCHFR.

Run No. 18:

This test case considers the effect of a reduction in the most limiting channel flow area due to manufacturing tolerances. A 1 percent reduction in free flow area will result in a 1.8 percent reduction in MCHFR:

It should be emphasized at this point that the errors considered in all the computer runs are at least equal to, and generally greater than, the maximum expected error. Thus, the computer runs present the maximum expected error in MCHFR and channel flows caused by the largest individual errors in all significant parameters.

\section{Conclusions:}

1. The model used for calculating the reactor core flow distribution is not sensitive to errors in core and coolant parameters.

2. Reduction of spacer local flow area due to uniform crud buildup has little effect upon the flow in the limiting channel. A 25 percent reduction in spacer flow area will cause a 1.2 percent reduction in coolant flow in the limiting channel, resulting in a 1.4 percent reduction in MCHFR. Uniform crud buildup in the upper and lower tie plates showed no effect upon core flow distribution. 
3. A statistical combination of all errors in core and coolant parameters yields \pm 2.2 percent total error in channel flow rate for the channel having the minimum CHFR.

TABLE 4-1

COMPUTER RUN. SUMMARY - EVALUATION OF ERRORS IN THE CALCULATION OF CORE FLOW DISTRIBUTION

\begin{tabular}{|c|c|c|c|c|c|}
\hline \multirow[b]{2}{*}{ Run No. } & \multirow[b]{2}{*}{ Description } & \multirow{2}{*}{$\begin{array}{c}\text { Percent } \\
\text { Change in } \\
\text { MC HFR }\end{array}$} & \multicolumn{2}{|c|}{$\begin{array}{l}\text { MCHFR Channel } \\
\text { Flow Rate }\end{array}$} & \multirow{2}{*}{$\begin{array}{l}\text { Percent } \\
\text { Change in } \\
\text { Core } \Delta \mathrm{P}\end{array}$} \\
\hline & & & $\begin{array}{r}\mathrm{lb} / \mathrm{h} \\
\times 103 \\
\end{array}$ & $\begin{array}{l}\text { Percent } \\
\text { Change } \\
\end{array}$ & \\
\hline 1. & $\begin{array}{l}\text { Reference case (one loop } \\
\text { natural circulation) }\end{array}$ & ref & 25.80 & ref & : ref \\
\hline 2. & $\begin{array}{l}\text { Reference case steam void. } \\
\text { fraction, plus } 10 \text { percent } \\
\text { assumed error (all channels) }\end{array}$ & -0.7 & 25.65 & -0.6 & -4.6 \\
\hline 3. & $\begin{array}{l}\text { Reference case friction } \\
\text { multiplier, plus } 35 \text { percent } \\
\text { assumed error (all channels) }\end{array}$ & -1.4 & 25.58 & -0.9 & +3.4 \\
\hline 4. & $\begin{array}{l}\text { Reference case loss coef - } \\
\text { ficient for cross -flow through } \\
\text { control rod drives, plus } 20 \\
\text { percent assumed error (all } \\
\text { channels) }\end{array}$ & 0 & 25.78 & -0.1 & 0 \\
\hline 5. & $\begin{array}{l}\text { Reference case loss coef- } \\
\text { ficient for orifice and lower } \\
\text { tie plate, plus } 5 \text { percent } \\
\text { assumed error (all channels) }\end{array}$ & 0 & 25.79 & $\approx 0$ & 0 \\
\hline 6. & $\begin{array}{l}\text { Reference case abrupt two } \\
\text { phase multiplier, plus } 30 \\
\text { percent assumed error (second } \\
\text { and third spacer and upper } \\
\text { tie plate for all channels) }\end{array}$ & -1.4 & 25.60 & -0.8 & +2.1 \\
\hline 7. & $\begin{array}{l}\text { Reference case channel } \\
\text { friction factor, plus } 10 \\
\text { percent assumed error } \\
\text { (all channels) }\end{array}$ & -0.7 & 25.75 & -0.2 & +0.8 \\
\hline 8. & $\begin{array}{l}\text { Reference case lower tie } \\
\text { plate flow area, minus } 3.6 \\
\text { percent due to crud build-- } \\
\text { up (all channels) }\end{array}$ & 0 & 25.82 & +0.1 & 0 \\
\hline 9. & $\begin{array}{l}\text { Reference case spacer flow } \\
\text { area minus } 25 \text { percent due } \\
\text { to crud buildup (all three } \\
\text { spacers in all channels) }\end{array}$ & -1.4 & 25.49 & -1.2 & +5.0 \\
\hline
\end{tabular}


TABLE 4-1 (Continued)

\begin{tabular}{|c|c|c|c|c|c|}
\hline Run No. & Description & $\begin{array}{l}\text { Percent } \\
\text { Change in } \\
\text { MC HFR }\end{array}$ & $\begin{array}{r}\text { MCHFI } \\
\text { Flov } \\
\begin{array}{ll}\mathrm{Ib} / \mathrm{h} \\
\mathrm{x} 10^{3}\end{array}\end{array}$ & $\begin{array}{l}\text { Channel } \\
\text { Rate } \\
\text { Percent } \\
\text { Change }\end{array}$ & $\begin{array}{l}\text { Percent } \\
\text { Change in } \\
\text { Core } \Delta \mathrm{P}\end{array}$ \\
\hline 10. & $\begin{array}{l}\text { Reference case upper tie } \\
\text { plate flow area minus } \\
3.6 \text { percent due to crud } \\
\text { buildup (all channels) }\end{array}$ & 0 & 25.78 & -0.1 & 0 \\
\hline 11. & $\begin{array}{l}\text { Refer ence case channel } \\
\text { inlet orifice area minus } 0.5 \\
\text { percent due to manufactur- } \\
\text { ing tolerances (MC HFR } \\
\text { channel only) }\end{array}$ & 0 & 25.79 & $\approx 0$ & 0 \\
\hline 12. & $\begin{array}{l}\text { Reference case orifice } \\
\text { loss coefficient plus } 1 \\
\text { percent assumed error } \\
\text { MC HFR channel only) }\end{array}$ & 0 & 25.79 & $\approx 0$ & 0 \\
\hline 13. & $\begin{array}{l}\text { Reference case lower tie } \\
\text { plate area minus } 2 \text { percent } \\
\text { due to manufacturing toler- } \\
\text { ances (MC HFR channel } \\
\text { only) }\end{array}$ & 0 & 25.79 & $\approx 0$ & 0 \\
\hline 14. & $\begin{array}{l}\text { Refer ence case lower tie } \\
\text { plate loss coefficient plus } \\
2 \text { percent assumed error } \\
\text { (MC HFR chanmel only) }\end{array}$ & 0 & 25.81 & $\approx 0$ & 0 \\
\hline 15. & $\begin{array}{l}\text { Reference case upper tie plate } \\
\text { flow area minus } 2 \text { percent due } \\
\text { to manufacturing tolerances } \\
\text { (MC HFR channel only) }\end{array}$ & 0. & 25.81 & $\approx 0$ & 0 \\
\hline 16. & $\begin{array}{l}\text { Reference case upper tie } \\
\text { plate loss coefficient plus } \\
2 \text { percent assumed error } \\
\text { (MCHFR channel only) }\end{array}$ & 0 & 25.77 & -0.1 & 0 \\
\hline 17. & $\begin{array}{l}\text { Reference case spacer local } \\
\text { flow area minus } 2 \text { percent } \\
\text { due to manufacturing toler- } \\
\text { ances (all three spacers } \\
\text { in MC HFR channel only) }\end{array}$ & -0.7 & $\begin{array}{c}25.66 \\
\quad \therefore .\end{array}$ & -0.5 & 0 \\
\hline 18. & $\begin{array}{l}\text { Reference case channel free } \\
\text { flow area minus } 1 \text { percent } \\
\text { due to manufacturing toler- } \\
\text { ances (MCHFR channel only) }\end{array}$ & -1.8 & 25.52 & -1.1 & 0 \\
\hline
\end{tabular}


D. Error in Reactor Power Determination

Reactor power is calculated from the following expression:

$$
\begin{aligned}
Q_{R}= & w_{F P}\left(h_{S P}-h_{F}\right)+w_{F S A}\left(h_{S S A}-h_{F}\right)+w_{F S B}\left(h_{S S B}-h_{F}\right) \\
& +w_{c u}\left(h_{c u 1}-h_{c u 2}\right)+w_{D}\left(h_{S P}-h_{D}\right)+Q_{L}-Q_{P}
\end{aligned}
$$

For the reference case test conditions (one loop natural circulation, one loop valved out, secondary steam flow rate $=108 \mathrm{MT} / \mathrm{h}$, all feedwater preheaters in operation) the different parameters of Equation (1) have the following values:

$Q_{R}: \quad$ reactor thermal power, 506.3 $\mathrm{MWt}$ or $435.5 \times 10^{6} \mathrm{Kcal} / \mathrm{h}$

$\mathrm{W}_{\mathrm{FP}}$ : primary feedwater flow rate: $807 \mathrm{MT} / \mathrm{h}$

$\mathrm{h}_{\mathrm{SP}}$ : $\quad$ primary steam enthalpy: $662.7 \mathrm{Kcal} / \mathrm{kg}\left(\right.$ at $\left.68.5 \mathrm{~kg} / \mathrm{cm}^{2}\right)$

$\mathrm{h}_{\mathrm{F}}: \quad$ preheated feedwater enthalpy: $194.8 \mathrm{Kcal} / \mathrm{kg}\left(\right.$ at $191^{\circ} \mathrm{C}, 105 \mathrm{~kg} / \mathrm{cm}^{2}$ )

$\mathrm{W}_{\text {FSA }}$ : feedwater flow to secondary steam gen. A: $108 \mathrm{MT} / \mathrm{h}$

$\mathrm{h}_{\mathrm{SSA}}: \quad$ enthalpy of steam from SSG-A: $669.9 \mathrm{Kcal} / \mathrm{kg}$ (at $35 \mathrm{~kg} / \mathrm{cm}^{2}$ )

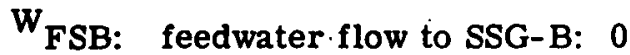

$\mathrm{h}_{\mathrm{SSB}}$ : enthalpy of steam from SSG-B: -

$\mathrm{W}_{\mathrm{cu}}$ : flow to clean-up system: $40 \mathrm{MT} / \mathrm{h}$

$h_{\text {cul }}:$ enthalpy of water to clean-up: $\sim 265 \mathrm{Kcal} / \mathrm{kg}$

$\mathrm{h}_{\text {cu2 }}$ : enthalpy of water from clean-up: $\sim 225 \mathrm{Kcal} / \mathrm{kg}$

$\mathrm{W}_{\mathrm{D}}$ : drive cooling flow: $6.3 \mathrm{MT} / \mathrm{h}$

$\mathrm{h}_{\mathrm{D}}$ : enthalpy of drive cooling water: $37.2 \mathrm{Kcal} / \mathrm{kg}\left(35^{\circ} \mathrm{C}, 105 \mathrm{~kg} / \mathrm{cm}^{2}\right)$

$\mathrm{Q}_{\mathrm{L}}$ : NSSS heat losses: $\sim 10^{6} \mathrm{Kcal} / \mathrm{h}$ (one loop valved)

$\mathbf{Q}_{\mathbf{p}}$ : recirculation pump impeller heat input: 0

$$
\begin{aligned}
& \mathrm{W}_{\mathrm{FP}}\left(\mathrm{h}_{\mathrm{SP}}-\mathrm{h}_{\mathrm{F}}\right)=807 \times 10^{3}(662.7-194.8)=377.63 \times 10^{6} \\
& \mathrm{~W}_{\text {FSA }}\left(\mathrm{h}_{\mathrm{SSA}}{ }^{-} \mathrm{h}_{\mathrm{F}}\right)=108 \times 10^{3}(669.9-194.8)=51,33 \times 10^{6} \\
& \mathrm{w}_{\mathrm{cu}}\left(\mathrm{h}_{\text {cu1 }}-\mathrm{h}_{\text {cu2 }}\right)=40 \times 10^{3}(265-225)=1.60 \times 10^{6} \\
& \mathrm{~W}_{\mathrm{D}}\left(\mathrm{h}_{\mathrm{SP}}-\mathrm{h}_{\mathrm{D}}\right)=6.3 \times 10^{3}(662.7-37.2)=3.94 \times 10^{6} \\
& \mathrm{Q}_{\mathrm{L}}=\frac{1.00 \times 10^{6}}{435.50 \times 10^{6} \mathrm{Kcal} / \mathrm{h}}
\end{aligned}
$$


1. Error on the Primary Feedwater Flow

Normal Control Room Instrumentation

Error due

to flow ele-

ment toler-

ance*: $\quad 1.10 \%$ of $807 \mathrm{MT} / \mathrm{h}= \pm 8.88 \mathrm{MT} / \mathrm{h}$

Differential

pressure

transmitter

error:

$0.5 \%$ of $900 \mathrm{MT} / \mathrm{h}= \pm 4.50 \mathrm{MT} / \mathrm{h}$

Control

room

recorder $1.5 \%$ of $900 \mathrm{MT} / \mathrm{h}= \pm 13.50 \mathrm{MT} / \mathrm{h}$

Total combined error: $\quad \pm 16.77 \mathrm{MT} / \mathrm{h}$

( $2 \sigma$ confidence)

$\sigma \quad\left(\mathrm{W}_{\mathrm{FP}}\right)=8.39 \mathrm{MT} / \mathrm{h}$

$\sigma_{r}\left(W_{F P}\right)=\frac{839}{807}=1.04 \%$

\section{Computer Instrumentation}

Error due

to flow ele-

ment toler-

ance*: $\quad 1.10 \%$ of $807 \mathrm{MT} / \mathrm{h}= \pm 8.88 \mathrm{MT} / \mathrm{h}$

Differential

pressure

transmitter

error: $0.5 \%$ of $900 \mathrm{MT} / \mathrm{h}= \pm 4.50 \mathrm{MT} / \mathrm{h}$

Computer

scanning and

conversion: $0.5 \%$ of $900 \mathrm{MT} / \mathrm{h}= \pm 4.50 \mathrm{MT} / \mathrm{h}$

Total combined error: $\quad \pm 10.92 \mathrm{MT} / \mathrm{h}$

( $2 \sigma$ confidence)

$\sigma\left(\mathrm{W}_{\text {FP }}\right)=5.46 \mathrm{MT} / \mathrm{h}$

$\sigma_{r}\left(W_{F P}\right)=\frac{546}{807}=0.68 \%$

\section{Error on Primary Steam Enthalpy}

Control Room Instrumentation

Drum pressure transmitter:

$0.5 \%$

Suppressed zero

pressure gage:

$0.5 \%$

Total combined error

on drum pressure:

( $2 \sigma$ confidence)

$$
\sigma\left(P_{D}\right): \quad 0.242 \mathrm{~kg} / \mathrm{cm}^{2}
$$

\section{Computer Instrumentation}

Drum pressure

transmitter: $\quad 0.5 \%$

(GE/MAC-55 1)

Computer scanning

and conversion: $\quad 0.5 \%$

Total combined error

on drum pressure: $\quad 0.71 \%$

(20 confidence)

$$
\sigma\left(P_{D}\right): \quad 0.242 \mathrm{~kg} / \mathrm{cm}^{2}
$$

* Flow nozzle machining and calibration error assumed equivalent to "ASME Power Test Code, Part 5: Measurement of Quantity of Materials, chapter 4: Flow Measurement, "Table 10, Page 88.

For the Bailey Meter flow nozzle used for the primary feedwater flow measurement, the ratio of throat to pipe I. D. is 0.7276 . The pipe I. D. is 9.197 inches and the pipe Reynolds Number at $807 \mathrm{MT} / \mathrm{h}$ and $190.5^{\circ} \mathrm{C}$ is $8.2 \times 10^{6}$. According to the ASME code the tolerance $(2 \sigma)$ for the flow nozzle discharge coefficient is increased linearly from $\pm 0.95 \%$ to $\pm 1.50 \%$ if the throat ratio increases from 0.7 to 0.8 , assuming that the pipe size (diameter) is in the range of 6 to 12 inches and that the pipe Reynolds number is larger than $3000 \times \mathrm{D}$. The tolerance for the feedwater flow nozzle is therefore: $0.95+0.276(1.5-0.95)=1.10 \%(2 \%)$. 
Corresponding $\sigma\left(\mathrm{h}_{\mathrm{SP}}\right)=0.07 \mathrm{Kcal} / \mathrm{kg}$ at $68.5 \mathrm{~kg} / \mathrm{cm}^{2}$

3. Error On Feedwater Enthalpy

Control Room Instrumentation

Resistance temperature

detector error: $\quad 0.5 \%$ or $1^{\circ} \mathrm{C}$

Resistance bridge

error:

$0.5^{\circ} \mathrm{C}$

Total combined error: $1.1^{\circ} \mathrm{C}$

on feedwater tem-

perature ( $2 \sigma$ confidence)

$$
\sigma\left(\mathrm{T}_{\mathrm{F}}\right)=0.55^{\circ} \mathrm{C}
$$

Corresponding $\sigma\left(\mathrm{h}_{\mathrm{F}}\right)=0.55 \mathrm{Kcal} / \mathrm{kg}$.
Corresponding $\sigma\left(\mathrm{h}_{\mathrm{SP}}\right)=0.07 \mathrm{Kcal} / \mathrm{kg}$ at $68.5 \mathrm{~kg} / \mathrm{cm}^{2}$.

\section{Computer Instrumentation}

Resistance temperature

detector error: $\quad 0.5 \%$ or $1^{\circ} \mathrm{C}$

Scanning and

conversion: $\quad 0.5^{\circ} \mathrm{C}$

Total combined error: $\quad 1.1^{\circ} \mathrm{C}$

on feedwater tem-

perature (2 $\sigma$ confidence)

$$
\sigma\left(T_{F}\right)=0.55^{\circ} \mathrm{C}
$$

Corresponding $\sigma\left(\mathrm{h}_{\mathrm{F}}\right)=0.55 \mathrm{Kcal} / \mathrm{kg}$

4. Error on Secondary Feedwater Flow

\section{Control Room Instrumentation}

Error due to

flow element

tolerance*: $0.95 \%$ of $108 \mathrm{MT} / \mathrm{h}= \pm 1.03 \mathrm{MT} / \mathrm{h}$

Differential

pressure

transmitter

error:

$0.5 \%$ of $150 \mathrm{MT} / \mathrm{h}= \pm 0.75 \mathrm{MT} / \mathrm{h}$

Control room

recorder

error:

$1.5 \%$ of $150 \mathrm{MT} / \mathrm{h}= \pm 2.25 \mathrm{MT} / \mathrm{h}$

Total combined error:

( $2 \sigma$ confidence)

$\sigma\left(\mathrm{W}_{\mathrm{FSA}}\right)=1.29 \mathrm{MT} / \mathrm{h}$

$\sigma_{r}\left(W_{F S A}\right)=\frac{129}{108}=1.20 \%$ $\pm 2.58 \mathrm{MT} / \mathrm{h}$

Tat

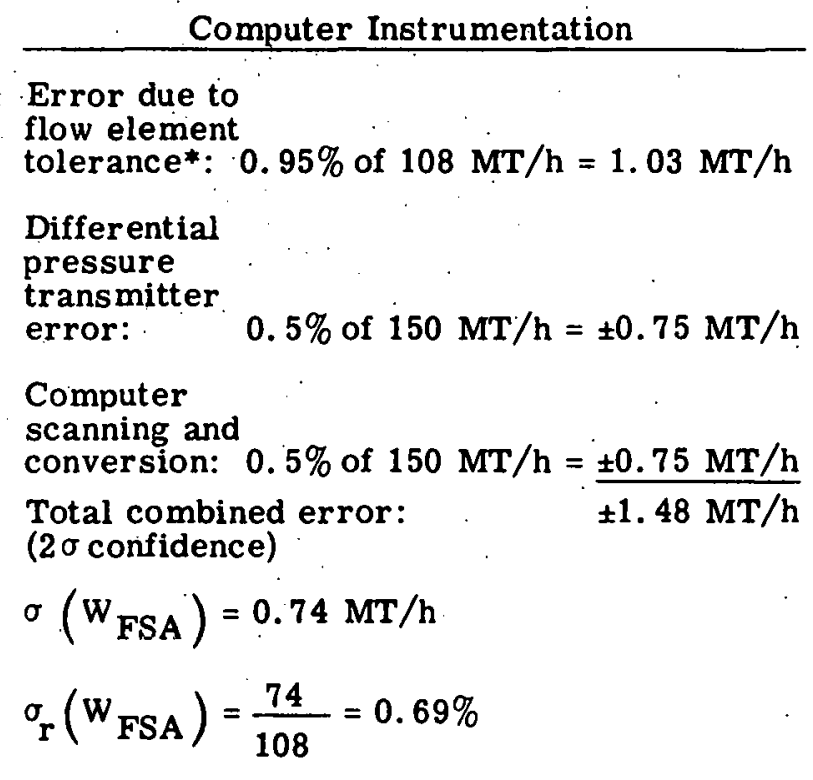

\footnotetext{
* Flow nozzle machining and calibration error assumed equivalent to ASME Power Test Code (see page 4-11)

- throat ratio of secondary flow nozzles: $\quad \beta=0.5204$

- pipe inside diameter: 5.591 inches
- pipe Reynolds Number at $108 \cdot \mathrm{MT} / \mathrm{h}$ and $190.5^{\circ} \mathrm{C}: \mathrm{R}_{\mathrm{D}}=1.8 \cdot 10^{6}$. ASME tolerance for $0.3 \leqslant \beta<0.7, R_{D} \geqslant 33,000 \times D$ and 6 inches $\leqslant D \leqslant 12$ inches is $\pm 0.95 \%$ ( $2 \sigma$.
} 


\section{Error on Secondary Steam Enthalpy}

\section{Control Room Instrumentation}

Secondary drum pressure

transmitter:

$0.5 \%$ (of $90 \mathrm{~kg} / \mathrm{cm}^{2}$ )

Recorder error

$1.5 \%$ (of $90 \mathrm{~kg} / \mathrm{cm}^{2}$ )

Total combined error: $1.58 \%$ (of $90 \mathrm{~kg} / \mathrm{cm}^{2}$ ) ( $2 \sigma$ confidence)

$\sigma\left(P_{\text {SSA }}\right)=\frac{0.0158}{2} 90=0.71 \mathrm{~kg} / \mathrm{cm}^{2}$

Corresponding $\sigma\left(\mathrm{h}_{\mathrm{SSA}}\right)=0.03 \mathrm{Kcal} / \mathrm{kg}$ (at $35 \mathrm{~kg} / \mathrm{cm}^{2}$ )

\section{Computer Instrumentation}

Secondary drum pressure transmitter: $\quad 0.5 \%$ (of $90 \mathrm{~kg} / \mathrm{cm}^{2}$ )

Computer scanning and conversion: $\quad 0.5 \%$ (of $90 \mathrm{~kg} / \mathrm{cm}^{2}$ ) Total combined error: $0.71 \%$ (of $90 \mathrm{~kg} / \mathrm{cm}^{2}$ ) (2\% confidence)

$\sigma\left(P_{S S A}\right) \frac{0.0071}{2} 90=\quad 0.32 \cdot \mathrm{kg} / \mathrm{cm}^{2}$

Corresponding $\sigma\left(\mathrm{h}_{\mathrm{SSA}}\right)=0.02 \mathrm{Kcal} / \mathrm{kg}$ (at $35 \mathrm{~kg} / \mathrm{cm}^{2}$ )

6. Error on the Clean-up System Heat Removal

The heat loss in the non-regenerative heat exchanger of the reactor clean-up system is:

$$
Q_{c u}=w_{c u}\left(h_{c u 1}-h_{c u 2}\right)=1.60 \times 10^{6} \mathrm{Kcal} / \mathrm{h} .
$$

Total error on this value is estimated with $3 \%$ ( $2 \sigma$ confidence).

$$
\sigma\left(Q_{c u}\right)=\frac{0.03}{2} 1.60 \times 10^{6}=24.10^{3} \mathrm{Kcal} / \mathrm{h}
$$

\section{Error on Heat Added to Rod Drive Coolant}

The amount of heal added to the rod drive coolant is:

$$
\mathrm{Q}_{\mathrm{D}}=\mathrm{W}_{\mathrm{D}}\left(\mathrm{h}_{\mathrm{SP}}-\mathrm{h}_{\mathrm{D}}\right)=3.94 \times 10^{6} \mathrm{Kcal} / \mathrm{h}
$$

The total error on this value is estimated with $3 \%$ ( $2 \sigma$ confidence).

$$
\sigma\left(Q_{D}\right)=\frac{0.03}{2} 3.94 \times 10^{6}=59.1 \times 10^{3} \mathrm{Kcal} / \mathrm{h}
$$

8. Error on NSSS Heat Losses

The error on the NSSS heat loss determination is estimated with $10 \%$ ( $2 \sigma$ confidence)

$$
\sigma\left(Q_{L}\right)=\frac{0.10}{2} 10^{6}=50 \times 10^{3} \mathrm{Kcal} / \mathrm{h} .
$$




\section{Determination of the Standard Deviation of Reactor Power}

The individual errors in the expression for $\mathbf{Q}_{\mathbf{R}}$ (Equation 1) are combined utilizing routine statistical assumptions. Expanding Equation (1) into a Taylor series about the nominal values and neglecting terms of higher order leads to the following expression for the variance of $Q_{R}$ :

$$
\begin{aligned}
\sigma^{2}\left(Q_{R}\right) & =\left(h_{S P}-h_{F}\right)^{2} \sigma^{2}\left(W_{F P}\right)+w_{F P}^{2} \sigma^{2}\left(h_{S P}\right)+w_{F P}^{2} \sigma^{2}\left(h_{F}\right) \\
& +\left(h_{S S A}-h_{F}\right)^{2} \sigma^{2}\left(W_{F S A}\right)+w_{F S A}^{2} \sigma^{2}\left(h_{S S A}\right)+w_{F S A}^{2} \sigma^{2}\left(h_{F}\right) \\
& +\sigma^{2}\left(Q_{C u}\right)+\sigma^{2}\left(Q_{D}\right)+\sigma^{2}\left(Q_{L}\right)
\end{aligned}
$$

Control Room

Instrumentation
$\left(\mathrm{h}_{\mathrm{SP}}-\mathrm{h}_{\mathrm{F}}\right)^{2} \sigma^{2}\left(\mathrm{~W}_{\mathrm{FP}}\right)$.
$\mathrm{W}_{\mathrm{FP}}^{2} \sigma^{2}\left(\mathrm{~h}_{\mathrm{SP}}\right)$.
$15.410 \times 10^{12}$
$0.0032 \times 10^{12}$
$0.197 \times 10^{12}$
$0.376 \times 10^{12}$
$0.00001 \times 10^{12}$
$0.00353 \times 10^{12}$
$0.00058 \times 10^{12}$
$0.00349 \times 10^{12}$
$0.0025 \times 10^{12}$
$15.99631 \times 10^{12}$
$4.00^{\circ} \times 10^{6} \mathrm{Kcal} / \mathrm{h}$
$0.92 \%$
$6.530 \times 10^{12}$
$0.0032 \times 10^{12}$
$0.197 \times 10^{12}$
$0.124 \times 10^{12}$
$0.000005 \times 10^{12}$
$0.00353 \times 10^{12}$
$0.00058 \times 10^{12}$
$0.00349 \times 10^{12}$
$0.0025 \times 10^{12}$
$\sigma^{2}\left(Q_{R}\right)$
$\sigma\left(\mathrm{Q}_{\mathrm{R}}\right)$
$\sigma_{r}\left(Q_{R}\right)=100 \frac{\sigma\left(Q_{R}\right)}{Q_{R}}$.
$6.864305 \times 10^{12}$.
$2.62 \times 10^{6} \mathrm{Kcal} / \mathrm{h}$
$0.60 \%$

Computer. Instrumentation

In terms of maximum probable error $(1.645 \sigma)$ the control room instrumentation glves $0.92 \%$ $\times 1.645=1.51 \%$ error (high side). Variability of repeated measurements would give $\pm 2 \sigma$ or $\pm 1.84 \%$ for $95 \%$ of the data. 


\section{E. Error in the Recirculation Flow Measurement}

Reactor recirculation flow measurement is based on the $\Delta \mathrm{P}$ across the secondary steam generators. The $\mathrm{W}-\Delta \mathrm{P}$ relationship of the secondary steam generators will be newly established prior to the test program. Instead of determining the $\Delta P$ across the steam generators as a difference of two dead-weight gage pressure measurements, the newly installed high precision differential pressure transmitters for the computer shall be used. It should thus be possible to improve the accuracy on recirculation flow measurements.

The steam generator calibration is based on the factory measured pump characteristic of the two recirculation pumps.

\section{Error on the Pump Characteristic}

Capacity measurement error: $0.75 \%$

(Assumes that test conforms to "Standards of Hydraulic Institute," 1961 Hydraulic Institute, 122E, 42nd Street, N. Y., and that Venturi meter or ASME long radius flow nozzle is used.)

Equivalent head measurement due to capacity measurement error near $\pm 0.71 \%$ rated operating point.

Pump head measurement: $\pm 1 \%$

(Instrument accuracy: $0.5 \%$ of full scale and assumed measurement at half of full scale.)

Variation in pump head measurement due to testing of both impellers $\pm 1 \%$ in same casing.

Performance curve plotting and reading error. $\pm 1 \%$

Estimated maximum change in pump characteristic after two years of operation.

Total combined error on pump head:

Corresponding standard deviation at rated conditions: $\sigma=0.0106 \times 37.5=0.3975 \mathrm{psi}$.

\section{Recalibration of Steam Generator}

If no differential pressure transmitter of an adequate range (50 psi) is available, the pump head has to be determined - as it has been done previously - by means of a laboratory type dead-weight gage. During previous tests it has been noticed that an operator error of about 0.7 psi ( $2 \sigma$ confidence) on a 1000 psi measurement has to be considered as normal (taking 
into account the existence of a certain amount of pressure "noise"). As in a difference measurement the methodical error of the gage can be neglected, the resulting standard deviation of the pump $\Delta P$ measurement will be:

$$
\sigma\left(\Delta \mathrm{P}_{\mathrm{p}}\right)=\sqrt{\sigma^{2}\left(\mathrm{P}_{1}\right)+\sigma^{2}\left(\mathrm{P}_{2}\right)}=\sqrt{2\left(\frac{0.7}{2}\right)^{2}}=0.495 \mathrm{psi}
$$

The total standard deviation on the pump head determination is:

$$
\sigma\left(H_{p}\right)=\sqrt{0.3975^{2}+0.495^{2}}=0.635 \mathrm{psi}
$$

At rated conditions a 1 psi change in pump head corresponds to a $0.28 \times 10^{6} \mathrm{lb} / \mathrm{h}$ change in pump flow. The corresponding standard deviation of the recirculation flow is therefore:

$$
\begin{aligned}
\sigma(\mathrm{w})=0.635 \times 0.28 \times 10^{6} & =0.1778 \times 10^{6} \mathrm{lb} / \mathrm{h} \\
& =80.6 \mathrm{MT} / \mathrm{h}
\end{aligned}
$$

The pressure drop across the secondary steam generator is measured by means of the computer $\Delta \mathrm{P}$ - transmitter. A high precision milliammeter will be connected to the transmitter during the calibration of the secondary steam generators.

$$
\begin{aligned}
& \text { Transmitter error } \quad 0.5 \% \text { (of } 2 \mathrm{~kg} / \mathrm{cm}^{2} \text { ) } \\
& \text { Milliammeter error } 0.5 \% \text { (of } 50 \text { milliamperes corresponding to } 2 \mathrm{~kg} / \mathrm{cm}^{2} \text { ) }
\end{aligned}
$$

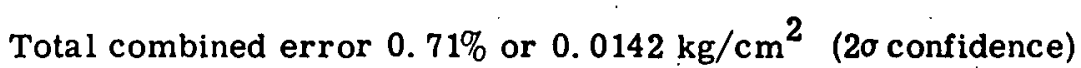

$$
\begin{aligned}
& \sigma(\Delta \mathrm{P})=0.0071 \mathrm{~kg} / \mathrm{cm}^{2} \text {. }
\end{aligned}
$$

The calibration factor of the secondary steam generators is:

$$
\mathrm{K}=\frac{\Delta \mathrm{P}}{\mathrm{W}^{2}}
$$

The variance of $\mathrm{K}$ is:

$$
\sigma^{2}(\mathrm{~K})=\frac{1}{\mathrm{~W}^{4}} \sigma^{2}(\Delta \mathrm{P})+4 \frac{\Delta \mathrm{P}^{2}}{\mathrm{~W}^{6}} \sigma^{2}(\mathrm{~W})=1.51 \cdot 10^{-18}
$$




$$
\begin{aligned}
& \text { at rated conditions } \\
& \mathrm{W} \simeq 5000 \mathrm{MT} / \mathrm{h} \\
& \Delta \mathrm{P} \simeq 0.927 \mathrm{~kg} / \mathrm{cm}^{2} \\
& \sigma(\mathrm{K})=1.229 \times 10^{-9} \\
& \mathrm{~K}=0.0371 \times 10^{-6} \text { as measured during previous tests } \\
& \sigma_{r}(\mathrm{~K})=100 \frac{\sigma(\mathrm{K})}{\mathrm{K}}=\frac{0.1229}{0.0371}=3.31 \%
\end{aligned}
$$

The error on $\mathrm{K}$ can he considerably reduced by repeating measurement at different recirculation flow rates and averaging the corresponding $\mathrm{K}$ values. For the following calculations it will be assumed however, that only one $\mathrm{K}$ measurement can be made.

Thus $\sigma(\mathrm{K})=1.229 \times 10^{-9}$

3. Recirculation Flow Error for the Reference Case Test Conditions

For the test conditions the total recirculation flow $\mathrm{W}_{\mathrm{T}}$ is equal to the one loop flow $\mathrm{W}$ :

$$
\mathrm{w}_{\mathrm{T}} \quad=\sqrt{\frac{\Delta \mathrm{P}}{\mathrm{K}}}
$$

The $\Delta \mathrm{P}$ across the secondary steam generator is measured by the new transmitter installed for the process computer.

$$
\text { error (2ఠ): } \quad 0.5 \% \text { (of } 2 \mathrm{~kg} / \mathrm{cm}^{2} \text { ) }
$$

Computer scanning and conversion error $(2 \sigma)$ is $0.5 \%$ (of $2 \mathrm{~kg} / \mathrm{cm}^{2}$ ). With a milliammeter of 30 milliamps full scale in the transmitter output circuit, a flow reading can be obtained independently from the computer. The error (20) of the milliammeter will be about $0.5 \%$ (of 50 milliamps $\triangleq 2 \mathrm{~kg} / \mathrm{cm}^{2}$ ).

The standard deviation of $\Delta \mathrm{P}$ as well for control room use as for the computer input will be:

$$
\sigma(\Delta \mathrm{p})=\frac{0.0071}{2} 2=0.0071 \mathrm{~kg} / \mathrm{cm}^{2}
$$


The variance on $\mathrm{W}_{\mathrm{T}}$ will therefore be:

$$
\sigma^{2}\left(\mathrm{~W}_{\mathrm{T}}\right)=\frac{1}{4} \frac{1}{\mathrm{~K} \Delta \mathrm{P}} \sigma^{2}(\Delta \mathrm{P})+\frac{1}{4} \frac{\Delta \mathrm{P}}{\mathrm{K}^{3}} \sigma^{2}(\mathrm{~K})
$$

with $\mathrm{W}_{\mathrm{T}}=3260 \mathrm{MT} / \mathrm{h}$ from computer calculations and $\mathrm{K}=0.0371 \times 10^{-6}$ from the previous calibration $\Delta \mathrm{P}=0.394 \mathrm{~kg} / \mathrm{cm}^{2}$

$$
\sigma\left(\mathrm{W}_{\mathrm{T}}\right)=61.4 \mathrm{MT} / \mathrm{h} \text { and } \sigma_{\mathrm{r}}\left(\mathrm{W}_{\mathrm{T}}\right)=1.88 \%
$$

Water returning from the clean-up system is added downstream of the secondary steam generator. It is therefore not included in $\mathrm{W}_{\mathrm{T}}$.

The error $(2 \sigma)$ on the clean-up flow measurement is estimated to be $2.5 \%$ of rated flow $(40 \mathrm{MT} / \mathrm{h})$ :

$$
\begin{aligned}
& \sigma\left(\mathrm{W}_{\mathrm{cu}}\right)=\frac{0.025}{2} 40=0.5 \mathrm{MT} / \mathrm{h} \\
& \sigma\left(\mathrm{W}_{\mathrm{T}}+\mathrm{W}_{\mathrm{cu}}\right)=\sqrt{\sigma^{2} \cdot\left(\mathrm{W}_{\mathrm{T}}\right)+\sigma^{2}\left(\mathrm{~W}_{\mathrm{cu}}\right)}=61.4 \mathrm{MT} / \mathrm{h} \quad \text { and } \\
& \sigma_{\mathrm{r}}\left(\mathrm{W}_{\mathrm{T}}+\mathrm{W}_{\mathrm{cu}}\right)=\frac{6140}{3300}=1.86 \%
\end{aligned}
$$

\section{Core Leakage Flow}

The core leakage flow versus recirculation flow has been calculated in a separate study (Section 5-B). As a consequence of interchannel boiling the relative leakage flow decreases rapidly as the recirculation flow drops below $6000 \mathrm{MT} / \mathrm{h}$. At $3300 \mathrm{MT} / \mathrm{h}$ the leakage flow is only 3. $1 \%$. The error ( $2 \sigma)$ on this value is estimated to be as high as $20 \%$ due to the fact that certain simplifying assumptions (e. g., neglecting rod drive cooling flow) had to be made.

$$
\begin{aligned}
& \mathrm{w}_{\ell}=0.031 \times 3300=102 \mathrm{MT} / \mathrm{h} \pm 20 \% \\
& \sigma\left(\mathrm{w}_{\ell}\right)=10.2 \mathrm{MT} / \mathrm{h}
\end{aligned}
$$

5. Total Core Flow Rate

The total core flow rate and corresponding error are as follows:

$$
\begin{aligned}
& \mathrm{W}_{\mathrm{T}}+\mathrm{W}_{\mathrm{cu}}-\mathrm{W}_{\ell}=3260+40-102=3198 \mathrm{MT} / \mathrm{h} \\
& \sigma\left(\mathrm{W}_{\mathrm{T}}+\mathrm{W}_{\mathrm{cu}}-\mathrm{W}_{\ell}\right)=\sqrt{\sigma^{2}\left(\mathrm{~W}_{\mathrm{T}}+\mathrm{W}_{\mathrm{cu}}\right)+\sigma^{2}\left(\mathrm{~W}_{\ell}\right)}=62.2 \mathrm{MT} / \mathrm{h} \\
& \sigma_{\mathrm{r}}\left(\mathrm{W}_{\mathrm{T}}+\mathrm{W}_{\mathrm{cu}}-\mathrm{W}_{\ell}\right)=\frac{6220}{3198}=1.95 \% .
\end{aligned}
$$




\section{F. Error in Core Power Distribution}

1. Error on Axial Wire Data

The evaluation of the error on axial wire data is based on the results of the wire uniformity test, performed at the Garigliano Power Plant in November 1963 (see Appendix A).

By comparing to each other the normalized results of the 20 wires for a given location, the combined magnitude of the following individual errors can be directly evaluated:

- local variation in wire thickness and $\mathrm{Cu}$ concentration;

- local concentration of impurities (mainly Mn);

- counting statistics;

- constancy of counting geometry;

- counting equipment stability;

- uncertainty in wire location;

- error on normalization.

The error due to the improper balance of fast neutron copper activation and fast fission distribution is a methodical error. With increasing hardness of the neutron spectrum, it tends to overestimate the local power. Therefore this error is in the safe direction and is not to be further considered here (see Appendix A).

For the following axial locations (in gun units*) the standard deviation of the 20 wire data points from their average value has been calculated:

- locations adjacent to in-core chamber B (location 108):

$$
\left.\begin{array}{ll}
\text { location 100: } & \sigma_{r}=4.30 \% \\
\text { location 120: } & \sigma_{r}=4.32 \%
\end{array}\right\} \quad \sigma_{r}=4.31 \%
$$

- locations adjacent to in-core chamber C (location 168):

$$
\left.\begin{array}{ll}
\text { location } 150: & \sigma_{r}=3.46 \% \\
\text { location } 160: & \sigma_{r}=3.25 \% \\
\text { location 175: } & \sigma_{r}=3.73 \% \\
\text { location } 180 & \sigma_{r}=3.02 \%
\end{array}\right\} \quad \sigma_{r}=3.37 \%
$$

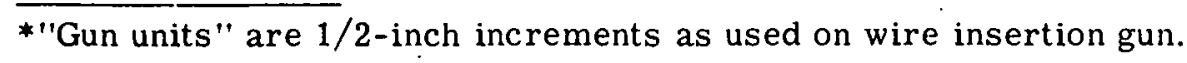


- locations adjacent to in-core chamber D (location 222):

$$
\left.\begin{array}{ll}
\text { location 210: } & \sigma_{r}=4.30 \% \\
\text { location 220: } & \sigma_{r}=5.14 \% \\
\text { location 225: } & \sigma_{r}=4.32 \% \\
\text { location 230: } & \sigma_{r}=5.08 \%
\end{array}\right\} \sigma_{r}=4.73 \%
$$

Averaging the variances for the 10 locations yields a standard deviation of $4.15 \%$. For all following calculations the standard deviation of the axial factor at the chamber locations ( $f_{i j}$ ) will be taken equal to $4.15 \%$ :

$$
\sigma_{r}\left(f_{i j}\right)=4.15 \%
$$

In cases where the axial flux gradient at the chamber locations is small, hand smoothing of the flux plot would considerably reduce the error on $f_{i j}$ : Further, an increase in wire counting time would substantially improve counting statistics (compare for instance $\sigma_{r}$ values at chamber $\mathrm{C}$ to values at chamber $\mathrm{D}$, where counting statistics are poor).

\section{$\underline{\text { Remark }}$}

The $f_{i j}$ values for symmetrical core positions are averaged $\left(f_{i j}^{*}\right)$ in order to reduce the error: Four strings, however, have no symmetrical counterpart in the core. For all following calculations only the most conservative value of $4.15 \%$ will therefore be used.

\section{Error on Radial Power Distribution Calculations}

The relative power of each fuel bundle is calculated by the TREDA computer code. The accuracy of this calculational method has been checked by comparing calculations to gamma scan results from 6 different BWR cores*, including cases in which fuel was scattered in the core not only by type but also by exposure.

From this comparison, the following relative standard deviations were obtained (calculated compared to measured):

$\sigma_{\mathbf{r}}\left(\mathrm{P}_{\mathrm{b}}\right)$

SENN, all measured fuel bundles

$3.5 \%$

SENN, all bundles with $P_{b}>1.3$

2. $2 \%$

hottest bundles of 6 different cores

4. $1 \%$

bundles with $P_{b}>1.3$ of 6 different cores

4. $1 \%$

SENN, radial wire data at $1580 \mathrm{MWD} / \mathrm{sT}$
4. $4 \%$

*W. R. Clancey and N. D. Witt, personal communication, Nov. 1964 
The 6 different cores, referred to, are:

Dresden, end of cycle II

Dresden, half power run

SENN, beginning of life

Humboldt Bay, beginning of life

Humboldt Bay, end of cycle I

Big Rock, October 1964.

For the above listed standard deviations it is difficult to know separately the contribution of the calculation error and the measurement error. It is believed however, that the major contribution is coming from the calculational model. The standard deviation for SENN radial wire data versus TREDA is somewhat higher than for the SENN gamma-scan versus TREDA. This is due to the greater uncertainties on radial wire data as compared to the gamma-scan method. However, radial wire data will provide a valuable way of checking TREDA calculations for the specific test conditions of the Development Program. An increasing discrepancy between TREDA and the radial wire data at higher core voids could easily be detected and taken into account.

The gamma scan, planned under the Garigliano Development Program, should give a most valuable contribution in reducing uncertainties on radial power distribution.

For the present error evaluation a conservative $\sigma$-value of $4.1 \%$ (from comparison of TREDA versus gamma-scan data for hot bundles of 6 different cores) shall be used for the bundle power error. When compared to the SENN results from the clean core gamma scan this figure appears to be very conservative.

\section{Error on Local Peak Calculations}

The corner rod peaking factors are calculated by a computer code and given for different adjacent control rod positions and void contents.

Only little experimental data is available for comparison with calculation. Two bundles (one from Dresden and one from VAL critical facility) have been disassembled for a gammascan of the corner rods. On a total of 20 corner rods the observed standard deviation of the corner rod peaking factors was $3.2 \%$ (including, of course, the error on the gamma-scan method itself).

An additional consideration in the local peaking factor that has to be included is that the calculations are done for nominal material concentrations and nominal dimensions. The effects of manufacturing tolerances have been shown to give about $4 \%(2 \sigma)$ uncertainty in the local peaking factor. When the calculation error is combined with the manufacturing tolerance error, the standard deviation on the local peaking factors becomes:

$$
\sigma_{r}\left(C_{b j}\right)=\sqrt{\overline{3.2}^{2}+\overline{2.0}^{2}}=3.8 \% \text {. }
$$




\section{G. Error in In-Core Chamber Readings}

Case of normal in-core calibration procedure, using wire data for axial distribution and TREDA-calculations for radial and local factors.

The neutron flux at the chamber location is proportional to the average power of the 4 adjacent corner rods:

$$
\begin{aligned}
& (\overline{C P})_{i j}=\frac{1}{4} \sum_{b=1}^{4} P_{b} C_{b j} \\
& i \quad \text { refers to in-core string number }(101-120) \\
& j \quad \text { refers to chamber level }(A, B, C, D) \\
& b \quad \text { refers to the } 4 \text { adjacent bundles of location } \mathrm{i} \\
& \mathrm{P}_{\mathrm{b}} \quad \text { relative bundle power } \\
& \mathrm{C}_{\mathrm{bj}} \quad \text { corner rod peaking factor. }
\end{aligned}
$$

For the error calculation it is necessary to make assumptions on the values of $P_{b}$ and $C_{b j}$. In order to make sure that the most unfavorable case is considered, the following values are given to $\mathrm{P}_{\mathrm{b}}$ and $\mathrm{C}_{\mathrm{bj}}$.

$$
\begin{aligned}
& P_{1}=P_{2}=P_{3}=P_{4}=1.3 \\
& C_{1 j}=C_{4 j}=1.42 \text { (for } \mathrm{Zr} \text { channels, } 53 \% \text { voids) } \\
& C_{2 j}=C_{3 j}=1.22 \text { (for } \mathrm{Zr} \text { channels, } 53 \% \text { voids) }
\end{aligned}\left\{\begin{array}{l}
\text { NOTE: Factor is constant } \\
\text { (or decreased) for further } \\
\text { increase in voids }
\end{array}\right.
$$

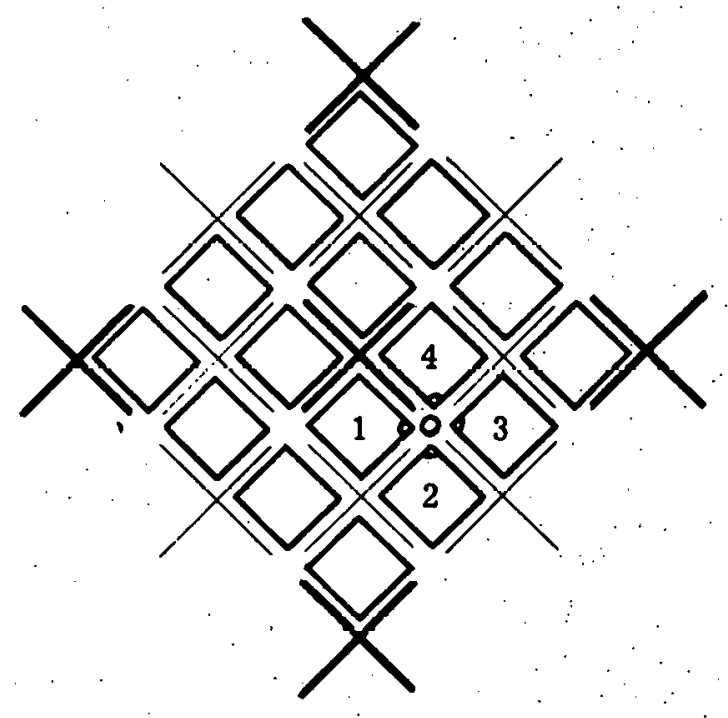




$$
\begin{aligned}
& \sigma^{2}(\overline{C P})_{i j}=\frac{1}{16} \sum_{b=1}^{4} C_{b j}^{2} \sigma^{2}\left(P_{b}\right)+P_{b}^{2} \sigma^{2}\left(C_{b j}\right) \\
& P_{b} \quad=1.3 ; \sigma^{2}\left(P_{b}\right)=(0.041 \times 1.3)^{2}=28.4 \times 10^{-4} \\
& C_{1 j} \quad=C_{4 j}=1.42 ; \sigma^{2}\left(C_{1 j}\right)=\sigma^{2}\left(C_{4 j}\right)=(0.038 \times 1.42)^{2}=29.15 \times 10^{-4} \\
& C_{2 j}=C_{3 j}=1.22 ; \sigma^{2}\left(C_{2 j}\right)=\sigma^{2}\left(C_{3 j}\right)=(0.038 \times 1.22)^{2}=21.5 \times 10^{-4} \\
& \sigma^{2}(C P)_{i j}=23.16 \times 10^{-4}
\end{aligned}
$$

The relative neutron flux at the chamber location is:

$$
\phi_{\mathrm{ij}} \quad=(\overline{\mathrm{CP}})_{\mathrm{ij}} \mathrm{f}_{\mathrm{ij}}^{*}=1.716 \times 1.6=2.745
$$

taking a most unfavorable axial power peaking factor of $f_{i j}^{*}=1.6$. The standard deviation of $\phi_{\mathrm{ij}}$ will be:

$$
\begin{aligned}
& \sigma^{2}\left(\phi_{i j}\right)=f_{i j}^{* 2} \sigma^{2}(\overline{C P})_{i j}+(\overline{C P})_{i j}^{2} \sigma^{2}\left(f_{i j}^{*}\right) \\
& \sigma^{2}\left(\phi_{i j}\right)=189 \times 10^{-4} \\
& \sigma_{r}\left(\phi_{i j}\right)=5.01 \% .
\end{aligned}
$$

The in-core chamber reading immediately after a recalibration is:

$$
\begin{aligned}
\mathrm{R}_{\mathrm{ij}} & =\frac{\eta \mathrm{Q}_{\mathrm{R}} \phi_{\mathrm{ij}}}{\mathrm{A}_{\mathrm{T}} \mathrm{K}}=\frac{0.97 \times 506.3 \times 10^{6} \times 2.745}{19.2 \times 10^{6} \times 0.75}=93.7 \\
\eta \quad & 0.97 \pm 0.005(2 \sigma): \text { fraction of heat developed in fuel. } \\
\sigma_{\mathrm{r}}(\eta) & =\frac{0.25}{0.97} \quad=0.258 \%
\end{aligned}
$$




$$
\begin{aligned}
& \mathrm{Q}_{\mathrm{R}}=506.3 \times 10^{6} \mathrm{~W} \text {; thermal reactor power } \\
& \sigma_{\mathrm{r}}\left(\mathrm{Q}_{\mathrm{R}}\right)=0.92 \% \text {, using control room instrumentation only } \\
& \mathrm{A}_{\mathrm{T}}=19.2 \times 10^{6} \mathrm{~cm}^{2} \pm 0.5 \%(3 \sigma), \text { total core heat transfer arca } \\
& \sigma_{\mathrm{r}}\left(\mathrm{A}_{\mathrm{T}}\right)=0.167 \% \\
& \mathrm{~K} \quad=0.75 \mathrm{~W} / \mathrm{cm}^{2} / \text { division, calibration factor. }
\end{aligned}
$$

To take into account the error on the operation of adjusting the amplifier gain, an error of $1 \%(2 \sigma)$ is assumed on the $\mathrm{K}$ value:

$$
\sigma_{\mathrm{r}}(\mathrm{K})=0.5 \%
$$

The standard deviation of the chamber reading immediately after recalibration of the in-core system is:

$$
\sigma_{r}\left(R_{i j}\right)=\sqrt{\sigma_{r}^{2}(\eta)+\sigma_{r}^{2}\left(Q_{R}\right)+\sigma_{r}^{2}\left(\dot{\phi}_{i j}\right)+\sigma_{r}^{2}\left(A_{T}\right)+\sigma^{2}(K)}=5.12 \%
$$

The meaning of this is that immediately after the recalibration of the in-core system the highest reading chamber indicates the heat flux at the corner rods adjacent to the chamber location with an error of $10.2 \%(2 \sigma$ confidence $)$.

A chamber reading made not later than 3 days after the recalibration of the system will total the following errors:

error at moment of calibration: drift in chamber sensitivity over 3 days: galvanometer (change in zero set point): reading error changes of the $P_{b}, f_{i j}$ and $C_{b j}$ values, due to small changes in flux distribution (minnr control rod pattern changes, change in subcooling)

Total combined error on reading:

Then $\sigma=5.5 \%$
$10.24 \%(2 \sigma)$
$1.0 \%(2 \sigma)^{*}$
$2.0 \%(2 \sigma)$
$1.5 \% \quad(2 \sigma)$
$3.0 \% \quad(2 \sigma)$

$\overline{11.00 \%(2 \sigma)}$

NOTE: This result has only been established to obtain an indication on possible in-core chamber reading errors. It will not be used directly in the error analysis on the MCHFR.

\footnotetext{
* From previous calibrations the drift rate of each in-core chamber is approximately known ( $\approx 10 \%$ per month) and could - at least partially - be corrected. The error remaining after correction is a statistical error and can be combined statistically.
} 
H. Error in the Control Room Method of MCHFR Determination

In translating the chamber readings into the bundle power of the hot or peak element, the readings are multiplied by the following $\mathrm{F}_{\mathrm{A}}$ factor:

$$
F_{A} \quad=P_{b} \frac{f_{i j}}{\phi_{i j}}
$$

and

$$
R_{i j} F_{A}=\frac{n Q_{r} \phi_{i j}}{A_{T} K} \frac{P_{b} f_{i j}}{\phi_{i j}}=\frac{n Q_{r} P_{b} f_{i j}}{A_{T} K}
$$

As can be seen, the $\phi_{\mathrm{ij}}$ factor, calibrated into the in-core system, is divided out again. It is therefore, not correct to combine the relative errors on $R_{i j}$ and on $F_{A}$. The error on the product $R_{i j} F_{A}$ has to be recalculated from the individual error on the variables $\eta, Q_{r}, P_{b}$, $f_{i j}, A_{r}$ and $K$.

$$
\text { with } \begin{aligned}
\sigma_{r}(\eta) & =0.258 \% \\
\sigma_{r}\left(Q_{R}\right) & =0.92 \% \text { (using control room instrument readings only) } \\
\sigma_{r}\left(A_{T}\right) & =0.167 \% \\
\sigma_{r}(K) & =0.5 \% \\
\sigma_{r}\left(P_{b}\right) & =4.1 \% \\
\sigma_{r}\left(f_{i j}\right) & =4.15 \% .
\end{aligned}
$$

The standard deviation of the product $R_{i j} F_{A}$, immediately after the recalibration of the in-core system, is:

$$
\sigma_{\mathrm{r}}\left(\mathrm{R}_{\mathrm{ij}} \mathrm{F}_{\mathrm{A}}\right)=5.94 \%
$$

If the MCHFR calculation is made not later than 3 days after the recalibration of the in-core system, the following additional errors have to be considered:

drift in chamber sensitivity over 3 days: (see footnote page 4-24)

$1.0 \% \quad(2 \sigma)$

galvanometer error (change in zero set point)

$2.0 \% \quad(2 \sigma)$

reading error

$1.5 \% \quad(2 \sigma)$

change of the $P_{b}$ and $f_{i j}$ values, due to small changes in flux

$3.0 \% \quad(2 \sigma)$

distribution (minor control rod pattern changes, change in subcooling) 
uncertainty on reactor power determination at the momeni

$1.84 \%(20)$ of the MCHFR calculation*.

The standard deviation of the product $\mathrm{R}^{\prime}{ }_{\mathrm{ij}} \mathrm{F}_{\mathrm{A}}^{\prime}$ at the moment of the MCHFR calculation is:

$$
\sigma_{r}\left(R_{i j}^{\prime} F_{A}^{\prime}\right)=6.34 \% \text {. }
$$

For the bundle considered the four $R_{i j}^{\prime} F_{A}^{\prime}$ values are plotted on a graph. A probable axial flux distribution line is drawn through these four points. During the high void tests of the Garigliano Development Program the MCHFR determination is done by the thermal engineer who will use previous wire irradiation data as a guide for the plotting of the axial flux distribution. A maximum plotting error of $5 \%(20)$ at the middle between two points will nevertheless have to be expected. At a distance of $1 / 4$ and $3 / 4$ of the span between points. the plotting error is estimated to be $2.5 \%(2 \sigma)$.

For each one of the 8 axial nodes the average heat flux is determined from the graph:

$$
\overline{(\bar{q} / \mathrm{A}})_{\mathrm{n}}=\mathrm{K} \times\left(\overline{\mathrm{R}_{\mathrm{ij}}^{\prime} \mathrm{F}_{A}^{\prime}}\right)_{\mathrm{n}} \text { with } \mathrm{K}=0.75 \mathrm{~W} / \mathrm{cm} / \mathrm{div} \text {. }
$$

As the $\left(R_{i j}^{\prime} F_{A}^{\prime}\right)_{n}$ values are all read at $1 / 4$ distance of each $R_{i j}^{\prime} F_{A}^{\prime}$ point (see Figure 4-1), the expected standard deviation on the node average heat flux is:

$$
\sigma_{r}(\overline{q / A})_{n}=\sqrt{\overline{6.34}^{2}+\overline{1.25}^{2}}=6.46 \%
$$

The node power at $120 \%$ overpower is:

$$
(O P)_{n} \cdot=(\overline{q / A})_{n} \cdot A_{n} \times 1.20
$$

As the error on the core heat transfer area has already been taken into account previously, the standard deviation on the node overpower will be the same as for the node average heat flux:

$$
\sigma_{\mathbf{r}}(\mathrm{OP})_{\mathrm{n}}=6.46 \% \text {. }
$$

* A new heat balance with a new error on reactor power is made at the moment of the MCHFR determination. Plant instrumentation, however, has remained unchanged since the last recalibration. It is therefore, conservative to introduce a second time the full error on $Q_{R}$ in this
error calculation. 


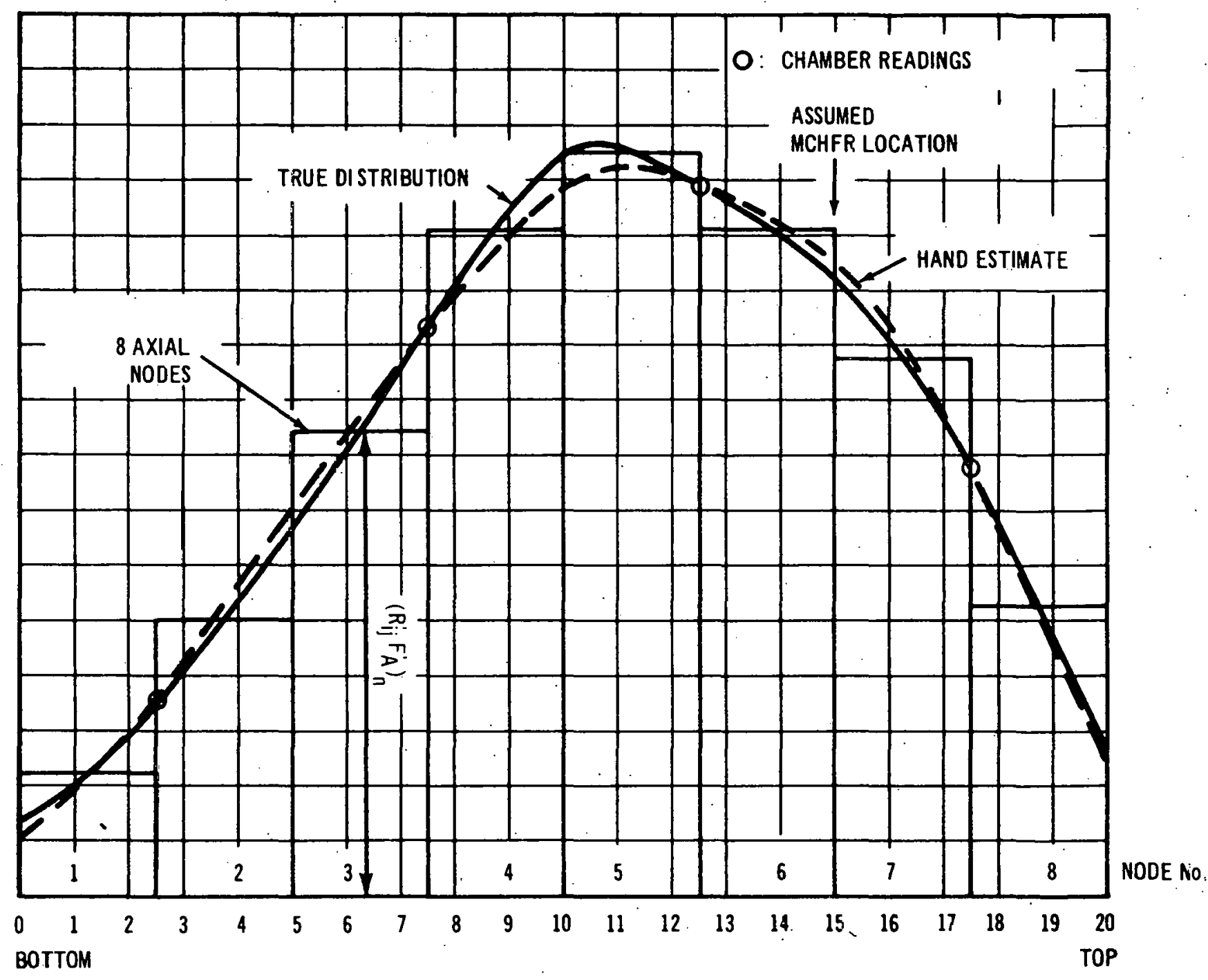


Computer calculations have shown that for both the hottest and the peak element the MCHFR occurred close to the exit of node 6 (using a total of 8 axial nodes). Total heat addition at over power at the exit of node 6 is:

$$
\mathrm{H}_{6}=\sum_{\mathrm{n}=1}^{6}(\mathrm{OP})_{\mathrm{n}}
$$

The following individual errors are common to all 6 nodes:

error on heat fraction developed in fuel; $\sigma(\eta)=0.258 \%$

error on reactor power, $\sigma\left(Q_{R}\right)$

$=0.92 \%$ (at moment of in-core calibration)

error on reactor power, $\sigma\left(Q_{R}\right)$

$=0.92 \%$ (at moment of MCHFR determination)

error on the calculated bundle power, $\sigma\left(P_{b}\right)=4.10 \%$

error on the heat transfer area, $\sigma\left(\mathrm{A}_{\mathrm{T}}\right) \quad=0.167 \%$

error due to the change of $P_{b}$ since the last

in-core recalibration, $\sigma_{r} \quad=\frac{1.5}{\sqrt{2}}=1.06 \%$

total combined:

$4.44 \%$

The following individual errors are common to two nodes, adjacent to an in-core chamber:
error on in-core chamber calibration $\sigma(\mathrm{K})=0.5 \%$
error on the axial factors $\sigma\left(f_{i j}\right)$
$=4.15 \%$
error due to the change of $f_{i j}$ since the last
in-core calibration, $\sigma_{r}$
$=\frac{1.5}{\sqrt{2}}=1.06 \%$
chamber drift, $\sigma_{\mathbf{r}}$
$=0.5 \%$
$=1.0 \%$
galvanometer error, $\sigma_{r}$
$=0.75 \%$
reading error, $\sigma_{r}$
$4.52 \%$
total combined:

The plotting error can be considered to be individual to each node. $\sigma_{\mathrm{r}}=1.25 \%$ 
In the following table, the correlated errors are combined linearly and the uncorrelated errors statistically:

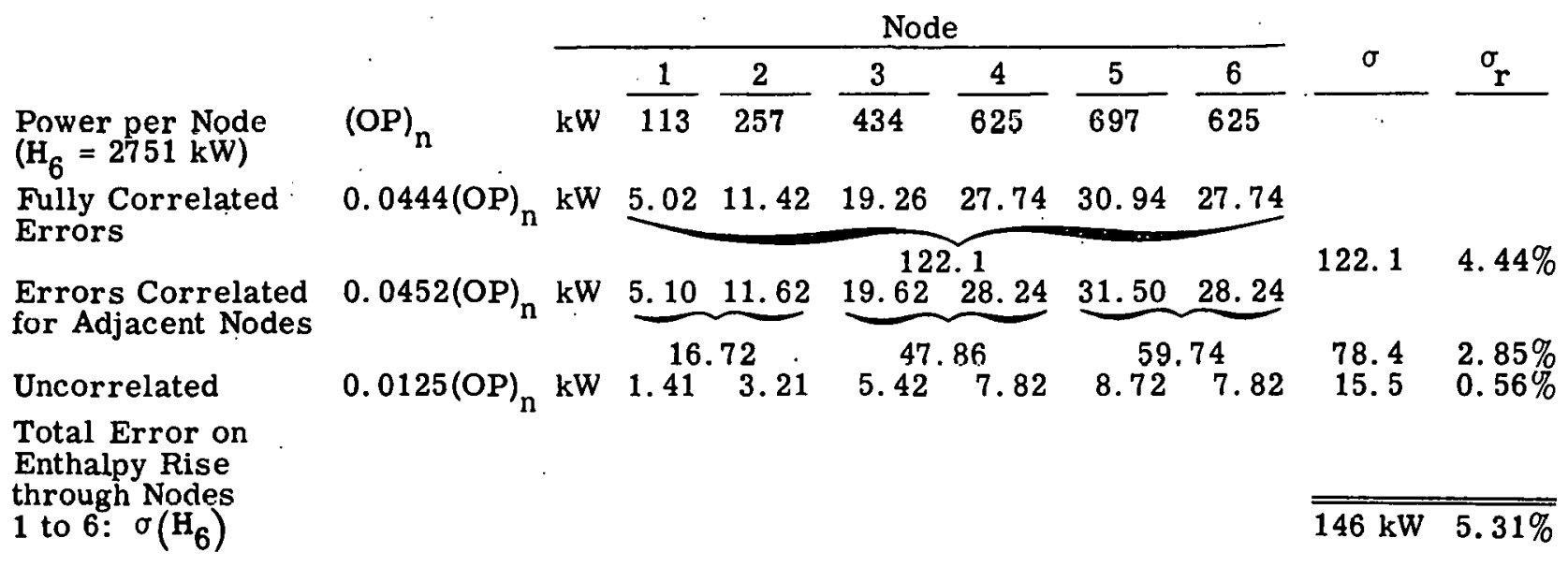

The average channel flow rate for the considered test conditions and rated reactor power is:

$$
\begin{aligned}
& \overline{\mathrm{W}_{\mathrm{ch}}} \cdot=\frac{\mathrm{W}_{\mathrm{T}}+\mathrm{W}_{\mathrm{cu}}-\mathrm{W}_{\ell}}{208}=\frac{3260+40-102}{208}=15.38 \mathrm{MT} / \mathrm{h} . \\
& \sigma_{\mathrm{r}}\left(\overline{\mathrm{W}_{\mathrm{ch}}}\right)=\sigma_{\mathrm{r}}\left(\mathrm{W}_{\mathrm{T}}+\mathrm{W}_{\mathrm{cu}}-\mathrm{W}_{\ell}\right)=1.95 \% .
\end{aligned}
$$

The recirculation flow rate at 1.20 overpower is: $3275 \mathrm{MT} / \mathrm{h}$

The corresponding core leakage flow rate is: $\quad 0.031 \times 3315=103 \mathrm{MT} / \mathrm{h}$

The average channel flow rate at overpower is:

$$
\left(\overline{\mathrm{w}_{\mathrm{ch}}}\right)_{\mathrm{OP}}=\frac{3275+40-103}{208}=15.45 \mathrm{MT} / \mathrm{h} .
$$

As the recirculation flow rate is slightly higher at overpower than at rated power, the corresponding relative flow error would be somewhat lower. However, the same error as for rated power is taken at 1.20 overpower:

$$
\sigma_{r}\left(\overline{W_{c h}}\right)_{O P}=\sigma_{r}\left(\overline{W_{c h}}\right)=1.95 \%
$$


The flow rate of a specific channel is

$$
\mathrm{W}_{\mathrm{ch}} \quad=\quad \mathrm{F}_{\mathrm{b}} \times \overline{\mathrm{W}_{\mathrm{ch}}}
$$

$F_{b}$ is the bundle flow factor, depending on the bundle power.

For the hottest element $\left(P_{b}=1.30 ; C_{b j}=1.22, f_{i j}=1.6\right): F_{b}=0.970$

For the peak element $\left(P_{b}=1.17, C_{b j}=1.50 ; f_{i j}=1.6\right): \quad F_{b}=0.947$

As the lowest MCHFR occurs on the peak element, error calculations will be performed for this one only.

The flow rate of the peak element at overpower is:

$$
\left(W_{\text {ch }}\right)_{\text {OP }}=0.947 \times 15.45=14.63 \mathrm{MT} / \mathrm{h} .
$$

In chapter C of Section IV a detailed analysis of the error on the flow rate of the MCH FRchannel has been presented. This analysis also takes into account a possible crud build-up in the core. The corresponding flow factor error is $2.2 \%(2 \sigma)$. The standard deviation on bundle power or $\sigma_{r}\left(\mathrm{H}_{8}\right)$ is slightly lower than $\sigma_{r}\left(\mathrm{H}_{6}\right)$. It is thus conservative to take $\sigma_{r}\left(\mathrm{H}_{8}\right)=5.31 \%$. For different test conditions at natural circulation, computer calculations have shown that (at $P_{b}=1.17$ ) the channel flow change rate with bundle power is 0.3 or less. Then a standard deviation on bundle power of $5.31 \%$ corresponds to a standard deviation of $1.6 \%$ on the bundle flow factor.

Thus

$$
\sigma_{r}\left(F_{b}\right) \quad=\sqrt{1.1^{2}+1.6^{2}}=1.94 \%
$$

and

$$
\sigma_{r}\left(W_{c h}\right)_{O P}=\sqrt{\sigma_{r}^{2}\left(\bar{W}_{c h}\right)+\sigma_{r}^{2}\left(F_{b}\right)}=2.75 \%
$$

The peak channel enthalpy rise from the core.inlet to the outlet of node 6 at overpower is:

$$
\Delta \mathrm{h}_{6} \quad=860 \frac{\mathrm{H}_{6}}{\left(\mathrm{~W}_{\mathrm{ch}}\right)_{\mathrm{OP}}}=161.7 \mathrm{Kcal} / \mathrm{kg}
$$


combining linearly the correlated error portions and statistically the uncorrelated portions:

$$
\sigma_{r}\left(\Delta h_{6}\right)=\sqrt{(5.31+1.6)^{2}+2.24^{2}}=7.26 \%
$$

The steam quality at the exit of node 6 of the peak channel at overpower is:

$$
\mathrm{x}_{6}=\frac{\mathrm{h}_{\mathrm{in}}+\Delta \mathrm{h}_{6}-\mathrm{h}_{\mathrm{sat}}}{\mathrm{h}_{\mathrm{fg}}}=\frac{249.4+161.7-302.1}{359.1}=0.3036
$$

The core inlet enthalpy $h_{\text {in }}$ is:

$$
h_{\text {in }}=\frac{w_{T} h_{r}+w_{c u} h_{c u}}{w_{T}+w_{c u}}
$$

The rod drive cooling water is added to the interchannel space and is not to be considered.

The error on $h_{c u}$ is negligible with respect to the error on $h_{r}$ :

$$
\sigma\left(h_{\text {in }}\right) \simeq \sigma\left(h_{r}\right)
$$

The temperature of the recirculation water at the secondary steam generator outlet will be measured by means of the newly installed resistance element used for the process computer.

resistance element error:

$0.5 \%(2 \sigma)$

resistance bridge error:

$0.5 \%$

Tntal combined error on temperature $0.71 \%(2 \sigma)$ measurement:

At the test conditions:

$$
\mathrm{T}_{\mathrm{r}} \quad=241^{\circ} \mathrm{C} \text { and } \sigma\left(\mathrm{T}_{\mathrm{r}}\right)=0.85^{\circ} \mathrm{C}
$$

the corresponding $\sigma$ on $h_{r}$ is $0.95 \mathrm{Kcal} / \mathrm{kg}$

the standard deviation of the system pressure is:

$$
\sigma\left(P_{D}\right)=0.242 \mathrm{~kg} / \mathrm{cm}^{2} \text {. }
$$


The corresponding $\sigma$ on $\mathrm{h}_{\mathrm{r}}$ is negligible:

therefore

$$
\sigma\left(\mathrm{h}_{\mathbf{r}}\right) \quad=\sigma\left(\mathrm{h}_{\mathrm{in}}\right)=0.95 \mathrm{Kcal} / \mathrm{kg} \text {. }
$$

The corresponding $\sigma$ on $h_{f g}$ and $h_{\text {sat }}$ are:

$$
\sigma\left(\mathrm{h}_{\mathrm{fg}}\right) \quad=0.39 \mathrm{Kcal} / \mathrm{kg} ; \sigma\left(\mathrm{h}_{\mathrm{sat}}\right)=0.32 \mathrm{Kcal} / \mathrm{kg}
$$

The variance of the steam quality at the exit of node 6 :

$$
\begin{aligned}
& \sigma^{2}\left(\mathrm{x}_{6}\right)=\frac{\sigma^{2}\left(\mathrm{~h}_{\mathrm{in}}\right)}{\mathrm{h}_{\mathrm{fg}}^{2}}+\frac{\sigma^{2}\left(\Delta \mathrm{h}_{6}\right)}{\mathrm{h}_{\mathrm{fg}}^{2}}+\frac{\sigma^{2}\left(\mathrm{~h}_{\mathrm{sat}}\right)}{\mathrm{h}_{\mathrm{fg}}^{2}}+\frac{\left(\mathrm{h}_{\mathrm{in}}+\Delta \mathrm{h}_{6}-\mathrm{h}_{\mathrm{sat}}\right)^{2}}{\mathrm{~h}_{\mathrm{fg}}^{4}} \sigma^{2}\left(\mathrm{~h}_{\mathrm{fg}}\right) \\
& =7.0 \times 10^{-6}+1069.3 \times 10^{-6}+0.8 \times 10^{-6}+0.1 \times 10^{-6}=1077.2 \times 10^{-6} \\
& \begin{aligned}
\text { and } \sigma\left(\mathrm{X}_{6}\right) & =0.03282 \\
\sigma_{\mathrm{r}}\left(\mathrm{X}_{6}\right) & =\frac{3.282}{0.3036}=10.81 \% .
\end{aligned}
\end{aligned}
$$

It is noted that the major contributer to this value is $\sigma\left(\Delta \mathrm{h}_{6}\right)$.

The peak heat flux, which is supposed to be located at the exit of node 6 , is determined in a similar way as the node average heat flux. The chamber reading is translated into the associated peak heat flux by multiplication with the following factor:

$$
F_{L} \quad=C_{b \max } P_{b} \frac{f_{i j}}{\phi_{i j}}
$$

and

$$
R_{i j} F_{L}=\frac{\eta Q_{r} C_{b \max } P_{b} f_{i j}}{A_{T} K}
$$

with

$$
\begin{aligned}
& \sigma_{r}(\eta)=0.258 \% \\
& \sigma_{r}\left(Q_{R}\right)=0.92 \% \\
& \sigma_{r}\left(A_{T}\right) \equiv 0.167 \%
\end{aligned}
$$




$$
\begin{aligned}
& \sigma_{r}(K)=0.50 \% \\
& \sigma_{r}\left(P_{b}\right)=4.1 \% \\
& \sigma_{r}\left(C_{b}\right)_{\max }=3.8 \% \\
& \sigma_{r}\left(f_{i j}\right)=4.15 \% \\
& \hline \sigma_{r}\left(R_{i j} F_{L}\right)=7.05 \%
\end{aligned}
$$

If the MCHFR calculation is made not later than 3 days after the recalibration of the in-core system, the following additional errors have to be considered:

$$
\begin{array}{ll}
\text { drift in chamber sensitivity over } 3 \text { days: } & 1.0 \%(2 \sigma) \\
\text { galvanometer error (change in zero set point): } & 2.0 \% \\
\text { reading error: } & 1.5 \% \\
\text { change of the } P_{b} \text { and } f_{i j} \text { values, due to small changes in flux } & 3.0 \% \\
\quad \begin{array}{l}
\text { distribution (minor control rod pattern changes, change in } \\
\text { subcooling): }
\end{array} & \\
\text { uncertainty on reactor power determination at the moment of the } & 1.84 \% \\
\quad \text { MCHFR calculation: } & \\
\sigma_{\mathrm{r}}\left(\mathrm{R}_{1 \mathrm{f}}^{\prime} \mathrm{F}_{\mathrm{L}}^{\prime}\right)=7.39 \% .
\end{array}
$$

For the bundle considered the four $\mathrm{R}_{\mathrm{ij}}^{\prime} \mathrm{F}_{\mathrm{L}}^{\prime}$ values are plotted on a graph. A probable "axial peak flux distribution" line is drawn through these 4 points. A maximum plotting error at the middle between two points of $5 \%(2 \sigma)$ has to be expected.

The peak heat flux at the exit of node 6 is:

$$
(\hat{q / A})_{6}=K\left(R_{i j}^{\prime} F_{L}^{\prime}\right)_{6}, K=0.75 \mathrm{~W} / \mathrm{cm} / \mathrm{div}
$$

As the $\left(R_{i j}^{\prime} \hat{F}_{A}^{\prime}\right)_{6}$ value is read at the middle between two $R_{i j}^{\prime} F_{L}^{\prime}$ points (see Figure 4-1), the expected standard deviation on the peak heat flux is:

$$
\sigma_{r}(\hat{q} / A)_{6}=\sqrt{{\overline{7.39^{2}}+\overline{2.5}^{2}}^{2}}=7.80 \%
$$


$(\widehat{\mathrm{q} / \mathrm{A}})_{6}=72.6 \mathrm{~W} / \mathrm{cm}^{2}$ (from separate computer calculations)

$\sigma(\hat{q} / \mathrm{A})_{6}=0.078 \times 72.6=5.66 \mathrm{~W} / \mathrm{cm}^{2}$

The steam quality at the exit of node 6 is $30 \%$ for the peak element and $36.4 \%$ for the hottest bundle. The third critical heat flux correlation will thus have to be applied:

$$
\text { MCHFR }=\frac{191-38.13 \mathrm{G}-205.9 \mathrm{X}}{(\mathrm{q} / \mathrm{A})}
$$

G: $\quad$ channel mass flow rate in $\mathrm{MT} / \mathrm{sm}^{2}$

$\mathrm{X}: \quad$ steam quality

$(\hat{q} / A): \quad$ peak heat flux in $\mathrm{W} / \mathrm{cm}^{2}$

As the lowest MCHFR (1.61) occurs on the peak element the error will be evaluated for this case:

$$
\begin{aligned}
\mathrm{G} & =0.231 \times 10^{6} \mathrm{lb} / \mathrm{h}^{-\mathrm{ft}^{2}}=0.313 \mathrm{MT} / \mathrm{sm}^{2} \\
\mathrm{X} & =0.3036 \\
\hat{\mathrm{q} / \mathrm{A}} & =0.230 \times 10^{6} \mathrm{Btu} / \mathrm{h}-\mathrm{ft}^{2}=72.6 \mathrm{~W} / \mathrm{cm}^{2}
\end{aligned}
$$

MCHFR $=1.605$

The errors on the variables $G, X$ and $q \hat{/ A}$ are partially correlated; only uncorrelated portions can be combined statistically:

$$
\sigma_{u n c}(M C H F R)=\sqrt{\left(\frac{38.13}{q / \hat{A}}\right)^{2} \sigma_{u n c}(G)+\left(\frac{205.9}{q \hat{A}}\right)^{2} \sigma_{u n c}^{2}(X)+\left(\frac{M C H F R}{q \hat{A}}\right)^{2} \sigma_{\text {unc }}^{2}(q / A)}
$$

Before entering the statistical combination, the correlated portions are combined linearly:

$$
\sigma_{\text {cor }}(\mathrm{MCHFR})=\frac{38.13}{\mathrm{q} / \mathrm{A}} \sigma_{\operatorname{cor}}(\mathrm{G})+\frac{205.9}{\mathrm{q} / \mathrm{A}} \sigma_{\operatorname{cor}}(\mathrm{X})+\frac{\mathrm{MCHFR}}{\mathrm{q} / \mathrm{A}} \sigma_{\operatorname{cor}}(\mathrm{q} / \mathrm{A})
$$

The details of the combination are shown in table 4-2. This table shows each of the independent input variables, $\mathrm{X}_{\mathrm{i}}$, their standard deviation, $\sigma\left(\mathrm{X}_{\mathrm{i}}\right)$, the intermediate variables through 
TABLE 4-2

CALCULATION OF ERROR IN MCHFR

\begin{tabular}{|c|c|c|c|c|c|c|c|c|c|c|c|}
\hline \multirow{2}{*}{$\begin{array}{c}\text { Independent } \\
\text { Variables, } x_{1}\end{array}$} & \multirow{2}{*}{$\begin{array}{l}\text { Error } \\
\text { in } X_{i} \\
\sigma_{r}\left(X_{i}\right)\end{array}$} & \multirow{2}{*}{$\begin{array}{l}\text { Effect of } \mathrm{X}_{\mathrm{i}} \\
\text { on } \sigma(\mathrm{MCH} F \mathrm{FR}) \\
\text { through }\end{array}$} & \multicolumn{6}{|c|}{ Slope Factors } & \multirow{2}{*}{$\begin{array}{l}\text { Sensitivity } \\
\frac{\partial M C H F R}{\partial x_{i}} x_{i}\end{array}$} & \multirow{2}{*}{ 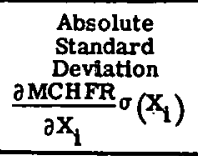 } & \multirow{2}{*}{$\begin{array}{l}\text { Absolute Variance } \\
{\left[\frac{\partial \mathrm{MCHFR}}{\partial \mathrm{X}_{1}} \sigma\left(\mathrm{X}_{1}\right)\right]^{2}}\end{array}$} \\
\hline & & & a & b & c & d & e & $f$ & & & \\
\hline $\begin{array}{l}\text { 1) } \quad Q_{R} \\
\text { Reactor Power } \\
\text { During In-core } \\
\text { Calibration and } \\
\text { MCHFR } \\
\text { Determination }\end{array}$ & $\begin{array}{l}\sqrt{2} \times 0.92 \\
=1.30 \%\end{array}$ & $\begin{array}{l}\quad \mathrm{G} \\
\mathrm{X} \text { Caused by } \mathrm{W}_{\mathrm{ch}} \\
\mathrm{X} \text { Direct } \\
\hat{\mathrm{g} / \mathrm{A}}\end{array}$ & & $\begin{array}{l}0.3 \\
0.3\end{array}$ & $\begin{array}{l}\frac{161.7}{359.1} \\
\frac{161.7}{359.1}\end{array}$ & $\begin{array}{r}\frac{38.13}{72.6} \\
\frac{205.9}{72.6} \\
\frac{205.9}{72.6} \\
1.605\end{array}$ & 0.313 & & $\begin{array}{l}0.0495 \\
0.3844 \\
1.2771 \\
\frac{1.605}{3.316}\end{array}$ & 0.0431 & $18.58 \times 10^{-4}$ \\
\hline $\begin{array}{l}\text { 2) } \quad P_{b} \\
\text { Bundle Power }\end{array}$ & $4.10 \%$ & Same as 1) & \multicolumn{6}{|c|}{ Same as 1) } & 3.316 & 0.1960 & $184.96 \times 10^{-4}$ \\
\hline $\begin{array}{l}\text { 3) } \quad \eta \\
\text { Heat Fraction } \\
\text { in Fuel }\end{array}$ & $0.26 \%$ & Same as 1) & \multicolumn{6}{|c|}{ Same as 1) } & 3.316 & 0.0086 & $0.73 \times 10^{-4}$ \\
\hline $\begin{array}{l}\text { 4) } \quad \mathrm{A}_{\mathrm{T}} \\
\text { Heat } \\
\text { area }\end{array}$ & $0.17 \%$ & Same as 1) & \multicolumn{6}{|c|}{ Same as 1) } & 3.316 & 0.0055 & $0.30 \times 10^{-4}$ \\
\hline $\begin{array}{l}\text { 5) } \quad \mathrm{f}_{\mathrm{ij}} \\
\text { Axial Power } \\
\text { Factors at the } \\
\text { Chamber } \\
\text { Locations }\end{array}$ & $4.15 \%$ & $\begin{array}{l}\quad \mathrm{G} \\
\mathrm{X} \text { Caused by } \mathrm{W}_{\mathrm{ch}} \\
\mathrm{X} \text { Direct } \\
\hat{\mathcal{q} / \mathrm{A}}\end{array}$ & $\begin{array}{l}\frac{2.85}{4.52} \\
\frac{2.85}{4.52} \\
\frac{2.85}{4.52}\end{array}$ & $\begin{array}{l}0.3 \\
0.3\end{array}$ & $\begin{array}{l}\frac{161.7}{359.1} \\
\frac{161.7}{359.1}\end{array}$ & $\begin{array}{l}\frac{38.13}{72.6} \\
\frac{205.9}{72.6} \\
\frac{205.9}{72.6} \\
1.605\end{array}$ & 0.313 & & $\begin{array}{l}0.0312 \\
0.2424 \\
0.8052 \\
\frac{1.605}{2.6838}\end{array}$ & 0.1114 & $124.10 \times 10^{-4}$ \\
\hline $\begin{array}{l}\text { 6) } \\
\text { Galvanometer } \\
\text { and Reading }\end{array}$ & $1.25 \%$ & Same as 5) & \multicolumn{6}{|c|}{ Same as 5) } & 2.6838 & 0.0335 & $11.22 \times 10^{-4}$ \\
\hline $\begin{array}{l}\text { 7) } \\
\text { Chamber Drift }\end{array}$ & $0.5 \%$ & Same as 5) & \multicolumn{6}{|c|}{ Same as 5) } & $2.6838^{\circ}$ & 0.0134 & $1.80 \times 10^{-4}$ \\
\hline \begin{tabular}{|l|} 
8) \\
Chamber \\
Calibration \\
\end{tabular} & $0.5 \%$ & Same as 5 & \multicolumn{6}{|c|}{ Same as 5) } & 2.6838 & 0.0134 & $1.80 \times 10^{-4}$ \\
\hline $\begin{array}{l}\text { 9) } \\
\text { Change in } P_{b} \\
\text { and } f_{i j} \text { since } \\
\text { last recalibra- } \\
\text { tion }\end{array}$ & $1.5 \%$ & Same as 2) and 51 & \multicolumn{6}{|c|}{ See 2) and 5) } & $\begin{array}{c}\begin{array}{c}\text { Average } \\
\text { of 2) and 5) } \\
2.9999\end{array} \\
\end{array}$ & 0.0450 & $20.25 \times 10^{-4}$ \\
\hline $\begin{array}{l}\text { 10) } C_{b \max } \\
\text { Corner Rod } \\
\text { Peaking Factor }\end{array}$ & $3.8 \%$ & $\hat{q / A}$ & & & & 1.605 & & & 1.605 & 0.0610 & $37.21 \times 10^{-4}$ \\
\hline $\begin{array}{l}\text { 11) } \\
\text { q/A plot }\end{array}$ & $2.5 \%$ & $\hat{q / A}$ & & & & 1.605 & & & 1.605 & 0.0401 & $16.08 \times 10^{-4}$ \\
\hline $\begin{array}{l}\text { 12) } W_{T}+W_{c u} \\
\text { Recirculation } \\
\text { Flow Rate }\end{array}$ & $\begin{array}{l}\cdots \\
1.86 \%\end{array}$ & $\begin{array}{l}\text { G } \\
\text { x Caused by } W_{c h}\end{array}$ & & & $\frac{161.7}{359.1}$ & $\begin{array}{l}\frac{38.13}{72.6} \\
\frac{205.9}{72.6}\end{array}$ & 0.313 & & $\begin{array}{l}0.1644 \\
\frac{1.2771}{1.4415}\end{array}$ & $\begin{array}{l}\ddots \\
0.0268\end{array}$ & $7.18 \times 10^{-4}$ \\
\hline \begin{tabular}{|l} 
13) $w_{\ell}$ \\
Core Leakage \\
Flow \\
\end{tabular} & $10 \%$ & $\begin{array}{l}\text { Seme as 12) } \\
\text { but Including } \\
\text { Slope Factor f }\end{array}$ & & & & & & 0.0586 & 0.0845 & 0.10084 & $0.71 \times 10^{-4}$ \\
\hline \begin{tabular}{|l|}
$14)$ \\
Flow Distribution \\
\end{tabular} & $1.1 \%$ & Same as 12) & \multicolumn{5}{|c|}{ Same as 12) } & & 1.4415 & 0.0159 & $2.52 \times 10^{-4}$ \\
\hline $\begin{array}{l}15) \\
q / A \text { plot }\end{array}$ & $1.25 \%$ & $\begin{array}{l}\mathrm{G} \\
\mathrm{X} \text { Caused by } \mathrm{W}_{\mathrm{cr}} \\
\mathrm{X} \text { Direct }\end{array}$ & $\begin{array}{l}\frac{0.56}{1.25} \\
\frac{0.56}{1.25} \\
\frac{0.56}{1.25}\end{array}$ & $\begin{array}{l}0.3 \\
0.3 .\end{array}$ & $\begin{array}{l}\frac{161.7}{359.1} \\
\frac{161.7}{359.1}\end{array}$ & $\begin{array}{r}\frac{38.13}{72.6} \\
\frac{205.9}{72.6} \\
\frac{205.9}{72.6}\end{array}$ & 0.313 & & $\begin{array}{l}0.0222 \\
0.1722 \\
0.5721 \\
0.7665 \\
\end{array}$ & 0.0096 & $0.92 \times 10^{-4}$ \\
\hline $\begin{array}{|lc|}16) & h_{\text {in }} \\
\text { Inlet } & \text { Enthalpy } \\
\end{array}$ & \begin{tabular}{|l|l}
0.95 \\
$\mathrm{Kcal} / \mathrm{kg}$ \\
\end{tabular} & $\mathrm{x}$ & & & & & & $=$ & & 0.0075 & $0.56 \quad 10^{-4}$ \\
\hline $\begin{array}{l}17) \\
h_{\text {fg }} \text { and } h_{\text {sat }} \\
\end{array}$ & & $x$ & & & & & & & & 0.0027 & $0.07 \times 10^{-4}$ \\
\hline
\end{tabular}


which they affect $\sigma$ (MCHFR), the slope factors which are discussed below, the sensitivity of MCHFR to the input variables, the absolute standard deviation caused by each input variable and the absolute variance attributed to each input variable. The variances are totaled and the square root is taken to obtain $\sigma$ (MCHFR).

Slope factors show the influence of various parameters listed on $\frac{\partial M C H F R}{\partial X_{i}}$. The various slope factors are as follows:

a. Ratio of $\sigma_{\mathrm{r}}\left(\mathrm{H}_{6}\right)$ to $\sigma(\mathrm{OP})_{\mathrm{n}}=\frac{2.85}{4.52}$ for partially correlated

$$
=\frac{0.56}{1.25} \text { for uncorrelated }
$$

b. Ratio of flow change (\%) due to bundle power change $(\%)=0.3$

c. Ratio of $\Delta h_{6}$ to $h_{f g}=\frac{161.7}{359.1}$

d. Coefficients of $\sigma$ terms in equation for $\sigma$ (MCHFR):

$$
\begin{aligned}
\text { for } \sigma(G), \text { coefficient } & =\frac{38.13}{72.6 \mathrm{~W} / \mathrm{cm}^{2}} \\
\text { for } \sigma(\mathrm{X}) \text {, coefficient } & =\frac{205.9}{72.6 \mathrm{~W} / \mathrm{cm}^{2}}
\end{aligned}
$$

for $\sigma\left(\hat{q} \hat{f}_{A}\right)$, coefficient $=1.605$

e. Channel mass flow rate,

$$
\mathrm{G}=0.313 \mathrm{MT} / \mathrm{sm}^{2}
$$

f. Ratio of change in core flow (\%) to change in leakage flow $(\%)=0.0586$

As shown at the bottom of Table 4-2, the result obtained is:
Absolute: $\sigma(\mathrm{MCH} F \mathrm{R})=0.207$
Relative: $\sigma(\mathrm{MCHFR})=12.9 \%$

The corresponding maximum probable error is $1.645 \sigma_{\mathrm{r}}(\mathrm{MCHFR})=21.2 \%$.

It is noted that this result is calculated for a particular reactor at a particular operating condition. The result is not necessarily applicable in other circumstances. The result is particularly influenced by the slope of the CHF limit line which is applicable. 


\section{Summary of Error Analysis}

The uncertainty values which have been calculated for the different key variables are as follows (at 120 percent power):

\begin{tabular}{lccc}
\hline \multicolumn{1}{c}{ Variable } & $\begin{array}{c}\sigma \\
\text { Standard } \\
\text { Deviation } \\
\%\end{array}$ & $\begin{array}{c}0.675 \sigma \\
\text { Probable } \\
\text { Error } \\
\%\end{array}$ & $\begin{array}{c}1.645 \sigma \\
\text { Maximum } \\
\text { Probable Error } \\
\%\end{array}$ \\
\hline Reactor Power & 0.92 & 0.62 & 1.51 \\
Recirculation Flow (Total core flow) & 1.86 & 1.25 & 3.06 \\
Channel Flow Rate & 2.75 & 1.86 & 4.52 \\
Local Fuel Heat Flux & 7.80 & 5.26 & 12.8 \\
Critical Heat Flux Ratio & 12.9 & 8.7 & 21.2 \\
\hline
\end{tabular}

It should be noted that the error in CHFR (critical heat flux ratio) is strongly dependent on the slope of the critical heat flux limit design line. The error is very different for operation in different parts of the curve. For the low flow cases considered here, the MCHFR always occurs in the third or high quality portion of the curve.

Proper interpretation of these results requires consideration of the following factors:

1. The expected value for each variable, or most probable value, is the value read on the instrument, or calculated from the instrument readings with no allowance for error.

2. The probable error and maximum probable error on each variable can be either plus or minus. However, the chief interest is in the direction of decreased reactor safety in each case. Therefore, the maximum probable error (95 percent confidence) is based on use of only one "tail" of the distribution curve and $1.645 \sigma$ instead of $1.96 \sigma$ for the "twotail" case.

3. The minimum critical heat flux ratio (if overpower occurs) is to be interpreted as follows based on a Temporary Technical Specification limit of 1.50 .

\section{Uncertainty Level}

Probable Error, $0.675 \sigma$ ( $75 \%$ confidence level)

Standard deviation, $\sigma$

Maximum Probable Error, $1.645 \sigma=21.2 \%$ (95\% confidence level)

Lower bound for MCHFR

$$
=8.7 \%
$$

$$
1.37
$$

1.31

1.18 
4. The critical heat flux ratio has been evaluated at an assumed overpower factor of 1.20 , but the occurrence of this amount of overpower is very unlikely. An overpower condition of more than 5 percent is very rare. In nearly one year of operation, the Garigliano reactor has had reported overpower conditions exceeding 5 percent only for planned transient tests. Thus, the occurrence of unplanned overpower conditions greater than 5 percent might be expected at a frequency in the order of once per year or less.

The analysis would be more correct if it were based on the sum of the products of (a) conditional probability of critical heat flux value less than 1.5 at a given reactor power and (b) probability of the reactor being at that power. The net effect of this more accurate calculation would be to effectively decrease the overpower allowance.

5. Since an overpower condition of 20 percent is very unlikely, it is significant to consider the MCHFR at the actual power for a typical case. The MCHFR at the operating power is substantially higher than at overpower. In fact, the conservatism introduced by the arbitrary 20 percent overpower calculational allowance is greater than the maximum probable error in MCHFR. Thus, we reach the unexpected conclusion:

After taking account of all uncertainties in the determination of MCHFR, the value of MCHFR will be above 1.50 at the actual operating power.

For the limiting case of one loop natural circulation, low subcooling and rated power of $506 \mathrm{MWt}$ :

\begin{tabular}{|c|c|c|}
\hline & $\begin{array}{l}\text { At Actual } \\
\text { Power } \\
\end{array}$ & $\begin{array}{c}\text { At } 120 \% \text { of } \\
\text { Actual Power } \\
\end{array}$ \\
\hline Expected Value of MCHFR & 1.93 & 1.50 \\
\hline $\begin{array}{c}\text { Maximum Probable error } \\
(1.645 \sigma=21.2 \%)\end{array}$ & -.41 & -0.32 \\
\hline Lowest Probable Value & 1.52 & 1.18 \\
\hline
\end{tabular}

6. The design critical heat flux correlation does not correspond to actual critical heat flux for the following reasons:

(a) The design critical heat flux correlation was based upon data available before April, 1962. Subsequent experimental critical heat flux investigations, including tests per-formed with multi-rod geometries which better represent fuel assemblies, have provided improved understanding of the flow and heat transfer processes. A tentative evaluation of all data available to date indicates that for the limiting conditons of flow and quality the design correlation for critical heat flux should be raised by as much as 50 percent and the slope of the critical heat flux correlation with respect to steam quality (second portion of curve) should be decreased by about one-third. 
Application of this revised critical heat flux correlation would result in substantial improvement to the minimum critical heat flux ratio for many reactor conditions:

(b) The present design correlation as well as the tentative design correlation referred to in (a) above are drawn below all data points; so that, although some data points are only slightly above the design correlation curve, typically the data points are $\sim 25$ percent above the design correlation curve.

7. The critical heat flux is not synonomous with burnout or clad failure. Above the critical heat flux, transition boiling begins. Transition boiling is characterized by rapid temperature oscillations of a magnitude which is dependent upon the mass velocity and steam quality. At still higher heat fluxes film boiling occurs, characterized by steady wall temperatures which are much higher than those during nucleate boiling.

Any overpower condition with heat fluxes in the range of 120 percent of rated values would be a transient condition of seconds or minutes duration; however, in a recent test, fuel rods were taken through the $\mathrm{CHF}$ point and operated well into the film boiling regime for a period of about an hour prior to clad failure. This in-pile test was performed in GETR.*

8. If burnout (clad failure) should occur it would be a localized condition.

The core MCHFR refers to the condition of the peak power locations in the reactor. The power peaking distribution is such that only a very small percentage of the fuel rods typically about 1 percent - would have the worst power peaking and CHFR, and only fraction of these would simultaneously have the worst tolerance condition and/or maximum calculational error.

Failure of a test fuel rod* purposely operated in GETR above the critical heat flux, well into the film boiling regime, was caused by local melting of the clad material. Damage to the clad and $\mathrm{UO}_{2}$ was localized, i.e., with four fuel rods and 34 inches active fuel length, the overheated area was 8 inches long and the molten area of clad was a fraction of an inch long, both confined to one half of the periphery of one fuel rod.

9. Another requirement for applying this analys is is that the function it describes, $\sigma$ (MCHFR), be "well behaved". The correlation for critical heat flux has several points at which the first derivative is discontinuous; however, for the Garigliano test conditions the critical heat flux in the region of greatest interest (where critical heat flux ratio is minimum) is not near such points. For the worst expected power distribution, the minimum critical heat flux ratio is quality dependent and occurs (at overpower) at a quality of 30 to 34 percent. Discontinuities in the first derivative of the critical heat flux curve occur at 20.6 and 24.8 percent qualities for the applicable flow of $G=0.23 \mathrm{lb} / \mathrm{hr} \mathrm{ft}^{2}$.

*T. Sorlie, S. Levy, M. F. Lyons, J. E. Boyden, "Consequences of Operating Fuel Rods Above the Critical Heat Flux (Burnout) in Boiling Water Reactors, "NUCLEONICS, April 1965. 
Thus, it is concluded that the design and operating limits of the reactor provide a very high degree of assurance that fuel damage due to burnout will not occur due to the design overpower condition and considering all instrument errors, extreme manufacturing tolerances, and calculational uncertainties.

It is worthwhile, at this point, to compare the results of this error analysis with the values given in the document: "Accuracy Evaluation of the Reactor Core Thermal Hydraulic Performance Evaluation Procedures" by A. P. Bray, W. R. Clancey and C. E. Morris, November 26, 1962. This document was used in obtaining approval for the original Technical Specification. The following table shows the difference between those values:

\begin{tabular}{l|c|c|c|c}
\hline & \multicolumn{2}{|c|}{ Maximum error } & \multicolumn{2}{c}{ Most probable error } \\
\cline { 2 - 5 } & 1962 & 1965 & 1962 & 1965 \\
\hline Local heat flux determination & $15 \%$ & $12.8 \%$ & $8 \%$ & $5.26 \%$ \\
Total Flow Determination & $5 \%$ & $3.1 \%$ & $3 \%$ & $1.25 \%$ \\
Channel Flow Determination & $12 \%$ & $4.5 \%$ & $8 \%$ & $1.86 \%$ \\
CHFR Calculation & $19 \%$ & $21.2 \%$ & $11 \%$ & $8.7 \%$ \\
\hline
\end{tabular}

It must be pointed out that the "maximum error" and the "most probable" obtained in the present statistical analysis are slightly different from the similar values given in the above mentioned document issued in 1962, as at that time, the error analysis was conducted with a different method. However, the table can be considered sufficiently accurate to make the comparison.

The reasons the values obtained today, are different from the ones shown in the Bray, Clancey and Morris document are:

1. The present analysis is for a very specific and special operating condition; this changes (reduces) the error in channel flow rate.

2. The analysis conducted in 1962 was done with a simplified method, without classifying each error with a degree of confidence. This approach is then not completely realistic and penalizes the calculation.

3. The errors applied in the calculation were often estimates, as at that time the available data from operating experience were much less than today. Thus, a great degree of conservatism was applied when assigning the errors to each MCHFR calculation factor. Today, after two years of additional reactor operation, a quantity of useful data has been collected so that the theoretical calculation methods, instrument accuracy and data reduction have been strongly improved since 1962 . 
4. The present analysis is based on consideration of maximum probable error ( $95 \%$ confidence) when considering only one "tail" of the probability distribution. This results in assigning 1.6450 as the "maximum probable error." The previous analysis considered both plus and minus error tails on the probability distribution and has an implied value of $2 \sigma$ for "maximum probable error" (95 percent confidence).

Consistent results have been obtained with a similar error analysis for other reactors. The values determined in most cases are slightly higher as other cores will usually operate in a region where the critical heat flux is much more dependent on steam quality than for the Garigliano Development Program tests. In other words, the critical heat flux correlation, * in the Garigliano test condition will be the third one which is less dependent upon quality than the second one which is usually the limiting factor for reactors at rated flow conditions.

J. Improvements in MCHFR Determination

As shown in the preceding section, the standard Garigliano control room method for determining minimum critical heat flux ratio (MCHFR) using the in-core chambers and nomograms has a standard deviation, $\sigma$, of $12.9 \%$. Now the possibility of improving this accuracy will be evaluated.

1. It is significant to note the relative sensitivity of the resultant error in MCHFR to each input variable. The variables of major importance are as follows (see Table 4-2):

\begin{tabular}{|c|c|c|}
\hline Variable & Variance & $\begin{array}{l}\% \text { of Total } \\
\text { Variance }\end{array}$ \\
\hline Bundle Power Factor, $P_{b}$ & $185 \times 10^{-4}$ & 43.2 \\
\hline Axial Power Factor, $\mathbf{f}_{\mathbf{i j}}$ & $124 \times 10^{-4}$ & 28.9 \\
\hline Corner Rod Peaking Factor, $\mathrm{C}_{\mathrm{b} \max }$ & $37 \times 10^{-4}$ & 8.6 \\
\hline Channel Flow $\left(\mathrm{w}_{\mathrm{T}}, \mathrm{w}_{\mathrm{cu}}, \mathrm{w}_{\ell}\right.$, Flow Distribution $)$ & $10 \times 10^{-4}$ & 2.3 \\
\hline $\begin{array}{l}\text { All Other (No Other Single Variance } \\
\text { Over } 20 \times 10^{-4} \text { or } 4.6 \% \text { of Total) }\end{array}$ & $73 \times 10^{-4}$ & 17.0 \\
\hline Total & $429 \times 10^{-4}$ & 100.0 \\
\hline
\end{tabular}

Thus it is seen that $80 \%$ of the total variance results from the three flux peaking factors: radial, axial and local. No significant improvement in the over-all result will be achieved except by reduction of these flux peaking errors.

*E. Jannsen and S. Levy, "Burn-Out Limit Curves for Boiling Water Reactors, " APE'D-3४y2, April 14, 1962. 
The first two are expected to be improved as a result of the Garigliano Development Program:

a. Radial power factor is calculated by the on-line computer. This results in use of recent and comprehensive data for its determination. Also the fuel gamma scan provides an independent experimental check of the computer results, and this is expected to yield improved computer methods.

b. Axial power factor is to be measured by the movable ion chambers. The movable ion chamber data will be immediately useful and also the development and test of such instruments has future value.

The data in Appendix A on flux wire accuracy suggests several improvements which would substantially improve the results:

1) Counting statistics - use longer counting times.

2) Wire uniformity - obtain better wires.

3) Reproducibility of counting geometry - some improvements may be possible.

2. After obtaining improved data from either better flux wire technique or movable ion chambers it is then possible to use this data for radial power factor improvement. The greatest promise is shown for a system of movable ion chambers having provision for inter-calibration between the various in-core locations. Such data provides an accurate calibration of in-core chambers (axial and radial factors) based only on experimental data.

In the normal method, the TREDA radial power factors are used to normalize the flux wires in relationship to each other. TREDA assumes that the core can be considered as eight symmetrical sections. If the core has a flux tilt or other asymmetry, it will not be shown by the TREDA computer calculations (but are shown by the on-line computer.) If the flux wires can be compared to each other by suitable normalization, they can be used directly for radial, as well as axial, factors for calibrating the in-core chambers. This is especially valuable when the in-core chambers are used with the on-line computer.

3. The on-line process computer can be used to calculate the flux distribution based on the in-core chamber readings as an imposed boundary condition. After the in-core chambers are calibrated, they are used to estimate the neutron flux distribution in the entire core. The on-line computer is the most accurate means available for doing this. The computer is programmed to calculate the core flux distribution either a.) without use of the in-core readings, in which case the calculations are equivalent to TREDA or, b.) as a users option, the 80 in-core chamber readings can be imposed as internal "boundary conditions" on the calculations. It is this second method that gives promise of greatest accuracy. 
It is evident that if the on-line computer, or TREDA, can calculate the radial power factor for every fuel bundle with a standard deviation of $4.1 \%$, as shown in a previous section of this report, then addition of data from 80 in-core chambers will improve the accuracy of the result.

The same type of gain is realized in the axial direction. The computer can interpolate between the four axial chamber readings more accurately than the reactor operator. The computer calculations take into account the void distribution, control rod positions and exposure distribution to arrive at an axial profile.

4. The operability of the on-line computer and improvements in determination of flux distribution are not required for performance of the proposed tests. These improvements are listed here as guides for future development work.

\section{K. Discussion of Technical Specifications Changes}

The effects of the requested temporary changes in the Technical Specifications are discussed below.

1. Minimum Critical Heat Flux Ratio

The Technical Specifications establish that the minimum critical heat flux ratio (or MCHF ratio or "burn-out" ratio) shall not decrease below 1.75 at overpower under normal steady state operation. It is requested that this limit be changed to 1.50 . In the SENN Final Hazard Summary Report (see Section IV-2) it is stated that the minimum "burn-out" ratio at overpower is 1.7 by contract agreement, ". . . . however, the minimum burn-out criteria generally applied for safety purposes at APED is 1.5".

At the time that the minimum "burn-out" ratio limit was established for SENN. APED requested that it be set at 1.5 , but as the Dresden plant had at that time a 2.0 limit, it was felt, as a matter of conservatism, that the 1.75 limit for SENN was adequate. Also, it was evident that the value of 1.75 imposed no limitation on normal operation of the plant, since normal "burn-out" ratio values are much higher than this. Further investigations made since that time have demonstrated that the 1.5 margin is adequate for all the General Electric boiling water reactors presently in operation. As a matter of fact, the Dresden plant is now licensed for a $1.5 \mathrm{MCHF}$ ratio limit. Other General Electric boiling water reactors in operation (Consumer's Research \& Development Program, and Humbolt Bay) are also licensed for a 1.5 limit. APED will probably ask for a further reduction of this limit in the near future, as a result of recent experimental investigations. Specifically, studies of the consequences* of exceeding the critical heat flux (or "burn-out") point have shown that in many cases the fuel is adequately cooled by

*T. Sorlie, S. Levy, M. F. Lyons, and J. E. Boyden "Consequences of Operating Fuel Rods Above the Critical Heat Flux (Burnout) in Boiling Water Reactors, " NUCLEONICS, April 1965. 
"transition boiling", or by "film boiling". For this reason, the term "critical heat flux" is more accurate than "burn-out heat flux" when describing the observed behavior. Then the margin of protection against this occurrence does not need to be as large as has been previously assumed.

The $1.5 \mathrm{MCHF}$ ratio limit during the test period at SENN will have a safety margin which is very adequate for the worst combination of reactor power and power fluctuation, equipment malfunction or operator error, and errors in margin computation.

It is expected that at high-void conditions, although the maximum heat flux will not increase very much, the critical heat flux will decrease strongly, by quality dependence, from the value presently determined at the plant during operation at rated flow and power. The 1.75 MCHF ratio limit is considered too restrictive and could result in the impossibility of performing useful tests, in order to obtain operating data from a large boiling water reactor under conditions of high core steam void content. These data will contribute greatly to the plant uprating studies.

All the critical heat flux ratio values quoted in this report are based on the design limit curves given by E. Janssen and S. Levy in "Burn-Out Limit Curves for Boiling Water Reactors," APED-3892, April 14, 1962. In the event that a better design and calculational basis is available by the time of the Garigliano tests, the improved data would be used for the reactor safety calculations.

\section{Overpower Allowance and High Flux Scram}

The overpower allowance (OP) is presently established at 1.25 and it is requested that it be lowered to 1.20 during the test period. This will give an additional 5 percent margin in order to more easily reach the desired test conditions. The 1.20 calculational allowance for above-normal reactor power is adequate, as this gives assurance that the reactor has the capability of delivering 120 percent of the plant design power rating and still meeting all thermal margins. The reactor experience up to this time indicates that in normal operation an overpower of 5 to 10 percent is the greatest expected. During these tests all operation will be performed carefully following pre-established procedures and responsible General Electric and SENN personnel who are well aware of all the analyses previously made will constantly check that no limits are exceeded. This will minimize the pussibilily of mallevering errors.

To give a greater safety margin to the reactor, it is at the same time suggested that the high flux scram setting should be reduced from 125 to 120 percent, thus compensating the change in overpower allowance. The 120 percent value has been selected to provide the safety of scram protection in case of any high flux condition, but at the same time to have adequate margin so that plant operation is not inter rupted by unnecessary scram 
shutdowns. The rod oscillator tests involve a flux oscillation of about plus and minus 10 percent, with 15 percent as a practical upper limit. This leaves a 5 percent margin for instrument or operator error without a scram. The reduction in high flux scram setting increases reactor safety and creates no added safety problem.

\section{Minimum Recirculation Flow at Rated Power}

The Technical Specifications establish that at rated power both recirculation pumps must be in operation. It is requested that this limit be temporarily changed for the tests, in order to obtain the desired void fraction at full power. This will be accomplished by tripping the recirculation pumps, which will cause the reactor power to decrease, as demonstrated during the start-up tests. Then the core power will be slowly and carefully restored to rated by control rod withdrawal in an adequate sequence. Frequent MCHF ratio computations and flow measurements will be performed in order to avoid exceeding any thermal limits.

The purpose of the Technical Specification limit on flow-to-power ratio is to provide additional insurance that the critical heat flux limits are not exceeded. This flow-topower ratio limit is an arbitrary and administrative type of limit. The present proposal is that reliance be placed on the basic technical considerations of critical heat flux instead of an arbitrary limit.

SENN has requested this same change in specifications for normal operation of the plant. Therefore, the permanent change of this specification may make the temporary change requested here unnecessary. 


\section{Effect of Normal Plant Transients}

The "normal" plant transients have been evaluated to determine their magnitude under the most severe conditions planned during the test program. This condition is: operation with one loop natural circulation at rated reactor power and with low subcooling (maximum primary steam flow). In order that the analysis be as accurate as possible it has been based on (1) the observed transient behavior recorded during the startup tests of the plant* and (2) the extensive analog computer analyses conducted during the design of the plant.**

\section{Conclusions}

The following conclusions were reached in this transient study:

1. Of the two transient tests considered significant from the test data, namely the Back-up Regulator Takeover Tests and the Generator Breaker Trip Tests, the Generator Breaker Trip Tests are considered the most significant.

2. The Back-up Regulator Takeover Tests and the Pump Trip Tests indicate that the reactor system response is essentially constant from 50 percent to 100 percent rated power. This implies that for a further increase in power or voids in the core the response will be essentially the same. Calculations indicate that the void coefficient is essentially constant, and that at rated voids of 20 percent, the coefficient is $33 \notin /$ percent void, and at 48 percent voids, the coefficient is $28 \notin /$ percent void. Therefore, the magnitude of the neutron and heat flux disturbances due to transients experienced during the Power Test Program can be extrapolated with confidence topredict the magnitude of the neutron and heat flux disturbances in the One Loop Natural Circulation Tests.

3. The magnitude of the flux disturbances due to the Generator Breaker Trip Tests increase essentially linearly with primary turbine steam flow. Therefore, by extrapolating the curve from the test data it is predicted that the maximum neutron flux during the transient at a primary steam flow of 900 metric tons/hour would be approximately 195 percent rated, as compared to the 171 percent rated at rated primary steam flow of 720 metric tons/ hour. The maximum heat flux expected at the 900 metric tons/hour point would be less than 110 percent rated, as compared to 108 percent for the 720 metric tons/hour if scram does not occur. Therefore, it is considered that the fuel will not be adversely affected by the Generator Breaker Trip transient during the tests.

4. Transients in core inlet subcooling have been examined and found to constitute no safety problem since the transients are relatively slow and would be terminated by the $120 \%$ high flux scram.

5. The following suggestions are made concerning the test conditions:

a. The Position Restored Regulator should be used as the operating regulator during the tests because of the relatively slower response characteristics as compared to the Force Restored Regulator. This will minimize the flux disturbance if a condition equivalent to the Bark-up Regulator Takeover Test should occur.

\footnotetext{
*W. I. Collett, Personal Communication, Nov. 1964.

**W. I. Collett, Personal Communication, May 1962.
} 
b. The Force Restored Regulation should be used as the back-up regulator and be set above the operating regulator but by a lower amount than the normal 15 psi. Operating with this smaller pressure difference between the regulators will likewise minimize the flux disturbance caused by conditions similar to the Back-up Regulator Takeover Test.

c. If the load limits are used to control the generator load, the governor should be set so as to come into action with a minimum of turbine speed increase to minimize the reactor disturbance if a generator breaker should trip.

\section{Analysis}

Two transient tests were consider ed of most significance in affecting the maximum heat flux from the fuel. These are the Back-up Pressure Regulator Takeover Tests and the Generator Breaker Trip Test.

\section{Back-up Regulator Tests}

The following conditions existed during the tests:

- The back-up regulator was set at $15 \mathrm{psi}$ above the operating regulator

- The set point handwheel was turned $1 / 2$ revolution to increase the set point 20 psi.

The test results indicated the following:

\begin{tabular}{|c|c|c|c|}
\hline $\begin{array}{c}\text { Primary Steam Flow } \\
\mathrm{MT} / \mathrm{hr}\end{array}$ & Power & $\Delta \emptyset / \phi_{0} *$ & $\begin{array}{l}\text { Transfer of } \\
\text { Regulators } \\
\end{array}$ \\
\hline 360 & $250 \mathrm{MWT}$ & $15 \%$ & FRR to PRR \\
\hline 720 & $476 \mathrm{MWT}$ & $15 \%$ & FRR to PRR \\
\hline 358 & $80 \mathrm{MWE}$ & $13 \%$ & FRR to PRR \\
\hline 350 & $80 \mathrm{MWE}$ & $14 \%$ & FRR to PRR \\
\hline 580 & $130 \mathrm{MWE}$ & $12 \%$ & FRR to PRR \\
\hline 720 & $160 \mathrm{MWE}$ & $7 \%$ & PRR to FRR \\
\hline
\end{tabular}

$* \Delta \varnothing / \varnothing_{0}$ is defined as difference between the maximum or minimum of the transient flux disturbance minus the initial flux divided by the initial flux.

The transfer of the Force Restored Regulator (FRR) to the Position Restored Regulator (PR.R.) indicates essentially the same response to a 20 psi disturbance from 50 percent to 100 percent rated power and corresponding primary steam flow assuming all other variables remain essentially the same, such as the magnitude of the set point change; the difference between the two regulator set points, regulator charcteristics, etc. The test at $160 \mathrm{MWE}$ was the transfer of the PRR to the FRR which demonstrates the difference between the response of the two regulators. This suggests that the PRR be used as the operating regulator during the tests to minimize this type of disturbance.

The effects of this test on fuel heat flux are negligible, 


\section{Recirculation Pump Trip Tests}

The Recirculation Pump Trip Tests were investigated to confirm the evidence that the response is essentially constant between 50 percent and 100 percent rated power and the corresponding primary steam flow. The following data is taken from the transient tests which show the relationship of the neutron flux change during the trip:

Two Pump Trip Tests

\begin{tabular}{lcc} 
Power & $\frac{\Delta \phi / \phi 0^{*}}{2}$ & $\frac{2}{\text { Primary Steam Flow }}$ \\
\hline $250 \mathrm{MWT}$ & $-74 \%$ & 360 \\
$476 \mathrm{MWT}$ & $-73 \%$ & 720 \\
$160 \mathrm{MWE}$ & $-74 \%$ & 720
\end{tabular}

*The negative sign indicates a transient decrease in the flux from the initial value:

Therefore, these tests confirm that the response to the same flow change is essentially constant between 50 percent and 100 percent rated power.

\section{Analysis of Trend in Void Coefficient}

In the two tests analyzed there is evidence that the response does not change significantly from 50 percent to 100 percent rated power. Since the void coefficient is directly related to the core voids which are directly related to the primary steam flow this indicates that for a further increase in primary steam flow, and thus core voids, the system response would remain essentially the same. The calculated void coefficient at rated conditions is $33 k$ /percent void for 20 percent core voids which are related to 720 metric tons/hour primary steam flow. For a high void condition of 48 percent (recirculation flow of $6 \times 10^{6} \mathrm{lb} / \mathrm{hr}$ and a primary steam flow of 900 metric tons/hour) the calculated void coefficient is $27 \mathrm{k} /$ percent void. 


\section{Generator Breaker Trip Tests}

The Transients of most significance in the plant are those caused by a generator breaker trip. The following data is taken from a series of Generator Breaker Trip Tests:

\begin{tabular}{ccc}
$\begin{array}{c}\text { Primary Steam } \\
\text { MT } / \mathbf{h r}\end{array}$ & $\begin{array}{c}\text { Power } \\
\text { MWE }\end{array}$ & $\frac{\Delta \phi / \varnothing_{0}}{24 \%}$ \\
\hline 350 & 80 & $33 \%$ \\
350 & 80 & $42 \%$ \\
450 & 100 & $36 \%$ \\
450 & 100 & $46 \%$ \\
520 & 115 & $45 \%$ \\
540 & 120 & $56 \%$ \\
610 & 135 & $65 \%$ \\
645 & 145 & $72 \%$ \\
720 & 160 &
\end{tabular}

Plotting these data in Figure 4-2 indicates the trend of $\Delta \phi / \phi_{0}$ to be nearly linear with power. The additional relationship of primary steam flow and $\Delta \phi / \varnothing$ o gives the correlation desired for the extrapolation since the primary turbine steam flow is directly related to the steam flow miss-match caused by the closure of the turbine primary admission valves. The predicted maximum neutron flux for a generator breaker trip at 900 metric tons/hr primary steam flow would be 195 percent of rated. The initial power for 900 metric tons/hr primary steam flow with one loop natural circulation and no secondary steam flow is approximately 506 MWT which is rated thermal power.

This predicted momentary flux increase is considered conservative since it assumes that the turbine bypass and admission valves which are both in operation to pass 900 metric tons $/ \mathrm{hr}$ will reduce the steam flow during the transient to an amount proportional to the 720 metric tons/hr test at $160 \mathrm{MWE}$.

The division of the steam flow would be approximately 720 metric tons/hr of the 900 metric tons $/ \mathrm{hr}$ to the turbine valves and 180 metric tons $/ \mathrm{hr}$ to the bypass valves. Since only the turbine valves close during the transient, the momentary reduction in steam flow, which causes the flux transient, may be similar in magnitude to the rated power test where 720 metric tons/hr was passed through the turbine valves. Therefore, the neutron flux disturbance and the related heat flux disturbance may be less than the above prediction for a generator breaker trip. In fact, the transient is probably not noticeably different from the previous test with 720 metric ton/hr through the turbine.

Of most interest is the magnitude of the heat flux disturbance during the transient. For a neutron flux disturbance peak of 182 percent from rated power, the peak heat flux is 108 percent of rated as determined in the analog calculations. For a neutron flux 


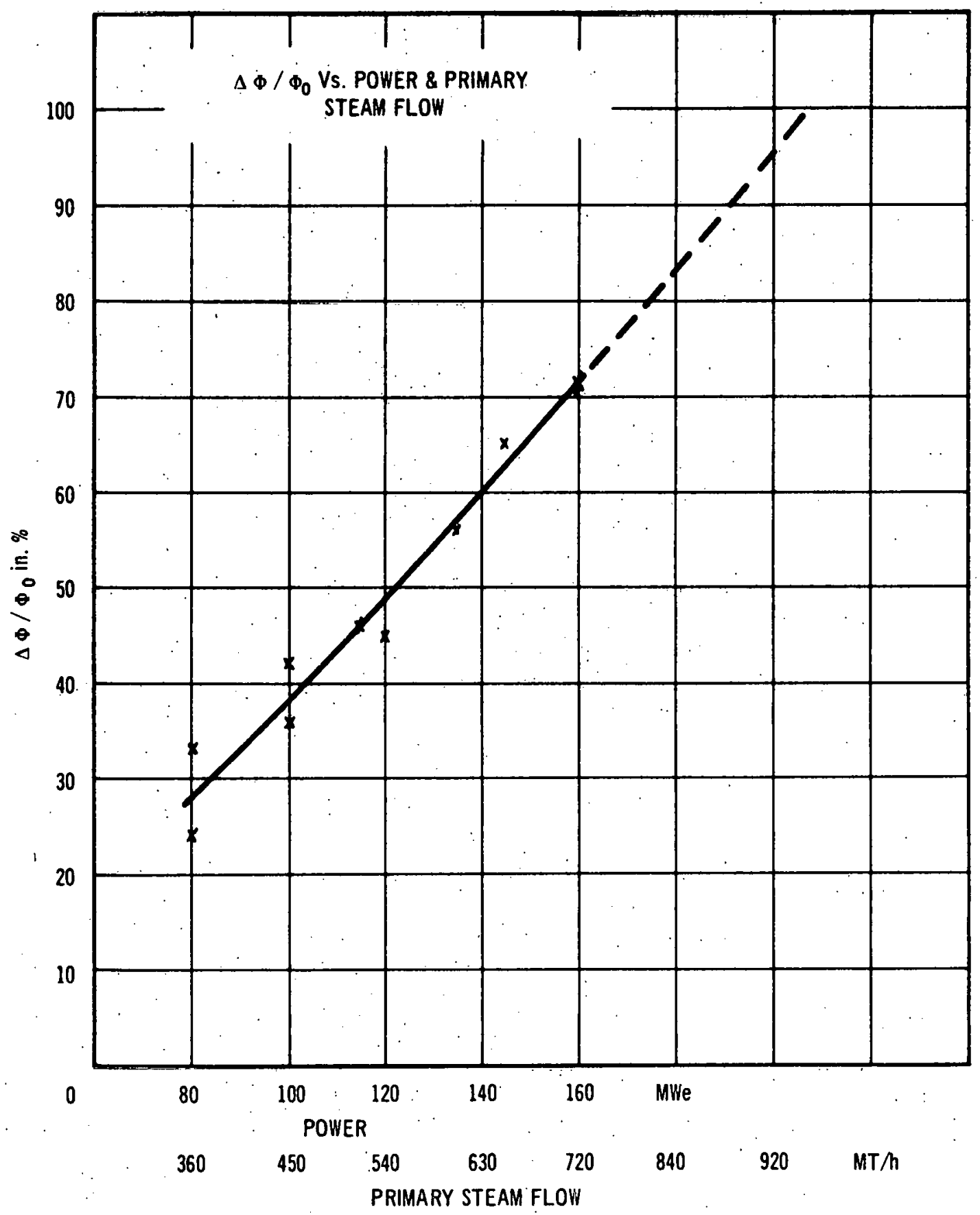

Figure 4-2. $\Delta \emptyset / \varnothing_{0}$ Vs Power and Primary Steam Flow 
disturbance peak of 295 percent from rated power, the peak heat flux is 114 percent of rated in the same study. Therefore, the heat flux disturbance from the predicted 195 percent neutron flux peak would have a peak less than 110 percent of rated for an initial rated power level. The above cases consider that the reactor did not scram. The conclusion is that the transient effect on the fuel due to a generator breaker trip during the proposed tests is not significantly different than those experienced during the rated power generator breaker trip tests. The boiling and voids outside the fuel channels (Section V-B) does not have an appreciable effect, and the extrapolation based on total primary steam flow (instead of turbine steam flow) is sufficiently conservative to allow for the voids outside channels.

\section{Transients in Subcooling}

1. Recirculation Pump Start

A recirculation pump can only be started if the corresponding main valve is fully closed and its by-pass valve open. Prior to a pump start, reactor power is reduced below rated in order to allow for a power increase both at the moment of the pump start and during the main valve opening. Starting of the pump in the loop having natural circulation is prevented by an interlock which prevents the pump start unless the discharge valve is closed. (Closure of discharge valves of both pumps causes a scram.) If by error the recirculation pump in the valved-off loop were started during the full power one loop natural circulation test, a neutron flux peak of about 12 percent would be experienced. This value was obtained by extrapolating test data recorded during the startup tests. As the peak duration ranges from 2 to $5 \mathrm{sec}$, the corresponding heat flux peak will not exceed 107 percent.

\section{Secondary Load Pick-up}

An accidental secondary load pick-up of $120 \mathrm{MT} / \mathrm{h}$ during a low subcooling one loop natural circulation test at full power would cause a 13 percent increase of reactor power. The transient is a very slow one, depending mainly upon the opening speed of the secondary control valve and the 9 sec time constant of the secondary steam generator.

\section{Trip of the Feedwater Preheaters}

During a low subcooling one loop natural circulation test at full power approximately $785 \mathrm{MT} / \mathrm{h}$ of primary steam will be sent to the turbine and $115 \mathrm{MT} / \mathrm{h}$ to the condenser. Under these conditions the generator power will be 130 to $135 \mathrm{MWe}$. For normal dual cycle operation the feedwater temperature at $135 \mathrm{MWe}$ is $184^{\circ} \mathrm{C}$. For a feedwater flow of $900 \mathrm{MT} / \mathrm{h}$ at $135 \mathrm{MWe}$ the feedwater temperature is about $170^{\circ} \mathrm{C}$. An accidental trip of all four feedwater preheaters would cause the feedwater temperature to drop from $170^{\circ} \mathrm{C}$ to about $35^{\circ} \mathrm{C}$. Assuming that the recirculation flow remains constant and equal to $3300 \mathrm{MT} / \mathrm{h}$, the reactor inlet enthalpy will change from $264 \mathrm{kcal} / \mathrm{kg}$ to $227 \mathrm{kcal} / \mathrm{kg}$, 
causing the inlet temperature to drop from $254^{\circ} \mathrm{C}$ to $221^{\circ} \mathrm{C}$. As a consequence of the increasing subcooling, the reactor power would gradually increase to about 150 percent, with a primary steam flow about 15 percent higher than the original valve. For a feedwater flow rate of about $1000 \mathrm{MT} / \mathrm{h}$ the first order time constant of the preheater system is estimated to be 90 seconds. In a first order approximation the time constant of the change in reactor subcooling is approximately 2 minutes, taking into account the time constants for the steam generator and the reactor inlet plenum. The scram level of 120 percent would be reached 50 to 60 seconds after the feedwater preheater trip. At the moment of the scram the fuel heat flux would only be slightly below 120 percent. 


\section{SECTION V}

\section{SPECIAL TOPICS AND ANALYSES}

\section{A. Stability Analyses}

To ensure the safety of the reactor at all times, the reactor stability has been considered first from the viewpoint of prior calculations of expected behavior and second, as an added precaution, the experimental procedures have been carefully evaluated to ensure safety even if the calculations were for some reason grossly incorrect.

The stability analysis information is presented as follows:

1. Analytic methods

2. Pre-test calculations

3. Dynamic Performance Criteria

4. Experimental Approach to test conditions

1. Analytic Methods

The analytic method used for the stability analysis is; first, the calculation of the core power distribution and flow distribution for steady-state conditions; next, an analytic model is used to predict the dynamic response. This model includes analytical representations of reactor kinetics, fuel rod dynamic heat transfer, hydrodynamic flow characteristics including twophase effects, and thermodynamic effects due to load and subcooling changes. The hydrodynamic portion of the model is based on the physical concepts of momentum interchange, conservation of energy and continuity of mass. These analytic representations are derived from the basic defining differential equations of physical phenomena and are, in turn, transformed into transfer functions. This model and its use has been described previously by Case and Holland. ${ }^{1}$ The specific computer codes used are proprietary.

2. Pretest Calculations

The above described method was applied to the more severe test conditions and the predicted behavior was determined. The conditions calculated in the first set of analyses were as follows:

\begin{tabular}{cccc} 
Case & Power & \multicolumn{1}{c}{ Flow } & Subcooling \\
\hline 1 & rated & 0.75 (1 loop Natural)* & $\begin{array}{l}\text { rated } \\
\text { minimum }\end{array}$ \\
2 & rated & 1 loop Natural & rated \\
3 & rated & 1 loop Natural & maximum \\
4 & rated & 1 loop Natural & \\
\hline
\end{tabular}

${ }^{1}$ Case, J. M. and Holland, L. K. "Consumers Big Rock Point Nuclear Power Reactor Stability Analysis," GEAP-3795, August 20, 1961

*(1 loop Natural $)=$ Natural circulation through stopped pump and other loop valved off. 


\begin{tabular}{|c|c|c|c|}
\hline Case & Power & Flow & Subcooling \\
\hline $\begin{array}{l}5 \\
6 \\
7\end{array}$ & $\begin{array}{l}\text { rated } \\
\text { rated } \\
\text { rated }\end{array}$ & $\begin{array}{l}2 \text { loop Natural } \\
2 \text { loop Natural } \\
2 \text { loop Natural }\end{array}$ & $\begin{array}{l}\text { minimum } \\
\text { rated } \\
\text { maximum }\end{array}$ \\
\hline 8 & rated & $\begin{array}{l}\text { raled } \\
(2 \text { loop forced) }\end{array}$ & rated \\
\hline
\end{tabular}

Core inlet subcooling is an important and interesting variable. Both the stability analytic model and tests in a stability test loop indicate that the amount of subcooling can have an important effect on the system stability. This is presumably an effect which is dependent on changes in the boiling boundary, i.e., the point at which the bulk coolant reaches the saturation temperature. Minimum subcooling is obtained by excluding secondary steam flow to the turbine and letting feedwater heaters run at rated conditions. Rated subcooling is obtained by letting the secondary steam generators run at rated conditions and the feedwater heaters run at rated condition. Maximum subcooling is obtained by letting the secondary steam generators run at rated conditions and turning off as many as possible of the four feed water heaters; however, this amount of secondary steam flow will be impossible when only one loop is in operation. The calculated case is indicative only and will be modified in further analyses. The actual subcooling will be less than that used in the analyses, and hence, the peak gain will be less than, shown here.

The results of the preliminary stability analyses are shown in Table 5-1. The terms used are defined as follows:

\begin{tabular}{|c|c|}
\hline $\mathrm{x}_{\mathrm{e}_{\mathrm{CH}}}{ }^{\%}$ & Exit quality of the average heat-input channel, in percent. \\
\hline $\mathrm{U}_{\mathbf{e}_{\mathrm{CH}}}{ }^{\%}$ & Exit void fraction of the average heat-input channel, in percent. \\
\hline$\overline{\mathrm{U}}_{\mathrm{c}} \%$ & Average corc exit void fraction inside channels in percent. \\
\hline \multicolumn{2}{|l|}{ Gain Margin } \\
\hline $\mathrm{db}$ & $\begin{array}{l}\text { The magnitude of the gain in decibels at }-180^{\circ} \text { in the open loop. } \\
\text { The reactor is stable if greater than zero. }\end{array}$ \\
\hline CPS & Frequency at which the gain margin occurs in cycles per second. \\
\hline \multicolumn{2}{|l|}{ Phasc Margin } \\
\hline Degrees & $\begin{array}{l}\text { The phase angle at } 0 \mathrm{db} \text { gain, subtracted from } 180^{\circ} \text {, in the open loop. } \\
\text { The reactor is stable if greater than zero. }\end{array}$ \\
\hline CPS & Frequency at which the phase margin occurs in cycles/sec. \\
\hline
\end{tabular}

These results were used to guide the selection of the specific reactor test conditions. 
TABLE 5-1

PRELIMINARY STABILITY ANALYSES FOR GARIGLIANO REACTOR

\begin{tabular}{|c|c|c|c|c|c|c|c|c|c|c|c|c|}
\hline \multirow{2}{*}{$\begin{array}{l}\text { Run } \\
\text { No. }\end{array}$} & \multirow{2}{*}{$\begin{array}{l}\text { Thermal } \\
\text { Power } \\
(\text { MW (t)) }\end{array}$} & \multirow{2}{*}{$\underset{\text { (psia) }}{\text { Pressure }}$} & \multirow{2}{*}{$\begin{array}{c}\text { Total } \\
\text { Core } \\
\text { Flow } \\
\left(10^{6} \mathrm{lb} / \mathrm{h}\right)\end{array}$} & \multirow{2}{*}{$\begin{array}{c}\Delta h_{\mathrm{s}} \\
\text { Subcool } \\
\text { (Btu//lb) }\end{array}$} & \multirow{2}{*}{ 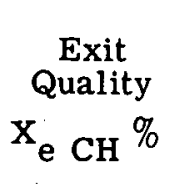 } & \multirow{2}{*}{$\begin{array}{c}\text { Exit } \\
\text { Voids } \\
\mathrm{U}_{\mathrm{e} \mathrm{CH}} \%\end{array}$} & \multirow{2}{*}{$\begin{array}{c}\text { Average } \\
\text { Voids in } \\
\text { Channels } \\
\overline{\mathrm{U}}_{\mathrm{c}} \%\end{array}$} & \multicolumn{2}{|c|}{ Gain Margin } & \multicolumn{2}{|c|}{ Phase Margin } & \multirow{2}{*}{$\begin{array}{c}\text { Damping } \\
\text { Coefficien }\end{array}$} \\
\hline & & & & & & & & $\mathrm{db}$ & At CPS & Degrees & At CPS & \\
\hline 1 & 503.9 & 1017 & 4.421 & 168.0 & 31.9 & 83.5 & 40.3 & 8.15 & 0.546 & 42.5 & 0.336 & 0.426 \\
\hline 2 & 503.5 & 1017 & 5.738 & 55.1 & 34.7 & 85.0 & .48 .1 & 13.62 & 0.598 & 76.2 & 0.242 & 0.535 \\
\hline 3 & 503.9 & 1017 & 5.523 & 135.4 & 26.7 & 79.2 & 37.7 & 8.63 & 0.598 & 43.8 & 0.356 & 0.403 \\
\hline 4 & 502.3 & 1017 & 5.573 & 184.8 & 18.7 & 71.0 & 28.2 & 4.32 & 0.632 & 21.0 & 0.497 & 0.269 \\
\hline 5 & 503.5 & 1017 & 10.62 & 42.8 & 20.5 & 72.8 & 38.9 & 11.81 & 0.719 & 71.0 & 0.332 & 0.430 \\
\hline 6 & 503.9 & 1017 & 10.373 & 74.3 & 15.9 & 68.1 & 30.1 & $10: 37$ & 0.741 & 53.9 & 0.376 & 0.341 \\
\hline 7 & 502.2 & 1017 & 10.356 & 101.1 & 11.4 & 61.3 & 22.3 & 6.62 & 0.798 & 33.9 & 0.534 & 0.220 \\
\hline 8 & 507.4 & 1017 & 23.321 & 35.8 & 7.0 & 52.0 & 20.7 & 17.00 & 1.270 & 93.0 & 0.322 & 0.517 \\
\hline
\end{tabular}

Note: See Table 5-2 for subsequent analyses. 
The results for the eight potential reactor test conditions are also shown in Figures 5-1, 5-2, and 5-3. Figure 5-1 illustrates the closed loop.response for one loop natural circulation flow and rated power for different subcoolings. It shows that for high subcooling the system is less damped and there is a higher response (higher and sharper peak in the magnitude curve). For lower subcoolings the response is less.

The magnitude value ( $\mathrm{db}$ or decibel) in this application is defined as $\mathrm{db}=20 \log \mathrm{M}$ where $\mathrm{M}$ is the ratio of flux response (in percent) to perturbation of reactivity, $\frac{\Delta k}{k} / \beta$ (in cents). The phase angle is the angle between the flux and reactivity perturbation in degrees. This is the same data that is to be obtained from the control rod oscillator tests - the transfer function from reactivity to flux.

Figure 5-2 is the same as Figure 5-1 except that the flow is two loop natural circulation. The difference of the response with different subcooling is less with two loop natural circulation than it is with one loop natural circulation. This gives an indication that when the reactor is operating in one loop, natural circulation the system is somewhat less damped than when it is operating in two loop natural circulation.

Figure 5-3 is the closed loop response for rated power and rated subcooling for different flows. It can be seen again that for higher flows the reactor is a little more damped. That is, the curve is flatter at higher flow rates.

Since the previous analysis described above, improved calculations have been made. These calculations indicate that

a. The reactor natural-circulation flow is slightly higher than calculated before $-7.25 \times 10^{6}$ $\mathrm{lb} / \mathrm{h}$ instead of $6 \times 10^{6} \mathrm{lb} / \mathrm{h}$.

b. The subcooling is less than shown previously. This is due to decreased secondary steam generator load when one loop is out of service and at reduced recirculation flow rates. Also, it may not be possible to bypass all four feedwater heaters at the same time, thus further reducing the subcooling.

These revised flow and subcooling values have been used in a new stability analysis. The results are shown in Table 5-2 and Figure 5-4. The peak response is slightly less than the previously calculated results. Otherwise the results are similar to the preliminary results. 


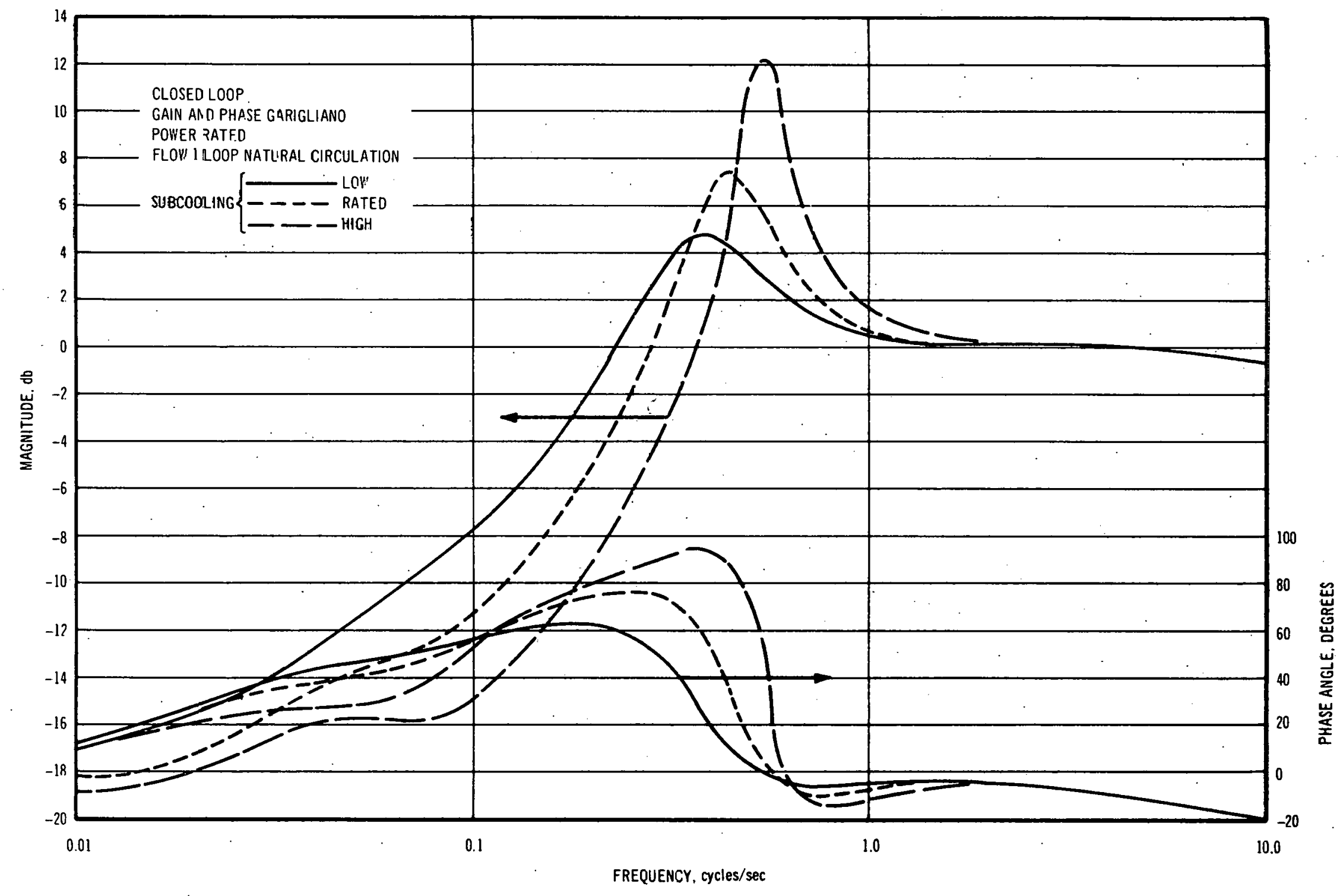




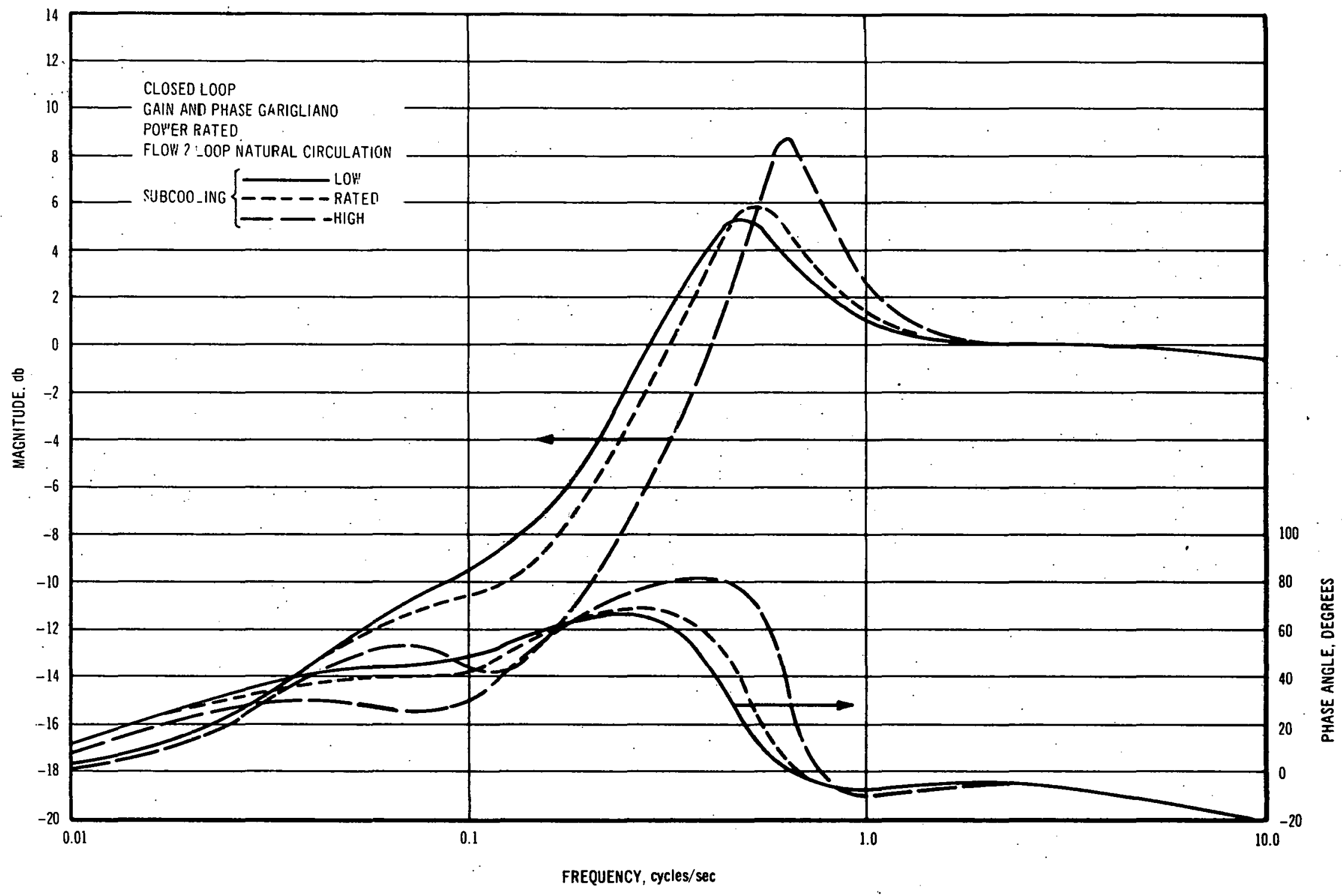




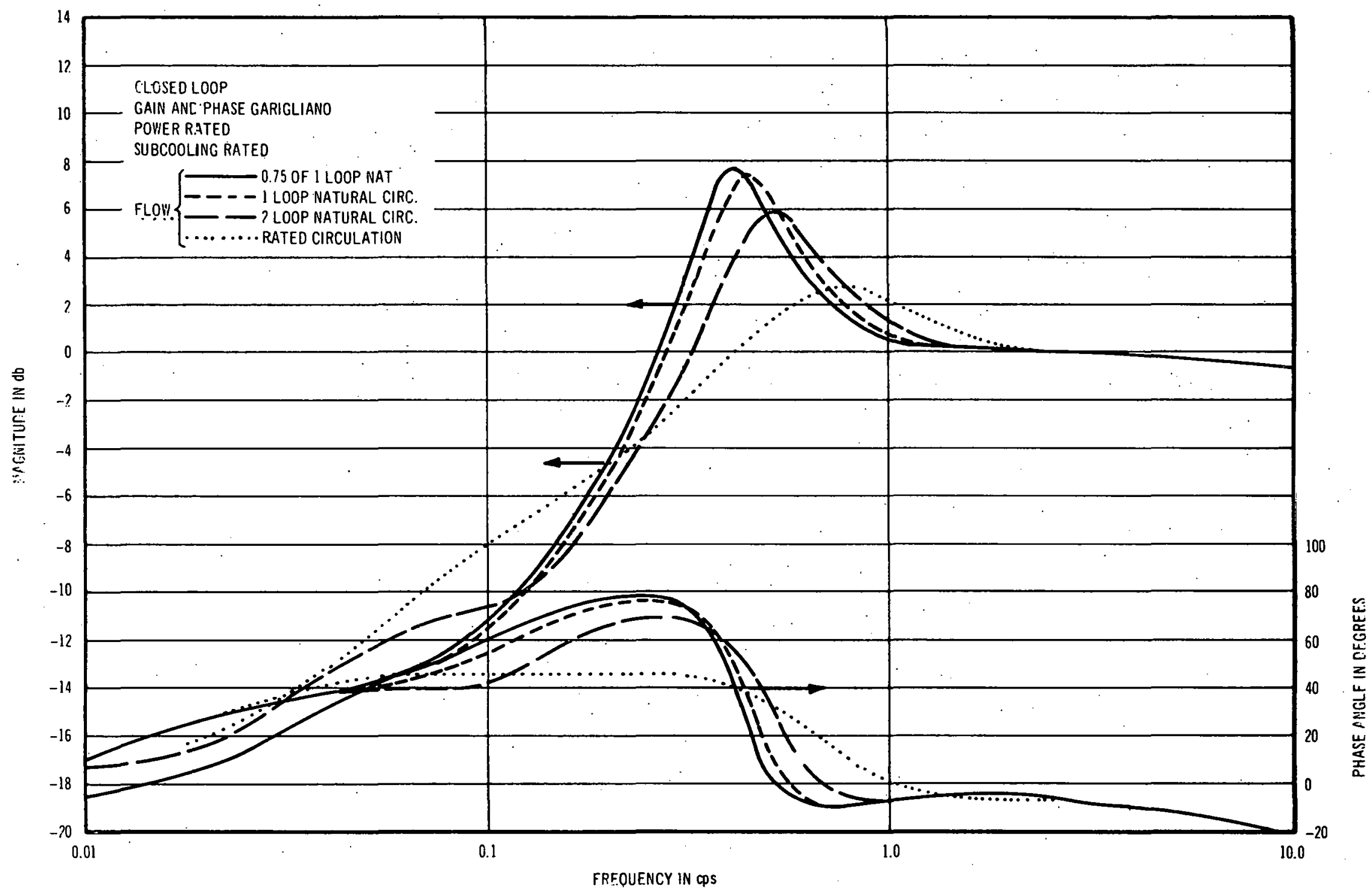


TABLE 5-2

REVISED RESULTS FOR

GARIG LIANO REACTOR AT FULL POWER

ONE-LOOP NATURAL CRCULATION

\begin{tabular}{|c|c|c|c|c|c|c|c|c|c|c|c|}
\hline \multirow[b]{2}{*}{ Subcoolirg } & \multirow[b]{2}{*}{$\begin{array}{c}\text { Subcooling } \\
\text { (Btu/lb) }\end{array}$} & \multicolumn{3}{|c|}{ Feedwater and Secondary Condition } & \multirow{2}{*}{$\begin{array}{c}\text { Reactor } \\
\text { Inlet } \\
\text { Temp. }\left({ }^{\circ} \mathrm{F}\right)\end{array}$} & \multirow[b]{2}{*}{$\begin{array}{l}\text { Power } \\
\text { [MW(t)] }\end{array}$} & \multirow{2}{*}{$\begin{array}{l}\text { Recir- } \\
\text { culation } \\
\text { Flow } \\
(\mathrm{lb} / \mathrm{h})\end{array}$} & \multicolumn{4}{|c|}{ Gain and Phase Margin } \\
\hline & & $\begin{array}{c}\text { Feedwater } \\
\text { Heater }\end{array}$ & $\begin{array}{l}\text { Secondary } \\
\text { Power }\end{array}$ & $\begin{array}{l}\text { Secondary } \\
\text { Steam Flow } \\
(\mathrm{lb} / \mathrm{h})\end{array}$ & & & & Gain & $\frac{\text { Gain and }}{\text { At cps }}$ & $\frac{\text { se Marg }}{\text { Phase }}$ & At cps \\
\hline Low & 61 & All 4 on & 0 & 0 & 496 & 512 & $7.27 \times 10^{6}$ & 13.0 & 0.614 & $79.0^{\circ}$ & 0.260 \\
\hline Rated & 86 & All 4 on & $68.75 \mathrm{MW}(\mathrm{t})$ & $0.276 \times 10^{6}$ & 475 & 511 & $7,22 \times 10^{6}$ & 10.3 & 0.618 & $55.6^{\circ}$ & 0.331 \\
\hline High & 122 & All 4 off & $68.75 \mathrm{MW}(\mathrm{t})$ & $0.204 \times 10^{6}$ & 443 & 504 & $7.35 \times 10^{6}$ & 6.9 & 0.634 & $34.6^{\circ}$ & 0.422 \\
\hline
\end{tabular}




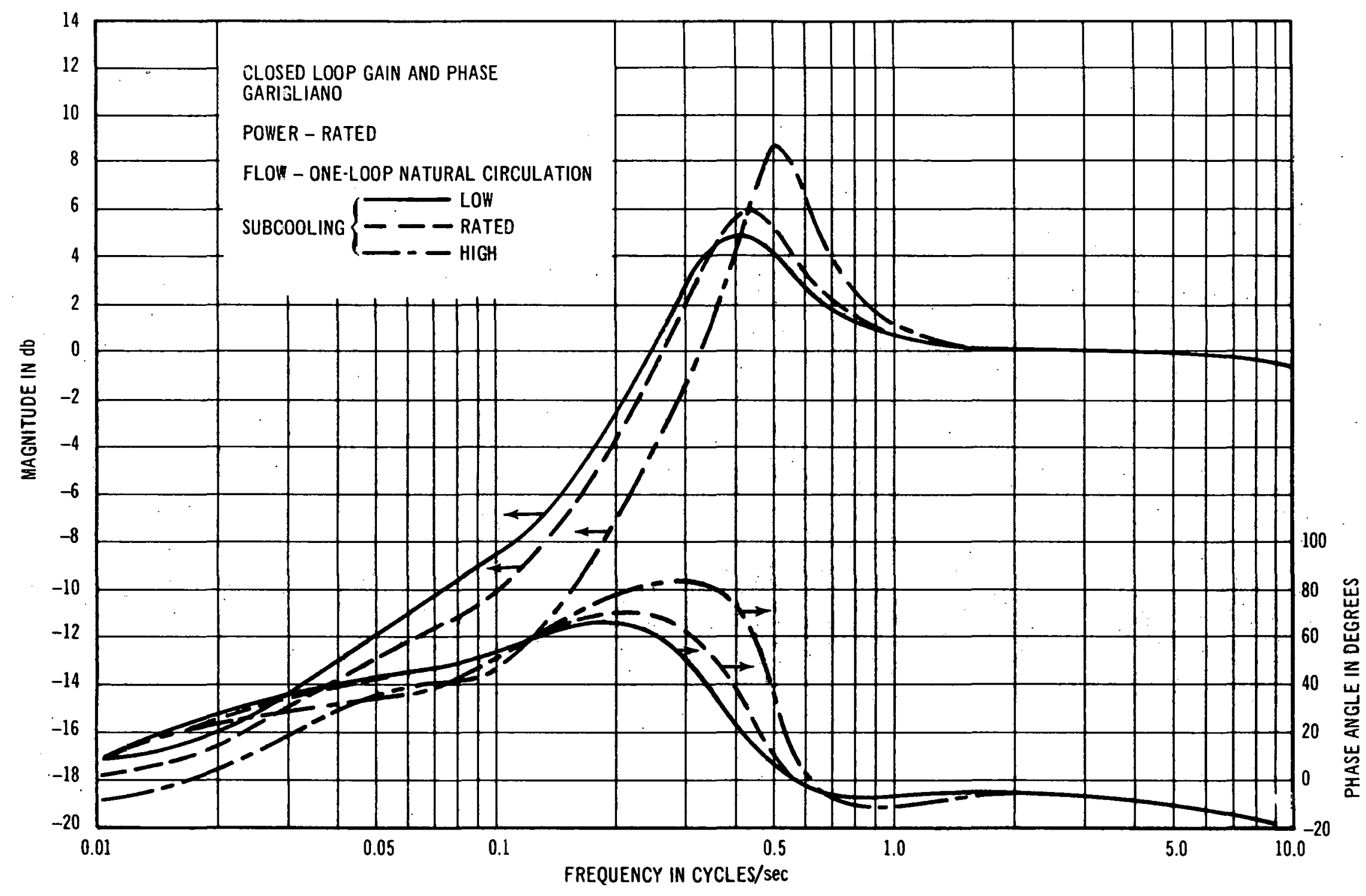

Figure 5-4. Garigliano Calculated Transfer Function (Flux Response, $\% /$ Reactivity $\frac{\Delta \mathrm{k} / \mathrm{k}}{\beta}$, cents) 
These calculated results indicate that the reactor can be operated at a range of conditions which have value as a stability test. It is, of course, of no interest to do a test that shows that the reactor is stable at rated flow and power. That is known already - it is operated at that condition every day. The stability tests have value when they (a) demonstrate operation at conditions different from rated, or (b) confirm the results of stability calculations which show the parametric dependence of the reactor transfer function as related to flow, power and subcooling. By maintaining two of the parameters constant, and allowing the other parameter to change, information can be obtained on the stability dependence of, (a) power with flow and subcooling constant, (b) flow with power and subcooling constant, and (c) subcooling with flow and power constant. By knowing the stability dependence of these parameters, an insight into the reactor performance at uprated conditions can be obtained.

\section{Dynamic Performance Criteria}

Stability is an aspect of reactor operation and safety which has been discussed very much, but often misunderstood. In order to clarify the meaning of the term "reactor stability" it is desirable to consider all three aspects of the reactor dynamic performance:

a. Absolute stability. This criterion is met if the reactor does not have diverging oscillations, that is, the envelope of the oscillations does not increase exponentially (until limited at a large amplitude by non-linear aspects of the system).

b. Relative stability or noise amplitude. This criterion is met if the amplitudes of the oscillations are "satisfactory". Permissible amplitude is a matter of judgment, but it must be below the setting of the high neutron flux safety circuits, usually 15 to 25 percent above the operating power.

The amplitude of oscillation (noise) depends both on the strength of any driving forces which may be present and the sensitivity (or gain, or relative stability) of the system for this excitation. Excessive oscillation can be prevented by reducing the driving forces or by reducing the system gain or sensitivity.

c. Transient response. This criterion is met if the reactor is "easy" to operate and maneuver through power changes, flow changes and all normal and emergency operations. That is, the transienl responses must be adequately dampcd.

Now it is possible to discuss the safety problems inherent in each of these aspects of reactor stability or dynamic performance.

\section{Experimental Approach to Test Conditions}

In preparing procedures and safety criteria for the reactor tests each of the three dynamic performance criteria has heen considered. The procedures have been prepared so that the 
reactor is protected against all stability problems regardless of any degree of stability or instability which could possibly be encountered. The specific precautions are as follows:

(a) Pre-test calculations have been performed; therefore, the expected test results are known.

(b) The calculated and measured results will be compared in the course of the tests, so that any significant differences between the calculated and measured results will be detected.

(c) The tests start with a test condition known to be safe--rated flow and power--and proceed in small steps toward the more severe conditions.

(d) The tests are supervised by experienced personnel of both ENEL and General Electric Company who are familiar with the expected results, required safety criteria and safety limits.

(e) The last basic protection of the reactor system from any possible damage resulting from instability is the high flux scram setting. This will be set at $120 \%$ of the actual power level for each test:

The safety precautions are discussed below in terms of the three performance criteria:

Absolute stability.

In the unlikely event that the reactor system reaches a point of absolute instability, the neutron flux would begin to oscillate at the natural frequency of the reactor system, approximately $0.6 \mathrm{cycles} / \mathrm{second}$. The amplitude of the oscillations would increase exponentially until either, (1) the operator intervenes, (2) the amplitude is limited by non-linear aspects of the system, or (3) the oscillation amplitude reaches $\pm 20 \%$ and the high flux scram shuts down the reactor. In any case, no more than one cycle of oscillation would exceed plus $20 \%$ of neutron flux. Since fuel surface heat transfer oscillation amplitude is considerably less than neutron flux amplitude, there is no possibility of damage to the fuel or the reactor.

As a practical matter, absolute instability has not been observed in a high pressure, $\mathrm{UO}_{2}$ fueled, power reactor. Operation has been first limited by relative stability or noise amplitude.

\section{Relative stability or noise amplitude:}

An underdamped system is characterized by a larger amplitude flux noise, an "overshoot" in response to step changes, and a higher peak in the transfer function. None of these characteristics is of itself harmful in any way. 
The safety criteria to be applied is that the oscillations and "overshoots" shall not be "excessive". The following criteria have been adopted:

\begin{tabular}{|c|c|}
\hline & $\begin{array}{l}\text { Percentage of actual } \\
\text { reactor power } \\
\end{array}$ \\
\hline $\begin{array}{l}\text { Nominal amplitude of in-core } \\
\text { neutron flux oscillations for rod } \\
\text { oscillator tests }\end{array}$ & $\pm 10 \%$ \\
\hline $\begin{array}{l}\text { Maximum planned in-core neutron flux } \\
\text { amplitude for any test including rod oscillator, } \\
\text { steady state noise or transients }\end{array}$ & $\begin{array}{c}+15 \% \\
.\end{array}$ \\
\hline High flux scram & $+20 \%$ \\
\hline
\end{tabular}

Transient response.

The safety criteria for transient response overshoot have been covered in the paragraph above.

It is concluded that, first, the pre-test calculations provide assurance of reactor absolute stability at the proposed test conditions, and second, the experimental methods and high flux scram provide the required precautions to give protection of the reactor against any conceivable condition of reactor stability or instability.

\section{B. Boiling Outside Fuel Channels}

Calculations have been conducted to determine the extent of boiling outside fuel channels and the effect on core reactivity and control rod worth. First a special hydraulic model was used to calculate the amount of flow between channels and the quality and void content. Then the reactivity effects were evaluated.

It is known that 3 percent of the reactor power is generated in the moderator as a result of neutron scattering and gamma reactions. Thus, the leakage water bypassing the fuel channels is heated by this source of energy.

Most of this heat is produced in the core region, and it is assumed that negligible energy is given to the water flowing around the core and between the thermal shield and vessel wall.

Part of the heat in the core region is produced in the water inside the fuel channels and part outside of them. It is necessary to know the amount of heat produced outside the channels at different recirculation flow, as when this decreases, the voids in the channels increases and the fraction of water inside then will be less. That will mean less heat produced in the channel water than in the leakage water. 
Assuming that no heat is produced outside the core region, in a single core cell 67.47 percent of the total moderator by weight is inside the channel and 32.53 percent outside, ${ }^{(1)}$ when no voids are in the reactor. Assuming now that " $\mathrm{V}$ " is the void fraction in the channel, the fraction Fo outside the channels of the total moderator in a cell is given by:

$$
F_{0}=\frac{F O^{*}}{1-F i^{*} V}
$$

where:

$$
\begin{aligned}
& \text { Fo }^{*}= \text { is the moderator fraction outside the channel with no voids } \\
& \text { in the reactor }=0.3253 \\
& \mathrm{Fi}_{1} \mathrm{i}^{*}= \text { is the moderator fraction inside the channel with no voids } \\
& \text { in the reactor }=0.6747
\end{aligned}
$$

Thus, the total power produced in the moderator must be multiplied by this number in order to know the real amount of heat given to the leakage flow.

Previous core calculations conducted at different recirculation flows ranging from $23 \times 10^{6}$ $\mathrm{lbs} / \mathrm{hr}$ to $6 \times 10^{6} \mathrm{lbs} / \mathrm{hr}$, and at different core inlet subcoolings, show how the channel void fraction changes with recirculation flow, thus giving the possibility to calculate the Fo term. Figure 5-5 shows how the power produced in the leakage flow changes with the recirculation flow.

To simulate the leakage flow in a computer run, a model has been established dividing the leakage flow in two paths: (1) Core region, (2) Reflector plus thermal shield-vessel wall space.

Figure 5-6 shows how these flow paths have been simulated by two different channels. Both of these have an inner "fuel" or heat-source rod of negligible dimension (0.04 inch OD), but the first one, simulating the core region, produces the whole moderator power; the second gives negligible heat.

An orifice of 1 in $^{2}$ for each channel gives the total pressure drop, as the channel dimensions are very large (100 inches $\times 100$ inches) and the friction factor constants have been assumed very small.

To calculate the loss factor for the entrance local pressure drop, leakage flow at rated condition have been taken from design calculations which give the expected bypass leakage with either stainless or Zircaloy channels. For our purpose, the average value between these two has been

(1) W. R. Clancey, personal communication, Nov 1962 


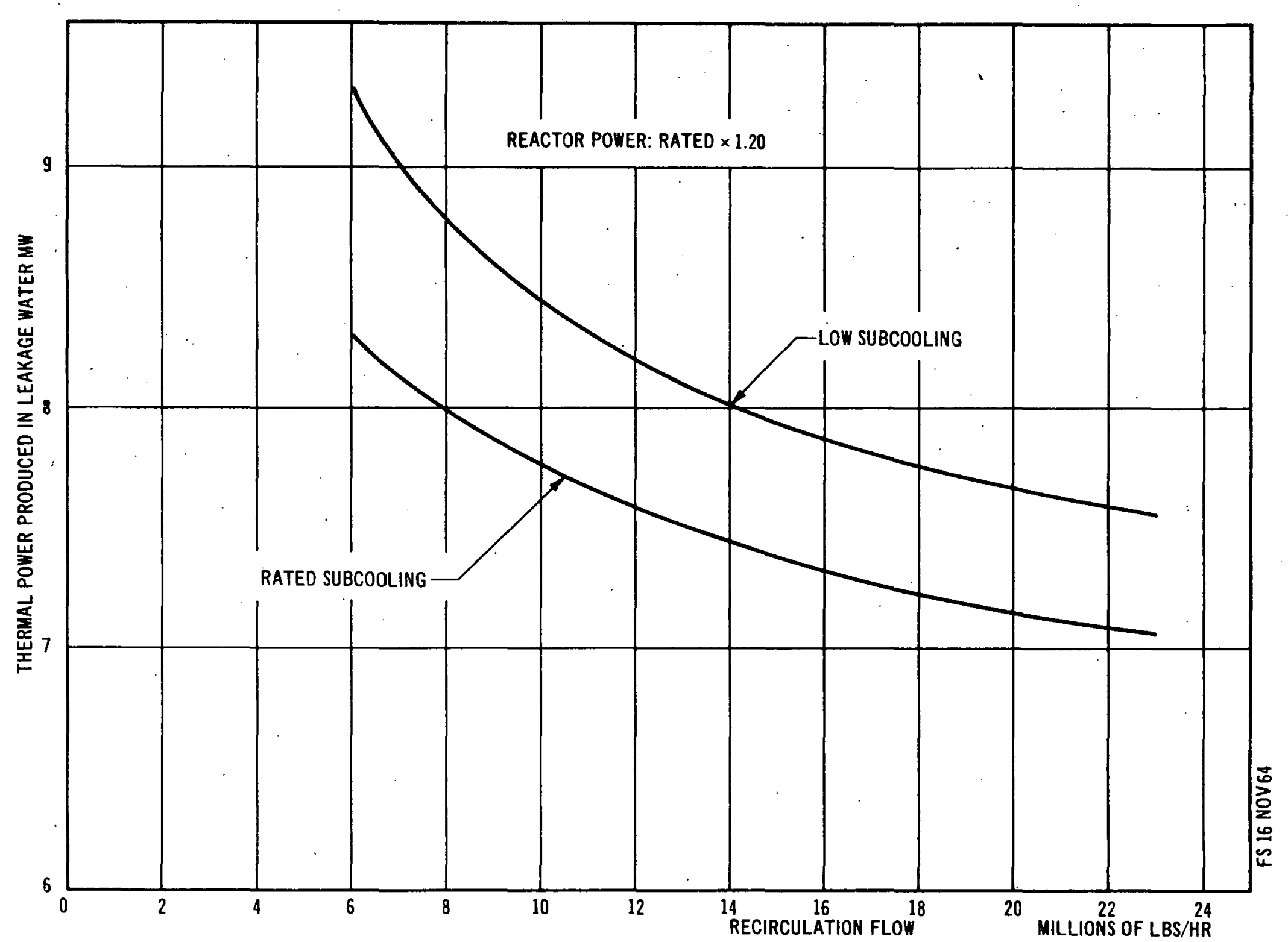




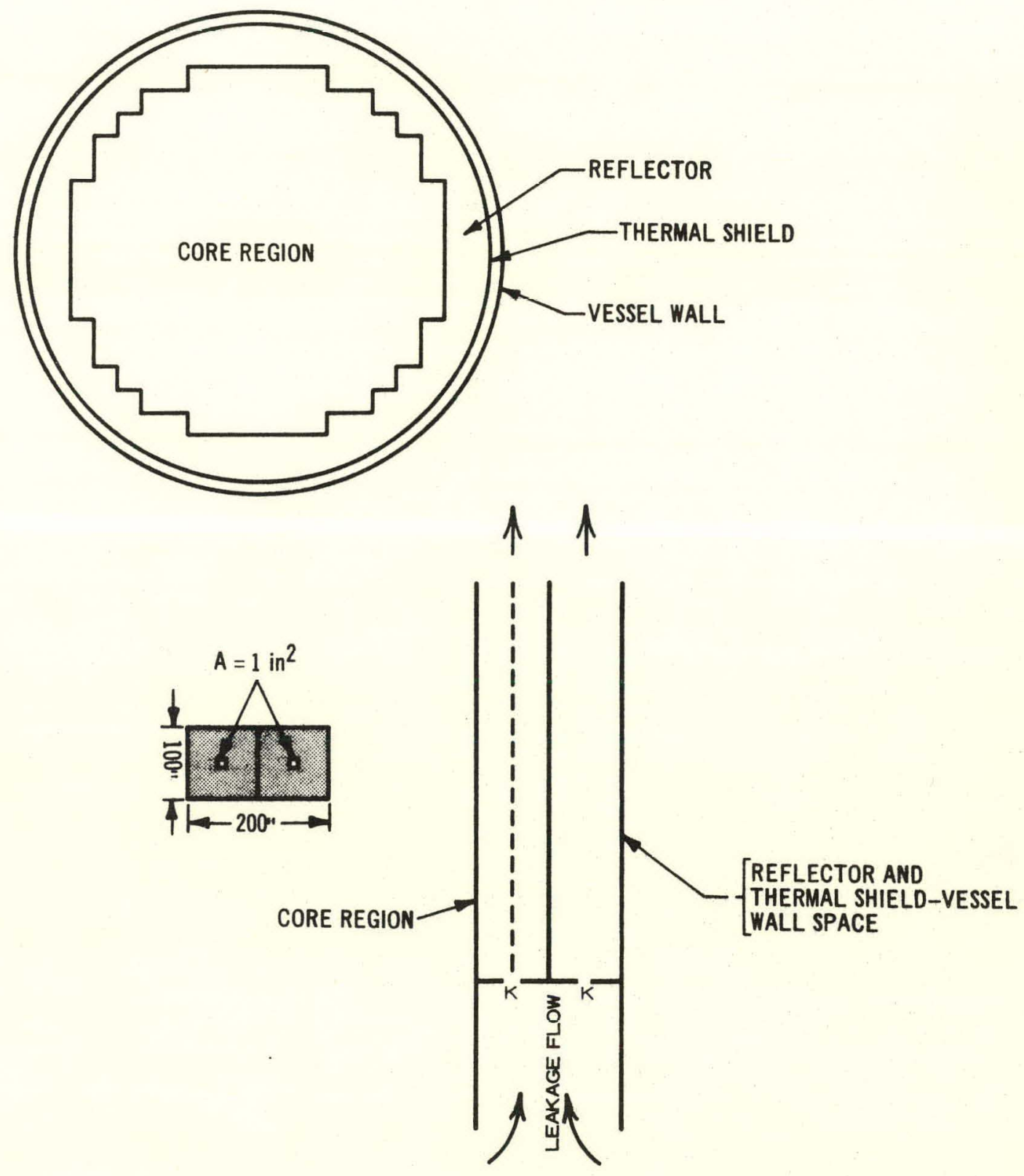

Figure 5-6. Core By-pass Flow Model 
taken, as the high void tests will be conducted with half of the stainless steel channels changed to Zircaloy. The loss factor for each leakage region has been calculated with the following formula:

$$
\mathrm{K}=\frac{\Delta \mathrm{P} \cdot \mathrm{A}^{2} \cdot \rho \cdot 2 \mathrm{~g}}{\mathrm{~W}_{1}^{2}}
$$

where:

$$
\begin{array}{ll}
\Delta \mathrm{P} & =\text { pressure drop across the core support plate } \\
\mathrm{A} & =\text { restriction area } \\
\rho & =\text { inlet water density } \\
\mathrm{W}_{1} & =\text { leakage flow }
\end{array}
$$

Computer calculations have been conducted with previously calculated core pressure drops for these two particular channels at different recirculation flows and at different inlet subcooling (with or without secondary steam flow), but at constant reactor overpower of 1.2. Figure 5-7 shows how leakage flow changes with recirculation flow.

At rated subcooling (full secondary steam flow) no boiling occurs in the leakage flow down to a recirculation flow of $10 \times 10^{6} \mathrm{lbs} / \mathrm{hr}$, which corresponds to both primary loops in natural circulation. Since tests will be conducted with one loop in natural circulation and the other throttled or valved out, it will be necessary to predict the loss in reactivity and the change in control rod worth. Figure 5-8 shows void distribution in the core region for different recirculation flows and subcoolings.

The void fraction in the leakage flow path outside the fuel channels is summarized as follows:

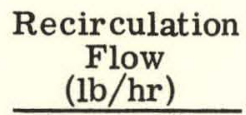

$12 \times 10^{6}$

10

8

6

12

10

8

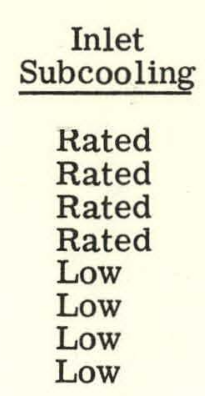

\begin{tabular}{cc}
\multicolumn{2}{c}{ Leakage Flow } \\
\hline Exit Void & Average Void \\
$\%$ & $\%$ \\
25 & 0 \\
51 & 2 \\
69 & 12 \\
16 & 24 \\
35 & 1.2 \\
53 & 7 \\
69 & 17 \\
& 31
\end{tabular}

The exit steam qualily for the leakage flow is shown in Figure 5-9.

It must be pointed out that this analysis has some degree of uncertainty as the hydraulic model is approximate and the power given to the moderator can be slightly different. For example, the moderator power has been considered uniform in the core region and negligible outside the core. As most of the heat is produced by neutron scattering the distribution will follow approximately the neutron flux distribution. However, the calculation is sufficiently accurate to permit estimating of the reactivity effects. 


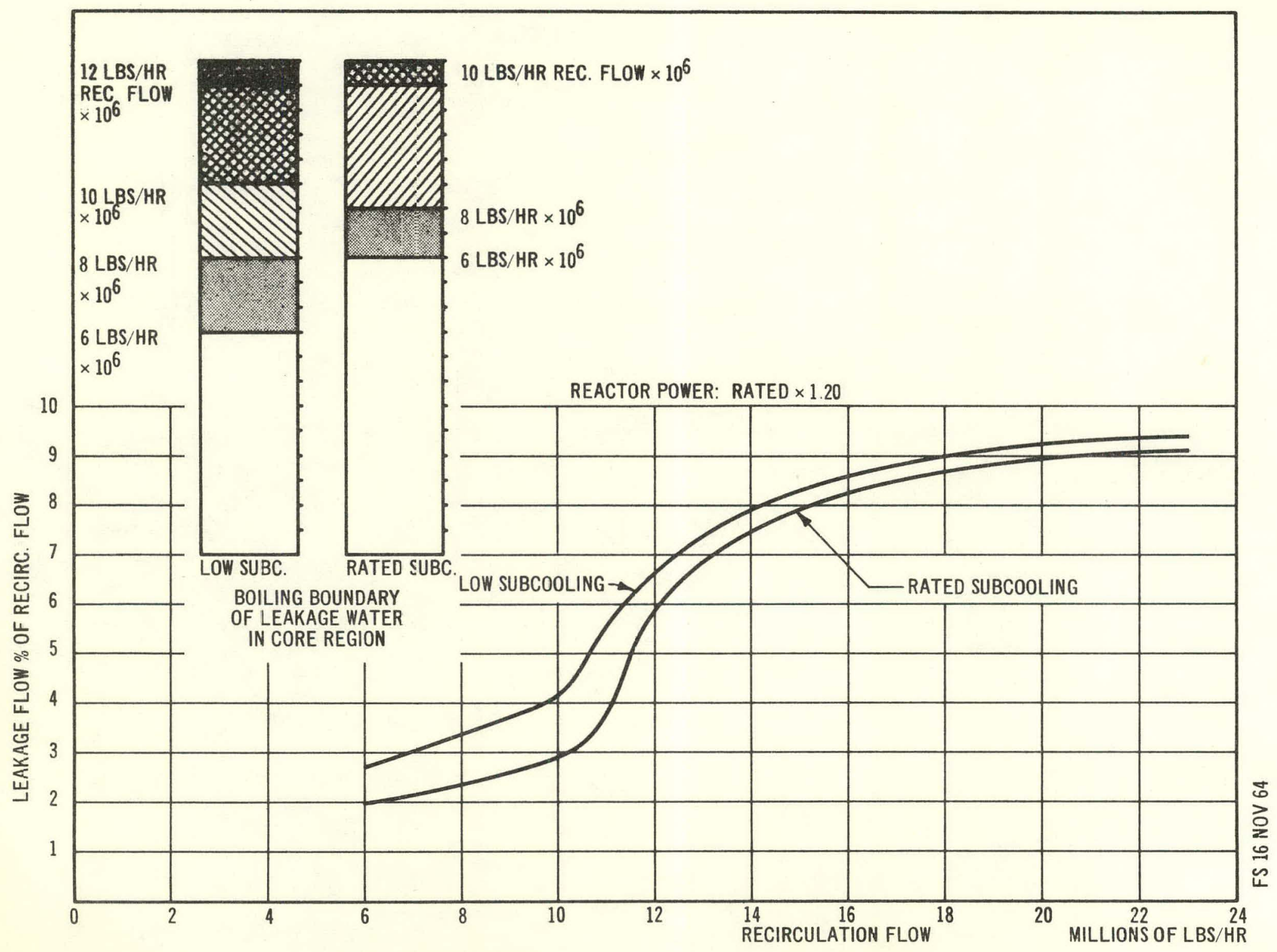




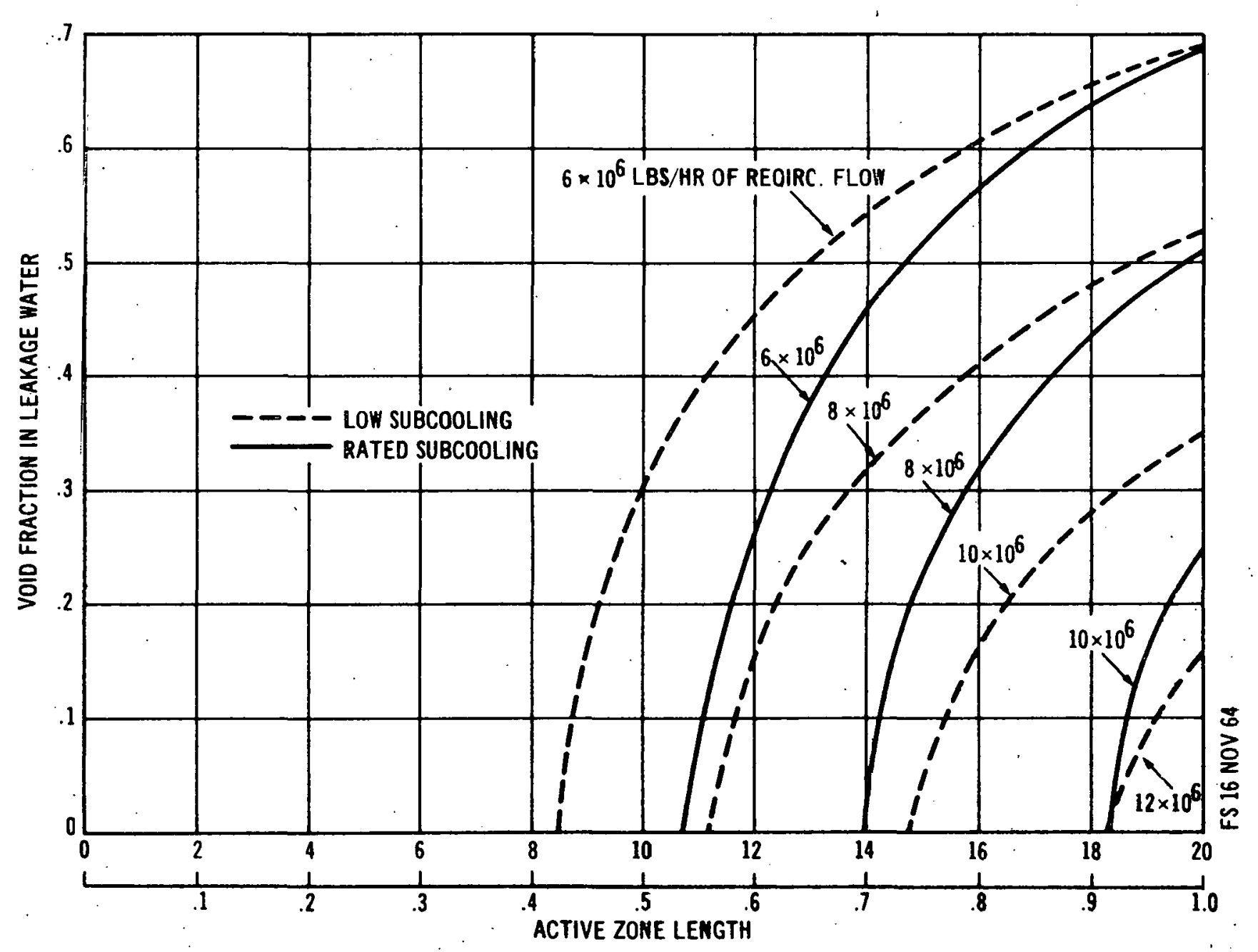

$\underset{\substack{1 \\ \infty}}{\stackrel{1}{\infty}}$ 


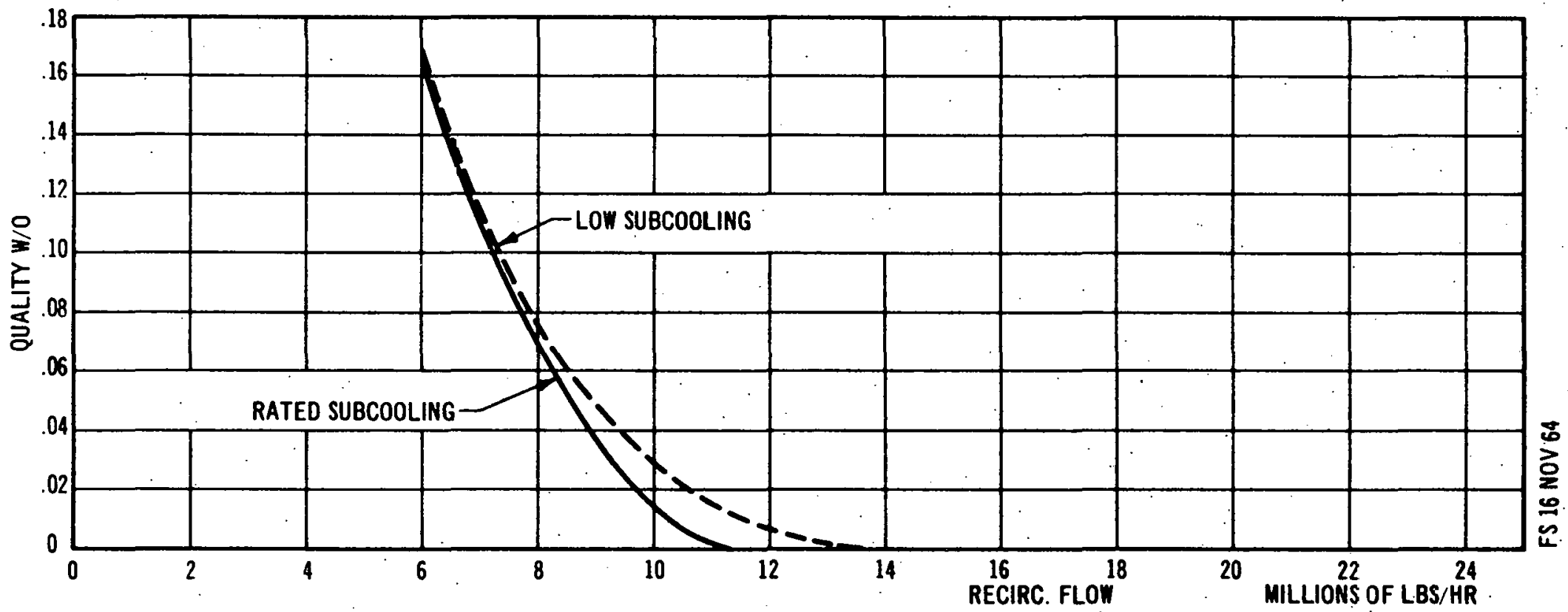


The reactivity effects of voids between fuel channels were evaluated. First, the case of a core region with no control rods is considered. There are two effects: an increase in core leakage resulting from increasing voids between channels and a reduction of bundle infinite reactivity $\left(\mathrm{k}^{\infty}\right)$. Each effect is negative, and the total effect is similar to the void coefficient for the water inside the channels. The variation with voids is gradual--no abrupt reactivity effects are indicated. This should not constitute any problem to reactor operation.

Next, the case of a controlled region (half of the control rods inserted) is considered. In this case the concern is whether there is any abrupt or large effect from change in control rod worth resulting from voids next to the control rods. A series of calculations was conducted as shown in Figure 5-10. This shows the decrease in reactivity $\left(\% \Delta \mathrm{k} \infty / \mathrm{k} \infty\right.$ and $\% \frac{\Delta \mathrm{keff}}{\mathrm{keff}}$ which includes neutron leakage) as a function of voids in the space between channels for a keff constant value of voids inside channels of 40 percent. Several points are to be noted. First, the change is gradual with void content outside the channel. Second, the void coefficient is negative. Third, the total reactivity in voids outside channels is in the same order of magnitude as the reactivity in voids inside channels. Fourth, the effect is always negative for any void fraction inside the channel. Fifth, the void coefficient for voids outside channels is a larger (more negative) number for the case with control rods than without control rods. Of course, at these high void contents the reactivity in voids is large and reactor power may be limited by the core reactivity available. However this is not a safety problem.

In conclusion, the reactivity change resulting from voids in the leakage path outside channels is not a problem to reactor operation or safety. The number of control rods in the top region of the reactor will be very small, if any, under conditions of high void outside channels.

\section{Stoppage of Turbine Flowmeters}

The four instrumented fuel assemblies have turbine flow meters at the inlet and outlet. Since there is some possibility that one or both flowmeters could stop rotating, the probable effects of this accident have been evaluated. Final data on this subject can be supplied only after calibration of the flowmeters with free and locked rotors which is scheduled for July 1965. However, preliminary data and safety criteria are presented here to show that this problem can be overcome and that there is no hazard to the fuel or the reactor system.

The analysis starts with the observation that core pressure drop is not measurably changed by the stoppage of one or all the turbine flowmeters. The fuel assemblies in question will have a flow reduction such that the new flow is sustained by lhe same pressure drop.

The turbine meters for Big Rock Point were similar to the one used for Garigliano. Measured values $^{1}$ of turbine pressure drop at $500 \mathrm{gpm}$ of cold water were:

$$
\begin{array}{ll}
\text { Free Rotor, } & \Delta P=1.00 \mathrm{psi} \\
\text { Locked Rotor, } & \Delta P=2.05 \mathrm{psi}
\end{array}
$$

TE. E. Polomik and C. L. Swan, "High Power Density Development Project - Potter Meter Calibration and Instrumented Fuel Bundle Pressure Drop," GEAP-4327, July 1963. 


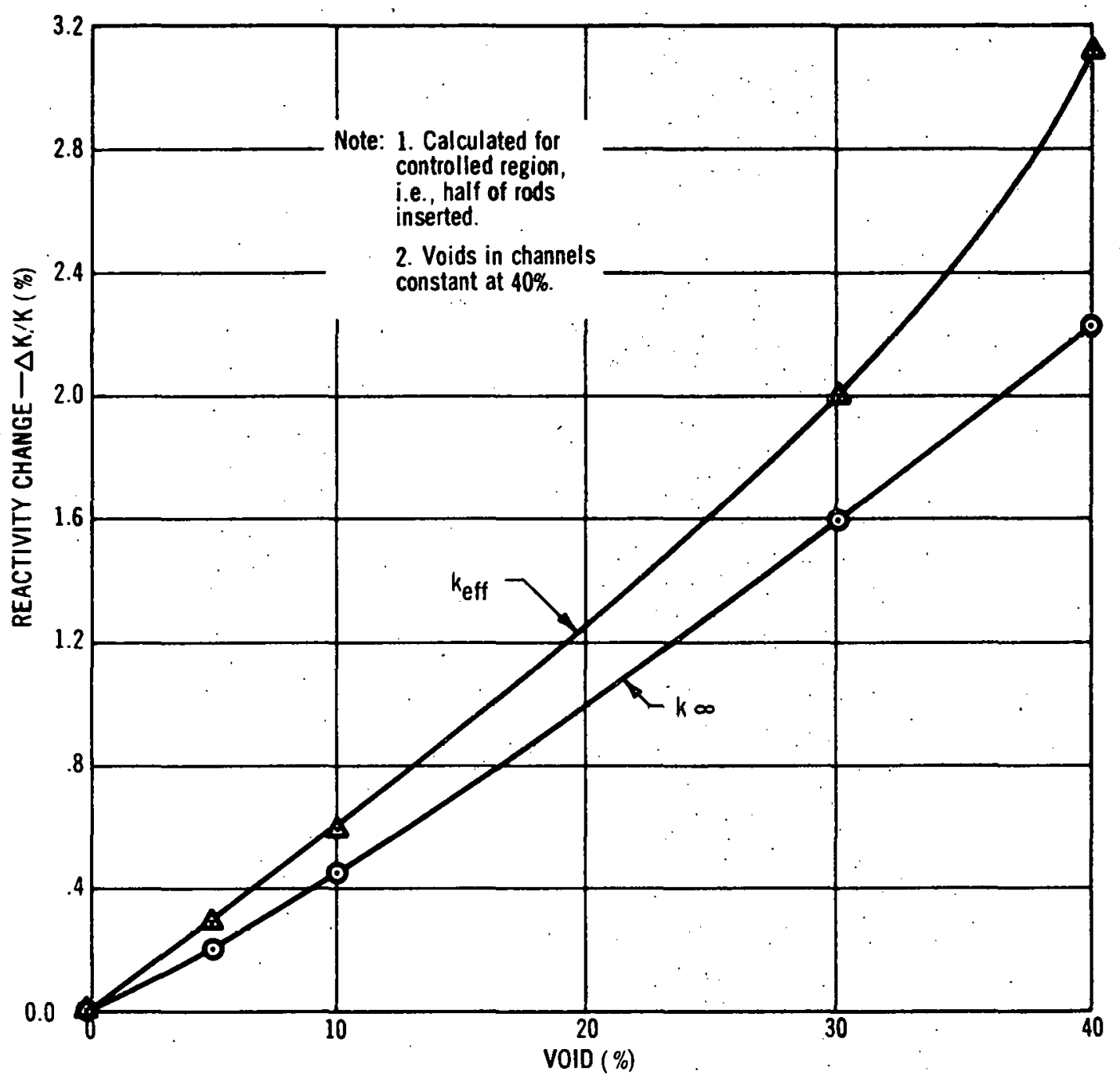

Figure 5-10. Reactivity Change vs Void Between Channels 
On this basis, the flow reduction calculated for Big Rock Point, if the flowmeters stopped rotating, was as follows:

$$
\begin{array}{ll}
\text { Upper Flowmeter Stopped } & -16 \% \text { flow reduction } \\
\text { Lower Flowmeter Stopped } & -8 \% \\
\text { Both Meters Stopped } & -24 \%
\end{array}
$$

The Garigliano turbine flowmeters have been redesigned to reduce the pressure drop. Calculated pressure drop data for Garigliano are as follows for a flow rate of $25 \mathrm{lb} / \mathrm{sec}$ or 90,000 $\mathrm{lb} / \mathrm{hr}$ of hot water (approximately rated reactor channel flow at Garigliano):

\begin{tabular}{clll} 
Meter Size, Inches & & \multicolumn{2}{c}{ Upper Meter } \\
\cline { 4 - 4 } Quality, Wt \% & & Locked & Free \\
\hline 0 & & $0.4 \mathrm{psi}$ & $0.1 \mathrm{psi}$ \\
5 & 0.8 & 0.2 \\
8 & 1.0 & 0.25 \\
10 & 1.2 & 0.3
\end{tabular}

Thus, if the reactor is being operated at rated flow and 8 percent exit quality and both turbines stop, the fuel channel $\Delta \mathrm{P}$ (for the same flow) increases by $0.75 \mathrm{psi}$ for the upper meter and $0.6 \mathrm{psi}$ for the lower meter or 1.35 psi total. The normal core $\Delta P$ is about 5 psi. The expected flow is then $\sqrt{5 /(5+1.35)}$ or 0.887 of the original value. The flow reduction is 11.3 percent.

Four criteria for safety have been established with regard to the flowmeters:

1. The $\Delta \mathrm{P}$ with both free and locked rotor will be measured as part of the flow calibration of the instrumented assemblies.

2. These measured values will be used to calculate the effect on the reactor in the event of turbine stoppage.

3. To prevent these fuel assemblies from.limiting reactor power, the or ifice size will be increased so that the flow will be approximately the same as the adjacent fuel assemblies, even with stopped turbines. The adequacy of the flow rate with stopped turbines will be demonstrated by flow calculations made for the modified or ifice area and a loss factor simulating stopped turbines. As a more conservative calculation it will be assumed that the instrumented assemblies have a power generation equal to the limiting assemblies in the reactor.

4. The reactor will be operated in such a way that all fuel channels, including the instrumented assemblies, have an acceptable critical heat flux ratio at all times--taking into account the possible stopnage of turbines. The calculations made at the time of the reactor tests will use the measured power distributions and measured flow pressure drop for stopped turbines. 
Use of the above criteria will ensure safety of the fuel assemblies and the reactor system in the event that some or all the turbine flowmeters stop, either during the reactor tests, or at any time they are in the reactor.

D. Effect of Fuel Non-Uniformity

At the time of the Garigliano tests the reactor core will contain fuel which is not entirely uniform in reactivity characteristics. This will have some effect on the core power distribution. These differences are as follows:

1. Variation in channel type. The center region of the core now has stainless steel channels on each fuel bundle. Peripheral bundles have Zircaloy channels. At the reactor shutdown (about October 1965) prior to the tests about one-half the stainless steel channels will be replaced by Zircaloy in a checkerboard pattern. Fuel will generally be returned to the same core positions.

2. Four new instrumented assemblies having Zircaloy channels will be installed, replacing four exposed bundles.

3. Variation in fuel bundle exposure.

The estimated effect of these differences is approximately as follows for a uniform radial flux distribution.

$\begin{array}{lc}\cdot & \begin{array}{c}\text { Approximate } \\ \text { Deviation } \\ \text { from Average } \\ \text { Bundle Power }\end{array} \\ \text { Stainless Steel Channel Fuel with Core Average Exposure } & -5.5 \% \\ \text { Zircaloy Channel, Fuel with Core Average Exposure } & +3.8 \% \\ \text { Zircaloy Channel, Fresh Fuel } & +10.9 \%\end{array}$

As part of the detailed calculation of core power distribution and control rod pattern, these effects will be taken into account. The control rod pattern can be altered as required to flatten the power distribution within reasonable limits, and to decrease the power of individual fuel bundles if they are limiting core operation.

\section{E. Critical Heat Flux Calculations}

Pre-test calculations are being made to show that the proposed test conditions are safe. The specific justification of the reactor safety during the tests is not based on these calculations which are made now. Rather the reactor safety at each test condition is to be justified at the time of the tests by calculations using observed data on flows, flux distributions and other operating conditions. These calculations at the time of the tests will be made either by hand or by use of the on-line computer. 


\section{Preliminary Results}

The present SENN core can be satisfactorily operated at full power down to $6 \times 10^{6} \mathrm{lb} / \mathrm{h}$ recirculation flow either with high inlet subcooling or with rated inlet subcooling. At very low inlet subcooling the core can be operated at full power down to $8 \times 10^{6} \mathrm{lb} / \mathrm{h}$ recirculation flows. These results have been obtained assuming that a Minimum Critical Heat Flux Ratio (MCHFR) of 1.5 and an Overpower allowance (OP) of 1.20 will be considered acceptable. The results are summarized in Figure 5-11.

\section{Discussion}

Before starting the thermal-hydraulics calculations, an approximation has been made on the expected power peaking factors and the axial flux shapes:

a. Radial peaking factors

It is assumed that the tests will be conducted immediately after the first SENN core rechanneling. Half of the present stainless steel channels will be replaced with Zircaloy channels in a spread configuration. Thus the radial peaking factors at that time will probably be slightly greater than the ones determined during initial operation after SENN start-up.

A radial peaking factor of 1.30 has been selected, which is 5 percent more than maximum peaking factor encountered at SENN.

b. Axial peaking factor

An axial peaking factor of 1.60 has been selected for the hottest and the peak element. At SENN the peaking factor, measured with irradiated wires, was about 11.5 percent less. These values have been increased in the calculations in order to have a good margin if the peaking factor would change as the void content increases, although during the Dresden high void tests it has been demonstrated that these factors tend to decrease. As a matter of conservatism the axial flux shapes follow approximately the distribution found at SENN during initial operation, although it is certain that at high void content the flux shape will be depressed from the core top toward the bottom.

c. Local peaking factors

Calculations previously made have shown that the "corner rod" peaking factors tend to decrease at void content greater than 40 percent. The hottest and peak channel vold fraction will certainly be greater than 40 percent at low recirculation flows; however, a local peaking factor corresponding to 40 percent void has been selected for the calculation.

Another item of interest is the leakage flow outside the channels. For the purpose of having preliminary results in order to start test planning, a constant 10 percent of recirculation flow 


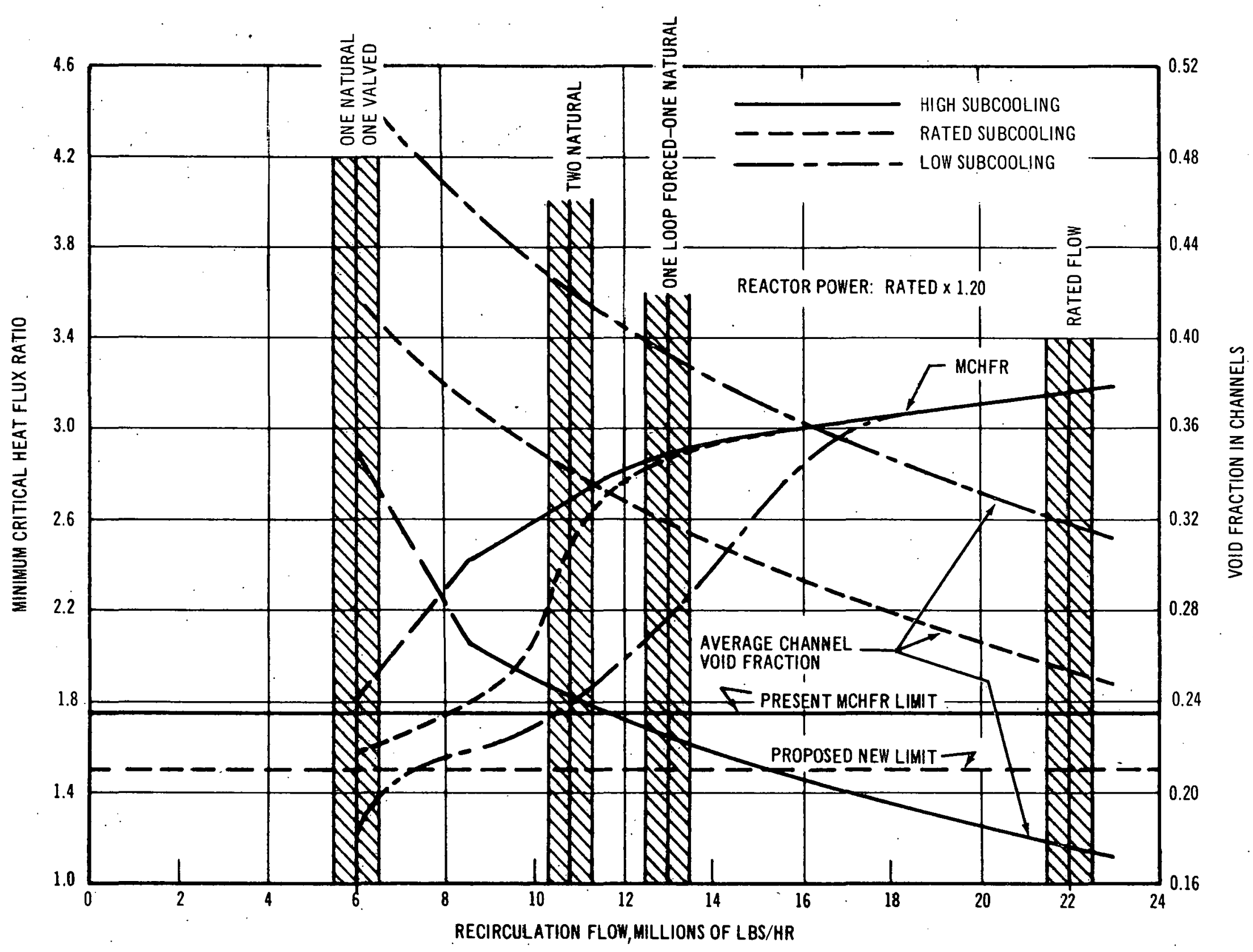


has been selected as leakage flow. This value is conservative from the MCHFR standpoint, as the leakage flow will be certainly less at low recirculation flows. A study has been made to demonstrate that each control rod is sufficiently cooled with high voids between channels. The maximum temperature at the center of the $\mathrm{B}_{4} \mathrm{C}$ tube is $973^{\circ} \mathrm{F}$, assuming that the control rods operate in an atmosphere of slightly superheated steam.

With all of these assumptions, COFFI runs have been made at recirculation flows from $23 \times 10^{6}$ down to $6 \times 10^{6} \mathrm{lb} / \mathrm{h}$, in the following conditions:

a. High inlet subcooling

(1) rated core power $\times 1.20$

(2) rated secondary steam flow*

(3) cold feedwater

b. Rated inlet subcooling

(1) rated core power $\times 1.20$

(2) rated secondary steam flow **

(3) rated feedwater temperature**

c. Low inlet subcooling

(1) rated core power $\times 1.20$

(2) no secondary steam flow

(3) rated feedwater temperature

Results of the first two cases are shown in Figure 5-11 and it can be seen that the reactor can be satisfactorily operated at full power down to $6 \times 10^{6} \mathrm{lb} / \mathrm{h}$ recirculation flow, with a MCHFR of about 1.8 in the first case and 1.56 in the second case. The third case result shows that the minimum allowable flow at full power is of $8 \times 10^{6} \mathrm{lb} / \mathrm{h}$ with a MCHFR of 1.56 . In the first case the maximum for average core void fraction (inside fuel channels) is $\sim 35$ percent; in the second case, 42 percent; and in the third case, 47 percent.

* When only one loop is in operation the secondary steam flow can not be rated. For this reason the curve shown on Figure 5-11 is not continued at very low recirculation flows.

** With one recirculation loop in operation, feedwater temperature will be adjusted in order to have the same subcooling as with full secondary steam flow. 
The low recirculation flows will be attained by recirculation pump trips. At full power two pumps running will give a recirculation flow of $22 \times 10^{6} \mathrm{lb} / \mathrm{h}$; one loop in natural circulation and the other in forced will result in a flow of approximately $13 \times 10^{6} \mathrm{lb} / \mathrm{h}$; one loop forced and the other valved out will result in a $12.5 \times 10^{6} \mathrm{lb} / \mathrm{h}$ recirculation flow; both loops in natural circulation will give a $10.8 \times 10^{6} \mathrm{lb} / \mathrm{h}$ recirculation flow. Finally one loop natural and the other valved out will give a flow of approximately $6 \times 10^{6} \mathrm{lb} / \mathrm{h}$. Before raising the power to rated, this value of flow will be carefully checked, and if it is less, the maximum power level will be correspondingly reduced. Also, the flux distribution will be measured to be sure that it is as favorable as the values assumed in this analysis.

\section{Revised Results}

A tabulation of the most recent and accurate values of MCHFR at several reactor conditions is shown in Table 5-3 and Figure 5-12. Recirculation flow rates have been recalculated, as shown, based on the best information available. The resulting higher flow rates tend to increase the MCHFR values above those obtained previously. 
TABLE 5-3.

CALCULATED REACTOR OPERATING CONDITIONS FOR

RATED POWER OF $506 \mathrm{MWt}$

\begin{tabular}{|c|c|c|c|c|c|c|}
\hline \multirow{2}{*}{$\begin{array}{l}\text { Primary } \\
\text { Steam } \\
\text { Flow }\end{array}$} & \multirow{2}{*}{$\begin{array}{l}\text { Secondary } \\
\text { Steam } \\
\text { Flow }\end{array}$} & \multirow[b]{2}{*}{ Subcooling } & \multirow[b]{2}{*}{$\begin{array}{l}\text { Recirculation } \\
\text { Flow }\end{array}$} & \multicolumn{2}{|c|}{ Minimum CHFR at } & \multirow[b]{2}{*}{ Notes } \\
\hline & & & & $\begin{array}{l}\text { Operating } \\
\text { Power }\end{array}$ & $\begin{array}{l}1.20 \times \text { Oper }- \\
\text { ating Power }\end{array}$ & \\
\hline rated & rated & Normal & rated & & 3.10 & $\begin{array}{c}2 \text { loops in forced circulation } \\
\text { Hot feedwater }\end{array}$ \\
\hline rated & rated & Normal & $49 \%$ of rated & - & 2.20 & $\begin{array}{l}2 \text { loops in natural circulation } \\
\text { Hot feedwater }\end{array}$ \\
\hline $132 \%$ & None & Low & $49 \%$ of rated & - & 1.80 & $\begin{array}{l}2 \text { loops in natural circulation } \\
\text { Hot feedwater }\end{array}$ \\
\hline $80 \%$ & $75 \%$ & High*. & $49 \%$ of rated & - & 2.60 & $\begin{array}{l}2 \text { loops in natural circulation } \\
\text { No feedwater heaters in service }\end{array}$ \\
\hline . $114 \%$ & $58 \%$ & Normal & $32.8 \%$ of rated & 2.10 & 1.61 & $\begin{array}{c}1 \text { loop in natural circulation } \\
\text { Hot feedwater }\end{array}$ \\
\hline $132 \%$ & None & Low & $32.8 \%$ of rated & 1.93 & 1.50 & $\begin{array}{c}1 \text { loop in natural circulation } \\
\text { Hot feedwater }\end{array}$ \\
\hline rated & $50 \%$ & High & $32.8 \%$ of rated & 2.44 & 1.72 & $\begin{array}{l}1 \text { loop in natural circulation } \\
\text { Only } 2 \text { feedwater heaters in } \\
\text { service }\end{array}$ \\
\hline $85 \%$ & $43 \%$ & High* & $32.8 \%$ of rated & 2.70 & 1.99 & $\begin{array}{l}1 \text { loop in natural circulation } \\
\text { No feedwater heaters in service }\end{array}$ \\
\hline
\end{tabular}




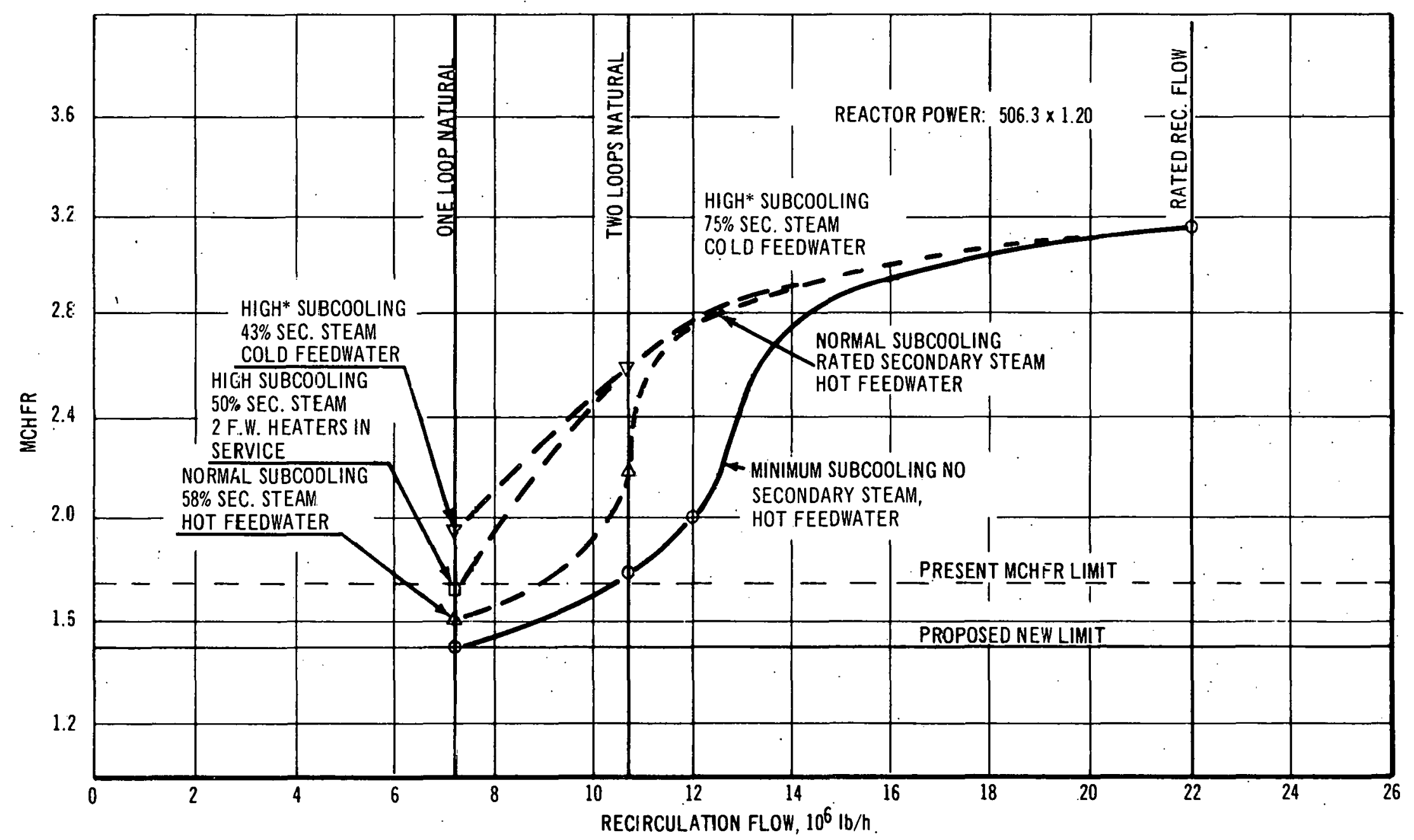




\section{APPENDIX A}

\section{ACCURACY OF FLUX WIRE DATA}

The accuracy of data obtained from flux wire irradiations is dependent on several factors as discussed below.

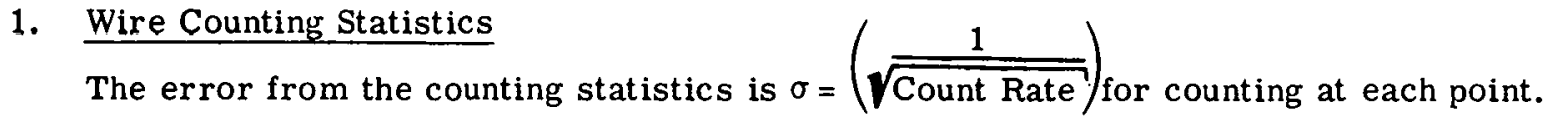
Thus for $\sigma=1 \%$ the count rate should be over 10,000 counts. In the case of a continuous scan mechanism as now used at Garigliano the combined effect of counting statistics and hand smoothing of the recorded trace should - and can - be arranged to give $\sigma=1 \%$ for counting statistics. Important variables are total counts measured for the entire wire length (i.e., wire drive speed) and the time constants for the electrical filter on the output of the count rate meter.

The reproducibility of the Garigliano wire counting equipment (counting wire at $2-1 / 2$ inch increments) can be evaluated by examination of data obtained by four counts of the same wire at various decay times*. The data for 5 wire locations $(60,100,140,180,200$ units) were normalized, percent deviation from the average of the 4 counts at each location was calculated and the standard deviation calculated. This standard deviation for 20 data points (4 counts at 5 locations) was $2.98 \%$. The counting statistics error for the average measured count rate (2019) is $\sigma=2.23 \%$. The difference (square root of difference of squared values) is $\sigma=1.98 \%$ for reproducibility of counting geometry, and instrument drift.

The corresponding values for counting reproducibility under laboratory conditions are $\sigma=1 \%$ for total of counting statistics, counting geometry and instrument drift. **

\section{Wire Uniformity}

The copper-titanium wires have a nominal copper content of $1 \% \pm 0.1 \%$. The more important specification is that the copper content within a given lot shall be $\pm 1 \%$ of the lot average (e.g., between 0.99 and $1.01 \% \mathrm{Cu}$ for $2 \sigma$ ). Thus, specified wire $\mathrm{Cu}$ uniformity is $\sigma=0.5 \%$. The specification on diameter variation (within one lot) is 0.031 nominal \pm 0.00015 inch or $3 \sigma=0.48 \%$ and $\sigma=0.14 \%$. The vendor is required to furnish certification of chemical analysis to show compliance with this specification.

* November $26-27,1963$

**W. R. Morgan, personal communication 
However, analysis of flux wires from Garigliano shows greater variation than specified:

a. Analysis of pieces cut from the ends of 42 flux wires.*

The 42 wire samples ("clips") were irradiated on a 3 inch diameter graphite log located in the center of the NTR. The wires were spaced around the log and the $\log$ was rotated during the entire irradiation. This assured that every wire received identical neutron exposures. Experiments of this type, involving up to fifty samples, have resulted in less than $1 \%$ standard deviation from the mean when counted as these were.

The results are tabulated below in saturated activity per gram of wire for both manganese and copper.

\section{SATURATED ACTIVITY IN COUNTS/GRAM}

\begin{tabular}{|c|c|c|c|c|c|c|c|}
\hline Sample Identity & $\mathrm{Mn}$ & $\mathrm{Cu}$ & \multicolumn{3}{|c|}{$\underline{\text { Sample Identity }}$} & $\mathrm{Mn}$ & $\mathrm{Cu}$ \\
\hline 1 & 1.72 & 7.83 & \multicolumn{3}{|c|}{$2 \mathrm{X}$} & 1.46 & 8.27 \\
\hline 2 & 1.54 & 8.29 & \multicolumn{3}{|c|}{$3 x$} & 1.47 & 8.42 \\
\hline 3 & 1.53 & 7.80 & \multicolumn{3}{|c|}{$4 X$} & 1.51 & 8.58 \\
\hline 4 & 1.62 & 7.54 & \multicolumn{3}{|c|}{$5 \mathrm{X}$} & 1.56 & 8.62 \\
\hline 5 & 1.63 & 7.85 & \multicolumn{3}{|c|}{$6 \mathrm{X}$} & 1.59 & 8.68 \\
\hline 6 & 1.64 & 8.14 & \multicolumn{3}{|c|}{$7 X$} & 1.58 & 8.89 \\
\hline 7 & 1.64 & 7,64 & \multicolumn{3}{|c|}{$8 \mathrm{X}$} & 1.57 & 8.54 \\
\hline 8 & 1.55 & 8.08 & \multicolumn{3}{|c|}{$9 \mathrm{X}$} & 1.64 & 7.74 \\
\hline 9 & 1.62 & 7.71 & \multicolumn{3}{|c|}{$10 \mathrm{X}$} & 1.52 & 8.46 \\
\hline 10 & 1.54 & 8.60 & \multicolumn{3}{|c|}{$11 \mathrm{X}$} & 1.53 & 8.26 \\
\hline 11 & 1.58 & 7.88 & \multicolumn{3}{|c|}{$12 \mathrm{X}$} & 1.58 & 8.58 \\
\hline 12 & 1.57 & 8.58 & \multicolumn{3}{|c|}{$13 x$} & 1.53 & 8.28 \\
\hline 13 & 1.62 & 7.64 & \multicolumn{3}{|c|}{$14 X$} & 1.66 & 7.76 \\
\hline 14 & 1.54 & 7.86 & \multicolumn{3}{|c|}{$15 \mathrm{X}$} & 1.59 & 7.94 \\
\hline 15 & 1.59 & 7.63 & \multicolumn{3}{|c|}{$16 \mathrm{X}$} & 1.56 & 8.52 \\
\hline 16 & 1.60 & 8.47 & \multicolumn{3}{|c|}{$17 \mathrm{X}$} & 1.60 & 7.56 \\
\hline 17 & 1.59 & 7.77 & \multicolumn{3}{|c|}{$18 X$} & 1.53 & 8.14 \\
\hline 18 & 1.68 & 7.64 & \multicolumn{3}{|c|}{$19 x$} & 1.50 & 7.82 \\
\hline 19 & 1.65 & 7.54 & \multicolumn{3}{|c|}{$20 \mathrm{X}$} & 1.60 & 8.50 \\
\hline 20 & 1.56 & 7.77 & \multicolumn{3}{|c|}{$21 x$} & 1.67 & 7.76 \\
\hline $1 x$ & 1.47 & 8.04 & \multicolumn{3}{|c|}{$22 x$} & 1.54 & 8.57 \\
\hline & & & \multicolumn{3}{|c|}{$\mathrm{Mn} \quad \mathrm{Cu}$} & & \\
\hline \multicolumn{2}{|c|}{ Average Counts/gram } & & \multicolumn{2}{|l|}{1.58} & \multicolumn{2}{|l|}{8.10} & \\
\hline \multicolumn{2}{|c|}{ Standard Deviation, $\sigma$} & & \multicolumn{2}{|l|}{$3.72 \%$} & $4.86 \%$ & & \\
\hline
\end{tabular}

*W. R. Morgan, personal communication, August 1, 1963 
The standard deviation for copper in the 20 wire pieces corresponding to the wires in use at Garigliano is 3.94 percent.

b. Reproducibility of data from irradiation of 20 wires in same reactor location.

Twenty flux wires were irradiated (November 1963) in turn in the same reactor location - with the same reactor control rod configuration and "same" reactor power. Wire decay times before counting were equal also. The results of this experiment provide valuable data on both wire uniformity and over-all counting reproducibility.

First, the average wire count rates were compared:

Average Count

2816

Standard Deviation, $\sigma$

$3.75 \%$

The correlation between the average wire count rates and the copper content of the pieces cut from the end of the same wires was examined next. To do this, the error on the whole-wire uniformity measurement had to be estimated first, taking into account the following individual errors:

- change in reactor power within the error band of the plant instrumentation (duration of test: $10 \mathrm{~h} 30 \mathrm{~min}$ )

$\sigma_{r}=1 \%$

- error due to variation of ir radiation time $(30 \mathrm{sec}$ of $25 \mathrm{~min}$ $=2 \%$ with $2 \sigma$ confidence)

$\sigma_{\mathbf{r}}=1 \%$

- error due to variation of decay time (5 min of $13 \mathrm{~h} 35 \mathrm{~min}$ $=0.6 \%$, with $2 \sigma$ confidence)

$\sigma_{r}=0.3 \%$

- error due to counting statistics (average total wire count: 118,272 counts)

$$
\sigma_{r}=0.3 \%
$$

- error due to changes in counting geometry (bends in the wire can cause considerable local changes in counting geometry; the over-all effect on the total wire count however is small)

- instrument drift during duration of test (10 h $30 \mathrm{~min})$

$$
\sigma_{\mathbf{r}}=0.5 \%
$$$$
\sigma_{r}=1 \%
$$

- allowance for varlous minur effects (medsureinent of wire is not continuous but made in 42 steps; steps are not equally long; variation of the $2 \mathrm{sec}$ step counting time; variation of the total wire counting time, etc.)

$$
\sigma_{r}=1 \%
$$

Total combined standard deviation of the uniformity measurement $\sigma_{r}=2.1 \%$ 
The standard deviation of the total wire uniformity separated from the measuring error would thus be:

$$
\sqrt{3.75^{2}-2.1^{2}}=3.11 \%
$$

Separating in a similar way the assumed measuring error of $\sigma_{r}=1 \%$ from the standard deviation of the wire piece uniformity determination, yields

$$
\sqrt{3.94^{2}-1^{2}}=3.81 \%
$$

for the local copper uniformity alone.

As expected the average wire uniformity (3.11\%) appears to be better than the local uniformity, as determined from the wire clip examination (3.81\%). However, the high standard deviation for the wire average uniformity indicates that there are not only local variations in copper concentration but also variation extending over considerable wire length.

In order to determine to what degree the wire piece cut from the end is representative for the copper concentration of the whole wire, the standard deviation of the clip uniformity factors versus the corresponding whole wire uniformity factors was calculated. The result of $4.22 \%$ includes of course the errors on the measuring techniques, estimated with $\sigma_{r}=1 \%$ for the clips and $\sigma_{r}=2.07 \%$ for the whole wires. Separating the experimental errors from this standard deviation gives:

$$
\sqrt{4.22^{2}-1^{2}-2.1^{2}}=3.52 \%
$$

for the comparison of clip to wire uniformity. If the clips were fully representative for the corresponding wires, this standard deviation should be close to zero. If the clips and the corresponding wires were completely uncorrelated, the standard deviation would be about

$$
\sqrt{3.11^{2}+3.81^{2}}=4.92 \%
$$

considering the standard deviation of $3.52 \%$ for clip versus wire uniformity in the possible range of 0 to 4.92 shows that, although there is a certain degree of correlation, the wire clips are not representative for their corresponding wires.

Next, the count rates of the 20 wires at location* 180 (near C in-core chamber) were compared:

Average Count

Counting Statistics Error for This Count, $\sigma$ Standard Deviation, $\sigma$
3930 .

1.60

3.93

*"Location" is distance $(1 / 2$-inch increments) from approximate bottom of core. 
If the wire count rates at location 180 are normalized to the average wire count rate before comparison to each other, the results are improved as the variations in wire average copper concentration and in reactor power are eliminated in this way:

Average Count 3930

Counting Statistics Error for This Count, $\sigma$ $1.60 \%$ Standard Deviation, $\sigma$ $3.02 \%$

In order to obtain an over-all representative value of the Garigliano wire reproducability, the same 20 wires were examined at 15 locations. The results, based on values nor malized to the average count of the entire wire are as shown in Figure A-1. As can be seen from this figure, the error increases at the bottom and the top of the core as a consequence of the poorer counting statistics and the higher axial flux gradient. The error is also higher in the vicinity of local flux gradients, caused by spacers and end connectors.

The standard deviation of 40 data points (at location 100 and 120) surrounding chamber $\mathrm{B}$, is 4.31 percent. The standard deviation of 80 data points (at location $150,160,175$, and 180 ) surrounding chamber $C$ is 3.37 percent. The standard deviation of 80 data points (at location 210, 220, 225, and 230) surrounding chamber $D$ is 4.73 percent.

The over-all standard deviation for these 200 data points is 4.15 percent. This value is taken as the over-all error in the present Garigliano wire count data.

It is noted that this value includes errors from:

(1) Wire non-uniformity effects

(2) Variation in counting geumetry

(3) Counting statistics

(4) Effect of wire impurities, such as manganese

(5) Drift of counting equipment

(6) Decay - by use of "same" decay time on all wires

(7) Error on integration and normalization

This value of $\sigma=4.15 \%$ is used as the over-all error in ratio of local/average data from flux wires in the vicinity of in-core chambers. 


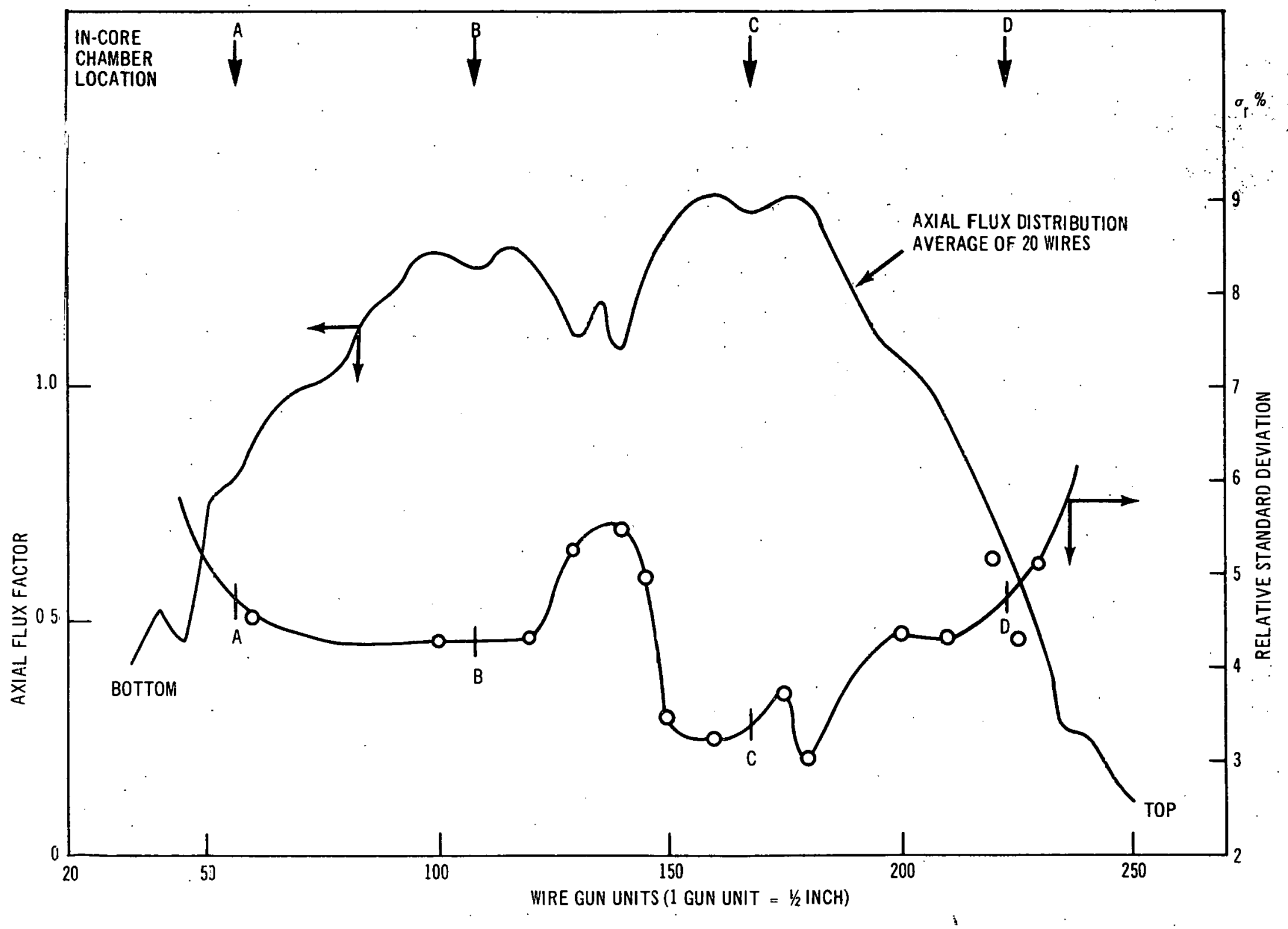




\section{c. Comparison of Wire Irradiation Data with First Fuel Gamma Probe Data} by W. R. Clancey

The preceding analysis does not include any neutron spectrum effects. These are examined below and found to be negligible.

One of the uncertainties associated with the use of wire activation data to obtain the axial power distribution is that the wire gamma activity that is measured is not an exact representation of the fission power distribution, but only of the neutron flux distribution. And, further, the neutron spectral sensitivity of the copper in the wires is not exactly the same as that of the uranium and plutonium in the fuel. That is, the absorption cross section of $\mathrm{Cu}-63$, as a function of neutron energy, does not match exactly that of $\mathrm{U}-235$ and $\mathrm{Pu}-239$.

However, at the time of the original gamma scan performed at SENN in December, 1963 , there was an opportunity to compare the two sources of power distribution measurements. Three days before the completion of the 8 -day power run, a complete set of wire irradiations were made with the same control rod pattern that existed throughout this power run. Comparisons have been made for three of the wires. Wire 108 is the only case where there were gamma scan data for the four fuel assemblies surrounding the wire tube.

For wire 112, one of the two gamma scans needed for comparison was obtained from a fuel assembly that was immediately adjacent to the wire, but the other one was from an assembly that was symmetric to the required position. For 107, all gamma scan data were from fuel assemblies that were "adjacent" only by reason of symmetry. The comparisons of 107 and 112 are meaningful because these were the positions that were in the region of the highest fuel assembly power, and data from these would be used in computing the MCHFR for the core.

Figures A-2, A-3 and A-4 show graphically the comparative shapes of the wire data and the gamma scan data. If either set of curves were used in a MCHFR type of calculation, there would be essentially no change in the result. However, the wire curves are used in the calibration of the in-core chambers by reading off the axial factors at the chamber locations. So it is meaningful to see what effect the use of the gamma scan data, rather than the wire data, would have on the $f_{i j}$ factors. Since the wire data was always smoothed (by eye) before reading the $f_{i j}$ values, this was done and Table A-1 shows the comparisons. The standard deviation of the differences is 3.46 percent. This value is lower than the 4.15 percent used in this report for wire data alone. 


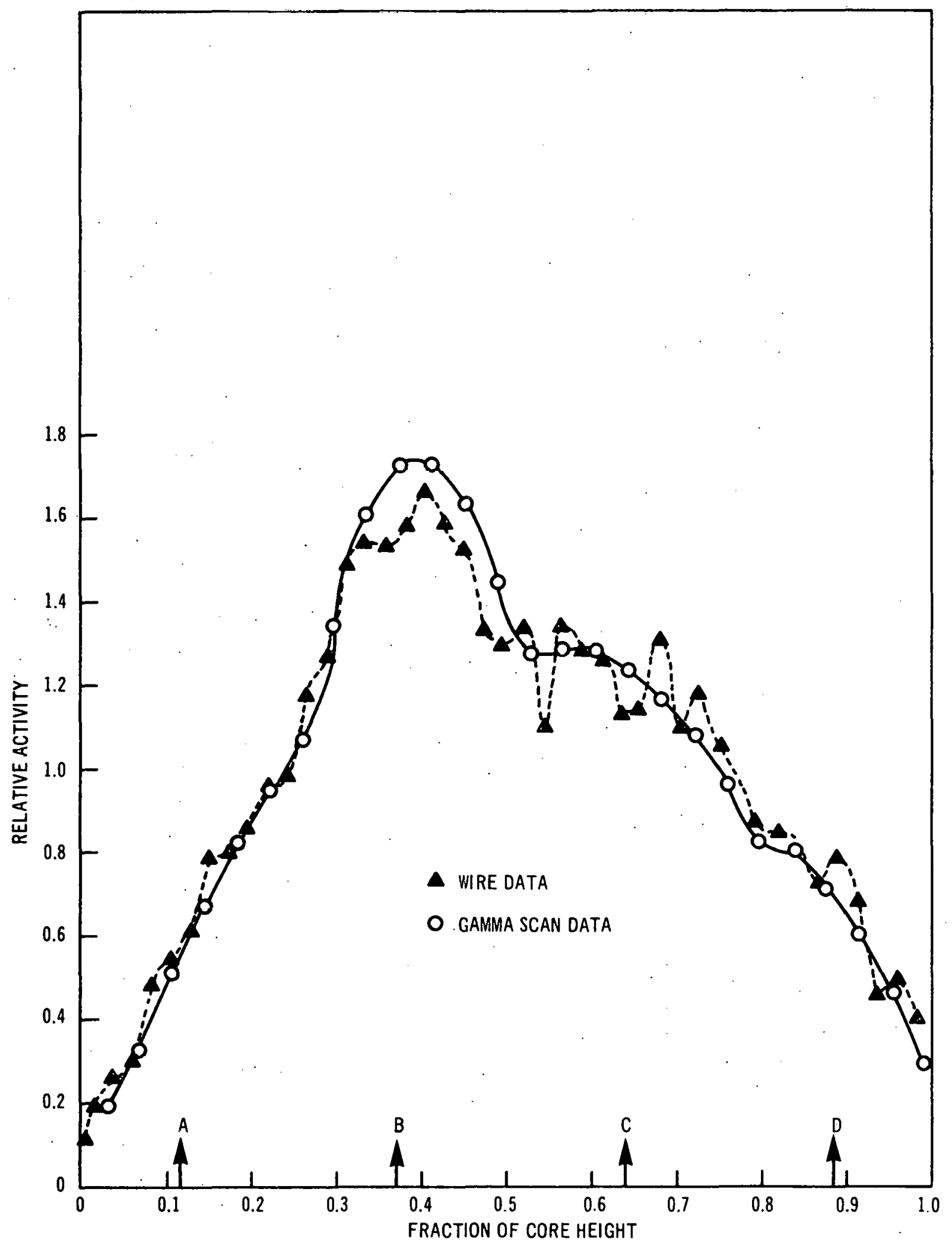

Figure A-2. Comparison of Wire 108 with Gamma Scan Data 


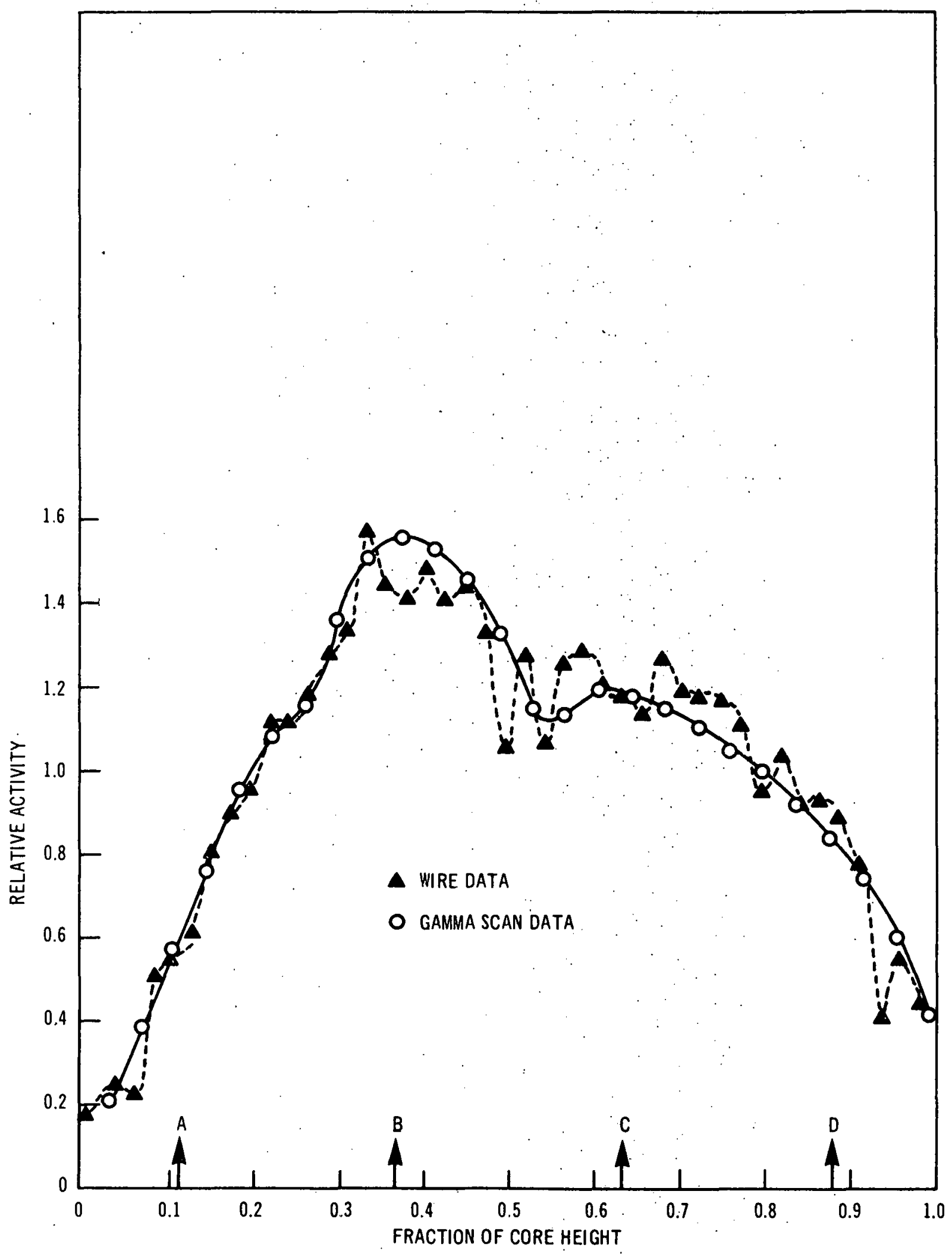

Figure A-3. Comparison of Wire 107 with Gamma Scan Data 


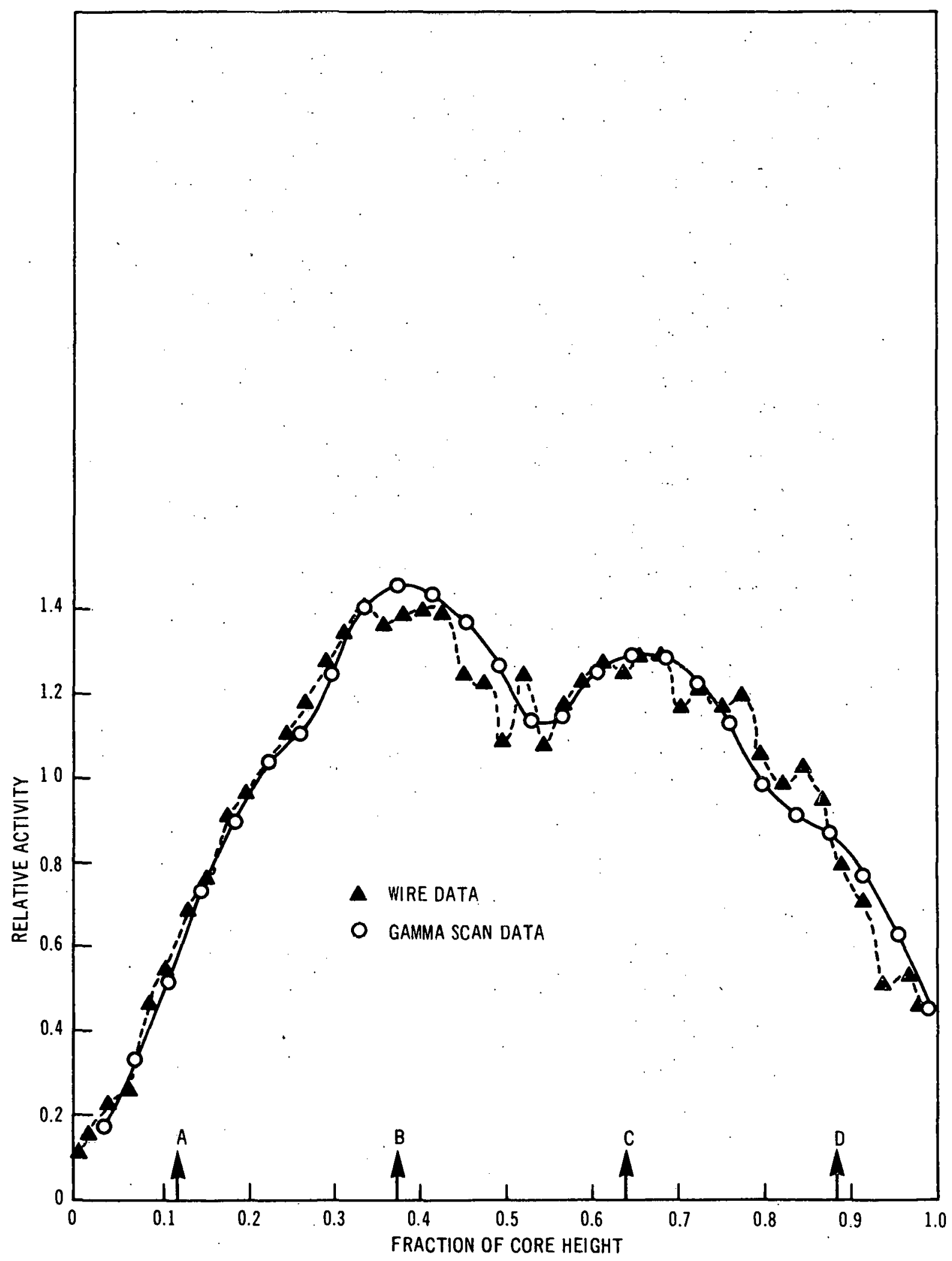

Figure A-4. Comparison of Wire 112 with Gamma Scan Data 
TABLE A-1

\section{COMPARISON OF $F_{i j}$ FROM WIRES AND GAMMA SCAN DATA \\ (Wire Data Smoothed)}

\begin{tabular}{|c|c|c|c|c|c|c|c|c|c|}
\hline Chamber & $\begin{array}{c}\text { Wire } \\
108\end{array}$ & $\begin{array}{c}\text { Gamma } \\
\text { Scan }\end{array}$ & $\begin{array}{c}\text { Percent } \\
\text { Difference }\end{array}$ & $\begin{array}{c}\text { Wire } \\
107\end{array}$ & $\begin{array}{c}\text { Gamma } \\
\text { Scan }\end{array}$ & $\begin{array}{c}\text { Percent } \\
\text { Difference }\end{array}$ & $\begin{array}{c}\text { Wire } \\
112\end{array}$ & $\begin{array}{c}\text { Gamma } \\
\text { Scan }\end{array}$ & $\begin{array}{c}\text { Percent } \\
\text { Difference }\end{array}$ \\
\hline $\mathrm{A}$ & 0.56 & 0.54 & +3.70 & 0.60 & 0.60 & 0 & 0.61 & 0.57. & +7.02 \\
$\mathrm{~B}$ & 1.63 & 1.71 & -4.68 & 1.50 & 1.55 & -3.23 & 1.42 & 1.45 & -2.07 \\
$\mathrm{C}$ & 1.24 & 1.24 & 0 & 1.22 & 1.19 & +2.52 & 1.28 & 1.28 & 0 \\
$\mathrm{D}$ & 0.71 & 0.68 & +2.90 & 0.86 & 0.82 & +4.88 & 0.83 & 0.85 & -2.35 \\
\hline
\end{tabular}

It is interesting to note that in all three cases, the wire data gives lower values at the $B$ level chamber. And, in general, the wire data tends to give equal or higher values at the $C$ and $D$.level chambers. Qualitatively, this should be conservative, since the MCHFR occurs higher in the core where the quality is higher and the calibration of the in-core chambers, based on wire data, would tend to predict. slightly higher heat fluxes in the top half of the core.

One further point that should be made is that in this comparison, the gamma activity of the fuel assembly was due to fission products generated by U-235 and U-238 fissions. For long exposure fuel where a large fraction of the fissions would be due to $\mathrm{Pu}-239$, the comparison between wire activity and fission product activity may not be quite so good because of the differences in the neutron energy dependence of the Pu-239 fission cross section compared to $\mathrm{U}-235$.

The fuel gamma scan data obtained during the October 1965 shutdown will be compared with flux wire data to obtain a further evaluation of errors in wire irradiation data. 


\section{APPENDIX B}

\section{LIST OF DIFFERENCES BETWEEN}

THIS REPORT AND PREVIOUS REPORT

This report is generally the same as the previous report, "Safeguards Report - Garigliano Development Program, " compiled by C. L. Howard, March 15, 1965. For the benefit of readers who are familiar with that report, the changes are summarized below.

1. Material from the "Preliminary Safeguards Report - Garigliano Development Program" by F. Santasilia and C. L. Howard, November 30, 1964, has been included. This material appears as follows:
Section I
A. Introduction
C. Background of Development Program
Section $\Pi$

\section{A-3 Equipment Design Calculations \\ A-4 Control Rod Worth}
Section III 'I'est Kegion Map
Section IV-K Discussion of Technical Specification Changes
Section V-E Critical Heat Flux Calculations

2. This report includes changes in Rod Oscillator System since preparation of the previous report:

a. Change the low pressure sink for bleed-off from the makeup water system from reactor pressure of 1000 psi to another location having a pressure of 400 psi or less. This permits operation with makeup water pressure of less than 1000 psi. This is required for control of position of the piston in the drive cylinder.

b. The equipment used to prevent over-pressure of the control rod drive will be moved as close to the drive as possible. The following equipment will be connected to the system at the point where the oscillator system is connected to the existing "insert" and "withdraw" lines for the control rod drive:

(1) Pressure relief valve (one in each linc)

(2) Water pressure limit switches

(3) Pressure transmitter 
c. A bleed-off valve is added to the large-area side of the drive cylinder. This valve is used to move the piston of the drive cylinder to the correct starting position while the isolation valve is closed.

d. Increase permitted rod oscillator frequency from 10 to approximately 15 cycles/ second. This reflects the favorable amplitude and frequency performance obtained in the preliminary equipment tests in San Jose.

These changes are minor and do not alter the basic system.

3. The error analysis in Section IV has been extensively revised. The overall results are not greatly different, but the presentation and some of the input data has been modified:

a. ASME tolerances for feedwater flow nozzles are used in the revised calculations (pages 4-11/12). The influence on the reactor power error is negligible.

b. The error on the recirculation pump characteristic has been included in the error analysis (pages 4-15/16). The results presented at the Rome meeting of April 1 and 2 were obtained by including, by mistake, the pump characteristic error for two loop forced circulation into the error analysis for one loop natural circulation. The correct results now shown are situated between the original ones and those given at the Rome meeting.

c. The experimental error on a dead-weight gage measurement (page 4-15) has been increased from $0.5 \mathrm{psi}$ to $0.7 \mathrm{psi}$ in order to be consistent with the corresponding value shown in the start-up test reports. In a careful measurement however the experimental error can easily be maintained at 0.5 psi or below.

d. On page 4-18 the clean-up flow (40 MT/h) has been added to the recirculation flow $(3260 \mathrm{MT} / \mathrm{h})$ before calculation of the core leakage flow (102 MT/h).

e. Instead of representing the peak channel flow as a sum of an average channel flow $\bar{W}_{c h}$ and a correction term $\Delta W_{\text {ch }}$ (with a $2 \sigma$ error of 30 percent assumed on $\left.\Delta W_{c h}\right)$, the peak channel flow is now defined as a product of a bundle flow factor $F_{b}$ and the average channel flow $\bar{W}_{c h}$ (page 4-29). The error on the flow factor has been estimated by separate computer calculations (see Section IV-C). This change has no influence on the results. Also, dependence of $F_{b}$ on $P_{b}$ has been taken into account.

f. In cases where the individual errors were partially correlated, the exact method of combination has been used. That is, the independent errors are added statistically and the dependent errors are added linearly. See Section IV-H, Table 4-2. 
g. The error in axial power factor has been revised upward based on the data in Appendix A.

4. New material has been added:

Section V-D Effect of Fuel Non-Uniformity

Section IV-L Transients in Subcooling

Appendix A . Wire Irradiation Errors

5. The procedural limits on nominal and maximum flux oscillation amplitude (10 and $15 \%$ ) were changed to specify in-core measurement.

6. Revision of text for normal plant transients (Section IV-L).

7. Revision of Stability (Section V-A) and Critical Heat Flux Data (Section V-E) to reflect latest calculated results.

8. Corrected typographical error in equation for Fo in Section V-B. 
U. S. Atomic Energy Commission

2111 Bancroft Way, Berkeley 4, Calif.

Attn: W. H. Brummett, Jr.,

Director, Contracts Division

Attn: Director, Reactor Division

U. S. Atomic Energy Commission

Division of Reactor Development

Washington 25, D. C.

Attn: Chief, Water Reactors Branch

Civilian Reactors

Attn: Chief, Reactor Engineering Branch, Naval Reactors

Attn: Chief, Research \& Development Branch

Nuclear Safety

Attn: Chief, Fuels \& Materials Dev. Branch

Nuclear Technology

Attn: Asst. Director, Office of Foreign Activities

U. S. Atomic Energy Commission

Chicago Operations Office

9800 Cass Avenue

Argonne, Illino is

Attn: Director, Reactor Program Div.

Societa Elettronucleare Nazionale (SENN)

Direzione Gencrale in Roma

Via Torino 6

Rome, Italy

Library

Atomic Energy Division

Allis-Chalmers Manufacturing Co.

6935 Arlington Road

Bethesda, Maryland 20014

Knolls Atomic Power Laboratory

P. O. Box 1072

Schenectady, New York

Attn: W. Cashin

Argonne National Laboratory

Argonne, Illinois

Attn: Robert Macheray

Northern States Power Company

Minneapolis 2, Minnesota

Attn: D. F. McElroy

General Nuclear Engineering Corp.

P. O. Box 245

Dunedin, Florida

Attn: J. M. West 
Allis-Chalmers Manufacturing Co.

Atomic Energy Division

Milwaukee 1, Wisconsin

Attn: H. Etherington

Allis-Chalmers Manufacturing $\mathrm{Co}$.

Nuclear Power Department

P. O. Box 8697

Washington 11, D. C.

Attn: H. C. Nickel

Consumers Power Company

$212 \mathrm{~W}$. Michigan Avenue

Jackson, Michigan

Attn: R. E. Kettner

Babcock and Wilcox Company

Atomic Energy Division

Lynchburg, Virginia

Attn: J. F. Mumm

Division of Technical Information Extension

P. O. Box 62

Oak Ridge, Tennessee

Attn: R. L. Metter

International General Electric Operations, S. A.

Casella Postale No. 5

Scauri (Latina), Italy

Attn: R. J. Ascherl 